\title{
WestVirginiaUniversity
}

THE RESEARCH REPOSITORY @ WVU

Graduate Theses, Dissertations, and Problem Reports

2010

\section{Three Essays on Caps Market and Unspanned Volatility}

\author{
Harumi Hattori \\ West Virginia University
}

Follow this and additional works at: https://researchrepository.wvu.edu/etd

\section{Recommended Citation}

Hattori, Harumi, "Three Essays on Caps Market and Unspanned Volatility" (2010). Graduate Theses, Dissertations, and Problem Reports. 3149.

https://researchrepository.wvu.edu/etd/3149

This Dissertation is protected by copyright and/or related rights. It has been brought to you by the The Research Repository @ WVU with permission from the rights-holder(s). You are free to use this Dissertation in any way that is permitted by the copyright and related rights legislation that applies to your use. For other uses you must obtain permission from the rights-holder(s) directly, unless additional rights are indicated by a Creative Commons license in the record and/ or on the work itself. This Dissertation has been accepted for inclusion in WVU Graduate Theses, Dissertations, and Problem Reports collection by an authorized administrator of The Research Repository @ WVU.

For more information, please contact researchrepository@mail.wvu.edu. 


\title{
Three Essays on Caps Market and Unspanned Volatility
}

\section{Harumi Hattori}

\author{
Dissertation submitted to the \\ College of Business and Economics \\ at West Virginia University \\ in partial fulfillment of the requirements \\ for the degree of
}

\author{
Doctor of Philosophy \\ in \\ Economics
}

\begin{abstract}
Alexei Egorov, Ph.D., Chair
Ronald Balvers, Ph.D.

Arabinda Basistha, Ph.D.

Stratford Douglas, Ph.D.

Alexander Kurov, Ph.D.
\end{abstract}

Morgantown, West Virginia

2010

Keywords: Caps;Unspanned Volatility;LIBOR;Jumps;

Implied Volatility;Macroeconomic Announcements;

Caps Term Premium;Granger Causality

Copyright 2010 Harumi Hattori 


\begin{abstract}

\section{Three Essays on Caps Market and Unspanned Volatility}

\title{
Harumi Hattori
}

In this thesis we study the caps market. Caps are a contract where the interest rates are capped at some fixed value $\bar{r}$. Purchasers of caps pay the prevailing interest rate if it is below $\bar{r}$, but pay the interest rate $\bar{r}$ if the prevailing rate is above $\bar{r}$. In the latter case the sellers of caps pay the difference. Therefore, the purchasers are able to prevent risks associated with the future change in interest rates. Caps consist of caplets which are European options on the forward rates called LIBOR (the London Inter-Bank Offer Rates). Caps are the derivatives of LIBOR. However, their relation is not so simple as the relation between a stock and its derivatives. One important difference is that the volatility in one market does not affect the volatility of the other market as much as in the stock and its derivative markets. This phenomenon is termed unspanned stochastic volatility (USV) and various research has been done. There are arguments supporting and against USV. This motivates further study of USV.

In Chapter 2, we study the modeling and calibration of LIBOR caps. We use an unspanned stochastic volatility model to discuss the pricing of caps. We calibrate the cap prices using the model and compare them with the market caps. We choose the parameters of the model so that the difference between prices of the theoretical (the model based) caps and those of the market caps will be minimum. A goal of this chapter is to examine the effects of jumps in interest rates and in stochastic volatility. We compare the calibrations of USV models without jumps, with jumps in both interest rates and volatility, with jumps in interest rates only, and with jumps in volatility only. The calibration of Vasicek model is also performed for the sake of reference. Another goal is to obtain the calibration results based on a few days of data. So far most calibration results are based on one-day data. We find out that the calibrations with jumps give better results than without jumps and between the jumps in interest rates and volatility the jumps in interest rates give better calibration results. The results indicate that the more detailed study of effects of jumps is important.

In Chapter 3, we examine the factors affecting the price of caps, so that accurate and efficient pricing and hedging of caps are possible. Since they are bond derivatives and the bonds are affected by the economic activities, it is interesting to examine how the economic activities influence the cap prices. We study empirically the effects of macroeconomic announcements and fed announcements on the implied volatility of difference caps. As mentioned earlier it has been observed that the prices of caps are driven by risk factors not spanned by the factors explaining LIBOR rates, even though caps are derivatives of LIBOR. We perform the regression analysis on the implied volatility of caps for all maturities and strike rates to see how the economic activities affect the cap prices. Using 21 series of macroeconomic announcements, first we do the event study to see which macroeconomic announcements affect the implied volatility. We also regress them with the principal components of macroeconomic announcements. Thirdly, we examine the effect of the fed announcements. For the regressions with the principal components and fed announcements, we compare the two ways to do the regressions. One way is to select the days when at least one new macroeconomic announcement becomes available to public and construct the time series with the data on the selected days. Another way is to construct the time series of a macroeconomic 
announcement by filling the days without that announcement the most recent data. We see vivid difference between the two regressions. We observe that the latter gives better results. This may show that the effects of macroeconomic announcements are not instantaneous but rather transient or persistent.

In Chapter 4 we study the caps term premiums. Cochrane and Piazzesi $[16,17]$ did the regression analysis of the bond term premium with the forward rates and observed that the term premium is regressed by a hump shaped linear combination of forward rates very well. The term premiums are the difference in the cost between holding one unit of $T$-year bonds and holding one unit of one-year bonds and then one unit of $(T-1)$-year bonds after one year. This is also termed excess return and measures the risk of holding longer maturity bonds. We examine whether the similar results hold for caps. If there is no uncertainty, the caps term premium is zero, because holding longer term caps and holding two shorter term caps would not make any difference. Uncertainty causes the deviation from being equal. We regress the term premium of caps with the difference caps and observe persistent patterns for longer maturity caps term premiums. This would aid the predictability of cap prices.

We use the Granger causality test to examine if the unspanned volatility of caps market Granger causes the caps term premium. As in Section 3.5, we use the residuals of the regressions of implied volatility with LIBOR and those with the conditional volatility of LIBOR bonds based on GARCH as proxies of the unspanned volatility. For the sake of comparison, we also examine if the implied volatility Granger cause the caps term premium. This way, we see if there are effects on using the residuals of regressions. We find out that the unspanned volatility based on GARCH performed much better than the those based on LIBOR. The regressions of implied volatility with LIBOR is much better than those with the conditional volatility of GARCH based LIBOR bonds. Therefore, the residuals of the regressions with LIBOR may contain less relevant information for the Granger causality.

Also, for the sake of investing we examine the relation between the performance of caps term premiums and the above three measures of volatility. We take 20 highest and lowest caps term premiums and 20 highest and lowest volatilities for each maturity and strike rates, and see if the higher volatility leads to the higher caps term premiums. 


\section{Acknowledgments}

First, I would like to thank my adviser, Professor Alexei Egorov, for his help throughout this entire process. I have learned immensely from him and his guidance and encouragement made it possible to complete the Ph.D. thesis and the Ph.D. degree.

Secondly, I would like to thank my committee members, Professors Ronald Balvers, Arabinda Basistha, Stratford Douglas, Alexander Kurov. Their advices throughout the process have been invaluable. Especially, I would like to thank Professor Alex Kurov who provided data for Chapter 3.

Thirdly, I would like to thank the Department of Economics and Finance and the Department of Mathematics at West Virginia University.

Finally, I would like to thank my family, Motoko and Eriko for their support. 


\section{Contents}

1 Overview of Dissertation 1

2 Calibration of Caps with Unspanned Volatility Models 4

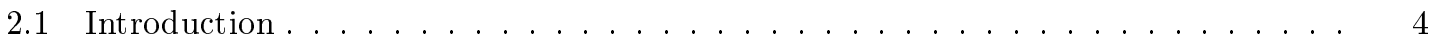

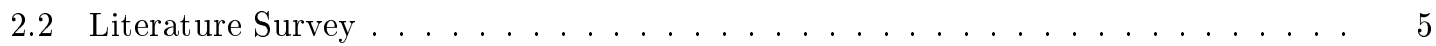

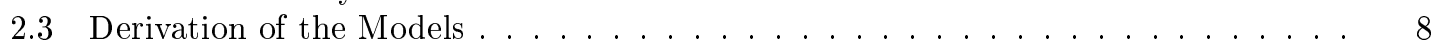

2.3.1 A Two Factor Unspanned Volatility Model . . . . . . . . . . . . . . . 9

2.3.2 Two Factor Unspanned Volatility Models with Jumps . . . . . . . . . . . . 11

2.4 Calibration of Caps . . . . . . . . . . . . . . . . . . . . . 13

2.4 .1 Data . . . . . . . . . . . . . . . . . . 13

2.4 .2 Implementation . . . . . . . . . . . . . . . . . . . . . . . . 14

2.4 .3 Vasicek Model . . . . . . . . . . . . . . . . . . . . . . . 17

2.4.4 An Example of the Two Factor Unspanned Volatility Model without Jumps 19

2.4.5 Examples of the Two Factor Unspanned Volatility Model with Jumps . . . 20

2.4 .6 Comparison of Models . . . . . . . . . . . . . . . . . . . 21

2.4 .7 Five Day Estimates . . . . . . . . . . . . . . . . . . . 24

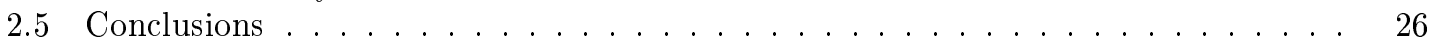

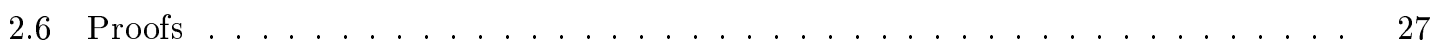

3 Caps Implied Volatility and Macroeconomic Announcements 35

3.1 Introduction . . . . . . . . . . . . . . . . . . . . 35

3.2 Caps and Implied Volatility . . . . . . . . . . . . . . . . . . . 36

3.3 Macroeconomic Announcements . . . . . . . . . . . . . . . . . . . 40

3.3.1 Implied Volatility and Macroeconomic Announcements . . . . . . . . . . . . 40

3.3.2 Event Study Analysis . . . . . . . . . . . . . . . . . . . . . . 41

3.3.3 Principal Component Analysis . . . . . . . . . . . . . . . . . . . 43

3.3.4 Daily Difference of the Implied Volatility and the Macroeconomic Announce-

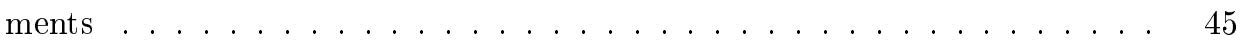

3.3.5 Unemployment Data . . . . . . . . . . . . . . . . . . . . . 45

3.4 Fed Fund Rates . . . . . . . . . . . . . . . . . . . . . . . 46

3.5 Unspanned Volatility . . . . . . . . . . . . . . . . . . . 54

3.5.1 LIBOR Based Unspanned Volatility . . . . . . . . . . . . . . . . 55

3.5 .2 GARCH Based Unspanned Volatility . . . . . . . . . . . . . . 57

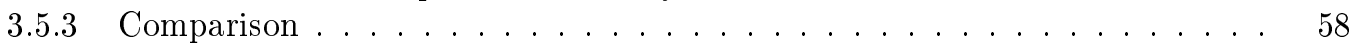

3.6 Impulse Response Function Analysis . . . . . . . . . . . . . . . . . . . . 59

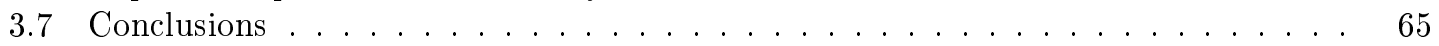


4 Caps Term Premiums $\quad \mathbf{6 7}$

4.1 Introduction . . . . . . . . . . . . . . . . . . . . . . . 67

4.2 LIBOR and Caps Data . . . . . . . . . . . . . . . . . . . . . 68

4.3 Caps Term Premium and Difference Caps . . . . . . . . . . . . . . . . . 70

4.3.1 Term Premium of Bonds and Caps . . . . . . . . . . . . . . . . 70

4.3.2 Regressions by Cochrane and Piazzesi . . . . . . . . . . . . . . . 72

4.3.3 Regressions of Caps Term Premiums with Difference Caps . . . . . . . . . 74

4.3.4 The Other Strike Rates . . . . . . . . . . . . . . . . . . 79

4.3.5 Real Time Forecasts and Trading Rule Profits . . . . . . . . . . . . . . 86

4.4 Caps Term Premiums and Unspanned Volatility . . . . . . . . . . . . . . . . . . . 87

4.4.1 Granger Causality Tests . . . . . . . . . . . . . . . . . 87

4.4.2 Caps Term Premiums and Volatility - An Investment Implication . . . . . . 89

4.5 Information Contents in Caps and LIBOR Bond Markets . . . . . . . . . . . . . . 94

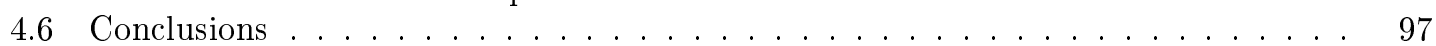

5 Conclusions $\quad 99$ 


\section{List of Figures}

2.1 Surface graph of the market cap prices. The surface graph of the market cap prices on $8 / 23 / 2000$ is given. . . . . . . . . . . . . . . . . .

2.2 Surface graph of implied volatility of the market cap prices. The surface graph of implied volatility of the market cap prices on $8 / 23 / 2000$ is sketched. . .

2.3 Graphs of the theoretical difference cap prices of Vasicek model and the market difference cap prices. In the above figure the Vasicek and the market cap prices are compared on $8 / 1 / 2000 . \ldots \ldots \ldots \ldots$. . . . . . . . . .

2.4 Comparison of theoretical difference cap prices with the market difference cap prices. In the above figure the theoretical difference cap prices of the two-factor unspanned volatility model with the market difference cap prices for two, five, and ten year maturity on $8 / 01 / 2000$ are compared. . . . . . . . . . . . . . . .

2.5 Comparison of theoretical difference cap prices with the market difference cap prices. In the above figure the theoretical difference cap prices of the two-factor unspanned volatility model with jumps and the market difference cap prices for two, five, and ten year maturity on $8 / 01 / 2000$ are compared. . . . . . . . . . . .

3.1 The surface graph of the daily average of the implied volatility of difference caps. In the above figure the surface graph of the daily average of the implied volatility of difference caps verses maturity and moneyness is given. The moneyness ranges from 0.6 to 1.5 and the maturity ranges from 2 years to 10 years. . . . . . .

3.2 The surface graph of calibrated implied volatility of difference caps. This is a surface graph of calibrated implied volatility of difference caps where $\sigma(T-t)=$ $\sigma_{0}+\sigma_{1} \exp \left(-\kappa_{1}(T-t)\right)+\sigma_{2} \exp \left(-\kappa_{2}(T-t)\right)$ is used to calibrate the implied volatility . 39

3.3 The volatility smiles for the calibrated implied volatility of difference caps. In the above figure the volatility smiles for the calibrated implied volatility of difference caps of the few maturities are given. . . . . . . . . . . . .

3.4 Impulse response functions for implied volatility and unemployment data. A typical impulse response functions for implied volatility and unemployment data are given. The maturity of the difference cap is 3 years and the moneyness is 0.8 and in in-the-money. . . . . . . . . . . . . . . . . .

3.5 Impulse response functions for implied volatility and unemployment data. A typical impulse response functions for implied volatility and unemployment data are given. The maturity of the difference cap is 3 years and the moneyness is 0.8 and in in-the-money. . . . . . . . . . . . . . . .

3.6 Impulse response functions for implied volatility and the expected component of Fed announcement. A typical impulse response functions for implied volatility and the expected component of Fed announcement are given. The maturity of the difference cap is 3 years and the moneyness is 0.8 and it is in-the-money. 
3.7 Impulse response functions for implied volatility and the expected component of Fed announcement. A typical impulse response functions for implied volatility and the expected component of Fed announcement are given. The maturity of the difference cap is 3 years and the moneyness is 1.2 and it is out-of-the-money.

3.8 Impulse response functions for implied volatility and the unexpected component of Fed announcement. A typical impulse response functions for implied volatility and the unexpected component of Fed announcement are given. The maturity of the difference cap is 3 years and the moneyness is 0.8 and it is

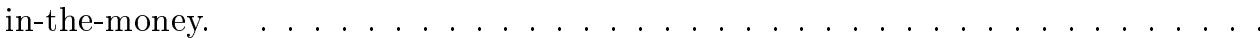

3.9 Impulse response functions for implied volatility and the unexpected component of Fed announcement. A typical impulse response functions for implied volatility and the unexpected component of Fed announcement are given. The maturity of the difference cap is 3 years and the moneyness is 1.2 and it is out-of-the-money.

4.1 Time series of LIBOR rates. The graphs of the time series of 6 month, 5 year, and 10 year LIBOR rates from August 1, 2000 to July 31, 2002 are given. . . . .

4.2 Time series of Treasury rates. The graphs of the time series of 6 month, 5 year, and 10 year Treasury rates from August 1, 2000 to July 31, 2002 are given. . . . .

4.3 The time series of LIBOR term premiums. The time series of LIBOR term premiums for 1 and 4 year maturities are given. . . . . . . . . .

4.4 The time series of caps term premiums. The time series of caps term premiums

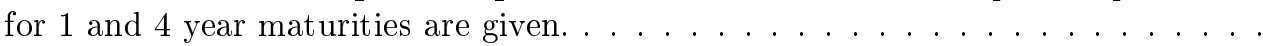

4.5 Impulse response functions for unspanned volatility and caps term premiums. The impulse response functions for the first principal component of the unspanned volatility and caps term premium are given. The cap is 3 year maturity

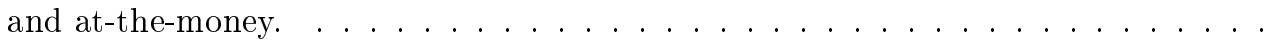

4.6 The graph of the first five coefficients. The graph of the first five coefficients in the regression $r x_{t+1}^{(n)}=D_{t} \beta^{(n)}+\varepsilon^{(n)}$ of caps term premiums $r x_{t+1}^{(n)}$ with difference caps $D_{t}=\left[1, d_{t}^{(i)}, d_{t}^{(i+1)}, d_{t}^{(i+2)}, \ldots, d_{t}^{(l)}\right]$. The strike rate is $0.04 \ldots \ldots \ldots \ldots$

4.7 The graph of the second four coefficients. The graph of the second four coefficients in the regression $r x_{t+1}^{(n)}=D_{t} \beta^{(n)}+\varepsilon^{(n)}$ of caps term premiums $r x_{t+1}^{(n)}$ with difference caps $D_{t}=\left[1, d_{t}^{(i)}, d_{t}^{(i+1)}, d_{t}^{(i+2)}, \ldots, d_{t}^{(l)}\right]$. The strike rate is 0.04 . .

4.8 The graphs of the first five coefficients of the restricted regressions. The graphs of the first five coefficients of the restricted regressions $r x_{t+1}^{(n)}=b_{n}\left(\gamma_{0}+\right.$ $\left.\gamma_{1} d_{t}^{(1)}+\gamma_{2} d_{t}^{(2)}+\cdots+\gamma_{l} d_{t}^{(l)}\right),(4.3 .3)$. The first five caps term premiums are regressed. The strike rate is $0.04 \ldots \ldots \ldots \ldots \ldots \ldots \ldots$

4.9 The graph of the second four coefficients of the restricted regressions. The graph of the second four coefficients of the restricted regressions $r x_{t+1}^{(n)}=b_{n}\left(\gamma_{0}+\right.$ $\left.\gamma_{1} d_{t}^{(1)}+\gamma_{2} d_{t}^{(2)}+\cdots+\gamma_{l} d_{t}^{(l)}\right)(4.3 .3)$. The strike rate is $0.04 \ldots \ldots \ldots \ldots \ldots$

4.10 The graphs of the first five coefficients with strike rate 0.06 . The graphs of the first five coefficients with strike rate 0.06 for the unrestricted regressions $r x_{t+1}^{(n)}=D_{t} \beta^{(n)}+\varepsilon^{(n)}$ of caps term premiums $r x_{t+1}^{(n)}$ with difference caps $D_{t}=$ $\left[1, d_{t}^{(i)}, d_{t}^{(i+1)}, d_{t}^{(i+2)}, \ldots, d_{t}^{(l)}\right]$ are given. $\ldots \ldots \ldots \ldots \ldots$

4.11 The graphs of the last four coefficients with strike rate 0.06 . The graphs of the last four coefficients with strike rate 0.06 for the unrestricted regressions $r x_{t+1}^{(n)}=D_{t} \beta^{(n)}+\varepsilon^{(n)}$ of caps term premiums $r x_{t+1}^{(n)}$ with difference caps $D_{t}=$

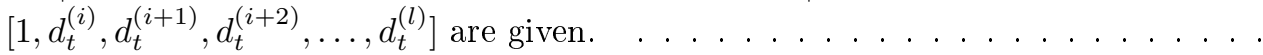


4.12 The graphs of the first five coefficients. The graphs of the first five coefficients of the restricted regressions $r x_{t+1}^{(n)}=b_{n}\left(\gamma_{0}+\gamma_{1} d_{t}^{(1)}+\gamma_{2} d_{t}^{(2)}+\cdots+\gamma_{l} d_{t}^{(l)}\right),(4.3 .3)$ for the strike rate 0.06 are given. . . . . . . . . . . . . . . . . . .

4.13 The graph of the second four coefficients. The graphs of the second four coefficients of the restricted regressions $r x_{t+1}^{(n)}=b_{n}\left(\gamma_{0}+\gamma_{1} d_{t}^{(1)}+\gamma_{2} d_{t}^{(2)}+\cdots+\gamma_{l} d_{t}^{(l)}\right)$, (4.3.3) for the strike rate 0.06 are given. . . . . . . . . . . . . . . . .

4.14 The graphs of the first five coefficients with strike rate 0.1 . The graphs of the first five coefficients with strike rate 0.1 for the unrestricted regressions $r x_{t+1}^{(n)}=D_{t} \beta^{(n)}+\varepsilon^{(n)}$ of caps term premiums $r x_{t+1}^{(n)}$ with difference caps $D_{t}=$ $\left[1, d_{t}^{(i)}, d_{t}^{(i+1)}, d_{t}^{(i+2)}, \ldots, d_{t}^{(l)}\right]$ are given. . . . . . . . . . . . .

.15 The graphs of the last four coefficients with strike rate 0.1 . The graphs of the last four coefficients with strike rate 0.1 for the unrestricted regressions $r x_{t+1}^{(n)}=D_{t} \beta^{(n)}+\varepsilon^{(n)}$ of caps term premiums $r x_{t+1}^{(n)}$ with difference caps $D_{t}=$ $\left[1, d_{t}^{(i)}, d_{t}^{(i+1)}, d_{t}^{(i+2)}, \ldots, d_{t}^{(l)}\right]$ are given. . . . . . . . . . . . . . .

4.16 The graph of the first five coefficients. The graph of the first five coefficients of the restricted regressions $r x_{t+1}^{(n)}=b_{n}\left(\gamma_{0}+\gamma_{1} d_{t}^{(1)}+\gamma_{2} d_{t}^{(2)}+\cdots+\gamma_{l} d_{t}^{(l)}\right),(4.3 .3)$ for the strike rate 0.1 are reported. . . . . . . . . . . . . . . . . .

4.17 The graph of the second four coefficients. The graph of the second four coefficients of the restricted regressions $r x_{t+1}^{(n)}=b_{n}\left(\gamma_{0}+\gamma_{1} d_{t}^{(1)}+\gamma_{2} d_{t}^{(2)}+\cdots+\gamma_{l} d_{t}^{(l)}\right)$, (4.3.3) for the strike rate 0.1 are reported... . . . . . . . . . . . . . .

4.18 The forecaster values. The forecaster values are $\gamma^{T} f_{t}$, the average caps term premiums are $\overline{r x}_{t+1}$, the trading rule profits are $\overline{r x}_{t+1} \times E_{t}\left(\overline{r x}_{t+1}\right) \ldots . . .$. . .

4.19 Impulse response functions for LIBOR bonds and caps. Graphs of impulse response functions for LIBOR bonds and caps are shown. The maturity of LIBOR bond and cap is 3 years and the cap is at the money. . . . . . . . . . . . .

4.20 Impulse response functions for LIBOR rates and implied volatility. Graphs of impulse response functions for LIBOR rates and implied volatility are shown. The maturity of LIBOR bond is 3 years. . . . . . . . . . . . . . . . . 


\section{List of Tables}

2.1 The prices of market caps on $\mathbf{8 / 1} \mathbf{1}$ 2000. The market caps on $8 / 1 / 2000$ are given for the sake of reference. The values of market caps violating the monotonicity or the convexity condition are removed from consideration. The caps with value zero are also removed. "NaN" indicates that the caps are removed. . . . . . . . . . . .

2.2 The market difference caps on $\mathbf{8 / 1 / 2 0 0 0}$. The market difference caps on $8 / 1 / 2000$ are given for the sake of reference. The values of market caps violating the monotonicity or the convexity condition are removed from consideration. The caps with value zero are also removed. "NaN" indicates that the corresponding caps are removed. . . . . . . . . . . . . . . . . .

2.3 A pseudo program explaining the basic algorithm. This is a basic algorithm for the program which gives an approximate values of parameters $\left[\kappa_{r}, \sigma_{r v}, \gamma_{v}, \kappa_{v}, \sigma_{v}, v\right]$.

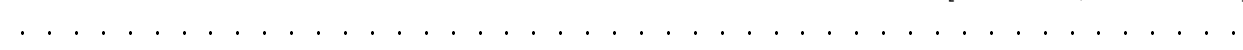

2.4 The result of calibration with the Vasicek model. In the following table the sum of the square of the error with the Vasicek model is given $(t=8 / 1 / 2000) . \kappa_{r}$ is the mean reversion coefficient and $\sigma$ is the volatility. . . . . . . . .

2.5 The parameter values of the two-factor unspanned volatility model. In the following table the parameter values of the two-factor unspanned volatility model are listed. $\kappa_{r}$ is the mean reversion coefficient of the interest rate. $\sigma_{r v}$ is the square root of covariance between the interest rate and stochastic volatility. $\gamma_{v}, \kappa_{v}$, and $\sigma_{v}$ are the mean, the mean reversion coefficient, and the volatility of stochastic volatility. $v$ is the stochastic volatility. . . . . . . . . . . . .

2.6 The parameter values of the two-factor unspanned volatility model. In the following table the parameter values of the two-factor unspanned volatility model are listed. $\kappa_{r}$ is the mean reversion coefficient of the interest rate. $\sigma_{r v}$ is the square root of covariance between the interest rate and stochastic volatility. $\gamma_{v}, \kappa_{v}$, and $\sigma_{v}$ are the mean, the mean reversion coefficient, and the volatility of stochastic volatility. $v$ is the stochastic volatility. $\lambda_{0}, \lambda_{r}$, and $\lambda_{v}$ are the intensity parameters and $\sigma_{J_{r}}$ and $\sigma_{J_{v}}$ are the variance of jump process for the interest rates and the volatility, respectively. The date for calibration is $8 / 01 / 2000$. . . . . . . . .

2.7 Comparison of a USV model with jumps and no jumps. For the following days, the model without jump, with jumps, with jump in interest rate only, and with jump in volatility only are calibrated. The values in the table are the relative errors with weight. . . . . . . . . . . . . .

2.8 The parameter values of USV model with no jumps. The table reports the parameter values of USV model with no jumps. . . . . . . . . . . . . . 
2.9 The parameter values of USV model with jumps. The table reports the parameter values of USV model with jumps. . . . . . . . . . . . . . .

2.10 The parameter values of USV model with jumps in interest rates. The table reports the parameter values of USV model with jumps in interest rates. . .

2.11 The parameter values of USV model with jumps in volatility. The table reports the parameter values of USV model with jumps in volatility only. . . . . .

2.12 Comparison of relative errors. The table reports the comparison of relative errors $V$ in (2.4.30) for the 5 day calibration starting from $8 / 1 / 2000$. . . . . . . . .

2.13 The values of $\min _{v(t)} S_{2}$. The values of $\min _{v(t)} S_{2}$ for the program based on Table 2.3, USV with no jumps, and USV with jumps for the 5 day calibration starting from $8 / 1 / 2000$ are reported. . . . . . . . . . . . . . . . . . . . .

2.14 The values of parameters. The values of parameters for the program based on Table 2.3, USV with no jumps, and USV with jumps for the 5 day calibration starting from $8 / 1 / 2000$ are reported. . . . . . . . . . . . . . . . . .

2.15 The values of $v(t)$. The values of $v(t)$ for the program based on Table 2.3, USV with no jumps, and USV with jumps for the 5 day calibration starting from $8 / 1 / 2000$ are reported. . . . . . . . . . . . . . . . . . . .

2.16 Comparison of relative errors. The table reports the comparison of relative errors $V$ in (2.4.30) for the 5 day calibration starting from $1 / 17 / 2002$. . . . . . . .

2.17 The values of $\min _{v(t)} S_{2}$. The values of $\min _{v(t)} S_{2}$ for USV with no jumps and USV with jumps for the 5 day calibration starting from $1 / 17 / 2002$ are reported. .

2.18 The values of parameters. The values of parameters for USV with no jumps and USV with jumps for the 5 day calibration starting from $1 / 17 / 2002$ are reported. .

2.19 The values of $v(t)$. The values of $v(t)$ for USV with no jumps, and USV with jumps for the 5 day calibration starting from $1 / 17 / 2002$ are reported. . . . . . . .

3.1 The number of observations of implied volatility. In the following table the numbers of observations of implied volatility for each maturity and moneyness are listed. . . . . . . . . . . . . . . . . . . . . .

3.2 List of macroeconomic announcements. In the following table the list of 21 macroeconomic announcements are given. . . . . . . . . . . . . .

3.3 Three categories of moneyness. Three categories of moneyness are given. . .

3.4 Three categories of maturities. Three categories of maturities are given. . . .

3.5 Event study analysis. The table reports the number of times the announcements are significant in the event study for the implied volatility with 21 economic announcements. "mo" stands for moneyness and "mat" is maturity. "in, at, and out" are the abbreviations for in-the-money, at-the-money, and "out-of-the-money. "sh, int, and lng" are the abbreviations for short, intermediate, and long maturities. The table also reports the number of times the signs of coefficients is positive. . . . . .

3.6 R-squared of the regression of implied volatilities. The R-squared for the regression of implied volatilities with three principal components of the macroeconomic data are given. Only the days where the announcements were made are filled with the data. The numbers with bold letters are significant in $90 \%$ F-statistics. .

3.7 R-squared for the regression of daily implied volatilities. The R-squared of the regression of daily implied volatilities with three principal components of the macroeconomic data are given. Between the two consecutive announcements economic data are filled with the same values. The numbers with bold letters are significant in $90 \%$ F-statistics. . . . . . . . . . . . . . . . . 
3.8 R-squared for the regression of the daily difference of implied volatilities. The R-squared for the regression of the daily difference of implied volatilities with the constant and the three principal components of the macroeconomic data. Only the days where the announcements were made are filled with the data. The numbers with bold letters are significant in $90 \%$ F-statistics. . . . . . . . . . . . . .

3.9 R-squared for the regression of implied volatilities with unemployment data. The R-squared for the regression of implied volatilities with unemployment data are given. Only the days where the announcements were made are filled with the data. The numbers with bold letters are significant in $90 \%$ F-statistics. . . . .

$3.10 \mathrm{R}$-squared for the regression of implied volatilities with daily unemployment data. R-squared for the regression of implied volatilities with daily unemployment data. Between the two consecutive announcements economic data are filled with the same values. The numbers with bold letters are significant in $90 \%$

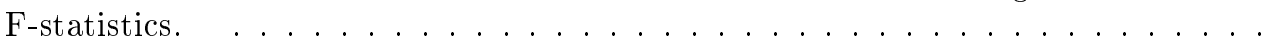

3.11 Regressions of implied volatility with Fed announcements. The table reports the results of Case 1 with the regressions $v_{t}=a+b \triangle i_{t}+\varepsilon_{t}$, where we use $\triangle i_{t}$. The numbers with bold letter indicate that the regression results are significant in

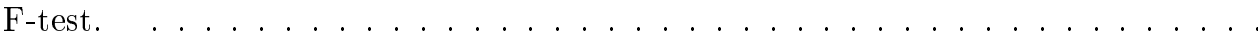

3.12 Regressions of implied volatility with Fed announcements. The table reports the results of Case 2 with the regressions $v_{t}=a+b \triangle i_{t}+\varepsilon_{t}$, where we use $\triangle i_{t}$. The numbers with bold letters are significant in $90 \%$ F-statistics. . . . . . . .

3.13 Regressions of implied volatility with Fed announcements. The table reports the results of Case 2 with the regressions $v_{t}=a+b \triangle i_{t}^{e}+c \triangle i_{t}^{u}+\varepsilon_{t}$, where we use $\triangle i_{t}^{e}$ and $\triangle i_{t}^{u}$. The numbers with bold letters are significant in $90 \% \mathrm{~F}$-statistics.

3.14 Regressions of implied volatility with Fed announcements. The table reports the results of Case (3) with the regressions $v_{t}=a+b \triangle i_{t}^{e}+c \triangle i_{t}^{u}+\varepsilon_{t}$, where we use the same values of $\triangle i_{t}$ between two meetings are used. The numbers with bold letters are significant in $90 \%$ F-statistics. . . . . . . . . . . . . . . .

3.15 Regressions of implied volatility with Fed announcements. The table reports the results of Case (3) with the regressions $v_{t}=a+b \triangle i_{t}^{e}+c \triangle i_{t}^{u}+\varepsilon_{t}$, where the most recent values of $\triangle i_{t}^{e}$ and $\Delta i_{t}^{u}$ between two meetings are used. The numbers with bold letters are significant in $90 \%$ F-statistics. . . . . . . . . . . . . . .

3.16 The coefficients of the intercepts and raw funds rate change. We report the coefficients of the intercepts and raw funds rate change in the regressions (3.4.2) of the nine portfolios. The numbers in parentheses are t-statistics. Bold letters are t-significant. This regression is Case (3) where we use the same values of $\triangle i_{t}$ or $\triangle i_{t}^{e}$ and $\triangle i_{t}^{u}$ between two meetings to do the regression and we use all implied volatility data available. The numbers with bold letters are significant in $90 \% \mathrm{~F}$-statistics. .

3.17 Coefficients of the intercepts, expected and unexpected funds rate change. Coefficients of the intercepts, expected and unexpected funds rate change in the regressions (3.4.3) of the nine portfolios. The numbers in parentheses are t-statistics. Bold letters are t-significant. This regression is Case (3) where we use the same values of $\triangle i_{t}$ or $\triangle i_{t}^{e}$ and $\triangle i_{t}^{u}$ between two meetings to do the regression and we use all implied volatility data available. The numbers with bold letters are significant in $90 \%$ F-statistics. . . . . . . . . . . . . . . . . . . . .

3.18 The result of the Newey West correction with 20 lags. We report the result of the Newey West correction with 20 lags in the regression of the implied volatility with raw funds rate change. The t-statistics are smaller then those in Table 3.16. The numbers with bold letters are significant in $90 \%$ F-statistics. . . . . . . . . . . 
3.19 The result of the Newey West correction with 20 lags. We report the result of the Newey West correction with 20 lags in the regression of the implied volatility with expected and unexpected funds rate change. The number of t-significant entries in the expected funds rate change dropped while the number of t-significant entries in the unexpected funds rate change remain the same. The numbers with bold letters are significant in $90 \%$ F-statistics. . . . . . . . . . . . . . .

3.20 R-square of the regression of implied volatility. The R-square for the regression of implied volatility with the three principal components of LIBOR. . . . . .

3.21 R-square of the regression of the residuals of the implied volatility. Rsquare for the regression of the LIBOR based residuals of the implied volatility with the three principal components of macroeconomic announcements. The numbers with bold letters are significant in $90 \%$ F-statistics. . . . . . . . . . . . . . .

$3.22 \mathrm{R}$-square of the regression of the residuals of the implied volatility. $\mathrm{R}$ square of the regression of the residuals of the implied volatility with the three principal components of macroeconomic announcements and the fed surprise data. The numbers with bold letters are significant in $90 \%$ F-statistics. . . . . . . . . .

$3.23 \mathrm{R}$-square of the regression of implied volatility. The R-square for the regression of implied volatility with the three principal components of GARCH based conditional volatility of LIBOR bonds. . . . . . . . . . . . . . .

$3.24 \mathrm{R}$-square of the regression of the residuals of the implied volatility. Rsquare for the regression of the GARCH based residuals of the implied volatility with the three principal components of macroeconomic announcements. The numbers with bold letters are significant in $90 \%$ F-statistics. . . . . . . . . . . . . .

4.2 The values of $\gamma_{i}$. The values of $\gamma_{i}$ in the regression $\overline{r x}_{t+1}=\frac{1}{4} \sum_{n=7}^{10} r x_{t+1}^{(n)}=$ $\gamma_{0}+\gamma_{1} d_{t}^{(1)}+\gamma_{2} d_{t}^{(2)}+\cdots+\gamma_{l} d_{t}^{(l)}$ are listed. The numbers in parentheses are $t$ statistics. The strike rate is $0.04 \ldots \ldots \ldots \ldots \ldots \ldots$

4.3 The values of $b_{n}$. The values of $b_{n}$ in the restricted regression $r x_{t+1}^{(\dot{n})}=b_{n}\left(\gamma_{0}+\right.$ $\left.\gamma_{1} d_{t}^{(1)}+\gamma_{2} d_{t}^{(2)}+\cdots+\gamma_{l} d_{t}^{(l)}\right)$. The strike rate is $0.04 \ldots \ldots \ldots \ldots \ldots$

4.1 The values of beta and their t-statistics. The values of beta and their tstatistics

for the regressions $r x_{t+1}^{(n)}=D_{t} \beta^{(n)}+\varepsilon^{(n)}$ of caps term premiums $r x_{t+1}^{(n)}$ with difference caps $D_{t}=\left[1, d_{t}^{(i)}, d_{t}^{(i+1)}, d_{t}^{(i+2)}, \ldots, d_{t}^{(l)}\right]$. The strike rate is $0.04 \ldots \ldots \ldots \ldots$.

4.4 The R-squared for $b_{n}$. The R-squared for $b_{n}$ in the restricted regression $r x_{t+1}^{(n)}=$ $b_{n}\left(\gamma_{0}+\gamma_{1} d_{t}^{(1)}+\gamma_{2} d_{t}^{(2)}+\cdots+\gamma_{l} d_{t}^{(l)}\right)$. The strike rate is $0.04 \ldots \ldots \ldots \ldots \ldots$

4.5 The values of $\mathbf{R}$-squared for the unrestricted regressions. The values of $\mathrm{R}$ squared for the unrestricted regressions $r x_{t+1}^{(n)}=D_{t} \beta^{(n)}+\varepsilon^{(n)}$ of caps term premiums $r x_{t+1}^{(n)}$ with difference caps $D_{t}=\left[1, d_{t}^{(i)}, d_{t}^{(i+1)}, d_{t}^{(i+2)}, \ldots, d_{t}^{(l)}\right]$ with strike rate 0.06 are listed. . . . . . . . . . . . . . . . . .

4.6 The values of $\gamma_{i}$. The values of $\gamma_{i}$ and t-statistics for the regression $\overline{r x}_{t+1}=$ $\frac{1}{4} \sum_{n=7}^{10} r x_{t+1}^{(n)}=\gamma_{0}+\gamma_{1} d_{t}^{(1)}+\gamma_{2} d_{t}^{(2)}+\cdots+\gamma_{l} d_{t}^{(l)}$ (4.3.4) with strike rate 0.06 are listed. . . . . . . . . . . . . . . . . . . . .

4.7 The values of $b_{n}$. The values of $b_{n}$ in the restricted regression $r x_{t+1}^{(n)}=b_{n}\left(\gamma_{0}+\right.$ $\left.\gamma_{1} d_{t}^{(1)}+\gamma_{2} d_{t}^{(2)}+\ldots+\gamma_{l} d_{t}^{(l)}\right),(4.3 .3)$ are listed. . . . . . . . . . . 
4.8 The values of $\mathbf{R}$-squared for the regressions with strike rate $\mathbf{0 . 1}$. The values of R-squared for the unrestricted regressions $r x_{t+1}^{(n)}=D_{t} \beta^{(n)}+\varepsilon^{(n)}$ of caps term premiums $r x_{t+1}^{(n)}$ with difference caps $D_{t}=\left[1, d_{t}^{(i)}, d_{t}^{(i+1)}, d_{t}^{(i+2)}, \ldots, d_{t}^{(l)}\right]$ with strike rate 0.1 are listed. . . . . . . . . . . . . . . . . . . . .

4.9 The values of $\gamma_{i}$. The values of $\gamma_{i}$ in the regression (4.3.4) with strike rate 0.1 are given. . . . . . . . . . . . . . . . . . .

4.10 The values of $b_{n}$. The values of $b_{n}$ in the regressions $r x_{t+1}^{(n)}=b_{n}\left(\gamma_{0}+\gamma_{1} d_{t}^{(1)}+\right.$ $\left.\gamma_{2} d_{t}^{(2)}+\cdots+\gamma_{l} d_{t}^{(l)}\right),(4.3 .3)$ with strike rate 0.1 are reported. . . . . . . . . . .

4.11 Implied volatility Granger causes caps term premiums. Table reports that the implied volatility Granger causes caps term premiums. The bold letters show that it is significant with the $90 \%$ F-tests. . . . . . . . . . . . . . .

4.12 R-square of the regressions of implied volatility with the LIBOR rates. The R-squared of the regressions of implied volatility of difference caps with the LIBOR rates are given. The residuals of regressions are a proxy of unspanned volatility. ...........................

4.13 Unspanned volatility Granger causes caps term premium. Table reports that the proxy based on LIBOR for unspanned volatility Granger causes caps term premiums. The bold letters show that it is significant with the $90 \%$ F-tests. . . . .

4.14 R-squares of the regressions of implied volatility with the GARCH based volatility. The R-squares of the regressions of implied volatility of difference caps with the GARCH based volatility are given. The residuals of regressions are a proxy of unspanned volatility. . . . . . . . . . . . . . . . . . . . .

4.15 GARCH based Unspanned volatility Granger causes caps term premium. Table reports that the proxy based on GARCH conditional volatility for unspanned volatility Granger causes caps term premiums. The bold letters show that it is significant with the $90 \%$ F-tests. The GARCH conditional volatility is created from

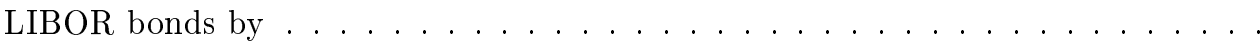

4.16 Match between the 20 highest GARCH based unspanned volatilities and the 20 highest caps term premiums. The table reports the number of the times the 20 highest GARCH based unspanned volatilities matches the 20 highest caps term premiums. . . . . . . . . . . . . . . . . . . . .

4.17 Match between the 20 highest GARCH based unspanned volatilities and the 20 lowest caps term premiums. The table reports the number of the times the 20 highest GARCH based unspanned volatilities matches the 20 lowest caps term premiums. . . . . . . . . . . . . . . . . . .

4.18 Match between the 20 lowest GARCH based unspanned volatilities and the 20 highest caps term premiums. The table reports the number of the times the 20 lowest GARCH based unspanned volatilities matches the 20 highest caps term premiums. . . . . . . . . . . . . . . . . . .

4.19 Match between the 20 lowest GARCH based unspanned volatilities and the 20 lowest caps term premiums. The table reports the number of the times the 20 lowest GARCH based unspanned volatilities matches the 20 lowest caps term premiums. ...........................

4.20 Match between the 20 highest LIBOR based unspanned volatilities and the 20 highest caps term premiums. The table reports the number of the times the 20 highest LIBOR based unspanned volatilities matches the 20 highest

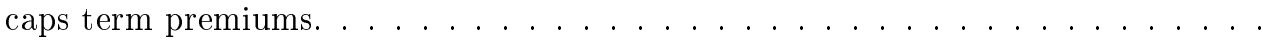


4.21 Match between the 20 highest LIBOR based unspanned volatilities and the 20 lowest caps term premiums. The table reports the number of the times the 20 highest LIBOR based unspanned volatilities matches the 20 lowest caps term premiums.............................

4.22 Match between the 20 lowest LIBOR based unspanned volatilities and the 20 highest caps term premiums. The table reports the number of the times the 20 lowest LIBOR based unspanned volatilities matches the 20 highest caps term premiums. . . . . . . . . . . . . . . . . . . . .

4.23 Match between the 20 lowest LIBOR based unspanned volatilities and the 20 lowest caps term premiums. The table reports the number of the times the 20 lowest LIBOR based unspanned volatilities matches the 20 lowest caps term premiums. ...........................

4.24 Match between the 20 highest implied volatilities and the 20 highest caps term premiums. The table reports the number of the times the 20 highest implied volatilities matches the 20 highest caps term premiums. . . . . . . . . . .

4.25 Match between the 20 highest implied volatilities and the 20 lowest caps term premiums. The table reports the number of the times the 20 highest implied volatilities matches the 20 lowest caps term premiums. . . . . . . . . . .

4.26 Match between the 20 lowest implied volatilities and the 20 highest caps term premiums. The table reports the number of the times the 20 lowest implied volatilities matches the 20 highest caps term premiums. . . . . . . . . .

4.27 Match between the 20 lowest implied volatilities and the 20 lowest caps term premiums. The table reports the number of the times the 20 lowest implied volatilities matches the 20 lowest caps term premiums. . . . . . . . . . . .

4.28 R-squared of the regressions of cap prices with the LIBOR bonds. The $\mathrm{R}$-squared of the regressions of cap prices with the LIBOR bonds are listed. 


\section{Chapter 1}

\section{Overview of Dissertation}

Caps are a contract where the interest rates are capped at some fixed value $\bar{r}$ called strike rate. Purchasers of caps pay the prevailing interest rate to the lender if it is below $\bar{r}$, but pay the interest rate $\bar{r}$ if the prevailing rate is above $\bar{r}$. In the latter case the sellers of caps pay the difference. Therefore, the purchasers are able to hedge risks associated with the future change in interest rates. Caps consist of caplets which are European options on bonds based on the London InterBank Offer Rates (LIBOR). Interest rate caps are among the most widely traded interest rate derivatives in the world. It is important to examine the factors affecting the price of caps, so that accurate and efficient pricing and hedging of caps are possible.

For the bond derivatives such as caps and floors, Collin-Dufresne, Goldstein, and others [18, 14, 19] and $\mathrm{Li}$ and Zhao [46] observed that the volatility of bond derivatives are not sensitive to the volatility of underlying assets. This was also observed by Heidari and Wu [37]. This suggests that the bond markets are not complete, which is contrary to the belief that bond markets are complete and all fixed income derivatives are replicated by bonds. It is difficult to hedge bond derivatives by bond itself. Consequently, the volatility risk in the bond markets is not hedged by bond itself and we need bond derivatives to hedge against the volatility risk. This volatility risk is commonly termed "unspanned volatility" or "unspanned stochastic volatility (USV)". The empirical work of Han [33], Jarrow, Li, and Zhao [40], and Rebonato [49] also supports the existence of USV.

On the other hand, there are studies questioning the existence of USV in the context of affine short rate models. Thompson [53], using a new class of specification tests, detects problems with the unrestricted affine model at the short end of the yield curve. In contrast to Collin-Dufresne, el. [19], he demonstrates that the USV restriction is rejected. Fan, Gupta, and Ritchken [29] find that methodological problems lead to the appearance of USV, while Bikbov and Chernov [10] find that measurement errors create the appearance of USV in the original study of Collin-Dufresne and Goldstein [18]. Fan, Gupta, and Ritchken question the methodology in [18] of using linear regressions of straddle returns on swap rates for assessing whether underlying bonds can span fixed income derivatives. The recent development in the modeling of USV is summarized in Nawalkha, Beliaeva, and Soto [47].

These contrasting observations or arguments motivate further study of USV. The main objective of this thesis is to study USV and make a contribution toward understanding the USV and caps market.

A goal of Chapter 2 is to discuss the pricing of caps based on the model (2.1.1) which has a character of "unspanned volatility". This model is a version of an HJM formulation discussed in [14]. One interesting aspect of the model is that the volatility which affects pricing of caps and floors is independent of bond market. Casassus, Collin-Dufresne, and Goldstein [14] analyzed this class of models and some calibration has been done. 
We calibrate the cap prices using the model (2.1.1) and compare them with the market caps. We choose the parameters of the model so that the difference between prices of the theoretical (the model based) caps and those of the market caps will be minimum. We compare the model with the Vasicek model, a benchmark model. We also study the effects of jump processes. For simplicity of calibration we use a specific form of jumps to examine the effects of jumps in the interest rate and volatility. The importance of jumps in interest rate models are discussed by Johannes [41], where he claims that unexpected news about macro economy generates jumps in interest rates and they are important for pricing interest rate options.

The main method of derivation of cap prices is the Fourier transform. We make use of the fact that the characteristic function is basically the Fourier transform of the solution. We apply the Fourier transform to the partial differential equation governing the caps and obtain the ordinary differential equations (ODEs). Then, after solving the ODEs, we apply the inverse transform to obtain the solution representations.

The class of models we study is called the affine-class. Despite some problems with the predictability, they became a dominant class of models because of its analytical tractability. For a wide class of affine jump diffusion models, Duffie, Pan, and Singleton [27] obtained closed-form solutions for both bond and bond-option prices. Collin-Dufresne and Goldstein [18], and Singleton and Umantsev [52] presented efficient approximation methods for pricing swaptions, and the closed-form moment conditions for empirical analysis are discussed in Singleton [51] and Pan [48].

The calibration is done for five models. They are the Vasicek model, the USV model without jumps, the USV model with jumps, the USV model with jump in the interest rate only, and the USV model with jump in the volatility only. To compare the models under different economic conditions, six days with 90 data days apart are chosen. Also, the calibration of parameters for five days spanning for five weeks is performed.

In Chapter 3 we study empirically the effects of macroeconomic announcements and fed announcements on the implied volatility of difference caps. The bonds are affected by the various economic activities. Since caps are bond derivatives, it is interesting to examine how the economic activities influence the cap prices. The difference cap is the difference of two consecutive maturity caps. As caps are the sum of caplets, it is difficult to isolate the effects of the announcements especially for the longer maturities. However, caplets are not observed on the market. We use difference caps to study the above effects on the caps market. By studying the difference caps we are able to isolate the effects on shorter to longer maturities.

For the bonds, Ludvigson and $\mathrm{Ng}$ [45] used the method of principal components to estimate common factors from a monthly panel of 132 measures of macroeconomic activity which may influence bond prices. They find that several estimated common factors have important forecasting power for future term premiums on U.S. government bonds. They also follow the idea of Cochrane and Piazzesi to construct single predictor state variables from these factors by forming linear combinations of the either five or six estimated common factors. They find that such state variables forecast bond term premiums at all maturities (two to five years), and do so virtually as well as a regression model that includes each common factor in the linear combination as a separate predictor variable. Concerning the bond derivatives, the effects of macroeconomic announcements to the implied volatility in swaption markets are studied in Fornari [32]. He observed a pattern of volatility spikes on certain announcements.

As mentioned earlier it has been observed that the prices of caps are driven by risk factors not spanned by the factors explaining LIBOR rates, even though caps are derivatives of bonds. Therefore, it is interesting to perform the regressions similar to [45] on the implied volatility of caps to see how the economic activities affect the cap prices. Using 21 series of macroeconomic announcements, we first perform the event analysis to see which macroeconomic announcements affect the caps implied volatility. We also apply the principal component analysis and use the first three principal components as the regressors. From the cap data we compute the daily implied 
volatility for all maturities and strike rates and regress them with the principal components on macroeconomic announcements. We also examine the effect of the fed announcements.

Out of 21 macroeconomic data except the weekly unemployment data, all other data are monthly and they are sparse in time. The question arises as to how we use the data. One way is to use only the days when at least one macroeconomic announcement is made. Another way is to construct the time series of a macroeconomic announcement by filling the days without that announcement the most recent data. We see vivid difference between two methods. The second method gives better results than the first method. This may show that the effects of macroeconomic announcements are not instantaneous but rather transient or persistent.

In Chapter 4 we study the caps term premium. The term premium of treasury bonds is first discussed in Cochrane and Piazzesi [16, 17]. In their paper the term premium is defined as the difference in the prices between holding one unit of $T$-year bonds and holding one unit of one-year bonds and then one unit of $(T-1)$-year bonds after one year. This is also termed excess return and measures the risk of holding longer maturity bonds. In finance this corresponds to selling one-year bond, buying $T$-year bond and selling it as $(T-1)$-year bond after one year.

We examine whether the similar results hold for Caps. We regress the caps term premium with the difference caps. As noted above Cochrane and Piazzesi did the similar analysis on the treasury bonds. If there is no uncertainty, the term premium is zero, because holding longer term caps and holding two shorter term caps would not make any difference. Uncertainty causes the deviation from being equal. It would be interesting to see if persistent patterns are observed or not. If such a pattern is observed, it would aid the predictability of cap prices. The patterns we observe are oscillatory and are different from the hump shape observed in [16].

We also study the effects of volatility on the caps term premium. Specifically, we examine the Granger causality of implied volatility and unspanned volatility on the caps term premiums. The unspanned volatility can be defined as a part of implied volatility of caps unsynchronized with the volatility in bonds. As in the previous Chapter we choose as the proxies the residuals of regressions of the implied volatility with the LIBOR and the GARCH based conditional volatility of LIBOR bonds. We compare the above three to see if there is a difference.

Also, for the sake of investing we examine the relation between the performance of caps term premiums and the above three measures of volatility. For each maturity and strike rate, we choose the dates when the 20 highest and lowest values of caps term premiums occur and also choose the dates when the 20 highest and lowest volatilities occur in each of the above measure of volatilities. Then, we see how many matches we get for each pairing. We see if the higher volatility leads to the higher caps term premiums or the other way is more likely to be the case. 


\section{Chapter 2}

\section{Calibration of Caps with Unspanned Volatility Models}

\section{$2.1 \quad$ Introduction}

Caps are a contract where the interest rates are capped at some fixed value $\bar{r}$. Purchasers of caps pay the prevailing interest rate if it is below $\bar{r}$, but pay the interest rate $\bar{r}$ if the prevailing rate is above $\bar{r}$. In the latter case the sellers of caps pay the difference. Therefore, the purchasers are able to prevent risks associated with the future change in interest rates. Caps consist of caplets which are European options on bonds based on LIBOR (the London Inter-Bank Offer Rates). The rates consist of spot, 3-month forward, 6 month forward, 1 year forward, 2 year forward, 3 year forward, 4 year forward, 5 year forward, 7 year forward and 10 year forward.

For the bond derivatives such as caps and floors, it has been observed that the volatility of bond derivatives are not sensitive to the volatility of underlying assets. Collin-Dufresne, Goldstein, and others $[18,14,19]$ and $\mathrm{Li}$ and Zhao [46] observed that the volatility of bond derivatives are not sensitive to the volatility of underlying assets. This was also observed by [37]. This suggests that the bond markets are not complete, which is contrary to the belief that bond markets are complete and all fixed income derivatives are replicated by bonds. It is difficult to hedge bond derivatives by bond itself. Consequently, the volatility risk in the bond markets is not hedged by bond itself and we need bond derivatives to hedge against the volatility risk. This volatility risk is commonly termed "unspanned volatility".

One model which has a character of "unspanned volatility" is

$$
\begin{aligned}
\frac{d P(t, T)}{P(t, T)} & =r d t-B_{r}(T-t) \sqrt{\alpha_{r}+v} d w_{r}^{Q}+\sigma_{r v} \sqrt{v} d w_{v}^{Q}, \\
d v_{t} & =\left(\gamma_{v}(t)-\kappa_{v} v_{t}\right) d t+\sigma_{v} \sqrt{v_{t}} d w_{v}^{Q}(t) .
\end{aligned}
$$

This is a version of an HJM formulation discussed in [14]. One interesting aspect of this model is that the volatility which affects pricing of caps and floors is independent of bond market. Casassus, Collin-Dufresne, and Goldstein [14] analyzed this class of models including the above model and some calibration has been done.

A goal of this paper is to discuss the pricing of caps based on the above model. We calibrate the cap prices using the above model and compare them with the market caps. We choose the parameters of the model so that the difference between prices of the theoretical (the model based) caps 
and those of the market caps will be minimum. We also study the effects of jump processes. The importance of jumps in interest rate models are discussed by Johannes [41], where he claims that unexpected news about macro economy generates jumps in interest rates and they are important for pricing interest rate options.

The main method of derivation of cap prices is the Fourier transform. We make use of the fact that the characteristic function is basically the Fourier transform of the solution. We apply the Fourier transform to the partial differential equation governing the caps and obtain the ordinary differential equations (ODEs). Then, after solving the ODEs, we apply the inverse transform to obtain the solution representations.

The class of models we study is called the affine-class. Despite some problems with the predictability, they became a dominant class of models because of its analytical tractability. For a wide class of affine jump diffusion models, Duffie, Pan, and Singleton [27] obtained closed-form solutions for both bond and bond-option prices. Collin-Dufresne and Goldstein [18], and Singleton and Umantsev [52] presented efficient approximation methods for pricing swaptions, and the closed-form moment conditions for empirical analysis are discussed in Singleton [51] and Pan [48].

In Section 2.2, the literature survey is performed and the derivation of models is discussed in Section 2.3. In Section 2.4various calibrations are performed including the comparison of five models for six different days with 90 days apart and the comparison of the USV models with and without jumps for five days spanning for five weeks.

\subsection{Literature Survey}

First, we summarize the various models on the interest rate and the bond derivatives. We restrict the models to mostly affine class since they are tractable and often closed solutions are available.

The most basic model for the interest rate is the Vasicek model [54]. In this model the interest rate $r(t)$ evolves according to

$$
d r=a(\theta-r) d t+v d w,
$$

where $\theta$ is the historical average of instantaneous interest rate, $a$ is the speed of mean reversion, $v$ is the constant volatility, and $d w$ is a standard Wiener process. The interest rate follows a mean reversion process. For this process the price $U(r, t)$ of a security paying continuously at a rate $h(r, t)$ and yielding a terminal payoff $g\left(r_{T}\right)$ at time $T$ satisfies the partial differential equation

$$
\begin{gathered}
U_{t}+\frac{1}{2} \sigma^{2} U_{r r}+a(\bar{r}-r) U_{r}-r U+h=0, \\
U(r, T)=g(r),
\end{gathered}
$$

where $\bar{r}=r_{0}+\frac{\lambda \sigma}{a}$. The exact solutions are obtained by Jamshidian [39]. An extension of (2.2.2) where the diffusion is affine was discussed in Cox, Ingersoll, and Ross [22].

These single variable models turn out to be inadequate to explain the phenomena such as volatility smile and fat tails. There are various models proposed to improve the above shortcomings. Typical modifications are to make volatility and/or mean reversion stochastic and/or to add jump processes. In what follows, we describe some of the models incorporating these features. We start with affine class where both drifts and diffusions are affine. The affine models are used most since they are analytically tractable and often closed or near closed solutions are available.

Within the affine class, a typical modification along the line of stochastic volatility models is to make both $\theta$ and $v$ stochastic and consider the process

$$
d Y(t)=\kappa(\Theta-Y(t)) d t+\Sigma \sqrt{S(t)} d W(t),
$$


where

$$
Y(t)=\left[\begin{array}{c}
r \\
\theta \\
v
\end{array}\right], \quad \Theta=\left[\begin{array}{c}
0 \\
\theta_{0} \\
v_{0}
\end{array}\right], \quad d W(t)=\left[\begin{array}{c}
d w_{r} \\
d w_{\theta} \\
d w_{v}
\end{array}\right],
$$

$\kappa$ and $\Sigma$ is a $3 \times 3$ matrix, and $S(t)$ is a diagonal matrix with the $i$ th diagonal element given by $S(t)_{i i}=\alpha_{i}+\beta_{i}^{\prime} Y(t)$. The above is a 3 -variate affine model and is a special case of $N$-variate models discussed in Duffie and Singleton [26]. For the above models, they defined the admissible class and studied the specification analysis. Using the method of simulated moments proposed by Duffie and Singleton [26] and Gallant and Tauchen [28], they examined the goodness-of-fit for various choices of the parameter vector $\psi=(\kappa, \Theta, \Sigma, \Lambda, \alpha)$, where $\Lambda=\left(\beta_{1}, \ldots, \beta_{N}\right)$ is the matrix of coefficients of $Y(t)$ in $S(t)_{i i}$. In particular when $N=3$, they classified the models into four subfamilies according to the number of variables appearing in the conditional volatility, i.e., in $S(t)$.

Concerning the relation between the bond prices and the prices of bond derivatives such as caps and floors, Collin-Dufresne, Goldstein, and others [18, 14, 19] and Li and Zhao [46] observed that the volatility of bond derivatives are not sensitive to the volatility of underlying assets. This was also observed by Heidari and Wu [37]. This suggests that the bond markets are not complete, which is contrary to the belief that bond markets are complete and all fixed income derivatives are replicated by bonds. Therefore, it is difficult to hedge bond derivatives by bond itself and consequently, the volatility risk in the bond markets is not hedged by bond itself and we need bond derivatives to hedge against such a risk. This volatility risk is commonly termed "unspanned volatility".

Casassus, Collin-Dufresne, and Goldstein [14] analyzed "unspanned volatility" models including (2.1.1) and some calibration has been done. In [18] they present empirical evidence suggesting that interest rate volatility risk cannot be hedged by a portfolio consisting solely of bonds. They also show that it is not possible for bivariate Markov affine models to exhibit USV behavior and demonstrate that even nonaffine bivariate models of the short rate cannot generate USV. Furthermore they identify necessary and sufficient conditions for a trivariate Markov system to exhibit USV. Collin-Dufresne, Goldstein, and Jones [19] observe that standard affine models have trouble simultaneously fitting some cross sectional and time-series properties of yield curve. They show another trade-off between capturing cross-sectional and time-series properties of term structure. The $A_{1}(3)$ model in [23] cannot simultaneously describe the yield curve's level, slope, curvature, and volatility. That is, volatility can not play the dual role. The maximum likelihood estimation results in weight placed on the first role than the second. They propose a representation for affine term structure models in terms of the derivatives of the term structure at zero and their quadratic co-variations.

Another effort is to add jump processes in the model. The importance of jumps in interest rate models are discussed by Johannes [41], where he claims that unexpected news about macro economy generates jumps in interest rates and they are important for pricing interest rate options. Chen and Scott [20] examined the possible stochastic volatility and jumps in short term interest rates for major countries. They studied the following model.

$$
\begin{aligned}
d r & =b \sqrt{v} d w+d z_{r} \\
d v & =\kappa\left(\gamma_{v}-v\right) d t+\sigma_{v} \sqrt{v} d w_{v}^{Q}+d z_{v} .
\end{aligned}
$$

They examine empirically the daily data on futures rates and implied volatilities and test for deviations from diffusion based models. They discretized the above model and obtained

$$
\begin{aligned}
\triangle F R(t) & =b \sqrt{v(t-1)} \Delta w_{1}(t)+\triangle Z_{1}(t) \\
v(t) & =\mu+\rho v(t-1)+\sigma \sqrt{v(t-1)} \Delta w_{2}+\triangle Z_{2}(t),
\end{aligned}
$$


where $\rho=\exp (-\kappa \Delta t)$ and $\mu=\theta(1-\rho)$. They apply a maximum likelihood method to obtain the log-likelihood function for a sample of observations on $\triangle F R(t)$ based on the method discussed in [9]. They observe the importance of stochastic volatility and jumps. The importance of jump processes is also suggested by Bakshi, Cao, and Chen [5], Bates [7], and Pan [48]. Huang and Wu [38] studied jump diffusion models for S\&P 500 options. They did the specification analysis to answer the two questions: (a) what types of jump structure best describes the underlying price movement and return innovation distribution? (b) Which component, the jump component or the diffusion component, determines the time variation of return volatility? For (a) they examined 4 jump processes. For (b) they apply stochastic time-change process to examine which component is more important than the other. It may be interesting to consider a specification analysis for the bond markets.

USV models combined with other effects such as jumps are useful in explaining the volatility smile. The implied volatility is not constant across strike rates and lower around at the money and higher in and out of the money. This is called the smile and USV models extended with jumps and USV models with constant-elasticity-of-variance and/or displaced-diffusion forward rate processes considered in Joshi and Rebonato [43] and Brace, Dun, and Barton [11] present two alternative perspectives on the existence of the caplet smile.

Aït-Sahalia [3] studied the maximum likelihood estimation for stochastic volatility models. He developed series approximations to the likelihood function for arbitrary multivariate continuous time diffusions at discrete time of observations. He uses closed form approximations to the true (but unknown) likelihood of the joint observations on the underlying asset and either option prices or volatility state variables themselves. The data we use are discrete sample of continuous process.

One interesting question is whether we can distinguish continuous diffusion processes and discontinuous jump processes. Aït-Sahalia [4] considered disentangling diffusion from jumps. Car and $\mathrm{Wu}[13]$ developed a simple robust method to distinguish the presence of continuous and discontinuous components in the price of an asset underlying options.

The models discussed so far are the affine class of term structure models. They became a dominant class of models because of its analytical tractability. For a wide class of affine jump diffusion models, Duffie, Pan, and Singleton [27] obtained closed-form solutions for both bond and bond-option prices. Collin-Dufresne and Goldstein [18], and Singleton and Umantsev [52] presented efficient approximation methods for pricing swaptions, and closed-form moment conditions for empirical analysis are discussed in Singleton [51] and Pan [48]. However, recently Duffee (2002) and Dai and Singleton [23] have reported that standard affine models have trouble simultaneously fitting some cross-sectional and time-series properties of the yield curve. For example, Duffee (2002) reports that standard three-factor affine models cannot match the observed relationship between expected returns on bonds and the slope of the term structure. The part of the reasons is that fitting expected returns is tied to physical measure dynamics and fitting the cross-section of bonds is determined by the risk-neutral distribution.

Affine term structure models (ATSMs) have a theoretical drawback. Ahn and Gao [2] suggest that both drifts and diffusions are nonlinear and studied a nonlinear term structure model based on the interest rate process given by

$$
d r=\kappa(\theta-r(t)) r(t) d t+\sigma r(t)^{\frac{3}{2}} d w .
$$

Furthermore, Ahn, Dittmar, and Gallant[1] indicate that the form of ATSMs results in a tradeoff between the structure of the correlation matrix for the state variables and their conditional variance. They studied quadratic models and have shown that there are class of quadratic term structure model (QTSM) which provides the term structure dynamics considerably better than ATSMs. Note that this trade-off was also indicated by Collin-Dufresne, Goldstein, and Jones [19].

Cotton, Fouque, Papanicolaou, and Sircar [21] proposed a stochastic volatility model where the 
volatility depends on the other variable(s)

$$
\begin{aligned}
d r & =a\left(r_{0}-r\right) d t+f(v) d w_{r} \\
d v & =\kappa\left(\gamma_{v}-v\right) d t+\sigma\left\{\rho d w_{r}+\sqrt{1-\rho^{2}} d w_{v}\right\} .
\end{aligned}
$$

They investigated the effect of fast mean-reverting stochastic volatility using the expansion method.

Another approach is to model the LIBOR markets directly. Jarrow, Li, and Zhao [40] considered the process in which the LIBOR markets follow the stochastic process.

$$
\frac{d L_{k}(t)}{L_{k}(t)}=\alpha_{k}(t) d t+\sum_{j=1}^{N} U_{T_{k-t, j}} \sqrt{V_{j}(t)} d w_{j}+d z_{k},
$$

where $V_{j}(t)$ are stochastic volatilities which follow

$$
d V_{j}(t)=\kappa_{j}\left(\bar{v}_{j}-V_{j}(t)\right) d t+\xi_{j} \sqrt{V_{j}(t)} d \tilde{w}_{j} .
$$

Their analysis shows that a low dimensional LIBOR rate model with three principal components, stochastic volatility for each component, and strong negative jumps are necessary to capture the volatility smile in the cap market reasonably well. The three yield factors capture the variations of the levels of LIBOR rates, while the stochastic volatility factors are essential to capture the time varying volatility of LIBOR rates. Even though a three-factor stochastic volatility model can price at-the-money caps reasonably well, it fails to capture the volatility smile in the cap market. Significant negative jumps in LIBOR rates are needed to do capture it. The importance of negative jumps is revealed only through the pricing of caps across moneyness.

\subsection{Derivation of the Models}

A cap is a financial instrument where a purchaser buys it in order to avoid variable interest rates. The price of caps is determined by the interest rate, strike rates, and maturity. The prices of market caps on 8/1/2000 are given in Table 2.1. The cap consists of "caplet", which is an European option with period $\tau$ called tenor. $\tau$ is usually $1 / 4$ year. Suppose at $t=0$ a cap with maturity $n$ years and with strike rate at $\bar{r}$ is purchased. Then, at each date $j \tau$ the purchaser receives $\tau(r((j-1) \tau, j \tau)-\bar{r})^{+}$, where $r((j-1) \tau, j \tau)$ is the $\tau$-year floating interest rate evaluated at $(j-1) \tau$. This means that the amount of the money the purchaser is determined at date $(j-1) \tau$ and then he receives it at $j \tau$. The price of cap is the sum of the present values of the above income stream. Therefore, if we denote the price of caplet at $t<(j-1) \tau$ by $C_{r}(t,(j-1) \tau, \bar{r})$, the price of cap at $t=0$ is given by

$$
\begin{aligned}
C_{\text {theo }}(0, m, \bar{r}) & =\sum_{j=1}^{m / \tau} C_{r}(0,(j-1) \tau, \bar{r}) \\
& =\sum_{j=1}^{m / \tau} E^{Q}\left[e^{-\int_{0}^{j \tau} r_{s} d s} \tau(r((j-1) \tau, j \tau)-\bar{r})^{+}\right] .
\end{aligned}
$$

In this section we derive the models for cap pricing which will be used in the calibrations. This model was derived by Casassus, Collin-Dufresne, and Goldstein [14]. First, we describe the basic aspects of the price of caps and caplets, and then we derive the formula for caplets. The derivation is obtained through series of lemmas. Their proofs are given in Section 2.6. 
Table 2.1: The prices of market caps on $\mathbf{8 / 1 / 2 0 0 0}$. The market caps on $8 / 1 / 2000$ are given for the sake of reference. The values of market caps violating the monotonicity or the convexity condition are removed from consideration. The caps with value zero are also removed. "NaN" indicates that the caps are removed.

\begin{tabular}{lrrrrrrrrrr}
\multicolumn{10}{c}{ Caps on 8/1/2000 } \\
$\begin{array}{l}\text { Strike rates } \\
\text { Maturity }\end{array}$ & 0.04000 & 0.04500 & 0.05000 & 0.05500 & 0.06000 & 0.06500 & 0.07000 & 0.08000 & 0.09000 & 0.10000 \\
\hline 0.5 & 0.00729 & 0.00603 & $\mathrm{NaN}$ & 0.00315 & $\mathrm{NaN}$ & 0.00109 & 0.00025 & $\mathrm{NaN}$ & $\mathrm{NaN}$ & $\mathrm{NaN}$ \\
1.0 & 0.02113 & 0.01753 & 0.01393 & 0.01036 & 0.00689 & 0.00373 & 0.00136 & 0.00014 & 0.00001 & $\mathrm{NaN}$ \\
1.5 & 0.03501 & 0.02908 & 0.02318 & 0.01737 & 0.01180 & 0.00683 & 0.00304 & 0.00054 & 0.00013 & 0.00003 \\
2.0 & 0.04821 & 0.04008 & 0.03204 & 0.02418 & 0.01678 & 0.01030 & 0.00497 & 0.00131 & 0.00039 & 0.00011 \\
2.5 & 0.06099 & 0.05077 & 0.04071 & 0.03097 & 0.02190 & 0.01403 & 0.00758 & 0.00247 & 0.00090 & 0.00031 \\
3.0 & 0.07338 & 0.06117 & 0.04924 & 0.03775 & 0.02717 & 0.01803 & 0.01070 & 0.00403 & 0.00169 & 0.00069 \\
3.5 & 0.08549 & 0.07138 & 0.05767 & 0.04456 & 0.03254 & 0.02218 & 0.01372 & 0.00564 & 0.00254 & 0.00112 \\
4.0 & 0.09722 & 0.08133 & 0.06595 & 0.05134 & 0.03799 & 0.02652 & 0.01697 & 0.00746 & 0.00354 & 0.00166 \\
4.5 & 0.10860 & 0.09103 & 0.07414 & 0.05813 & 0.04360 & 0.03112 & 0.02038 & 0.00950 & 0.00474 & 0.00235 \\
5.0 & 0.11953 & 0.10043 & 0.08251 & 0.06486 & 0.04925 & 0.03586 & 0.02392 & 0.01170 & 0.00608 & 0.00316 \\
6.0 & 0.14129 & 0.11921 & 0.09819 & 0.07833 & 0.06044 & 0.04504 & 0.03102 & 0.01627 & 0.00896 & 0.00502 \\
7.0 & 0.16190 & 0.13713 & 0.11364 & 0.09146 & 0.07151 & 0.05427 & 0.03828 & 0.02112 & 0.01211 & 0.00723 \\
8.0 & 0.18116 & 0.15382 & 0.12794 & 0.10357 & 0.08148 & 0.06229 & 0.04496 & 0.02556 & 0.01528 & 0.00918 \\
9.0 & 0.19930 & 0.16965 & 0.14164 & 0.11525 & 0.09132 & 0.07048 & 0.05146 & 0.02991 & 0.01796 & 0.01102 \\
10.0 & 0.21652 & 0.18476 & 0.15480 & 0.12657 & 0.10094 & 0.07857 & 0.05817 & 0.03454 & 0.02112 & 0.01314 \\
\hline
\end{tabular}

\subsubsection{A Two Factor Unspanned Volatility Model}

The price of caplets in (2.3.3) is given in terms of interest rate. However, it is common to use the underlying bonds to price caplets. In this Subsection we first derive the price of caplets using underlying bonds and then from Lemma 2.6.4 we obtain the price of caplets in (2.3.3).

We derive the pricing of caps based on the two factor unspanned volatility model. The details are given in Lemma 2.6.1 through Lemma 2.6.4. The derivation consists of two steps. First, we derive the price process of bonds and then we derive the cap price. We assume that the interest rate $r_{t}$ and the volatility $v_{t}$ follow the stochastic processes given by

$$
\begin{aligned}
& d r_{t}=\kappa_{r}\left(\theta-r_{t}\right) d t+\sqrt{\alpha_{r}+v_{t}} d w_{r}^{Q}(t)+\sigma_{r v} \sqrt{v_{t}} d w_{v}^{Q}(t), \\
& d v_{t}=\left(\gamma_{v}(t)-\kappa_{r} v_{t}\right) d t+\sigma_{v} \sqrt{v_{t}} d w_{v}^{Q}(t) .
\end{aligned}
$$

Let $P(t, T)$ be the price at $t$ of the bond which matures at $T$. Therefore, $P(T, T)=1$. Since we assume the unspanned volatility, the bond prices do not depend on the volatility. Consequently, we assume that the bond price $P(t, T)$ is given by

$$
P(t, T)=\exp \left\{A(t, T)-B_{r}(T-t) r_{t}\right\},
$$

where there is no contribution from the volatility to the movement of $P(t, T)$. To determine $A(t, T)$ and $B_{r}(T-t)$, we consider $y^{i}(t)=\ln P\left(t, T_{i}\right)-\int_{0}^{t} r_{s} d s$, which is basically the volatility part of the processes (2.3.4) and (2.3.5). Applying the Ito's lemma for $y^{i}(t)$, we have

$$
\begin{aligned}
d y^{i}(t)= & -\left[\left(A^{\prime}+B_{r}^{\prime} r_{t}\right) d t+B_{r}\left(\kappa_{r}\left(\theta-r_{t}\right) d t+\sqrt{\alpha_{r}+v_{t}} d w_{r}^{Q}(t)+\sigma_{r v} \sqrt{v_{t}} d w_{v}^{Q}(t)\right.\right. \\
& \left.+\frac{1}{2} \frac{1}{P^{T_{i}}} \frac{\partial^{2} P^{T_{i}}}{\partial r^{2}}\left(\alpha_{r}+v_{t}+\sigma_{r v}^{2} v_{t}\right) d t\right] \\
& +\frac{1}{2}\left[-\frac{1}{\left(P^{T_{i}}\right)^{2}}\left(\frac{\partial P^{T_{i}}}{\partial r}\right)^{2}+\frac{1}{P^{T_{i}}} \frac{\partial^{2} P^{T_{i}}}{\partial r^{2}}\right]\left(\alpha_{r}+v_{t}+\sigma_{r v}^{2} v_{t}\right) d t-r_{t} d t .
\end{aligned}
$$


Then, substituting (2.3.6) in (2.3.8) and setting the $r_{t}$ and constant terms equal to zero, we obtain

$$
\begin{aligned}
r_{t}: & B_{r}^{\prime}+\kappa_{r} B_{r}-1=0, \\
\text { const } & : \quad A^{\prime}-\kappa_{r} \theta B_{r}+\frac{1}{2} \alpha_{r} B_{r}^{2}=0 .
\end{aligned}
$$

Solving them, we see that

$$
\begin{aligned}
B_{r}(\tau) & =\frac{1}{k_{r}}\left(1-e^{-k_{r} \tau}\right) \\
A(t, T) & =\int_{t}^{T}\left(\kappa_{r} \theta B_{r}-\frac{1}{2} \alpha_{r} B_{r}^{2}\right) d s .
\end{aligned}
$$

Then, $d y^{i}(t)$ satisfies

$$
d y^{i}(t)=-\left[\sqrt{\alpha_{r}+v_{t}} d w_{r}^{Q}(t)+\sigma_{r v} \sqrt{v_{t}} d w_{v}^{Q}(t)+\frac{1}{2}\left(\alpha_{r}+v_{t}+\sigma_{r v}^{2} v_{t}\right) B_{r}^{2} d t\right] .
$$

The details of the derivation of $A(t, T), B_{r}(\tau)$, and $d y^{i}(t)$ are given in 2.6.1.

Now we derive the price of caplets. The payoff of caplet (an European bond option) with exercise date $T_{0}=(j-1) \tau$ is

$$
C_{P}\left(T_{0}, T_{0}, K\right)=\left(P\left(T_{0}, T_{1}\right)-K\right) 1_{\left\{P^{T_{1}}\left(T_{0}\right)>K\right\}},
$$

where $K$ is the strike price and $T_{1}=T_{0}+\tau=j \tau$. The relation between $K$ and the strike rate $\bar{r}$ of caplet is given by

$$
K=\frac{1}{1+\tau \bar{r}} .
$$

The price of the caplet at date $t(t=0$ is the beginning of the contract) before the expiration can be expressed as

$$
\begin{aligned}
C_{P}\left(t, T_{0}, K\right) & =E_{t}^{Q}\left[e^{-\int_{t}^{T_{0}} r_{s} d s}\left(P\left(T_{0}, T_{1}\right)-K\right) 1_{\left\{P\left(T_{0}, T_{1}\right)>K\right\}}\right] \\
& =E_{t}^{Q}\left[e^{-\int_{t}^{T_{0}} r_{s} d s} e^{\ln P\left(T_{0}, T_{1}\right)} 1_{\left\{\ln P\left(T_{0}, T_{1}\right)>\ln K\right\}}-K E_{t}^{Q}\left[e^{-\int_{t}^{T_{0}} r_{s} d s} 1_{\left\{\ln P\left(T_{0}, T_{1}\right)>\ln K\right\}}\right]\right. \\
& =\Psi_{t, 1}(\ln K)-K \Psi_{t, 0}(\ln K)
\end{aligned}
$$

where

$$
\Psi_{t, a}(k)=E_{t}^{Q}\left[e^{-\int_{t}^{T_{0}} r_{s} d s} e^{a \ln P\left(T_{0}, T_{1}\right)} 1_{\left\{P\left(T_{0}, T_{1}\right)>k\right\}}\right] .
$$

To obtain the form of $\Psi_{t, a}(k)$, we introduce

$$
\psi_{t}(a)=E_{t}^{Q}\left[e^{-\int_{t}^{T_{0}} r_{s} d s} e^{a P\left(T_{0}, T_{1}\right)}\right]
$$

We assume that $\psi_{t}(a)$ is given by

$$
\psi_{t}(a)=P\left(t, T_{0}\right) \exp \left\{M_{a}(t)+N_{a}(t) v(t)+a \ln P\left(T_{0}, T_{1}\right)\right\}
$$

and consider the process

$$
X(t)=e^{-\int_{0}^{t} r_{s} d s} \psi_{t}(a)=e^{-\int_{0}^{t} r_{s} d s} P\left(t, T_{0}\right) \exp \left(M_{a}(t)+N_{a}(t) v(t)+a \log \frac{P\left(t, T_{1}\right)}{P\left(t, T_{0}\right)}\right) .
$$


Using the fact that $X(t)$ is a martingale, we obtain the following differential equations for $M_{a}(t)$ and $N_{a}(t)$

$$
\begin{aligned}
0= & N_{a}^{\prime}-N_{a}(t)\left\{\kappa_{v}+\sigma_{v} \sigma_{r v}\left(a B_{r}\left(T_{1}-t\right)+(1-a) B_{r}\left(T_{0}-t\right)\right)\right\} \\
& +\frac{1}{2} N_{a}(t)^{2} \sigma_{v}^{2}+\frac{\left(1+\sigma_{r v}^{2}\right)}{2} V(t) \\
0= & M_{a}^{\prime}+N_{a}(t) \gamma_{v}(t)+\frac{\alpha_{r}}{2} V(t)
\end{aligned}
$$

with the terminal data $M_{a}\left(T_{0}\right)=0$ and $N_{a}\left(T_{0}\right)=0$. Here, $V(t)$ is given by

$$
V(t)=a(a-1)\left\{B_{r}\left(T_{1}-t\right)-B_{r}\left(T_{0}-t\right)\right\}^{2} .
$$

The details of the derivation of $A(t, T), B_{r}(\tau)$, and $d y^{i}(t)$ are given in 2.6.2.

Using the expression for $\psi_{t}(a)$, the expression for $\Psi_{t, a}(k)$ is given as

$$
\begin{aligned}
\Psi_{t, a}(k) & =\frac{1}{2 \pi} \int_{-\infty}^{\infty}\left[\frac{1}{i \omega}-\frac{\cos \omega A-i \sin \omega A}{i \omega}\right] \psi_{t}(a+i \omega) e^{-i \omega k} d \omega \\
& =\frac{1}{2} \psi_{t}(a)+\frac{1}{2} P\left(t, T_{0}\right) e^{a x}\left\{-\int_{-\infty}^{k-x} g_{a}(\bar{k}) d \bar{k}+\int_{k-x}^{\infty} g_{a}(\bar{k}) d \bar{k}\right\} \\
& =P\left(t, T_{0}\right) e^{a x} \int_{k-x}^{\infty} g_{a}(\bar{k}) d \bar{k},
\end{aligned}
$$

where $x=\log P\left(T_{0}, T_{1}\right)$ and $^{1}$

$$
g_{a}(\bar{k})=\frac{1}{2 \pi} \int_{-\infty}^{\infty} e^{M_{a+i \omega}(t)+N_{a+i \omega}(t) v(t)} e^{-i \omega \bar{k}} d \omega .
$$

The details of the derivation of (2.3.15) are given in 2.6.3.

Using (2.3.15), we can express the price of caplet $C_{p}\left(t, T_{0}, K\right)$ as follows.

$$
C_{P}\left(t, T_{0}, K\right)=P\left(t, T_{1}\right) \int_{\ln K-x}^{\infty} g_{1}(\bar{k}) d \bar{k}-K P\left(t, T_{0}\right) \int_{\ln K-x}^{\infty} g_{0}(\bar{k}) d \bar{k} .
$$

This form is very similar to the forms of various bond option prices.

In practice it is easier to use the following formula based on put-call parity to compute the price of caplets. The details are given in Lemma 2.6.4. Using this lemma, we have that, for $t \leq(j-1) \tau$, the caplet $C_{r}(t, j \tau, \bar{r})$ is given by

$$
\begin{aligned}
C_{r}(t, j \tau, \bar{r})= & (1+\tau \bar{r}) E^{Q}\left[\exp \left(-\int_{t}^{(j-1) \tau} r_{s} d s\right)\left\{P((j-1) \tau, j \tau)-\frac{1}{1+\tau \bar{r}}\right\}^{+}\right] \\
& +P(t,(j-1) \tau)-(1+\tau \bar{r}) P(t, j \tau) \\
= & (1+\tau \bar{r}) C_{P}(t, j \tau, K)+P(t,(j-1) \tau)-(1+\tau \bar{r}) P(t, j \tau) .
\end{aligned}
$$

\subsubsection{Two Factor Unspanned Volatility Models with Jumps}

We consider the case where jumps are added to (2.3.5). A possible jump-diffusion process is given by

$$
\begin{aligned}
d r_{t} & =\kappa_{r}\left(\theta-r_{t}\right) d t+\sqrt{\alpha_{r}+v_{t}} d w_{r}^{Q}(t)+\sigma_{r v} \sqrt{v_{t}} d w_{v}^{Q}(t)+d J_{r}, \\
d v_{t} & =\left(\gamma_{v}(t)-\kappa_{r} v_{t}\right) d t+\sigma_{v} \sqrt{v_{t}} d w_{v}^{Q}(t)+d J_{v} .
\end{aligned}
$$

\footnotetext{
${ }^{1}$ For the proof see Lemma 2.6.2.
} 
There are various jump processes, for example, the Poisson process and Levy process. There are several jump processes for which analytical expressions are possible. We restrict our attention to such jumps so that the calibrations will be simpler. We change $B_{r}$ slightly and assume that $P\left(t, T_{i}\right)$ and $\psi_{t}(a)$ are given by

$$
\begin{gathered}
P\left(t, T_{i}\right)=\exp \left\{A\left(t, T_{i}\right)+B_{r}\left(t, T_{i}\right) r_{t}\right\} . \\
\psi_{t}(a)=P\left(t, T_{0}\right) \exp \left\{M_{a}(t)+N_{a}(t) v(t)+a \ln P\left(T_{0}, T_{1}\right)\right\},
\end{gathered}
$$

The process $X\left(t, r_{t}, v_{t}\right)$ satisfies

$$
\begin{aligned}
d X= & -X r_{t}+(1-a) X \frac{d P\left(t, T_{0}\right)}{P\left(t, T_{0}\right)}+a X \frac{d P\left(t, T_{1}\right)}{P\left(t, T_{1}\right)}+X\left(M_{a}^{\prime}+N_{a}^{\prime} v(t)\right)+X N_{a}(t) d v \\
& +\frac{1}{2} \frac{\partial^{2} X}{\partial v^{2}}(d v)^{2}+\frac{1}{2} \frac{\partial^{2} X}{\partial P^{T_{0}}(t)^{2}}\left(d P\left(t, T_{0}\right)\right)^{2}+\frac{1}{2} \frac{\partial^{2} X}{\partial P\left(t, T_{1}\right)^{2}}\left(d P^{T_{1}}(t)\right)^{2}+\frac{1}{2} \frac{\partial^{2} X}{\partial r^{2}}(d r)^{2} \\
& +\frac{\partial^{2} X}{\partial v \partial P^{T_{1}}(t)} d v d P\left(t, T_{1}\right)+\frac{\partial^{2} X}{\partial v \partial P^{T_{0}}} d v d P\left(t, T_{0}\right)+\frac{\partial^{2} X}{\partial P^{T_{0}} \partial P^{T_{1}}(t)} d P\left(t, T_{1}\right) d P\left(t, T_{0}\right) \\
& +\frac{\partial^{2} X}{\partial v \partial r} d v d r+\frac{\partial^{2} X}{\partial r \partial P^{T_{0}}} d r d P\left(t, T_{0}\right)+\frac{\partial^{2} X}{\partial r \partial P^{T_{1}}(t)} d P\left(t, T_{1}\right) d r \\
& +\left(\lambda_{0}+\lambda_{r} r_{t}+\lambda_{v} v_{t}\right) \int_{-\infty}^{\infty} \int_{-\infty}^{\infty}\left\{X\left(t, r_{t}+x, v_{t}+y\right)-X\left(t, r_{t}, v_{t}\right)\right\} d G d x d y=0,
\end{aligned}
$$

where $\left(\lambda_{0}+\lambda_{r} r_{t}+\lambda_{v} v_{t}\right)$ is the arrival intensity of jumps which reflects the jump intensity of interest rate and volatility. We assume that the jump sizes of interest rate and volatility are distributed as a normal with zero mean and standard deviation $\sigma_{J_{r}}$ and $\sigma_{J_{v}}$, respectively.

Then, $A\left(t, T_{i}\right), B_{r}\left(t, T_{i}\right), M_{a}(t)$, and $N_{a}(t)$ satisfy the following differential equations. The proof is given in Lemma 2.6.6. From $r_{t}$ terms

$$
\begin{aligned}
0= & B^{\prime}\left(t, T_{0}\right)-B_{r}\left(t, T_{0}\right) \kappa_{r}-1 \\
& +\lambda_{r}\left(\exp \left\{\frac{1}{2} \sigma_{J_{v}}^{2} N_{a}(t)^{2}+\frac{1}{2} \sigma_{J_{r}}^{2}\left(a B_{r}\left(t, T_{1}\right)+(1-a) B_{r}\left(t, T_{0}\right)\right)^{2}\right\}-1\right) \\
0= & B^{\prime}\left(t, T_{1}\right)-B_{r}\left(t, T_{1}\right) \kappa_{r}-1 \\
& +\lambda_{r}\left(\exp \left\{\frac{1}{2} \sigma_{J_{v}}^{2} N_{a}(t)^{2}+\frac{1}{2} \sigma_{J_{r}}^{2}\left(a B_{r}\left(t, T_{1}\right)+(1-a) B_{r}\left(t, T_{0}\right)\right)^{2}\right\}-1\right)
\end{aligned}
$$

From the constant terms,

$$
\begin{aligned}
& 0=A^{\prime}\left(t, T_{0}\right)+B_{r}\left(t, T_{0}\right) \kappa_{r} \theta+\frac{1}{2} B_{r}\left(t, T_{0}\right)^{2} \alpha_{r} \\
& 0=A^{\prime}\left(t, T_{1}\right)+B_{r}\left(t, T_{1}\right) \kappa_{r} \theta+\frac{1}{2} B_{r}\left(t, T_{1}\right)^{2} \alpha_{r}
\end{aligned}
$$

$M_{a}(t)$ and $N_{a}(t)$ satisfy the following differential equations. From $v_{t}$ terms,

$$
\begin{aligned}
0= & N_{a}^{\prime}-N_{a}(t)\left\{\kappa_{v}-\sigma_{v} \sigma_{r v}\left(a B_{r}\left(t, T_{1}\right)+(1-a) B_{r}\left(t, T_{0}\right)\right)\right\} \\
& +\frac{1}{2} N_{a}(t)^{2} \sigma_{v}^{2}+\frac{\left(1+\sigma_{r v}^{2}\right)}{2} V(t) \\
& +\lambda_{v}\left(\exp \left\{\frac{1}{2} \sigma_{J_{v}}^{2} N_{a}(t)^{2}+\frac{1}{2} \sigma_{J_{r}}^{2}\left(a B_{r}\left(t, T_{1}\right)+(1-a) B_{r}\left(t, T_{0}\right)\right)^{2}\right\}-1\right) \\
0= & M_{a}^{\prime}+N_{a}(t) \gamma_{v}(t)+\frac{\alpha_{r}}{2} V(t) \\
& +\lambda_{1}\left(\exp \left\{\frac{1}{2} \sigma_{J_{v}}^{2} N_{a}(t)^{2}+\frac{1}{2} \sigma_{J_{r}}^{2}\left(a B_{r}\left(t, T_{1}\right)+(1-a) B_{r}\left(t, T_{0}\right)\right)^{2}\right\}-1\right)
\end{aligned}
$$




\subsection{Calibration of Caps}

In this section we use the model derived in the previous section and examine the parameter estimation in more detail. There are several goals. First, we compare the unspanned volatility models with a benchmark model such as Vasicek model. Second, we estimate the parameters for an unspanned volatility model through calibration. Third, we examine the effects of jumps in the process. We examine the several alternatives depending on to which processes we add the jumps. Especially interesting case is the case where we add a jump process to the stochastic volatility. First, we discuss the data and then explain how the calibration is carried out. In the examples we examine the several models without the jumps and with jumps so that the first and third goals are achieved.

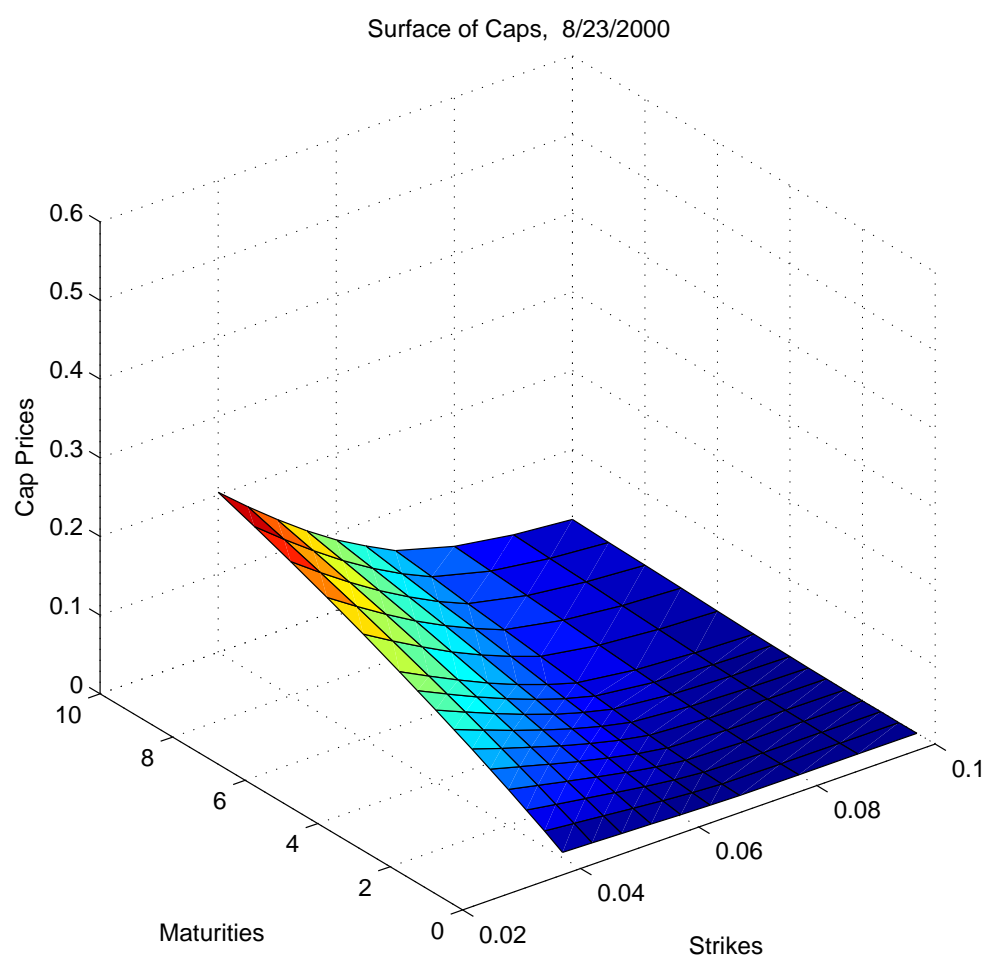

Figure 2.1: Surface graph of the market cap prices. The surface graph of the market cap prices on $8 / 23 / 2000$ is given.

\subsubsection{Data}

We use the caps and the LIBOR data from August 1st, 2000 to July 31st, 2002. We remove the outliers and inconsistent data. Caps data set spans from August 1, 2000 to July 31, 2002. Throughout the whole sample period, caps have 15 different maturities, which are $0.5,1.0,1.5$, $2.0,2.5,3.0,3.5,4.0,4.5,5.0,6.0,7.0,8.0,9.0$, and 10.0 years. For each maturity, there are 10 different strike prices, which changed several times during the period. Between August 1, 2000 and October 17, 2001 the strike prices were 4.0, 4.5, 5.0, 5.5, 6.0, 6.5, 7.0, 8.0, 9.0, and 10.0\%. The strike prices were lowered to 1.0, 1.5, 2.0, 2.5, 3.0, 3.5, 4.0, 4.5, 5.0, and 5.5\% between October 18 , 
2001 and November 1, 2001. Between November 2, 2001 and July 15, 2002 they were 2.5, 3.0, 3.5, 4.0, 4.5, 5.0, 5.5, 6.0, 6.5, and 7.0\%. Then, between July 16, 2001 and April 14, 2003 they were lowered to $2,2.5,3.0,3.5,4.0,4.5,5.0,5.5,6.0$, and $6.5 \%$. The change in the strike rates reflects the collapse of the world trade center on September 11th, 2001. There are caps with maturities $m=0.5,1.0,1.5$. These are excluded from calibration due to the short maturities. This practice is commonly done.

To obtain the quarterly data we use the spline to interpolate the caps data. We construct the zero coupon bond prices $P^{T}(t)$ from the LIBOR data using the relation

$$
P(t, t+\tau)=\frac{1}{1+\tau L(t, \tau)}
$$

As a reference the surface graphs of caps and implied volatility are given in Figures 2.1 and 2.2, respectively.

Surface of Implied Volatility, 8/23/2000

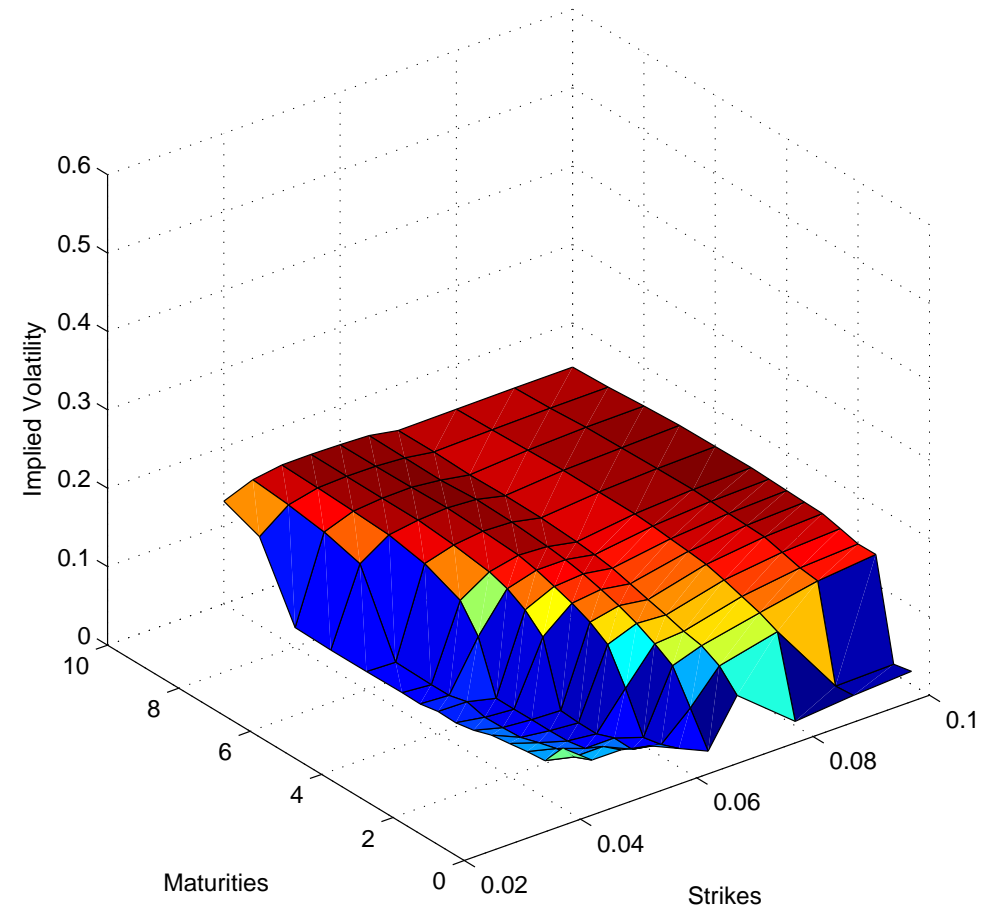

Figure 2.2: Surface graph of implied volatility of the market cap prices. The surface graph of implied volatility of the market cap prices on $8 / 23 / 2000$ is sketched.

\subsubsection{Implementation}

Let $C_{r}\left(t_{0}, t_{0}+(j-1) \tau, \bar{r}\right)$ be the price of a caplet at calender date $t_{0}$ with the expiration date $t_{0}+(j-1) \tau$ with strike rate $k$. The price of $m$ th theoretical cap $C_{t h e o}(t, m, k)$ with the strike 
price $k$ is given by

$$
C_{\text {theo }}\left(t_{0}, m, k\right)=\sum_{j=1}^{N(m) / \tau} C_{r}\left(t_{0}, t_{0}+(j-1) \tau, \bar{r}\right),
$$

where $N(m)$ is the $m$ th component of the set of maturities $N=[0.5,1,1.5,2,2.5,3,3.5,4,4.5,5,5.5,6,7,8,9,10]$. If we denote the market price of $m$ th cap with the strike rate $k$ by $C_{m a r}\left(t_{0}, m, k\right)$. Then, it seems natural to choose the parameters $S$ so that we minimize

$$
\min _{S} \sum_{t_{0}} \sum_{m} \sum_{k}\left[C_{\text {theo }}\left(t_{0}, m, k\right)-C_{\text {mar }}\left(t_{0}, m, k\right)\right]^{2} .
$$

This minimization has a drawback that caplets with lower maturities are calculated more than once. Unfortunately we can not use the caplets for the above calculation because they are not observable. An observable quantity which we use for calibration is called the difference cap. This is defined as

$$
C_{\text {theo-diff }}\left(t_{0}, m, k\right)=C_{\text {theo }}\left(t_{0}, m, k\right)-C_{\text {theo }}\left(t_{0}, m-1, k\right),
$$

where $C_{\text {theo }}\left(t_{0}, m-1, k\right)=0$ is used if $m=1$. The difference caps consist of two to four caplets. The market difference caps are defined in a similar way. Therefore, for the calibration we minimize

$$
\min _{S} \sum_{t_{0}} \sum_{m} \sum_{k}\left[C_{\text {theo-diff }}\left(t_{0}, m, k\right)-C_{\text {mar-diff }}\left(t_{0}, m, k\right)\right]^{2} .
$$

For the sake of reference, the difference caps on $8 / 1 / 2000$ are given in Table 2.2 .

Table 2.2: The market difference caps on $8 / \mathbf{1} / \mathbf{2 0 0 0}$. The market difference caps on $8 / 1 / 2000$ are given for the sake of reference. The values of market caps violating the monotonicity or the convexity condition are removed from consideration. The caps with value zero are also removed. "NaN" indicates that the corresponding caps are removed.

Difference caps on $8 / 1 / 2000$

\begin{tabular}{lrlrlrlllll}
\hline $\begin{array}{l}\text { Strike rates } \\
\text { Maturity }\end{array}$ & 0.04000 & 0.04500 & 0.05000 & 0.05500 & 0.06000 & 0.06500 & 0.07000 & 0.08000 & 0.09000 & 0.10000 \\
\hline 0.5 & 0.00729 & 0.00603 & $\mathrm{NaN}$ & 0.00315 & $\mathrm{NaN}$ & 0.00109 & 0.00025 & $\mathrm{NaN}$ & $\mathrm{NaN}$ & $\mathrm{NaN}$ \\
1.0 & 0.01384 & 0.01150 & $\mathrm{NaN}$ & 0.00721 & $\mathrm{NaN}$ & 0.00264 & 0.00111 & $\mathrm{NaN}$ & $\mathrm{NaN}$ & $\mathrm{NaN}$ \\
1.5 & 0.01388 & 0.01155 & 0.00925 & 0.00701 & 0.00491 & 0.00310 & 0.00168 & 0.00040 & 0.00012 & $\mathrm{NaN}$ \\
2.0 & 0.01320 & 0.01100 & 0.00886 & 0.00681 & 0.00498 & 0.00347 & 0.00193 & 0.00077 & 0.00026 & 0.00008 \\
2.5 & 0.01278 & 0.01069 & 0.00867 & 0.00679 & 0.00512 & 0.00373 & 0.00261 & 0.00116 & 0.00051 & 0.00020 \\
3.0 & 0.01239 & 0.01040 & 0.00853 & 0.00678 & 0.00527 & 0.00400 & 0.00312 & 0.00156 & 0.00079 & 0.00038 \\
3.5 & 0.01211 & 0.01021 & 0.00843 & 0.00681 & 0.00537 & 0.00415 & 0.00302 & 0.00161 & 0.00085 & 0.00043 \\
4.0 & 0.01173 & 0.00995 & 0.00828 & 0.00678 & 0.00545 & 0.00434 & 0.00325 & 0.00182 & 0.00100 & 0.00054 \\
4.5 & 0.01138 & 0.00970 & 0.00819 & 0.00679 & 0.00561 & 0.00460 & 0.00341 & 0.00204 & 0.00120 & 0.00069 \\
5.0 & 0.01093 & 0.00940 & 0.00837 & 0.00673 & 0.00565 & 0.00474 & 0.00354 & 0.00220 & 0.00134 & 0.00081 \\
6.0 & 0.02176 & 0.01878 & 0.01568 & 0.01347 & 0.01119 & 0.00918 & 0.00710 & 0.00457 & 0.00288 & 0.00186 \\
7.0 & 0.02061 & 0.01792 & 0.01545 & 0.01313 & 0.01107 & 0.00923 & 0.00726 & 0.00485 & 0.00315 & 0.00221 \\
8.0 & 0.01926 & 0.01669 & 0.01430 & 0.01211 & 0.00997 & 0.00802 & 0.00668 & 0.00444 & 0.00317 & 0.00195 \\
9.0 & 0.01814 & 0.01583 & 0.01370 & 0.01168 & 0.00984 & 0.00819 & 0.00650 & 0.00435 & 0.00268 & 0.00184 \\
10.0 & 0.01722 & 0.01511 & 0.01316 & 0.01132 & 0.00962 & 0.00809 & 0.00671 & 0.00463 & 0.00316 & 0.00212 \\
\hline
\end{tabular}

Another common practice is to compare the implied volatilities of the theoretical and the market caps. The implied volatility is the volatility of the Black formula corresponding to the prices of caps. For this purpose let $V_{\text {theo }}(t, m, k)$ and $V_{m a r}(t, m, k)$ be the theoretical and the 
market implied volatilities of difference caps, respectively. Then, we choose the parameters so that we minimize

$$
\min _{S} \sum_{t_{0}} \sum_{m} \sum_{k}\left[V_{\text {theo-diff }}\left(t_{0}, m, k\right)-V_{\text {mar-diff }}\left(t_{0}, m, k\right)\right]^{2} .
$$

We also consider minimizing

$$
\min _{S} \sum_{t_{0}} \sum_{m} \sum_{k}\left[\frac{C_{\text {theo-diff }}\left(t_{0}, m, k\right)-C_{\text {mar-diff }}\left(t_{0}, m, k\right)}{w}\right]^{2},
$$

where $w$ is the weight given by

$$
w=\left\{\begin{array}{cl}
C_{\text {mar-diff }}\left(t_{0}, m, k\right), & 0.01 \leq C_{\text {mar-diff }}\left(t_{0}, m, k\right), \\
0.01 & C_{\text {mar-diff }}\left(t_{0}, m, k\right)<0.01 .
\end{array}\right.
$$

Also,

$$
\min _{S} \sum_{t_{0}} \sum_{m} \sum_{k}\left[\log \left(\frac{C_{\text {theo-diff }}\left(t_{0}, m, k\right)}{C_{\text {mar-diff }}\left(t_{0}, m, k\right)}\right)\right]^{2}
$$

can be used. It turns out that to use the caps prices is easier to calibrate. In what follows we consider the minimization of (2.4.27). In what follows, this error is referred as weighted relative error. The parameters we search are

$$
S=\left[\kappa_{r}, \sigma_{r v}, \gamma_{v}, \kappa_{v}, \sigma_{v}, v\right] .
$$

The parameter $\alpha_{r}$ turns out to be not important. Therefore, it was set to zero for the calibration. The parameter $\theta$ does not have to be estimated since we compute the bond price $P$ from the LIBOR forward rates and $\theta$ does not show up in $X$. The pseudo program explaining the basic algorithm is given in 2.3. This algorithm gives approximate values of the parameters. MATLAB minimization program such as "fmincon" could be used to find the local minimum near the approximate values of the parameters.

Table 2.3: A pseudo program explaining the basic algorithm. This is a basic algorithm for the program which gives an approximate values of parameters $\left[\kappa_{r}, \sigma_{r v}, \gamma_{v}, \kappa_{v}, \sigma_{v}, v\right]$.

(1) for $\kappa_{r}$ do.

(2) for $\sigma_{r v}$ do.

(3) while

(4) determine analytically $\gamma_{v}, \kappa_{v}, \sigma_{v}$ from a value of $v$

(5) for $v$ do.

(6) solve $\Psi_{t, a}(k)$ and find the value of $v$ minimizing (2.4.25) or (2.4.28).

(5) end

(3) end

(7) compute the jump process if jumps are considered.

(2) end

(1) end

The remarks concerning the program are given below.

1. There are several MATLAB optimization programs such as "fmincon" which performs constrained optimizations and "fminunc" which performs unconstrained optimizations. These programs tend to stack at irrelevant values of parameters and do not seem to work well unless good initial values for the parameters are chosen. We use a basic sweeping scheme combined with analytical derivation of the parameters $\gamma_{v}, \kappa_{v}, \sigma_{v}$. 
2. We first consider the equation (2.3.5) and assign numbers for the parameters $\kappa_{r}, \sigma_{r v}$ in Loops (1) and (2).

3. In Loop (3), ideally we repeat Step (4) and Loop (3) till we get a convergence. In practice it was unnecessary to repeat Loop (3) more than once.

4. In Step (4), we use the average value of implied volatility as the staring value of $v$ in the first iteration of Loop (3). Then, after that we use the value of $v$ in Loop (5).

5. In Loop (5) we increase $v$ from zero. We stop the loop if either the the difference of two consecutive values in (2.4.25) is small, (2.4.25) is increasing, or the value of a caplet is less than zero.

6. Step (6) is involved. It is explained separately.

7. After the values of the parameters are obtained in the above pseudo program, MATLAB minimization program such as "fmincon" could be used with the values of parameters obtained in the program as the initial values for parameters.

To do Step (6) and obtain $\Psi_{t, a}(k)$ in (2.6.33), we compute (2.6.34) using FFT (the fast Fourier transform). For a given vector $x_{n}$, FFT computes $X_{k}$, the discrete Fourier transform of $x_{n}$, and is given in the following form.

$$
X_{m}=\sum_{n=1}^{N_{0}} e^{-\frac{2 \pi i}{N_{0}}(n-1)(m-1)} x_{n}, \quad m=1,2, \ldots, N_{0},
$$

where $N_{0}$ is the number of evaluation points for FFT and $N_{0}=2^{N}$, with $N$ being a positive integer, is chosen in practice. To save time $N=7$ has been used for most computation. To increase the accuracy it may be necessary to take larger values of $N$. To put $g_{a}(\bar{k})$ in (2.6.34) in the above form, the integration is approximated by the sum as follows.

$$
\begin{aligned}
g_{a}(\bar{k}) & =\frac{1}{2 \pi} \int_{-\infty}^{\infty} e^{M_{a+i \omega}(t)+N_{a+i \omega}(t) v(t)} e^{-i \omega \bar{k}} d \omega \\
& =\frac{\Delta}{\pi} \operatorname{Re}\left[\sum_{n=0}^{N_{0}-1} e^{M_{a+i n \Delta}(t)+N_{a+i n}(t) v(t)} e^{-i n \Delta \bar{k}}\right] \\
& =\frac{\Delta}{\pi} \operatorname{Re}\left[\sum_{n=1}^{N_{0}} e^{M_{a+i(n-1) \Delta}(t)+N_{a+i(n-1) \Delta}(t) v(t)} e^{-i(n-1) \Delta \bar{k}}\right]
\end{aligned}
$$

where $\Delta=\sqrt{\frac{2 \pi}{N_{0}}}$. The details are carried out in Lemma 2.6.5 in Section 2.6. $M_{a+i \omega}(t)$ and $N_{a+i \omega}(t)$ in (2.3.12) and (2.3.11) are obtained by a MATLAB function such as "ode45" which computes the solutions of ODEs.

\subsubsection{Vasicek Model}

The Vasicek model is a benchmark for the interest rate models and interest rate derivatives. In the Vasicek model the interest rate process is given by

$$
d r_{t}=\kappa_{r}\left(\theta-r_{t}\right) d t+\sigma d w_{r}
$$


Jamshidian [39] obtained the explicit formula for the option price. Let $P(t, T)$ be the price at time $t$ of a pure discount bond maturing at time $T$. Then, the price of a call option $C\left(t, T_{0}, K\right)$ on the $T_{1}$-maturity pure discount bond with exercise rate $K$ and expiration $T_{0}\left(<T_{1}\right)$ is given by

$$
C\left(t, T_{0}, K\right)=P\left(t, T_{1}\right) N(h)-K P\left(t, T_{0}\right) N\left(h-\sigma_{P}\right),
$$

where

$$
\begin{aligned}
\sigma_{P} & =\sigma \frac{\left(1-e^{-2 \kappa_{r}\left(s-T_{0}\right)}\right)}{\kappa_{r}} \sqrt{\frac{\left(1-e^{-2 \kappa_{r}\left(T_{1}-t\right)}\right)}{2 \kappa_{r}}} \\
h & =\ln \left[P\left(t, T_{1}\right) / P\left(t, T_{0}\right) K\right] / \sigma_{P}+\sigma_{P} / 2
\end{aligned}
$$

and $N(h)$ is the normal distribution with average 0 and variance $h$. In caps $T_{1}=T_{0}+\tau$ and the strike price $K$ and the strike rate $\bar{r}$ are related as follows.

$$
K=\frac{1}{1+\tau \bar{r}} .
$$

The prices of caplets are given by put on the bond and can be obtained by using the put-call parity

$$
C_{r}\left(t, T_{0}, \bar{r}\right)=\tau\left\{C\left(t, T_{0}, K\right)+P\left(t, T_{1}\right) K-P\left(t, T_{0}\right)\right\}
$$

The parameters to be estimated are $\kappa_{r}$ and $\sigma$. We choose $\kappa_{r}$ and $\sigma$ to minimize (2.4.27). The date of the data is $8 / 1 / 2000$. The following are the results if we use the MATLAB function "fminunc". This is a subroutine computing unconstrained optimizations. For (2.4.27), the result is given in Table 2.4. MATLAB function "fmincon" which performs constrained optimization did not converge. A few graphs comparing the theoretical and the market difference caps are given in Figure 2.3. For (2.4.26), the MATLAB subroutine "fminunc" did not converge. The implied volatility surface is more complicated than that of cap prices. This might be the reason why the function did not converge.

Table 2.4: The result of calibration with the Vasicek model. In the following table the sum of the square of the error with the Vasicek model is given $(t=8 / 1 / 2000) . \kappa_{r}$ is the mean reversion coefficient and $\sigma$ is the volatility.

\begin{tabular}{c|c|c} 
Relative minimum (2.4.27) & $\kappa_{r}$ & $\sigma$ \\
\hline 2.8812 & 2.0299 & 0.0033
\end{tabular}



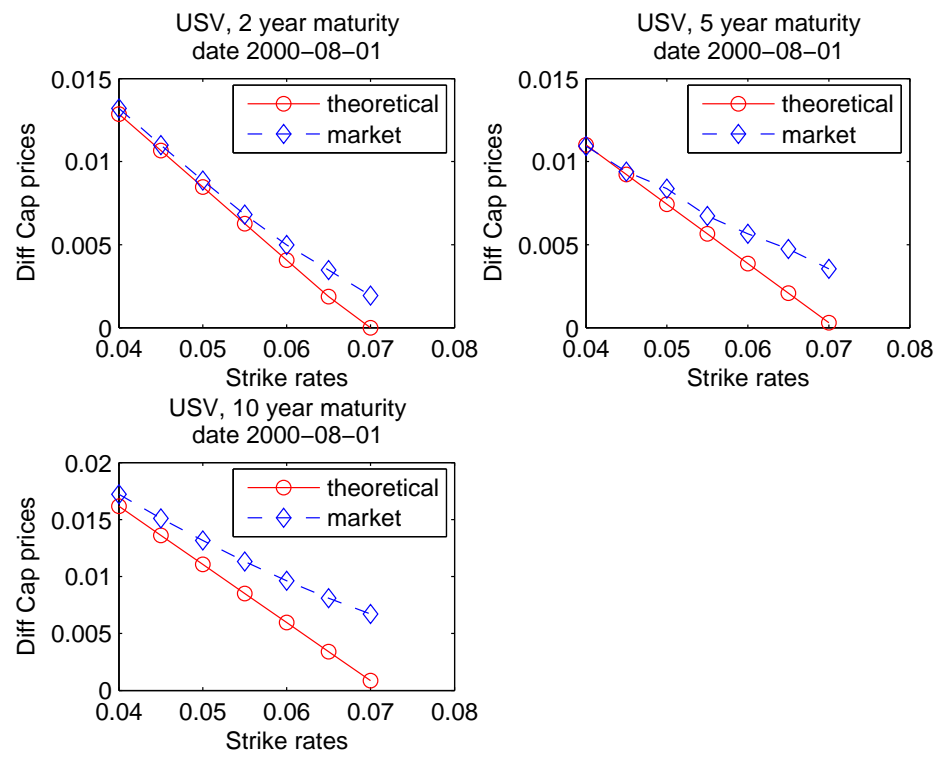

Figure 2.3: Graphs of the theoretical difference cap prices of Vasicek model and the market difference cap prices. In the above figure the Vasicek and the market cap prices are compared on $8 / 1 / 2000$.

\subsubsection{An Example of the Two Factor Unspanned Volatility Model with- out Jumps}

An example of the calibration of the two-factor unspanned volatility model without jumps is given. The parameters to be estimated are

$$
S=\left[\kappa_{r}, \sigma_{r v}, \gamma_{v}, \kappa_{v}, \sigma_{v}, v\right] .
$$

The parameter $\alpha_{r}$ turns out to be not important. Therefore, it was set to zero for the calibration. The date of the data for calibration is $8 / 1 / 2000$. Here and what follows, the MATLAB optimization function "fmincon" with $10^{-3}$ tolerance is used to minimize the relative error with weight. The value of the weighted error is 0.0494 . The value of $(2.4 .25)$ is $6.4 \times 10^{-6}$. The values of parameters are given in Table 2.5. An example comparing the theoretical and market difference caps for 2,5 and 10 year maturities are given in Figures 2.4. For the market caps data, we clean the data and remove the outliers and inconsistent data. 

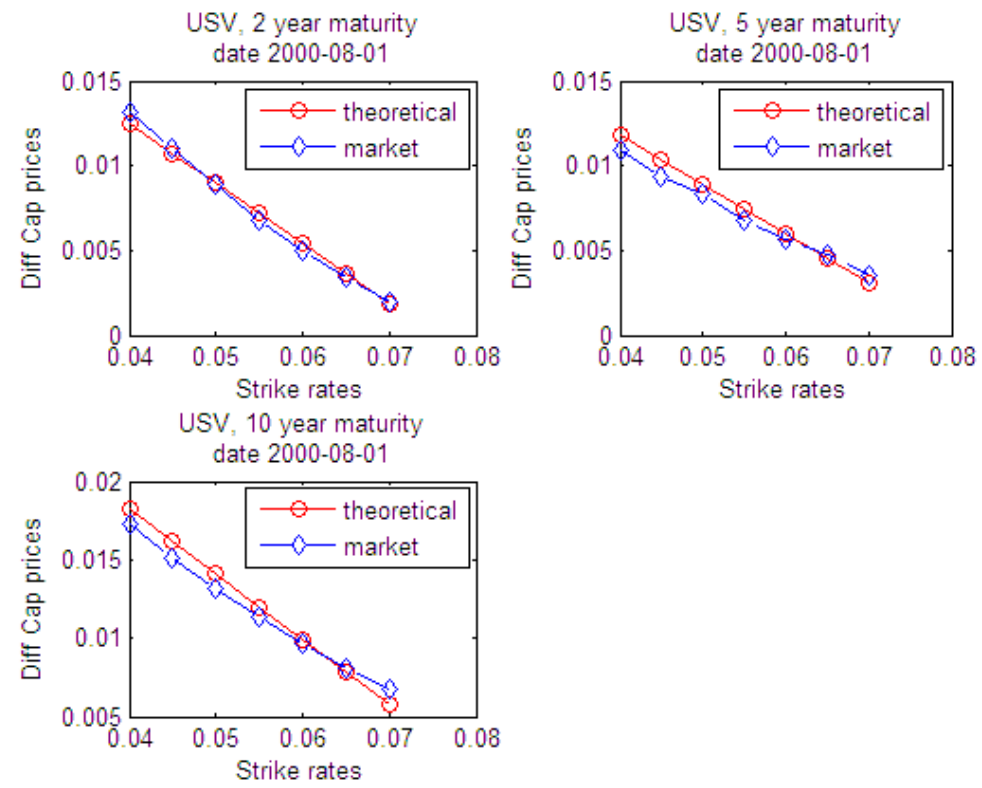

Figure 2.4: Comparison of theoretical difference cap prices with the market difference cap prices. In the above figure the theoretical difference cap prices of the two-factor unspanned volatility model with the market difference cap prices for two, five, and ten year maturity on $8 / 01 / 2000$ are compared.

Table 2.5: The parameter values of the two-factor unspanned volatility model. In the following table the parameter values of the two-factor unspanned volatility model are listed. $\kappa_{r}$ is the mean reversion coefficient of the interest rate. $\sigma_{r v}$ is the square root of covariance between the interest rate and stochastic volatility. $\gamma_{v}, \kappa_{v}$, and $\sigma_{v}$ are the mean, the mean reversion coefficient, and the volatility of stochastic volatility. $v$ is the stochastic volatility.

\begin{tabular}{l|l|l|l|l|l}
$\kappa_{r}$ & $\sigma_{r v}$ & $\gamma_{v}$ & $\kappa_{v}$ & $\sigma_{v}$ & $v$ \\
\hline 0.898 & 0.08 & 0.23 & 0.0004 & 0.012 & 1.54
\end{tabular}

\subsubsection{Examples of the Two Factor Unspanned Volatility Model with Jumps}

The parameters to be estimated are

$$
S_{J}=\left[\kappa_{r}, \sigma_{r v}, \gamma_{v}, \kappa_{v}, \sigma_{v}, v, \lambda_{0}, \lambda_{r}, \lambda_{v}, \sigma_{J_{r}}, \sigma_{J_{v}}\right] .
$$

The date of the data for calibration is $8 / 1 / 2000$. The value of $(2.4 .25)$ is $6.14 \times 10^{-6}$ and the weighted relative error 2.4.28 is 0.0493 . The values of parameters are given in Table 2.6. 
Table 2.6: The parameter values of the two-factor unspanned volatility model. In the following table the parameter values of the two-factor unspanned volatility model are listed. $\kappa_{r}$ is the mean reversion coefficient of the interest rate. $\sigma_{r v}$ is the square root of covariance between the interest rate and stochastic volatility. $\gamma_{v}, \kappa_{v}$, and $\sigma_{v}$ are the mean, the mean reversion coefficient, and the volatility of stochastic volatility. $v$ is the stochastic volatility. $\lambda_{0}, \lambda_{r}$, and $\lambda_{v}$ are the intensity parameters and $\sigma_{J_{r}}$ and $\sigma_{J_{v}}$ are the variance of jump process for the interest rates and the volatility, respectively. The date for calibration is $8 / 01 / 2000$.

\begin{tabular}{l|l|l|l|l|l|l|l|l|l|l}
$\kappa_{r}$ & $\sigma_{r v}$ & $\gamma_{v}$ & $\kappa_{v}$ & $\sigma_{v}$ & $v$ & $\lambda_{0}$ & $\lambda_{r}$ & $\lambda_{v}$ & $\sigma_{J_{r}}$ & $\sigma_{J_{v}}$ \\
\hline 0.898 & 0.08 & 0.236 & 0.00002 & 0.012 & 1.5 & 0.004 & 0.000003 & 0.01 & 0.1 & 0.1
\end{tabular}
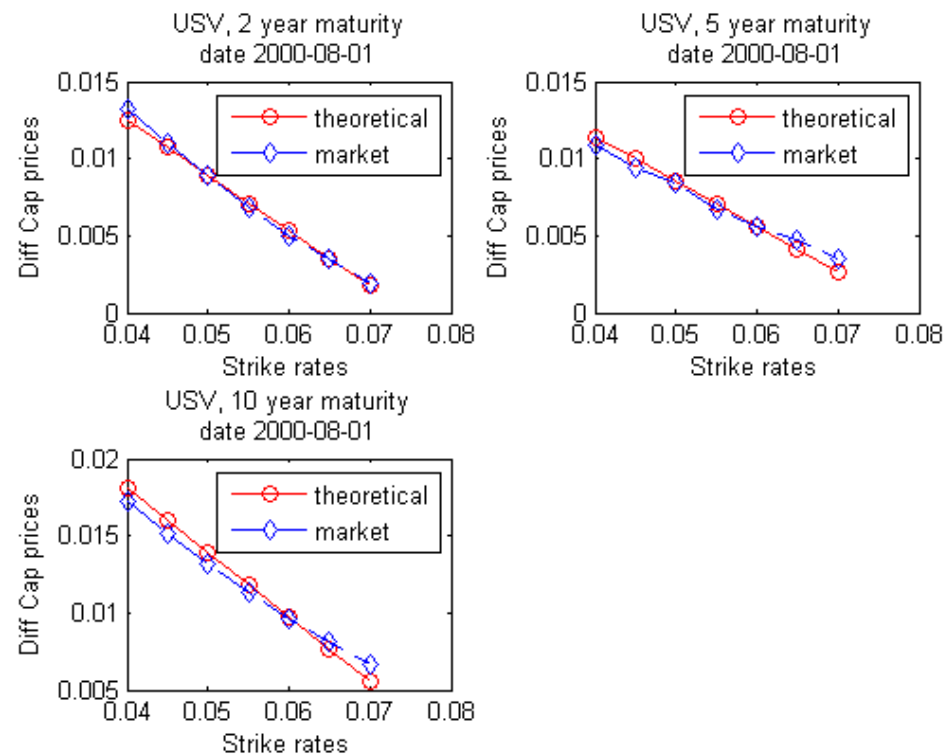

Figure 2.5: Comparison of theoretical difference cap prices with the market difference cap prices. In the above figure the theoretical difference cap prices of the two-factor unspanned volatility model with jumps and the market difference cap prices for two, five, and ten year maturity on 8/01/2000 are compared.

\subsubsection{Comparison of Models}

In this subsection we compare five models. They are the Vasicek model, the USV model without jumps, the USV model with jumps, the USV model with jump in the interest rate only, and the USV model with jump in the volatility only. To compare the models under different economic conditions, the 1st, 90th, 180th, 270th, 360th, and 450th data are chosen from the data for comparison. We minimize relative errors with weight. It should be noted that the starting values of parameters $\kappa_{r}, \sigma_{r v}, \gamma_{v}, \kappa_{v}, \sigma_{v}$, and $v$ for the USV models containing jumps are the final values of the corresponding parameters for the USV model with no jump. For jump related parameters $\lambda_{0}=0, \lambda_{r}=0, \lambda_{v}=0, \sigma_{J_{r}}=0.1$, and $\sigma_{J_{v}}=0.1$ are used. In Table 2.7 we report the results of five models. The results of USV models are generally much better than the Vasicek model. As 
is expected, the USV model with jumps perform better than USV model without jumps. One interesting result is that the USV model with jump in interest rate performs better than the USV model with jump in volatility. The fact that both $\sigma_{J_{r}}$ and $\sigma_{J_{v}}$ are closed to or equal to the starting values suggests that further calibrations with different starting values is necessary. Nevertheless, it is interesting to observe that there are two days $(4 / 23 / 2001$ and $9 / 5 / 2010)$ when the difference between the USV models with and without jumps is comparatively larger than the other four days.

Table 2.7: Comparison of a USV model with jumps and no jumps. For the following days, the model without jump, with jumps, with jump in interest rate only, and with jump in volatility only are calibrated. The values in the table are the relative errors with weight.

\begin{tabular}{c|ccccc}
\hline date & Vasicek & $\begin{array}{c}\text { USV } \\
\text { no jumps }\end{array}$ & $\begin{array}{c}\text { USV } \\
\text { jumps }\end{array}$ & $\begin{array}{c}\text { USV jump in } \\
\text { interest only }\end{array}$ & $\begin{array}{c}\text { USV jump in } \\
\text { volatility only }\end{array}$ \\
\hline $8 / 1 / 2000$ & 2.8812 & 0.049357 & 0.049302 & 0.049356 & 0.049357 \\
$12 / 14 / 2000$ & 26.6804 & 0.42725 & 0.42717 & 0.42724 & 0.42725 \\
$4 / 23 / 2001$ & 3.3588 & 0.24107 & 0.23273 & 0.23274 & 0.24107 \\
$9 / 5 / 2001$ & NaN & 0.6491 & 0.62039 & 0.6491 & 0.6491 \\
$1 / 17 / 2002$ & 6.5265 & 0.078166 & 0.077767 & 0.077768 & 0.078166 \\
$5 / 30 / 2002$ & 4.2722 & 0.22009 & 0.21985 & 0.21985 & 0.21985 \\
\hline
\end{tabular}

Table 2.8: The parameter values of USV model with no jumps. The table reports the parameter values of USV model with no jumps.

\begin{tabular}{c|cccccc}
\hline date & $\kappa_{r}$ & $\sigma_{r v}$ & $\gamma_{v}$ & $\kappa_{v}$ & $\sigma_{v}$ & $v$ \\
\hline $8 / 1 / 2000$ & 0.898 & 0.08 & 0.23 & 0.0004 & 0.012 & 1.54 \\
$12 / 14 / 2000$ & 1.656 & 1.466 & 0.692 & $2 \mathrm{e}-05$ & 0.341 & 0.57823 \\
$4 / 23 / 2001$ & 0.0001 & 2.02 & 0.213 & 2.728 & 0.456 & 0.52356 \\
$9 / 5 / 2001$ & 0.00099 & 3.976 & 0.07 & 2.558 & 0.269 & 0.11595 \\
$1 / 17 / 2002$ & 0.00097 & 2.197 & 0.211 & $2.42 \mathrm{e}-05$ & 1.691 & 0.21879 \\
$5 / 30 / 2002$ & 0.613 & 2.883 & 0.45 & 0.029 & 2.83 & 0.02147 \\
\hline
\end{tabular}


Table 2.9: The parameter values of USV model with jumps. The table reports the parameter values of USV model with jumps.

\begin{tabular}{c|cccccc}
\hline date & $\kappa_{r}$ & $\sigma_{r v}$ & $\gamma_{v}$ & $\kappa_{v}$ & $\sigma_{v}$ & $v$ \\
\hline $8 / 1 / 2000$ & 0.898 & 0.08 & 0.236 & $2 \mathrm{e}-05$ & 0.0117 & 1.5 \\
$12 / 14 / 2000$ & 1.657 & 1.465 & 0.691 & $2 \mathrm{e}-05$ & 0.341 & 0.57823 \\
$4 / 23 / 2001$ & 0.0389 & 2.024 & 0.203 & 2.726 & 0.464 & 0.62356 \\
$9 / 5 / 2001$ & 0.401 & 3.724 & 0.188 & 2.727 & 0.411 & 0.21595 \\
$1 / 17 / 2002$ & 0.0122 & 2.198 & 0.208 & 0.00018 & 1.691 & 0.23479 \\
$5 / 30 / 2002$ & 0.612 & 2.884 & 0.45 & 0.029 & 2.83 & 0.0 \\
\hline \multicolumn{7}{c}{$\lambda_{r}$} \\
\hline date & $\lambda_{0}$ & $\lambda_{v}$ & $\sigma_{J_{r}}$ & $\sigma_{J_{v}}$ \\
\hline $8 / 1 / 2000$ & 0.0043 & $3.41 \mathrm{e}-06$ & 0.011 & 0.1 & 0.1 \\
$12 / 14 / 2000$ & 0.00518 & $1.536 \mathrm{e}-05$ & 0.00838 & 0.1 & 0.1 \\
$4 / 23 / 2001$ & 0.0322 & -0.0005 & 0.00338 & 0.117 & 0.09999 \\
$9 / 5 / 2001$ & 0.161 & 0.00839 & -0.0256 & 0.231 & 0.104 \\
$1 / 17 / 2002$ & 0.0072 & 0.0001 & 0.00032 & 0.0923 & 0.1 \\
$5 / 30 / 2002$ & 0.0005 & $5.72 \mathrm{e}-07$ & $1.73 \mathrm{e}-05$ & 0.1 & 0.1 \\
\hline
\end{tabular}

Table 2.10: The parameter values of USV model with jumps in interest rates. The table reports the parameter values of USV model with jumps in interest rates.

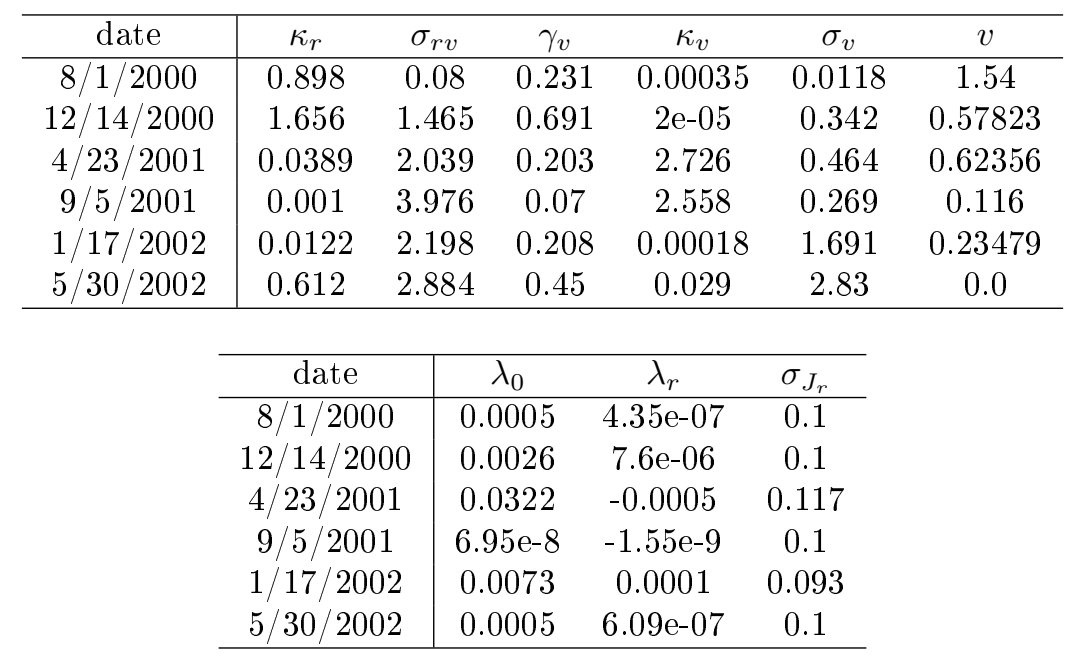


Table 2.11: The parameter values of USV model with jumps in volatility. The table reports the parameter values of USV model with jumps in volatility only.

\begin{tabular}{c|cccccc}
\hline date & $\kappa_{r}$ & $\sigma_{r v}$ & $\gamma_{v}$ & $\kappa_{v}$ & $\sigma_{v}$ & $v$ \\
\hline $8 / 1 / 2000$ & 0.898 & 0.08 & 0.236 & $4 \mathrm{e}-05$ & 0.0118 & 1.54 \\
$12 / 14 / 2000$ & 1.656 & 1.466 & 0.692 & $2 \mathrm{e}-05$ & 0.341 & 0.57823 \\
$4 / 23 / 2001$ & 0.0001 & 2.02 & 0.213 & 2.728 & 0.456 & 0.52356 \\
$9 / 5 / 2001$ & 0.001 & 3.98 & 0.07 & 2.56 & 0.269 & 0.11595 \\
$1 / 17 / 2002$ & 0.001 & 2.197 & 0.211 & 2.42 & 1.691 & 0.21879 \\
$5 / 30 / 2002$ & 0.612 & 2.88 & 0.452 & 0.029 & 2.83 & 0.0 \\
\hline
\end{tabular}

\begin{tabular}{c|ccc}
\hline date & $\lambda_{0}$ & $\lambda_{v}$ & $\sigma_{J_{v}}$ \\
\hline $8 / 1 / 2000$ & $-7.2 \mathrm{e}-8$ & $1.17 \mathrm{e}-7$ & 0.1 \\
$12 / 14 / 2000$ & $-1.38 \mathrm{e}-7$ & $-1.49 \mathrm{e}-7$ & 0.1 \\
$4 / 23 / 2001$ & $3.3 \mathrm{e}-7$ & $2.19 \mathrm{e}-8$ & 0.1 \\
$9 / 5 / 2001$ & $6.95 \mathrm{e}-8$ & $-1.55 \mathrm{e}-9$ & 0.1 \\
$1 / 17 / 2002$ & $-7.04 \mathrm{e}-8$ & $5.07 \mathrm{e}-9$ & 0.1 \\
$5 / 30 / 2002$ & $-6.3 \mathrm{e}-7$ & $-6.09 \mathrm{e}-8$ & 0.1 \\
\hline
\end{tabular}

\subsubsection{Five Day Estimates}

It should be interesting to have estimates which spans several weeks. For this purpose we take one day a week for five weeks and find the parameters minimizing the relative errors for five day samples. The calibrations are done for both USV model with no jumps and with jumps. The unspanned volatility may fluctuate each day. What we did is the following.

$$
V=\min _{S_{1}} \sum_{t=0}^{4} \min _{v(t)} S_{2},
$$

where $S_{1}$ for the USV model with no jumps is

$$
S_{1}=\left[\kappa_{r}, \sigma_{r v}, \gamma_{v}, \kappa_{v}, \sigma_{v}\right],
$$

$S_{1}$ for the USV model with jumps is

$$
S_{1}=\left[\kappa_{r}, \sigma_{r v}, \gamma_{v}, \kappa_{v}, \sigma_{v}, \lambda_{0}, \lambda_{r}, \lambda_{v}, \sigma_{J_{r}}, \sigma_{J_{v}}\right],
$$

and

$$
S_{2}=\sum_{m} \sum_{k}\left[\frac{C_{\text {theo-diff }}(5 t+1, m, k)-C_{\text {mar-diff }}(5 t+1, m, k)}{w}\right]^{2} .
$$

We first use the program based on Table 2.3 to obtain the approximate values of the parameters $S_{1}$, $v(t)$, and $\min _{v(t)} S_{2}$. Then, we use them as the initial values to obtain the values of the parameters $S_{1}, v(t)$, and $\min _{v(t)} S_{2}$ for the USV model with no jumps. Finally, we use them as the initial values to obtain the values of the parameters $S_{1}, v(t)$, and $\min _{v(t)} S_{2}$ for the USV model with jumps. The results of five day calibration starting from $8 / 1 / 2000$ are given in Tables 2.12 to 2.15 . The five day calibration is also performed starting from $1 / 17 / 2002$ and the results are reported in Tables 2.16 to 2.19. We see the difference between the USV with and without jumps. These two starting days are chosen on the basis of the speed of convergence for the corresponding one day calibrations. 
Table 2.12: Comparison of relative errors. The table reports the comparison of relative errors $V$ in (2.4.30) for the 5 day calibration starting from $8 / 1 / 2000$.

\begin{tabular}{c|c|c|c} 
& Approximate & $\begin{array}{c}\text { USV } \\
\text { no jumps }\end{array}$ & $\begin{array}{c}\text { USV } \\
\text { jumps }\end{array}$ \\
\hline$V$ in $(2.4 .30)$ & 0.4224 & 0.41999 & 0.30798
\end{tabular}

Table 2.13: The values of $\min _{v(t)} S_{2}$. The values of $\min _{v(t)} S_{2}$ for the program based on Table 2.3, USV with no jumps, and USV with jumps for the 5 day calibration starting from $8 / 1 / 2000$ are reported.

\begin{tabular}{c|ccccc}
\hline & $8 / 1 / 2000$ & $8 / 8 / 2000$ & $8 / 15 / 2000$ & $8 / 28 / 2000$ & $9 / 6 / 2000$ \\
\hline Approximate & 0.0498 & 0.0719 & 0.0856 & 0.0885 & 0.1265 \\
USV no jumps & 0.0497 & 0.0702 & 0.0831 & 0.0881 & 0.129 \\
USV jumps & 0.0355 & 0.0491 & 0.0593 & 0.0672 & 0.0968 \\
\hline
\end{tabular}

Table 2.14: The values of parameters. The values of parameters for the program based on Table 2.3 , USV with no jumps, and USV with jumps for the 5 day calibration starting from $8 / 1 / 2000$ are reported.

\begin{tabular}{l|lllll}
\hline & $\kappa_{r}$ & $\sigma_{r v}$ & $\gamma_{v}$ & $\kappa_{v}$ & $\sigma_{v}$ \\
\hline Approximate & 0.9 & 0.08 & 0.2261 & 0.0003 & 0.0118 \\
USV no jumps & 0.865 & 0.0828 & 0.274 & 0.0254 & 0.0218 \\
USV jumps & 0.939 & 0.170 & 0.136 & 0.0536 & 0.108 \\
\hline
\end{tabular}

\begin{tabular}{c|ccccc} 
& $\lambda_{0}$ & $\lambda_{r}$ & $\lambda_{v}$ & $\sigma_{J_{r}}$ & $\sigma_{J_{v}}$ \\
\hline USV jumps & 0.275 & -0.00293 & 1 & 0.168 & 0.103
\end{tabular}

Table 2.15: The values of $v(t)$. The values of $v(t)$ for the program based on Table 2.3, USV with no jumps, and USV with jumps for the 5 day calibration starting from $8 / 1 / 2000$ are reported.

\begin{tabular}{c|ccccc}
\hline & $8 / 1 / 2000$ & $8 / 8 / 2000$ & $8 / 15 / 2000$ & $8 / 28 / 2000$ & $9 / 6 / 2000$ \\
\hline Approximate & 1.6 & 1.5 & 1.4 & 1.5 & 1.7 \\
USV no jumps & 1.5 & 1.46 & 1.36 & 1.46 & 1.6 \\
USV jumps & 0.8 & 0.8 & 0.74 & 0.76 & 0.9 \\
\hline
\end{tabular}

Table 2.16: Comparison of relative errors. The table reports the comparison of relative errors $V$ in (2.4.30) for the 5 day calibration starting from $1 / 17 / 2002$.

\begin{tabular}{c|c|c} 
& USV no jumps & USV jumps \\
\hline$V$ in (2.4.30) & 0.43215 & 0.42972
\end{tabular}


Table 2.17: The values of $\min _{v(t)} S_{2}$. The values of $\min _{v(t)} S_{2}$ for USV with no jumps and USV with jumps for the 5 day calibration starting from $1 / 17 / 2002$ are reported.

\begin{tabular}{c|ccccc}
\hline & $1 / 17 / 2002$ & $1 / 24 / 2002$ & $1 / 31 / 2002$ & $2 / 7 / 2002$ & $2 / 15 / 2002$ \\
\hline USV no jumps & 0.0836 & 0.0928 & 0.0534 & 0.088 & 0.114 \\
USV jumps & 0.09 & 0.0936 & 0.0533 & 0.0828 & 0.11 \\
\hline
\end{tabular}

Table 2.18: The values of parameters. The values of parameters for USV with no jumps and USV with jumps for the 5 day calibration starting from $1 / 17 / 2002$ are reported.

\begin{tabular}{|c|c|c|c|c|c|}
\hline & $\kappa_{r}$ & $\sigma_{r v}$ & $\gamma_{v}$ & $\kappa_{v}$ & $\sigma_{v}$ \\
\hline USV no jump & 0.0472 & 2.118 & 0.262 & 0.0841 & 1.876 \\
\hline USV jumps & 0.0461 & 2.12 & 0.274 & 0.0833 & 1.875 \\
\hline & & $\lambda_{r}$ & $\lambda_{v}$ & $\sigma_{J_{r}}$ & $\sigma_{J_{v}}$ \\
\hline
\end{tabular}

Table 2.19: The values of $v(t)$. The values of $v(t)$ for USV with no jumps, and USV with jumps for the 5 day calibration starting from $1 / 17 / 2002$ are reported.

\begin{tabular}{c|ccccc}
\hline & $1 / 17 / 2002$ & $1 / 24 / 2002$ & $1 / 31 / 2002$ & $2 / 7 / 2002$ & $2 / 15 / 2002$ \\
\hline USV no jumps & 0.26 & 0.52 & 0.07 & 0.16 & 0.114 \\
USV jumps & 0.22 & 0.48 & 0.03 & 0.12 & 0.074 \\
\hline
\end{tabular}

\subsection{Conclusions}

We studied the calibration of difference caps using USV models. The basic model is a version of an HJM formulation discussed in [14]. One interesting aspect of this model is that the volatility which affects pricing of caps and floors is independent of bond market. In other words, the volatility of bond derivatives are not sensitive to the volatility of underlying assets. We calibrate the cap prices using the above model and compare them with the market caps. We choose the parameters of the model so that the difference between prices of the theoretical (the model based) difference caps and those of the market difference caps will be minimized. We also study the effects of jump processes. The various unexpected news such as in macro economy and politics generates jumps in interest rates and they are important for pricing interest rate options.

The class of models we study is called the affine-class. Despite some problems with the predictability, they became a dominant class of models because of its analytical tractability. The main method of derivation of cap prices is the Fourier transform. We make use of the fact that the characteristic function is basically the Fourier transform of the solution. We apply the Fourier transform to the partial differential equation governing the caps and obtain the ordinary differential equations (ODEs). Then, after solving the ODEs, we apply the inverse transform to obtain the solution representations.

We calibrated the caps data. We compared the USV models with the Vasicek model. We also compared the models with and without jumps to see the effects of jumps. We observe that USV models with jumps provide better results. We also notice that jumps in interest rates calibrate the 
data better than the jumps in volatilities. Further calibrations should be carried out especially for the models with jumps. Possible future calibrations include changing the starting values, increasing the number of points where the FFT is evaluated, and examining the forms of jumps.

\subsection{Proofs}

In this section the proofs of lemmas and theorems of the chapter are given.

Lemma 2.6.1. Assume that the price of the bond is given by (2.3.6). Then, $A(t, T)$ and $B_{r}(T-t)$ satisfy

$$
\begin{aligned}
r_{t} & : \quad B_{r}^{\prime}+\kappa_{r} B_{r}-1=0, \\
\text { const } & : \quad A^{\prime}-B_{r} \kappa_{r} \theta+\frac{1}{2} B_{r}^{2} \alpha_{r}=0 .
\end{aligned}
$$

Furthermore, $y^{i}(t)=\ln \left(P\left(t, T_{i}\right) e^{-\int_{0}^{t} r_{s} d s}\right)$ satisfies

$$
d y^{i}(t)=-\frac{1}{2} B_{r}^{2}\left(T_{i}-t\right)\left\{v_{t}+\sigma_{r v}^{2} v_{t}\right\} d t-B_{r}\left\{\sqrt{\alpha_{r}+v_{t}} d w_{r}^{Q}(t)+\sigma_{r v} \sqrt{v_{t}} d w_{v}^{Q}(t)\right\} .
$$

Proof of Lemma 2.6.1. If we set $f=\ln \left(P^{T_{i}}(t)\right)$, up to the order $d t$ we see that

$$
d f=f_{t} d t+f_{P}\left(\frac{\partial P}{\partial t} d t+\frac{\partial P}{\partial r} d r_{t}+\frac{1}{2} \frac{\partial^{2} P}{\partial r^{2}}\left(d r_{t}\right)^{2}\right)+\frac{1}{2}\left(f_{P P}\left(\frac{\partial P}{\partial r}\right)^{2}+f_{P} \frac{\partial^{2} P}{\partial r^{2}}\right)\left(d r_{t}\right)^{2} .
$$

Therefore, $d y^{i}(t)=d \ln \left(P\left(t, T_{i}\right)\right)-r_{t} d t$ satisfies

$$
\begin{aligned}
d y^{i}(t)= & A^{\prime} d t+B_{r}^{\prime}\left(T_{i}-t\right) r_{t} d t \\
& -B_{r}\left\{\kappa_{r}\left(\theta-r_{t}\right) d t+\sqrt{\alpha_{r}+v_{t}} d w_{r}^{Q}(t)+\sigma_{r v} \sqrt{v_{t}} d w_{v}^{Q}(t)\right\} \\
& -\frac{1}{2} B_{r}^{2}\left\{\alpha_{r}+v_{t}+\sigma_{r v}^{2} v_{t}\right\} d t-r_{t} d t .
\end{aligned}
$$

Equating the coefficients of the like terms, we have

$$
\begin{aligned}
r_{t} & : \quad B_{r}^{\prime}+\kappa_{r} B_{r}-1=0, \\
\text { const } & : \quad A^{\prime}-B_{r} \kappa_{r} \theta+\frac{1}{2} B_{r}^{2} \alpha_{r}=0 .
\end{aligned}
$$

Substituting the above relations back to $d y^{i}(t)$, we see that

$$
d y^{i}(t)=-\frac{1}{2} B_{r}^{2}\left(T_{i}-t\right)\left\{v_{t}+\sigma_{r v}^{2} v_{t}\right\} d t-B_{r}\left\{\sqrt{\alpha_{r}+v_{t}} d w_{r}^{Q}(t)+\sigma_{r v} \sqrt{v_{t}} d w_{v}^{Q}(t)\right\} .
$$

Lemma 2.6.2. $\psi_{t}(a)$ is given by

$$
\psi_{t}(a)=P\left(t, T_{0}\right) \exp \left\{M_{a}(t)+N_{a}(t) v(t)+a \ln P\left(T_{0}, T_{1}\right)\right\},
$$

where $M_{a}(t)$ and $N_{a}(t)$ satisfy the following differential equations

$$
\begin{aligned}
0= & N_{a}^{\prime}-N_{a}(t)\left\{\kappa_{v}+\sigma_{v} \sigma_{r v}\left(a B_{r}\left(T_{1}-t\right)+(1-a) B_{r}\left(T_{0}-t\right)\right)\right\} \\
& +\frac{1}{2} N(t)^{2} \sigma_{v}^{2}+\frac{\left(1+\sigma_{r v}^{2}\right)}{2} V(t), \\
0= & M_{a}^{\prime}+N_{a}(t) \gamma_{v}(t)+\frac{\alpha_{r}}{2} V(t),
\end{aligned}
$$




$$
V(t)=a(a-1)\left\{B_{r}\left(T_{1}-t\right)-B_{r}\left(T_{0}-t\right)\right\}^{2}
$$

with the terminal data $M_{a}\left(T_{0}\right)=0$ and $N_{a}\left(T_{0}\right)=0$.

Proof of Lemma 2.6.2. Let

$$
X(t)=e^{-\int_{0}^{t} r_{s} d s} P\left(t, T_{0}\right) \exp \left(M_{a}(t)+N_{a}(t) v(t)+a \log \frac{P\left(t, T_{1}\right)}{P\left(t, T_{0}\right)}\right) .
$$

Then, we see that

$$
X(t)=\exp \left(M_{a}(t)+N_{a}(t) v(t)+a y^{1}(t)+(1-a) y^{0}(t)\right)
$$

Since $X(t)$ is the present value of $\psi_{t}(a)$, we choose $M_{a}(t)$ and $N_{a}(t)$ so that $X(t)$ is a martingale. Computing $d X$, we find out that

$$
\begin{aligned}
d X= & X\left[\left(M_{a}^{\prime}+N_{a}^{\prime} v_{t}\right) d t+N_{a}(t)\left(\gamma_{v}(t)-\kappa_{v} v_{t}\right) d t+a \frac{1}{2} B_{r}^{2}\left(T_{1}-t\right)\left\{\alpha_{r}+v_{t}+\sigma_{r v}^{2} v_{t}\right\} d t\right. \\
& +\frac{1}{2}(1-a) B_{r}^{2}\left(T_{0}-t\right)\left\{\alpha_{r}+v_{t}+\sigma_{r v}^{2} v_{t}\right\} d t+\frac{1}{2} N_{a}(t)^{2} \sigma_{v}^{2} v_{t} d t \\
& +\frac{1}{2} a^{2} B_{r}^{2}\left(T_{1}-t\right)\left\{\alpha_{r}+v_{t}+\sigma_{r v}^{2} v_{t}\right\} d t+\frac{1}{2}(1-a)^{2} B_{r}^{2}\left(T_{0}-t\right)\left\{\alpha_{r}+v_{t}+\sigma_{r v}^{2} v_{t}\right\} d t \\
& -a N_{a}(t) B_{r}\left(T_{1}-t\right) \sigma_{v} \sigma_{r v} v_{t} d t+a(1-a) B_{r}\left(T_{1}-t\right) B_{r}\left(T_{0}-t\right)\left\{\alpha_{r}+v_{t}+\sigma_{r v}^{2} v_{t}\right\} d t \\
& \left.-(1-a) N_{a}(t) B_{r}\left(T_{0}-t\right) \sigma_{v} \sigma_{r v} v_{t} d t\right] .
\end{aligned}
$$

From this we obtain

$$
\begin{aligned}
v_{t}:: & 0=N_{a}^{\prime}-N_{a}(t)\left\{\kappa_{v}+\sigma_{v} \sigma_{r v}\left(a B_{r}\left(T_{1}-t\right)+(1-a) B_{r}\left(T_{0}-t\right)\right)\right\} \\
& +\frac{1}{2} N_{a}(t)^{2} \sigma_{v}^{2}+\frac{\left(1+\sigma_{r v}^{2}\right)}{2} V(t) \\
\text { const }: \quad & 0=M_{a}^{\prime}+N_{a}(t) \gamma_{v}(t)+\frac{\alpha_{r}}{2} V(t),
\end{aligned}
$$

where $V(t)$ is given by (2.6.32).

Lemma 2.6.3. $\Psi_{t, a}(k)$ is expressed as

$$
\begin{aligned}
\Psi_{t, a}(k) & =\frac{1}{2} \psi_{t}(a)+\frac{1}{2} P\left(t, T_{0}\right) e^{a x}\left\{-\int_{-\infty}^{k-x} g_{a}(\bar{k}) d \bar{k}+\int_{k-x}^{\infty} g_{a}(\bar{k}) d \bar{k}\right\} \\
& =P\left(t, T_{0}\right) e^{a x} \int_{k-x}^{\infty} g_{a}(\bar{k}) d \bar{k},
\end{aligned}
$$

where $x=\log P\left(T_{0}, T_{1}\right)$ and

$$
g_{a}(\bar{k})=\frac{1}{2 \pi} \int_{-\infty}^{\infty} e^{M_{a+i \omega}(t)+N_{a+i \omega}(t) v(t)} e^{-i \omega \bar{k}} d \omega .
$$

Proof of Lemma 2.6.3. $\quad \Psi_{t, a}(\bar{k})$ is expressed as

$$
\begin{aligned}
\Psi_{t, a}(\bar{k}) & =E_{t}^{Q}\left[e^{-\int_{t}^{T_{0}} r_{s} d s} e^{a x} H(x-\bar{k})\right] \\
& =\int_{-\infty}^{\infty} H(x-\bar{k}) e^{-\int_{t}^{T_{0}} r_{s} d s} e^{a x} d F,
\end{aligned}
$$


where $H(x-\bar{k})$ is a Heaviside function and $d F$ is a probability measure for $x$. Then, from the convolution theorem, the Fourier transform of $\Psi_{t, a}(\bar{k})$ is given by

$$
\begin{aligned}
& \int_{-\infty}^{\infty} \Psi_{t, a}(\bar{k}) e^{i \omega \bar{k}} d \bar{k} \\
= & \int_{-\infty}^{\infty} H(u) e^{-i \omega u} d u \int_{-\infty}^{\infty} e^{-\int_{t}^{T_{0}} r_{s} d s} e^{(a+i \omega) x} d F \\
= & \lim _{A \rightarrow \infty}\left[-\frac{e^{-i \omega u}}{i \omega}\right]_{0}^{A} \psi_{t}(a+i \omega) \\
= & \lim _{A \rightarrow \infty}\left[\frac{1}{i \omega}-\frac{\cos \omega A-i \sin \omega A}{i \omega}\right] \psi_{t}(a+i \omega) .
\end{aligned}
$$

Taking the inverse, we have

$$
\Psi_{t, a}(k)=\frac{1}{2 \pi} \int_{-\infty}^{\infty}\left[\frac{1}{i \omega}-\frac{\cos \omega A-i \sin \omega A}{i \omega}\right] \psi_{t}(a+i \omega) e^{-i \omega k} d \omega
$$

In (2.6.36), there is a singularity at $\omega=0$ in the integrand. To avoid the difficulty associated with this singularity, Carr and Madan [12] used the exponential weight to shift the singularity. We suggest an alternative. Assume

$$
g_{a}(\bar{k})=\frac{1}{2 \pi} \int_{-\infty}^{\infty} e^{M_{a+i \omega}(t)+N_{a+i \omega}(t) v(t)} e^{-i \omega \bar{k}} d \omega, \quad e^{M_{a+i \omega}(t)+N_{a+i \omega}(t) v(t)}=\int_{-\infty}^{\infty} g_{a}(\bar{k}) e^{i \omega \bar{k}} d \bar{k} .
$$

exists. Then, $\psi_{t}(a+i \omega)$ is written as

$$
\psi_{t}(a+i \omega)=P\left(t, T_{0}\right) e^{(a+i \omega) x} \int_{-\infty}^{\infty} g_{a}(\bar{k}) e^{i \omega \bar{k}} d \bar{k} .
$$

Using (2.6.31) and (??), we obtain (2.6.33).

Lemma 2.6.4. The caplet $C_{p}(t, j \tau, \bar{r})$ is given by

$$
\begin{aligned}
C_{p}(t, j \tau, \bar{r})= & (1+\tau \bar{r}) E^{Q}\left[\exp \left(-\int_{t}^{(j-1) \tau} r_{s} d s\right)\left\{P((j-1) \tau, j \tau)-\frac{1}{1+\tau \bar{r}}\right\}^{+}\right] \\
& +P(t,(j-1) \tau)-(1+\tau \bar{r}) P(t, j \tau) .
\end{aligned}
$$

Proof of Lemma 2.6.4. If we use the approximations

$$
\begin{aligned}
e^{-\int_{(j-1) \tau}^{j \tau} r_{s} d s} \approx e^{-\tau r(j-1) \tau} & \approx \frac{1}{1+\tau r((j-1) \tau, j \tau)}, \\
r((j-1) \tau, j \tau) & \approx r_{(j-1) \tau},
\end{aligned}
$$

the market value at $t$ of the caplet paying at date $k \tau$ is expressed as

$$
\begin{aligned}
C_{r}(t, j \tau, \bar{r}) & =E^{Q}\left[e^{-\int_{t}^{(j-1) \tau} r_{s} d s} e^{-\int_{(j-1) \tau}^{j \tau} r_{s} d s}\{1+\tau R((j-1) \tau, k \tau)-(1+\tau \bar{r})\}^{+}\right] \\
& \approx(1+\tau \bar{r}) E^{Q}\left[e^{-\int_{t}^{(j-1) \tau} r_{s} d s}\left\{\frac{1}{1+\tau \bar{r}}-e^{-\int_{(j-1) \tau}^{j \tau} r_{s} d s}\right\}^{+}\right] .
\end{aligned}
$$


From the formula for the zero-coupon bonds, we see that

$$
\begin{aligned}
\frac{P(t,(j-1) \tau)}{1+\tau \bar{r}}= & E^{Q}\left[\exp \left(-\int_{t}^{(j-1) \tau} r_{s} d s\right) \frac{1}{1+\tau \bar{r}}\right] \\
= & E^{Q}\left[\exp \left(-\int_{t}^{(j-1) \tau} r_{s} d s\right) \frac{1}{1+\tau \bar{r}} H\left(P((j-1) \tau, j \tau)-\frac{1}{1+\tau \bar{r}}\right)\right] \\
& +E^{Q}\left[\exp \left(-\int_{t}^{(j-1) \tau} r_{s} d s\right) \frac{1}{1+\tau \bar{r}} H\left(\frac{1}{1+\tau \bar{r}}-P((j-1) \tau, j \tau)\right)\right] .
\end{aligned}
$$

Similarly

$$
\begin{aligned}
P(t, j \tau)= & E^{Q}\left[\exp \left(-\int_{t}^{(j-1) \tau} r_{s} d s\right) P((j-1) \tau, j \tau) H\left(P((j-1) \tau, j \tau)-\frac{1}{1+\tau \bar{r}}\right)\right] \\
& +E^{Q}\left[\exp \left(-\int_{t}^{(j-1) \tau} r_{s} d s\right) P((j-1) \tau, j \tau) H\left(\frac{1}{1+\tau \bar{r}}-P((j-1) \tau, j \tau)\right)\right](2.6
\end{aligned}
$$

From these, we have

$$
\begin{aligned}
& \frac{P(t,(j-1) \tau)}{1+\tau \bar{r}}-P(t, j \tau) \\
= & -E^{Q}\left[\exp \left(-\int_{t}^{(j-1) \tau} r_{s} d s\right)\left\{P((j-1) \tau, j \tau)-\frac{1}{1+\tau \bar{r}}\right\}^{+}\right] \\
& +E^{Q}\left[\exp \left(-\int_{t}^{(j-1) \tau} r_{s} d s\right)\left\{\frac{1}{1+\tau \bar{r}}-P((j-1) \tau, j \tau)\right\}^{+}\right] .
\end{aligned}
$$

Therefore, combining (2.6.37) and (2.6.40), we obtain

$$
\frac{P(t,(j-1) \tau)}{1+\tau \bar{r}}-P(t, j \tau)=-E^{Q}\left[\exp \left(-\int_{t}^{(j-1) \tau} r_{s} d s\right)\left\{P((j-1) \tau, j \tau)-\frac{1}{1+\tau \bar{r}}\right\}^{+}\right]+\frac{C_{r}(t, j \tau, \bar{r})}{1+\tau \bar{r}}
$$

and from this we have

$$
\begin{aligned}
C_{r}(t, j \tau, \bar{r})= & (1+\tau \bar{r}) E^{Q}\left[\exp \left(-\int_{t}^{(j-1) \tau} r_{s} d s\right)\left\{P((j-1) \tau, j \tau)-\frac{1}{1+\tau \bar{r}}\right\}^{+}\right] \\
& +P(t,(j-1) \tau)-(1+\tau \bar{r}) P(t, j \tau)
\end{aligned}
$$

Lemma 2.6.5. The discretization of $g_{a}(\bar{k})$ for FFT is written as follows.

$$
g_{a}\left(\bar{k}_{m}\right)=\frac{1}{\pi} \operatorname{Re}\left[\sum_{n=1}^{N_{0}} e^{-i 2 \pi \alpha(n-1)(m-1)} x_{n}\right],
$$

where $x_{n}=\Delta_{\omega} e^{M_{a+i(n-1) \Delta_{\omega}}(t)+N_{a+i(n-1) \Delta_{\omega}}(t) v(t)} e^{-i(n-1) \Delta_{\omega} k_{1}}, \alpha=\frac{\Delta_{\omega} \Delta_{k}}{2 \pi}, \bar{k}_{m}=\Delta_{k}(m-1)+k_{1}$. Here, $k_{1}$ is a number smaller than the values of $k$ and in FFT $\Delta_{\omega}=\Delta_{k}=\sqrt{\frac{2 \pi}{N_{0}}}$ are often chosen.

Proof of Lemma 2.6.5. Rewriting $g_{a}(\bar{k})$, we have

$$
\begin{aligned}
g_{a}(\bar{k}) & =\frac{1}{2 \pi} \int_{-\infty}^{\infty} e^{M_{a+i \omega}(t)+N_{a+i \omega}(t) v(t)} e^{-i \omega \bar{k}} d \omega \\
& =\frac{1}{\pi} \operatorname{Re}\left[\int_{0}^{\infty} e^{M_{a+i \omega}(t)+N_{a+i \omega}(t) v(t)} e^{-i \omega \bar{k}} d \omega\right] .
\end{aligned}
$$


First, discrediting in $\omega$, we obtain

$$
\begin{aligned}
g_{a}(\bar{k}) & =\frac{1}{2 \pi} \int_{-\infty}^{\infty} e^{M_{a+i \omega}(t)+N_{a+i \omega}(t) v(t)} e^{-i \omega \bar{k}} d \omega \\
& =\frac{\Delta_{\omega}}{\pi} \operatorname{Re}\left[\sum_{n=1}^{N_{0}} e^{M_{a+i(n-1) \Delta_{\omega}}(t)+N_{a+i(n-1) \Delta_{\omega}}(t) v(t)} e^{-i(n-1) \Delta_{\omega} \bar{k}}\right]
\end{aligned}
$$

where $\Delta_{\omega}=\sqrt{\frac{2 \pi}{N_{0}}}$. To use the FFT, we introduce $\bar{k}_{m}=\Delta_{k}(m-1)+k_{1}$. Then,

$$
\begin{aligned}
g_{a}\left(\bar{k}_{m}\right) & =\frac{\Delta_{\omega}}{\pi} \operatorname{Re}\left[\sum_{n=1}^{N_{0}} e^{M_{a+i(n-1) \Delta_{\omega}}(t)+N_{a+i(n-1) \Delta_{\omega}}(t) v(t)} e^{-i(n-1) \Delta_{\omega} \bar{k}}\right] \\
& =\frac{\Delta_{\omega}}{\pi} \operatorname{Re}\left[\sum_{n=1}^{N_{0}} e^{-i(n-1)(m-1) \Delta_{\omega} \Delta_{k}} e^{M_{a+i(n-1) \Delta_{\omega}}(t)+N_{a+i(n-1) \Delta_{\omega}}(t) v(t)} e^{-i(n-1) \Delta_{\omega} k_{1}}\right] \\
& =\frac{1}{\pi} \operatorname{Re}\left[\sum_{n=1}^{N_{0}} e^{-i 2 \pi \alpha(n-1)(m-1)} x_{n}\right]
\end{aligned}
$$

where $\alpha=\frac{\Delta_{\omega} \Delta_{k}}{2 \pi}$ and $x_{n}=\Delta_{\omega} e^{M_{a+i(n-1) \Delta_{\omega}}(t)+N_{a+i(n-1) \Delta_{\omega}}(t) v(t)} e^{-i(n-1) \Delta_{\omega} k_{1}}$.

Lemma 2.6.6. $A\left(t, T_{i}\right), B_{r}\left(t, T_{i}\right), M_{a}(t)$ and $N_{a}(t)$ satisfy the following differential equations. From $r_{t}$ terms

$0=B^{\prime}\left(t, T_{0}\right)-B_{r}\left(t, T_{0}\right) \kappa_{r}-1+\lambda_{r}\left(\exp \left\{\frac{1}{2} \sigma_{J_{v}}^{2} N_{a}(t)^{2}+\frac{1}{2} \sigma_{J_{r}}^{2}\left(a B_{r}\left(t, T_{1}\right)+(1-a) B_{r}\left(t, T_{0}\right)\right)^{2}\right\}-1\right)$

$0=B^{\prime}\left(t, T_{0}\right)-B_{r}\left(t, T_{1}\right) \kappa_{r}-1+\lambda_{r}\left(\exp \left\{\frac{1}{2} \sigma_{J_{v}}^{2} N_{a}(t)^{2}+\frac{1}{2} \sigma_{J_{r}}^{2}\left(a B_{r}\left(t, T_{1}\right)+(1-a) B_{r}\left(t, T_{0}\right)\right)^{2}\right\}-1\right)$

From $v_{t}$ terms,

$$
\begin{aligned}
0= & N_{a}^{\prime}-\kappa_{v} N_{a}(t)+\frac{1}{2} \sigma_{v}^{2} N_{a}(t)^{2} \\
& +\sigma_{v} \sigma_{r v}\left\{(1-a) B_{r}\left(t, T_{0}\right)+a B_{r}\left(t, T_{1}\right)\right\} N_{a}(t) \\
& -\frac{1}{2}\left(1+\sigma_{r v}^{2}\right) V(t)+\lambda_{v}\left\{e^{\frac{1}{2} \sigma_{J_{v}}^{2} N_{a}(t)^{2}}-1\right\} \\
& +\lambda_{v}\left(\exp \left\{\frac{1}{2} \sigma_{J_{v}}^{2} N_{a}(t)^{2}+\frac{1}{2} \sigma_{J_{r}}^{2}\left(a B_{r}\left(t, T_{1}\right)+(1-a) B_{r}\left(t, T_{0}\right)\right)^{2}\right\}-1\right) .
\end{aligned}
$$

From the constant terms,

$$
\begin{gathered}
0=A^{\prime}\left(t, T_{0}\right)+B_{r}\left(t, T_{0}\right) \kappa_{r} \theta+\frac{1}{2} B_{r}\left(t, T_{0}\right)^{2} \alpha_{r} \\
0=A^{\prime}+B_{r}\left(t, T_{1}\right) \kappa_{r} \theta+\frac{1}{2} B_{r}\left(t, T_{1}\right)^{2} \alpha_{r} \\
0=M_{a}^{\prime}+\gamma_{v}(t) N_{a}(t)-\frac{1}{2} \alpha_{r} V(t)+\lambda_{1}\left\{e^{\frac{1}{2} \sigma_{J_{v}}^{2} N_{a}(t)^{2}}-1\right\} \\
+\lambda_{1}\left(\exp \left\{\frac{1}{2} \sigma_{J_{v}}^{2} N_{a}(t)^{2}+\frac{1}{2} \sigma_{J_{r}}^{2}\left(a B_{r}\left(t, T_{1}\right)+(1-a) B_{r}\left(t, T_{0}\right)\right)^{2}\right\}-1\right)
\end{gathered}
$$


Proof of Lemma 2.6.6. We rewrite $X(t)$ as follows.

$$
X(t)=e^{-\int_{0}^{t} r_{s} d s}\left(P\left(t, T_{0}\right)\right)^{1-a}\left(P\left(t, T_{1}\right)\right)^{a} \exp \left(M_{a}(t)+N_{a}(t) v(t)\right) .
$$

Then, $d X$ consists of the continuous part and discontinuous part, and is written as

$$
\begin{aligned}
d X= & -X r_{t}+(1-a) X \frac{d P\left(t, T_{0}\right)}{P\left(t, T_{0}\right)}+a X \frac{d P\left(t, T_{1}\right)}{P\left(t, T_{1}\right)}+X\left(M_{a}^{\prime}+N_{a}^{\prime} v(t)\right)+X N_{a}(t) d v \\
& +\frac{1}{2} \frac{\partial^{2} X}{\partial v^{2}}(d v)^{2}+\frac{1}{2} \frac{\partial^{2} X}{\partial P^{T_{0}}(t)^{2}}\left(d P\left(t, T_{0}\right)\right)^{2}+\frac{1}{2} \frac{\partial^{2} X}{\partial P\left(t, T_{1}\right)^{2}}\left(d P^{T_{1}}(t)\right)^{2}+\frac{1}{2} \frac{\partial^{2} X}{\partial r^{2}}(d r)^{2} \\
& +\frac{\partial^{2} X}{\partial v \partial P^{T_{1}}(t)} d v d P\left(t, T_{1}\right)+\frac{\partial^{2} X}{\partial v \partial P^{T_{0}}} d v d P\left(t, T_{0}\right)+\frac{\partial^{2} X}{\partial P^{T_{0}} \partial P^{T_{1}}(t)} d P\left(t, T_{1}\right) d P\left(t, T_{0}\right) \\
& +\frac{\partial^{2} X}{\partial v \partial r} d v d r+\frac{\partial^{2} X}{\partial r \partial P^{T_{0}}} d r d P\left(t, T_{0}\right)+\frac{\partial^{2} X}{\partial r \partial P^{T_{1}}(t)} d P\left(t, T_{1}\right) d r \\
& +\left(\lambda_{0}+\lambda_{r} r_{t}+\lambda_{v} v_{t}\right) \int_{-\infty}^{\infty} \int_{-\infty}^{\infty}\left\{X\left(t, r_{t}+x, v_{t}+y\right)-X\left(t, r_{t}, v_{t}\right)\right\} d G d x d y,
\end{aligned}
$$

where $\left(\lambda_{0}+\lambda_{r} r_{t}+\lambda_{v} v_{t}\right)$ is the arrival intensity and for simplicity we assume that the jump magnitudes follows Gaussian distribution. Then, the jump term is given by

$$
\begin{aligned}
& \int_{-\infty}^{\infty} \int_{-\infty}^{\infty}\left\{X\left(t, r_{t}+x, v_{t}+y\right)-X\left(t, r_{t}, v_{t}\right)\right\} d G d x d y \\
& e^{-\int_{0}^{t} r_{s} d s} \int_{-\infty}^{\infty} \int_{-\infty}^{\infty}\left[\operatorname { e x p } \left\{M_{a}(t)+N_{a}(t)(v(t)+y)\right.\right. \\
& \left.+a\left(A\left(t, T_{1}\right)+B_{r}\left(t, T_{1}\right)\left(r_{t}+x\right)\right)+(1-a)\left(A\left(t, T_{0}\right)+B_{r}\left(t, T_{0}\right)\left(r_{t}+x\right)\right)\right\} \\
& -\exp \left\{M_{a}(t)+N_{a}(t) v(t)\right. \\
& \left.\left.+a\left(A\left(t, T_{1}\right)+B_{r}\left(t, T_{1}\right) r_{t}\right)+(1-a)\left(A\left(t, T_{0}\right)+B_{r}\left(t, T_{0}\right) r_{t}\right)\right\}\right] d G d x d y \\
= & X(t) \int_{-\infty}^{\infty} \int_{-\infty}^{\infty}\left[\exp \left\{N_{a}(t) y+a B_{r}\left(t, T_{1}\right) x+(1-a) B_{r}\left(t, T_{0}\right) x\right\}-1\right] d G d x d y \\
= & X(t) \int_{-\infty}^{\infty} \int_{-\infty}^{\infty} \frac{1}{\sqrt{2 \pi \sigma_{J_{r}}^{2}}} \frac{1}{\sqrt{2 \pi \sigma_{J_{v}}^{2}}} e^{-\frac{x^{2}}{2 \sigma_{J_{r}}^{2}}} e^{-\frac{y^{2}}{2 \sigma_{J_{v}}^{2}}} \\
& {\left[\exp \left\{N_{a}(t) y+a B_{r}\left(t, T_{1}\right) x+(1-a) B_{r}\left(t, T_{0}\right) x\right\}-1\right] d x d y } \\
= & X(t)\left[\exp \left\{\frac{1}{2} \sigma_{J_{v}}^{2} N_{a}(t)^{2}+\frac{1}{2} \sigma_{J_{r}}^{2}\left(a B_{r}\left(t, T_{1}\right)+(1-a) B_{r}\left(t, T_{0}\right)\right)^{2}\right\}-1\right] .
\end{aligned}
$$


Therefore, we see that

$$
\begin{aligned}
\frac{1}{d t} E^{Q}(d X)= & E^{Q}\left\{X ( t ) \left[-r_{t}+(1-a)\left\{A^{\prime}\left(t, T_{0}\right)+B^{\prime}\left(t, T_{0}\right) r_{t}+B_{r}\left(t, T_{0}\right) \kappa_{r}\left(\theta-r_{t}\right)\right.\right.\right. \\
& \left.+\frac{1}{2} B_{r}\left(t, T_{0}\right)^{2}\left(\alpha_{r}+v_{t}+\sigma_{r v}^{2} v_{t}\right)\right\} \\
& +a\left\{A^{\prime}+B^{\prime} r_{t}+B_{r}\left(t, T_{1}\right) \kappa_{r}\left(\theta-r_{t}\right) d t+\frac{1}{2} B_{r}\left(t, T_{1}\right)^{2}\left(\alpha_{r}+v_{t}+\sigma_{r v}^{2} v_{t}\right)\right\} \\
& +M_{a}^{\prime}+N_{a}^{\prime} v(t)+N_{a}(t)\left(\gamma_{v}(t)-\kappa_{v} v_{t}\right)+\frac{1}{2} N_{a}(t)^{2} \sigma_{v}^{2} v_{t} \\
& +\frac{1}{2}(1-a)(-a) B_{r}\left(t, T_{0}\right)^{2}\left(\alpha_{r}+v_{t}+\sigma_{r v}^{2} v_{t}\right)+\frac{1}{2} a(a-1) B_{r}\left(t, T_{1}\right)^{2}\left(\alpha_{r}+v_{t}+\sigma_{r v}^{2} v_{t}\right) \\
& +(1-a) N_{a}(t) B_{r}\left(t, T_{0}\right) \sigma_{v} \sigma_{r v} v_{t}+a N_{a}(t) B_{r}\left(t, T_{1}\right) \sigma_{v} \sigma_{r v} v_{t} \\
& +(1-a) a B_{r}\left(t, T_{0}\right) B_{r}\left(t, T_{1}\right)\left(\alpha_{r}+v_{t}+\sigma_{r v}^{2} v_{t}\right) \\
& \left.\left.+\left(\lambda_{0}+\lambda_{r} r_{t}+\lambda_{v} v_{t}\right)\left(\exp \left\{\frac{1}{2} \sigma_{J_{v}}^{2} N_{a}(t)^{2}+\frac{1}{2} \sigma_{J_{r}}^{2}\left(a B_{r}\left(t, T_{1}\right)+(1-a) B_{r}\left(t, T_{0}\right)\right)^{2}\right\}-1\right)\right]\right\}
\end{aligned}
$$

Equating the like terms, we obtain

$$
\begin{array}{cl}
\text { const }: \quad 0= & (1-a)\left\{A^{\prime}\left(t, T_{0}\right)+B_{r}\left(t, T_{0}\right) \kappa_{r} \theta+\frac{1}{2} B_{r}\left(t, T_{0}\right)^{2} \alpha_{r}\right\} \\
+ & a\left\{A^{\prime}\left(t, T_{1}\right)+B_{r}\left(t, T_{1}\right) \kappa_{r} \theta+\frac{1}{2} B_{r}\left(t, T_{1}\right)^{2} \alpha_{r}\right\}+M_{a}^{\prime}+N_{a}(t) \gamma_{v}(t) \\
+ & \frac{1}{2}(1-a)(-a) B_{r}\left(t, T_{0}\right)^{2} \alpha_{r}+\frac{1}{2} a(a-1) B_{r}\left(t, T_{1}\right)^{2} \alpha_{r}+(1-a) a B_{r}\left(t, T_{0}\right) B_{r}\left(t, T_{1}\right) \alpha_{r} \\
+ & \lambda_{0}\left(\exp \left\{\frac{1}{2} \sigma_{J_{v}}^{2} N_{a}(t)^{2}+\frac{1}{2} \sigma_{J_{r}}^{2}\left(a B_{r}\left(t, T_{1}\right)+(1-a) B_{r}\left(t, T_{0}\right)\right)^{2}\right\}-1\right) \\
r_{t} \quad: \quad & 0=-r_{t}+(1-a)\left\{B^{\prime} r_{t}-B_{r}\left(t, T_{0}\right) \kappa_{r} r_{t}\right\}+a\left\{B^{\prime} r_{t}-B_{r}\left(t, T_{1}\right) r_{t}\right\} \\
& +\lambda_{r} r_{t}\left(\exp \left\{\frac{1}{2} \sigma_{J_{v}}^{2} N_{a}(t)^{2}+\frac{1}{2} \sigma_{J_{r}}^{2}\left(a B_{r}\left(t, T_{1}\right)+(1-a) B_{r}\left(t, T_{0}\right)\right)^{2}\right\}-1\right) \\
v_{t} \quad: \quad 0= & \frac{(1-a)}{2} B_{r}\left(t, T_{0}\right)^{2}\left(v_{t}+\sigma_{r v}^{2} v_{t}\right)+\frac{a}{2} B_{r}\left(t, T_{1}\right)^{2}\left(v_{t}+\sigma_{r v}^{2} v_{t}\right) \\
+ & N_{a}^{\prime} v_{t}-N_{a}(t) \kappa_{v} v_{t}+\frac{1}{2} N_{a}(t)^{2} \sigma_{v}^{2} v_{t} \\
& +\frac{1}{2}(1-a)(-a) B_{r}\left(t, T_{0}\right)^{2}\left(v_{t}+\sigma_{r v}^{2} v_{t}\right)+\frac{1}{2} a(a-1) B_{r}\left(t, T_{1}\right)^{2}\left(v_{t}+\sigma_{r v}^{2} v_{t}\right) \\
& +(1-a) N_{a}(t) B_{r}\left(t, T_{0}\right) \sigma_{v} \sigma_{r v} v_{t}+a N_{a}(t) B_{r}\left(t, T_{1}\right) \sigma_{v} \sigma_{r v} v_{t} \\
& +(1-a) a B_{r}\left(t, T_{0}\right) B_{r}\left(t, T_{1}\right)\left(v_{t}+\sigma_{r v}^{2} v_{t}\right) \\
+ & \lambda_{v} v_{t}\left(\exp \left\{\frac{1}{2} \sigma_{J_{v}}^{2} N_{a}(t)^{2}+\frac{1}{2} \sigma_{J_{r}}^{2}\left(a B_{r}\left(t, T_{1}\right)+(1-a) B_{r}\left(t, T_{0}\right)\right)^{2}\right\}-1\right)
\end{array}
$$

The reasonable relations are as follows. From the constant terms,

$$
\begin{gathered}
0=(1-a)\left\{A^{\prime}\left(t, T_{0}\right)+B_{r}\left(t, T_{0}\right) \kappa_{r} \theta+\frac{1}{2} B_{r}\left(t, T_{0}\right)^{2} \alpha_{r}\right\} \\
0=a\left\{A^{\prime}\left(t, T_{1}\right)+B_{r}\left(t, T_{1}\right) \kappa_{r} \theta+\frac{1}{2} B_{r}\left(t, T_{1}\right)^{2} \alpha_{r}\right\}
\end{gathered}
$$




$$
\begin{aligned}
0= & M_{a}^{\prime}+N_{a}(t) \gamma_{v}(t)+\frac{\alpha_{r}}{2} V(t) \\
& +\lambda_{0}\left(\exp \left\{\frac{1}{2} \sigma_{J_{v}}^{2} N_{a}(t)^{2}+\frac{1}{2} \sigma_{J_{r}}^{2}\left(a B_{r}\left(t, T_{1}\right)+(1-a) B_{r}\left(t, T_{0}\right)\right)^{2}\right\}-1\right)
\end{aligned}
$$

From $r_{t}$ terms

$$
\begin{aligned}
0= & (1-a)\left\{B^{\prime}\left(t, T_{0}\right) r_{t}-B_{r}\left(t, T_{0}\right) \kappa_{r} r_{t}-r_{t}\right\} \\
+ & (1-a) \lambda_{r} r_{t}\left(\exp \left\{\frac{1}{2} \sigma_{J_{v}}^{2} N_{a}(t)^{2}+\frac{1}{2} \sigma_{J_{r}}^{2}\left(a B_{r}\left(t, T_{1}\right)+(1-a) B_{r}\left(t, T_{0}\right)\right)^{2}\right\}-1\right) \\
0= & a\left\{B^{\prime}\left(t, T_{0}\right) r_{t}-B_{r}\left(t, T_{1}\right) r_{t}-r_{t}\right\} \\
& +a \lambda_{r} r_{t}\left(\exp \left\{\frac{1}{2} \sigma_{J_{v}}^{2} N_{a}(t)^{2}+\frac{1}{2} \sigma_{J_{r}}^{2}\left(a B_{r}\left(t, T_{1}\right)+(1-a) B_{r}\left(t, T_{0}\right)\right)^{2}\right\}-1\right)
\end{aligned}
$$

From $v_{t}$ terms,

$$
\begin{aligned}
0= & N_{a}^{\prime}-N_{a}(t)\left\{\kappa_{v}+\sigma_{v} \sigma_{r v}\left(a B_{r}\left(t, T_{1}\right)+(1-a) B_{r}\left(t, T_{0}\right)\right)\right\} \\
& +\frac{1}{2} N(t)^{2} \sigma_{v}^{2}+\frac{\left(1+\sigma_{r v}^{2}\right)}{2} V(t) \\
& +\lambda_{v} v_{t}\left(\exp \left\{\frac{1}{2} \sigma_{J_{v}}^{2} N_{a}(t)^{2}+\frac{1}{2} \sigma_{J_{r}}^{2}\left(a B_{r}\left(t, T_{1}\right)+(1-a) B_{r}\left(t, T_{0}\right)\right)^{2}\right\}-1\right) .
\end{aligned}
$$

After computing the integrals we obtain the equations in the theorem. 


\section{Chapter 3}

\section{Caps Implied Volatility and Macroeconomic Announcements}

\subsection{Introduction}

In this chapter we empirically examine the effects of macroeconomic announcements on the implied volatility of difference caps. It has been observed that the prices of caps are driven by risk factors not spanned by the factors explaining LIBOR rates, even though caps are derivatives of bonds. The question is then what influences the volatility of difference caps. One possible explanation is that the various macroeconomic activities influence the caps implied volatility. For the bonds, Ludvigson and $\mathrm{Ng}$ [45] used the method of principal components to estimate common factors from a monthly panel of 132 measures of macroeconomic activity which may influence bond prices. They find that several estimated common factors have important forecasting power for the term premiums on U.S. government bonds. They also follow the idea of Cochrane and Piazzesi to construct single predictor state variables from these factors by forming linear combinations of the either five or six estimated common factors. They find that such state variables forecast excess bond returns at all maturities (two to five years), and do so virtually as well as a regression model that includes each common factor in the linear combination as a separate predictor variable. Fleming and Remolona [31] studied the effect of macroeconomic announcements to the U.S. Treasury markets. Concerning the bond derivatives, the effects of macroeconomic announcements to the implied volatility in swaption markets are studied in Fornari [32]. He observed a pattern of volatility spikes on certain announcements. For the stock markets, Basistha and Kurov [6] investigated the relation between the macroeconomic cycles and the stock market's reaction to monetary policy. Flannery and Protopapadakis [30] identified the macroeconomic variables affecting the aggregate stock return.

It is interesting to perform the regressions similar to [45] on the implied volatility of difference caps to see how the economic activities affect the cap prices. These are done in Sections 3.3 and 3.4. In Section 3.3, using 21 series of macroeconomic announcements listed in Table 3.2, we first perform the event analysis to see which macroeconomic announcements affect the caps implied volatility. We also apply the principal component analysis and use the first three principal components as the regressors. Since there are 15 maturities and 10 strike rates in the caps data, we compute the daily implied volatility for all maturities and strike rates and regress them with the principal components on macroeconomic announcements. We also use the unemployment data as a single regressor to examine the effects of unemployment data (initial unemployment claim). 
The reason for choosing the unemployment data is that it is a weekly data and therefore it reflects the macroeconomic activity better than other macroeconomic announcements. In Section 3.4, we examine the effect of the target federal funds rate. This is the single most important number which determines economic activity. Therefore, this should influence the caps market.

Macroeconomic announcements are sparse in time. The unemployment data is a weekly data and the fed announcement comes out every six weeks. The other announcements are monthly. The question is how the data can be applied. What is done normally is to use only the days when the data is available to do the regression (Method 1). This is in a sense assuming that the effect of announcement is instantaneous. However, it is more reasonable to assume that the effect of announcement lasts more than one day, i.e., the effect of data is transient or persistent. If this is the case, for each economic announcement we could fill the days when there is no announcement with the most recent announcement (Method 2). The regressor becomes a step-shaped function. In this way we are able to use all days when the caps data are available instead of the days when both caps data and an announcement are available. We compare two ways of using the data. We show that the second way has much better values of R-squared for the regressions. In Section 3.6 we apply the impulse response functions to justify the second way of applying the data.

In Section 3.5 we consider the effects of macroeconomic announcements to the unspanned volatility. We obtain the unspanned volatility as the residuals of regressions of the implied volatility with the principal components of LIBOR. Then, using Method 2, we do the regression analysis of the unspanned volatility with the principal components of macroeconomic announcements and the fed announcements to see how well the unspanned volatility is explained with these data. The conclusion of the chapter is given in Section 3.7.

\subsection{Caps and Implied Volatility}

In this section we describe the data used in the chapter. Caps consist of "caplet", which is an European option with period $\tau$ called tenor. $\tau$ is usually $1 / 4$ year ( 3 months). Suppose at $t=0$ we enter a contract for a cap with maturity $n$ years and with strike rate at $\bar{r}$. Then, at each date $k \tau$ the purchaser receives $\tau(L((k-1) \tau, k \tau)-\bar{r})^{+}$on a dollar, where $L((k-1) \tau, k \tau)$ is the $\tau$-year LIBOR forward rate at $(k-1) \tau$. For example, a 10-year cap on 3-month LIBOR struck at $6 \%$ represents a portfolio of 39 separately exercisable caplets with quarterly maturities ranging from 6 months to 10 years, where each caplet has a strike price of $6 \%$. The price of the first caplet is known and is incorporated in the price of the cap.

Caps data set spans from August 1, 2000 to July 31, 2002. Throughout the whole sample period, caps have 15 different maturities, which are $0.5,1.0,1.5,2.0,2.5,3.0,3.5,4.0,4.5,5.0,6.0$, 7.0, 8.0, 9.0, and 10.0 years. For each maturity, there are 10 different strike prices, which changed several times during the period. Between August 1, 2000 and October 17, 2001 the strike prices were $4.0,4.5,5.0,5.5,6.0,6.5,7.0,8.0,9.0$, and $10.0 \%$. The strike prices were lowered to $1.0,1.5$, 2.0, 2.5, 3.0, 3.5, 4.0, 4.5, 5.0, and 5.5\% between October 18, 2001 and November 1, 2001. Between November 2, 2001 and July 15, 2002 they were 2.5, 3.0, 3.5, 4.0, 4.5, 5.0, 5.5, 6.0, 6.5, and 7.0\%. Then, between July 16, 2001 and April 14, 2003 they were lowered to 2, 2.5, 3.0, 3.5, 4.0, 4.5, 5.0, $5.5,6.0$, and $6.5 \%$.

Caps are the present value and therefore, the caplets near the maturity for longer maturity cap are priced very low. Since the price of caplets are not available, to see the effect of caplets we consider the difference between the prices of caps with adjacent maturities referred as difference caps. In what follows, we deal with only the sum of the few caplets between two neighboring maturities and the same strike. For example, 1.5-year difference caps represent the sum of the 1.25- and 1.5-year caplet. Since LIBOR rates change daily and the strike rates changed several times during the observation period, we use moneyness to measure the prices of difference caps. 
The moneyness is defined as the ratio between the strike rates and the average LIBOR forward rates underlying the few caplets that form the difference cap. To estimate the price of difference caps for a fixed moneyness, we use linear spline to interpolate difference cap prices with respect to strike price to obtain prices at fixed moneyness.

Caps data set spans from August 1, 2000 to July 31, 2002 and there are 494 observation days. After removing the data that violate the arbitrage conditions (convexity condition) and zero entries, we obtain the number of the observations of difference caps for each maturity and moneyness in Table 3.1.

Table 3.1: The number of observations of implied volatility. In the following table the numbers of observations of implied volatility for each maturity and moneyness are listed.

\begin{tabular}{lrllllllrrrr}
\multicolumn{10}{c}{ Number of observations of difference caps } \\
$\begin{array}{l}\text { Moneyness } \\
\text { Maturity }\end{array}$ & 0.6 & 0.7 & 0.8 & 0.9 & 1.0 & 1.1 & 1.2 & 1.3 & 1.4 & 1.5 \\
\hline 0.5 years & 37 & 108 & 134 & 175 & 227 & 166 & 75 & 59 & 16 & 7 \\
1.0 & 45 & 171 & 207 & 210 & 194 & 76 & 3 & 0 & 0 & 0 \\
1.5 & 179 & 287 & 396 & 469 & 478 & 487 & 395 & 276 & 201 & 127 \\
2.0 & 215 & 304 & 465 & 483 & 494 & 494 & 491 & 421 & 354 & 205 \\
2.5 & 230 & 356 & 479 & 494 & 494 & 494 & 485 & 429 & 341 & 272 \\
3.0 & 244 & 409 & 493 & 494 & 494 & 487 & 454 & 361 & 312 & 248 \\
3.5 & 254 & 444 & 494 & 494 & 494 & 484 & 413 & 334 & 299 & 238 \\
4.0 & 265 & 461 & 494 & 494 & 491 & 481 & 372 & 309 & 297 & 229 \\
4.5 & 268 & 476 & 494 & 494 & 486 & 468 & 346 & 304 & 297 & 226 \\
5.0 & 270 & 485 & 494 & 494 & 486 & 454 & 327 & 300 & 297 & 224 \\
6.0 & 275 & 491 & 494 & 494 & 485 & 424 & 311 & 297 & 297 & 219 \\
7.0 & 286 & 493 & 494 & 494 & 484 & 390 & 306 & 297 & 296 & 208 \\
8.0 & 300 & 494 & 494 & 492 & 483 & 348 & 306 & 297 & 294 & 194 \\
9.0 & 312 & 494 & 494 & 489 & 483 & 338 & 303 & 297 & 292 & 182 \\
10.0 & 332 & 494 & 494 & 485 & 478 & 318 & 299 & 297 & 290 & 162 \\
\hline
\end{tabular}




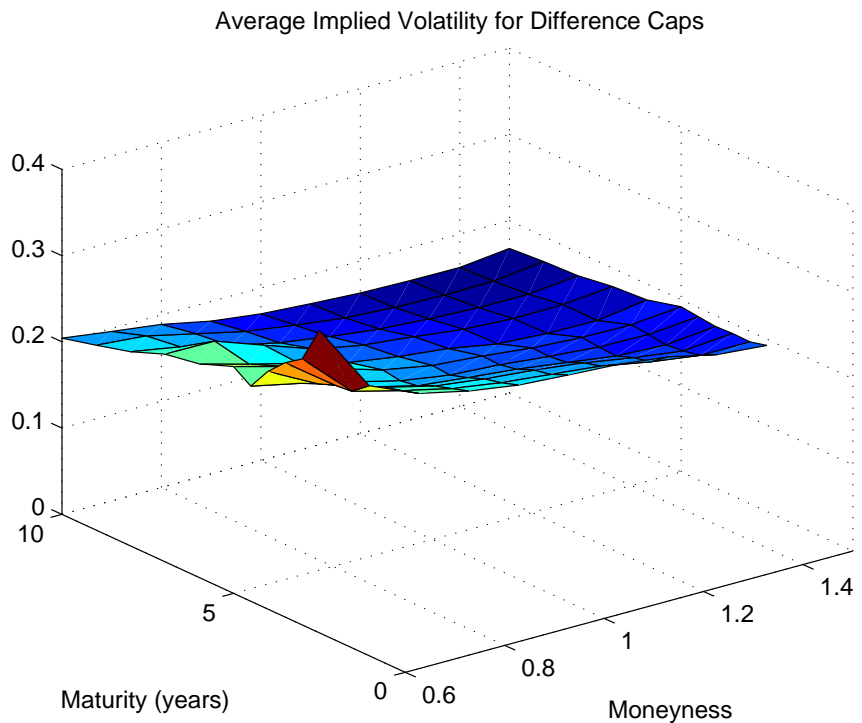

Figure 3.1: The surface graph of the daily average of the implied volatility of difference caps. In the above figure the surface graph of the daily average of the implied volatility of difference caps verses maturity and moneyness is given. The moneyness ranges from 0.6 to 1.5 and the maturity ranges from 2 years to 10 years.

The implied volatility is the value of volatility in the Black model and for difference caps it is calculated as follows. Consider a difference cap $c$ on LIBOR of tenor $\tau$ consisting of caplets maturing at time $t_{k}=t_{0}+(k-1) \tau, k=1, \ldots, n$, where $t_{0}$ is the beginning of the contract and $n$ is either 2 or 4 . Let $c_{k}$ be the value of the $k$ th caplet. Therefore, $c=\sum_{k=1}^{n} c_{k}$. The Black model for the value of the caplet is given by

$$
c_{k}=\tau P\left(t, t_{k+1}\right)\left[L_{t}\left(t_{k}, t_{k+1}\right) N\left(d_{1}\right)-\bar{r} N\left(d_{2}\right)\right],
$$

where $L_{t}\left(t_{k}, t_{k+1}\right)$ is the 3 -month LIBOR forward rate, $N$ is the cumulative normal distribution with the mean zero and the unit variance, and

$$
\begin{aligned}
d_{1} & =\frac{1}{\sigma_{k} \sqrt{t_{k}-t}} \ln \frac{L_{t}\left(t_{k}, t_{k+1}\right)}{K}+\frac{1}{2} \sigma_{k} \sqrt{t_{k}-t} \\
d_{2} & =d_{1}-\sigma_{k} \sqrt{t_{k}-t} .
\end{aligned}
$$

In the above formula $\sigma_{k}$ is the Black's volatility for the $k$ th caplet. The value of volatility $\sigma$ satisfying $c=\sum_{k=1}^{n} c_{k}(\sigma)$ for a market value of a difference cap $c$ is called the implied volatility of the difference cap. We find the value of $\sigma$ by minimizing the difference between $c$ and the difference cap obtained from the market caps.

The implied volatility of the Black model is used as a measure of volatility in the caps market. To show some properties of difference caps, a few graphs are provided. In Figure 3.1 we show the time average of the implied volatility verses maturity and moneyness. The surface graph and the volatility smile of implied volatility for difference caps are presented in Figures 3.2 and 3.3. They are based on the approximation for the volatility

$$
\sigma(T-t)=\sigma_{0}+\sigma_{1} \exp \left(-\kappa_{1}(T-t)\right)+\sigma_{2} \exp \left(-\kappa_{2}(T-t)\right)
$$


where $T-t$ is the maturity. This approximation is suggested in Jong and Driessen [42] to study the term premiums in the bond market. We determine the parameters $\sigma_{0}, \sigma_{1}, \sigma_{2}, \kappa_{1}$, and $\kappa_{2}$ for each maturity and moneyness so that the errors between $\sigma(T-t)$ and the time series of implied volatility of the difference cap with maturity $(T-t)$ for each moneyness are minimized. We should expect that the resulting difference caps are smoothed out. In Figure 3.3 the difference caps with maturities 0.5 and 1.5 years have clear volatility smiles. The relative errors range from 0.55 to 157.46 and the absolute errs range from 0.003 to 16.11 with majority being less than one.

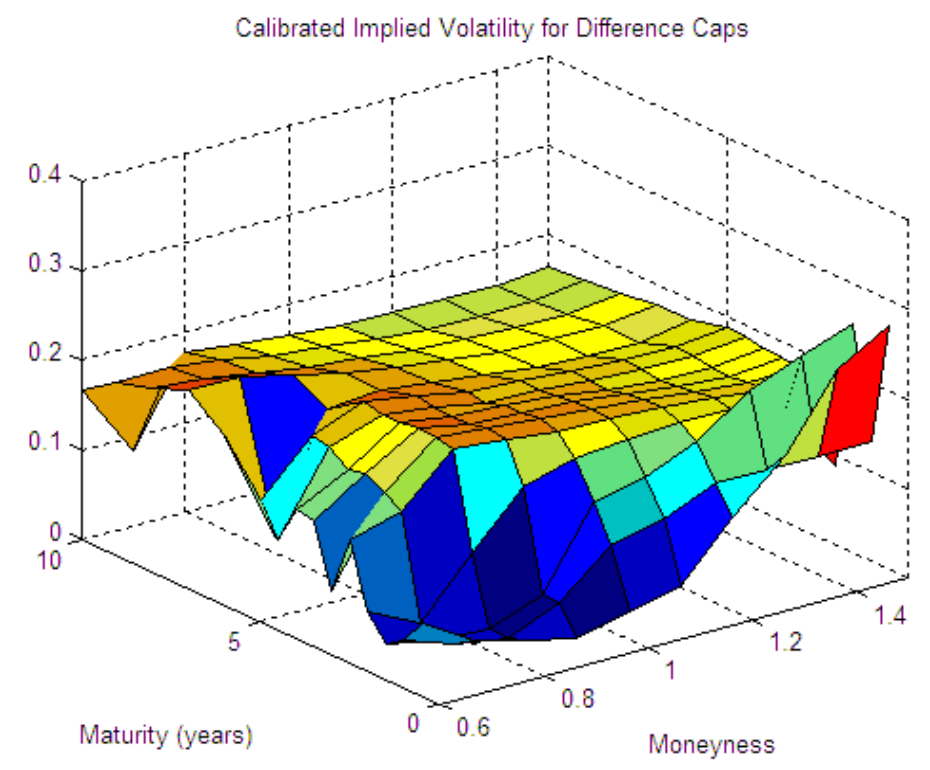

Figure 3.2: The surface graph of calibrated implied volatility of difference caps. This is a surface graph of calibrated implied volatility of difference caps where $\sigma(T-t)=\sigma_{0}+\sigma_{1} \exp \left(-\kappa_{1}(T-\right.$ $t))+\sigma_{2} \exp \left(-\kappa_{2}(T-t)\right)$ is used to calibrate the implied volatility . 


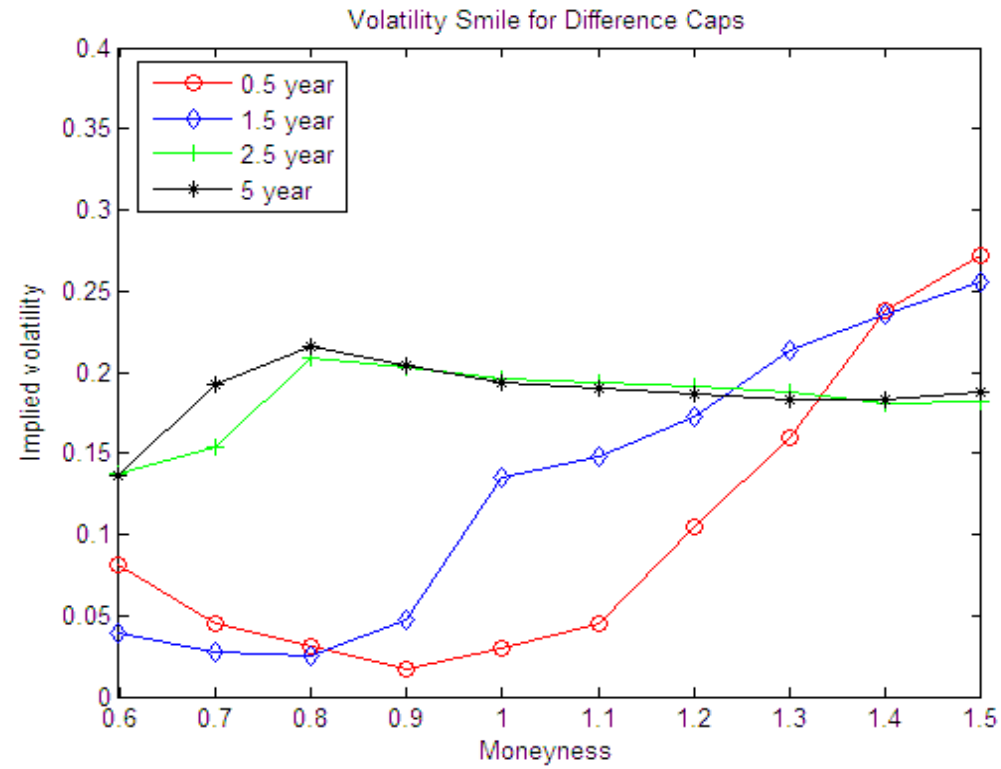

Figure 3.3: The volatility smiles for the calibrated implied volatility of difference caps. In the above figure the volatility smiles for the calibrated implied volatility of difference caps of the few maturities are given.

\subsection{Macroeconomic Announcements}

\subsubsection{Implied Volatility and Macroeconomic Announcements}

We examine the effects of the macroeconomic announcements on the implied volatility of difference caps. Ludvigson and $\mathrm{Ng}$ [45] studied the effects of the macroeconomic announcements on the prices of bonds. It may be interesting to see how the macroeconomic announcements affect the volatility of caps. In what follows, using 21 series of macroeconomic announcements available to us, we examine this possibility. They consist of time series of data measuring the various aspects of macroeconomic activities and are listed in Table 3.2. The Initial Unemployment Claims are weekly. All the other announcements are monthly. 
Table 3.2: List of macroeconomic announcements. In the following table the list of 21 macroeconomic announcements are given.

\begin{tabular}{cl} 
Monthly announcements & \\
\hline Real Activity: & Nonfarm Payroll Employment (EMP) \\
& Retail Sales (RES) \\
& Industrial Production (INP) \\
& Capacity Utilization (CAPU) \\
& Personal Income (PEI) \\
& Gross Domestic Product (GDP) \\
& New Home Sales (NHS) \\
Consumption: & Personal Consumption Expenditures (PEC) \\
& Durable Goods Orders (DGO) \\
Investment: & Factory Orders (FOR) \\
& Construction Spending (COS) \\
& Business Inventories (BIN) \\
Net Exports: & Trade Balance (EXP) \\
Prices: & Producer Price Index (PPI) \\
& Consumer Price Index (CPI) \\
Forward-Looking: & Consumer Confidence Index (CCO) \\
& NAPM Index (NAPM) \\
& Housing Starts (HSS) \\
& Index of Leading Indicators (LIN) \\
Lagging indicator & Unemployment Rate (UNE) \\
Weekly Announcements & \\
\hline & Initial Unemployment Claims (INCL)
\end{tabular}

\subsubsection{Event Study Analysis}

It is interesting to see which economic announcements affects the caps implied volatility. For this purpose, we choose the days when at least one macroeconomic announcement is made and construct the time series of implied volatilities and the regressors of macroeconomic announcements. If a particular announcement is not made on the chosen date, we put zero for that announcement. Then, we regress the time series of implied volatility of 15 maturity and 10 moneyness with the 21 macroeconomic announcements. After obtaining the $95 \%$ confidence intervals of the coefficients of the regressors, we counted the number of times when the zero is not in the interval, i.e., the number of times when the null hypothesis is rejected. This shows that which macroeconomic announcement influence the implied volatility. The result is shown in Table 3.5. We have 142 time series of implied volatility. To see the effect of announcements for moneyness and maturity, the numbers are counted for in-the-money, at-the-money, and out-of-the-money in the moneyness and short, intermediate, and long maturities for maturity. Also, the number of times when the coefficients are positive are counted. We see that the influence of PPI is most significant and the signs of the coefficient are all negative. National Association of Purchasing Management (NAPM) Index comes second. The signs of the coefficients are mostly positive. It is somewhat puzzling that the signs of PPI and NAPM are different. These are related to production side. The other important indices on the production side are Industrial Production (INP) and Factory Orders (FOR). Indices important on the consumer side are Retail Sale (RES) and Personal Consumption Expenditures (PEC). The other important indices on the consumer side are Consumer Confidence Index and Unemployment 
Rate. Also, concerning the moneyness, both PEC and RES are affecting the out-of-the-money caps more than in-the-money or at-the-money caps. FOR and CCO are affecting in-the-money and at-the-money caps.

Table 3.3: Three categories of moneyness. Three categories of moneyness are given.

\begin{tabular}{c|c}
\hline Moneyness & \\
\hline In the money & Moneyness 0.6, 0.7, 0.8 \\
At the money & Moneyness 0.9, 1.0, 1.1 \\
Out of money & Moneyness 1.2 1.3, 1.4, 1.5 \\
\hline
\end{tabular}

Table 3.4: Three categories of maturities. Three categories of maturities are given.

\begin{tabular}{c|c}
\hline Maturities & \\
\hline Short maturities & Maturities 0.5 to 2.5 years \\
Intermediate maturities & Maturities 3.0 to 5 years \\
Long maturities & Maturities 6 to 10 years \\
\hline
\end{tabular}


Table 3.5: Event study analysis. The table reports the number of times the announcements are significant in the event study for the implied volatility with 21 economic announcements. "mo" stands for moneyness and "mat" is maturity. "in, at, and out" are the abbreviations for in-the-money, at-the-money, and "out-of-the-money. "sh, int, and lng" are the abbreviations for short, intermediate, and long maturities. The table also reports the number of times the signs of coefficients is positive.

\begin{tabular}{|c|c|c|c|c|c|c|c|c|}
\hline \multirow{3}{*}{$\frac{\text { number of time series }}{\text { announcements }}$} & \multirow{3}{*}{$\begin{array}{c}142 \\
\text { number of } \\
\text { significance }\end{array}$} & 43 & 45 & 54 & 42 & 50 & 50 & \multirow{3}{*}{$\begin{array}{c}142 \\
\text { number of } \\
\text { positive sign }\end{array}$} \\
\hline & & \multicolumn{3}{|c|}{$\mathrm{mo}$} & \multicolumn{3}{|c|}{ mat } & \\
\hline & & in & at & out & sh & int & $\operatorname{lng}$ & \\
\hline PEC & 16 & 1 & 0 & 15 & 1 & 9 & 6 & 1 \\
\hline EXP & 2 & 1 & 1 & 0 & 0 & 1 & 1 & 0 \\
\hline INP & 14 & 2 & 2 & 10 & 3 & 4 & 7 & 1 \\
\hline COS & 4 & 2 & 1 & 1 & 2 & 0 & 2 & 1 \\
\hline PPI & 57 & 12 & 24 & 21 & 10 & 33 & 14 & 0 \\
\hline PEI & 6 & 2 & 1 & 3 & 0 & 1 & 5 & 3 \\
\hline HSS & 3 & 1 & 0 & 2 & 1 & 2 & 0 & 2 \\
\hline NHS & 3 & 2 & 1 & 1 & 0 & 0 & 3 & 3 \\
\hline BIN & 1 & 0 & 0 & 0 & 1 & 0 & 0 & 1 \\
\hline FOR & 14 & 9 & 5 & 1 & 4 & 4 & 6 & 0 \\
\hline NAPM & 28 & 11 & 12 & 5 & 12 & 9 & 7 & 25 \\
\hline CAPU & 1 & 1 & 0 & 0 & 1 & 0 & 0 & 0 \\
\hline GDP & 7 & 1 & 2 & 4 & 1 & 0 & 6 & 1 \\
\hline EMP & 5 & 4 & 0 & 1 & 5 & 4 & 0 & 1 \\
\hline CPI & 5 & 1 & 0 & 4 & 1 & 0 & 0 & 0 \\
\hline $\mathrm{CCO}$ & 12 & 7 & 4 & 1 & 3 & 3 & 9 & 6 \\
\hline LIN & 3 & 1 & 2 & 0 & 0 & 2 & 0 & 3 \\
\hline DGO & 8 & 0 & 2 & 6 & 1 & 1 & 5 & 1 \\
\hline RES & 18 & 0 & 2 & 16 & 0 & 2 & 6 & 4 \\
\hline UNE & 11 & 1 & 7 & 3 & 2 & 0 & 9 & 11 \\
\hline INCL & 1 & 0 & 0 & 1 & 1 & 0 & 0 & 0 \\
\hline
\end{tabular}

\subsubsection{Principal Component Analysis}

We compute the average and the standard deviations of each time series to standardize the data. We use the principal component analysis. There are at least two ways to use the data to apply the principal component analysis.

- Method 1: Among the days when the cap prices are available, we choose the days when at least one announcement is made. We then apply the principal component analysis to obtain the first three principal components of the time series of the 21 macroeconomic announcements. We regress the implied volatility of difference caps with the three principal components. The result is given in Table 3.6.

- Method 2: It is reasonable to think that each macroeconomic announcement affects the implied volatility till the next announcement. This suggests that for each macroeconomic data we use the same value of announcement between two announcements of the same series. After processing the data we compute the principal components to do the regression. In this case we use all implied volatilities in the data period. We regress the implied volatility of 
caps with the three principal components obtained in the above manner. The result is given in Table 3.7.

Table 3.6: R-squared of the regression of implied volatilities. The R-squared for the regression of implied volatilities with three principal components of the macroeconomic data are given. Only the days where the announcements were made are filled with the data. The numbers with bold letters are significant in $90 \%$ F-statistics.

\begin{tabular}{|c|c|c|c|c|c|c|c|c|c|c|}
\hline & & $\begin{array}{l}\text { qua } \\
\text { n th }\end{array}$ & $\begin{array}{l}\text { or t } \\
\text { sta }\end{array}$ & $d$ th & inc & $\mathrm{m}$ & $\begin{array}{l}\text { lat } \\
\text { ts }\end{array}$ & & & \\
\hline \multicolumn{10}{|l|}{ Maturity } & 1.5 \\
\hline 0.5 years & $\mathrm{NaN}$ & 0.0561 & 0.0139 & 0.0563 & 0.0068 & 0.0460 & 0.0940 & 0.2577 & $\mathrm{NaN}$ & $\mathrm{NaN}$ \\
\hline 1 & 0.0673 & 0.0219 & 0.0092 & 0.0230 & 0.3017 & 0.1008 & $\mathrm{NaN}$ & $\mathrm{NaN}$ & $\mathrm{NaN}$ & $\mathrm{NaN}$ \\
\hline 1.5 & 0.0066 & 0.0081 & 0.0083 & 0.0151 & 0.0178 & 0.0153 & 0.0086 & 0.0093 & 0.0044 & 0.0319 \\
\hline 2 & 0.0386 & 0.0040 & 0.0067 & 0.0023 & 0.0035 & 0.0066 & 0.0115 & 0.0085 & 0.0242 & 0.0336 \\
\hline 2.5 & 0.0222 & 0.0054 & 0.0164 & 0.0149 & 0.0146 & 0.0152 & 0.0174 & 0.0284 & 0.0291 & 0.0788 \\
\hline 3 & 0.0047 & 0.0185 & 0.0133 & 0.0159 & 0.0157 & 0.0176 & 0.0296 & 0.0342 & 0.0685 & 0.0157 \\
\hline 3.5 & 0.0037 & 0.0271 & 0.0129 & 0.0118 & 0.0141 & 0.0160 & 0.0275 & 0.0309 & 0.0162 & 0.0195 \\
\hline 4 & 0.0040 & 0.0204 & 0.0093 & 0.0093 & 0.0111 & 0.0168 & 0.0138 & 0.0394 & 0.0085 & 0.0107 \\
\hline 4.5 & 0.0004 & 0.0141 & 0.0100 & 0.0114 & 0.0107 & 0.0287 & 0.0256 & 0.0519 & 0.0065 & 0.0137 \\
\hline 5 & 0.0026 & 0.0097 & 0.0071 & 0.0095 & 0.0093 & 0.0332 & 0.0238 & 0.0397 & 0.0023 & 0.0157 \\
\hline 6 & 0.0067 & 0.0107 & 0.0122 & 0.0196 & 0.0219 & 0.0284 & 0.0422 & 0.0083 & 0.0085 & 0.0132 \\
\hline 7 & 0.0080 & 0.0045 & 0.0044 & 0.0085 & 0.0163 & 0.0224 & 0.0335 & 0.0103 & 0.0067 & 0.0136 \\
\hline 8 & 0.0039 & 0.0127 & 0.0144 & 0.0130 & 0.0209 & 0.0220 & 0.0389 & 0.0089 & 0.0091 & 0.0288 \\
\hline 9 & 0.0046 & 0.0083 & 0.0090 & 0.0088 & 0.0158 & 0.0154 & 0.0227 & 0.0090 & 0.0093 & 0.0233 \\
\hline 10 & 0.0053 & 0.0045 & 0.0061 & 0.0058 & 0.0097 & 0.0158 & 0.0289 & 0.0088 & 0.0072 & 0.0107 \\
\hline
\end{tabular}

We see the significant improvement in $R^{2}$ of Method 2 over Method 1. Roughly speaking we observe 5 to 10 fold improvement in the values of $R^{2}$. If we fill the data between the two consecutive announcements with the value of the most recent announcement of the same economic activity, the randomness is smoothed out and we are in a sense averaging out the data and obtaining the averaged result of the activity between the announcements. In Method 1 we are treating the effect as an instantaneous one and in Method 2 permanent one. They are two extreme ways to interpret the effects of macroeconomic announcements. In practice the effect would be somewhere in between. We could incorporate the decay effect by putting the exponential decaying data. 
Table 3.7: R-squared for the regression of daily implied volatilities. The R-squared of the regression of daily implied volatilities with three principal components of the macroeconomic data are given. Between the two consecutive announcements economic data are filled with the same values. The numbers with bold letters are significant in $90 \%$ F-statistics.

\begin{tabular}{|c|c|c|c|c|c|c|c|c|c|c|}
\hline \multicolumn{11}{|c|}{$\begin{array}{l}\text { R-squared for the regression of caps daily implied volatility } \\
\text { with the constant and three principal components }\end{array}$} \\
\hline $\begin{array}{l}\text { Moneyness } \\
\text { Maturity }\end{array}$ & 0.6 & 0.7 & 0.8 & 0.9 & 1.0 & 1.1 & 1.2 & 1.3 & 1.4 & 1.5 \\
\hline 0.5 years & 0.1746 & 0.1680 & 0.2132 & .0741 & 1232 & 0.2437 & 0.5088 & 0.6045 & 0.7135 & 0.1288 \\
\hline 1 & 0.2520 & 0.0853 & 0.1630 & 0.5231 & 0.4058 & 0.6580 & $\mathrm{NaN}$ & $\mathrm{NaN}$ & $\mathrm{NaN}$ & $\mathrm{NaN}$ \\
\hline 1.5 & 0.2947 & 0.2323 & 0.1861 & 0.3161 & 0.3187 & 0.2556 & 0.2755 & 0.2092 & 0.1634 & 0.2787 \\
\hline 2 & 0.2050 & 0.2532 & 0.1023 & 0.0429 & 0.0568 & 0.1043 & 0.1862 & 0.1781 & 0.1209 & 0.3634 \\
\hline 2.5 & 0.0268 & 0.3178 & 0.2736 & 0.2473 & 0.2428 & 0.2479 & 0.2412 & 0.1870 & 0.2521 & 0.2726 \\
\hline 3 & 0.2008 & 0.3048 & 0.2079 & 0.2322 & 0.2541 & 0.2530 & 0.2287 & 0.2620 & 0.2994 & 0.1847 \\
\hline 3.5 & 0.2402 & 0.3318 & 0.2442 & 0.2598 & 0.2585 & 0.2396 & 0.1970 & 0.2360 & 0.1850 & 0.2241 \\
\hline 4 & 0.2669 & 0.2604 & 0.1949 & 0.2137 & 0.2010 & 0.1962 & 0.1839 & 0.2166 & 0.1057 & 0.1253 \\
\hline 4.5 & 0.2201 & 0.2685 & 0.2136 & 0.2265 & 0.2171 & 0.2081 & 0.2542 & 0.3052 & 0.2040 & 0.2598 \\
\hline 5 & 0.3168 & 0.2882 & 0.2065 & 0.2029 & 0.1964 & 0.1833 & 0.2468 & 0.2364 & 0.2153 & 0.2669 \\
\hline 6 & 0.3362 & 0.2344 & 0.2136 & 0.2537 & 0.2454 & 0.2179 & 0.3237 & 0.2266 & 0.1823 & 0.2142 \\
\hline 7 & 73 & 55 & 73 & & & & & 159 & 052 & .1291 \\
\hline 8 & 0.3286 & 0.2160 & 0.2327 & 0.2226 & 0.2481 & 0.2516 & 0.3523 & 0.1784 & 0.1548 & 0.1675 \\
\hline 9 & 0.2029 & 0.1467 & 0.1560 & 0.1609 & 0.1956 & 0.2342 & 0.3095 & 0.1910 & 0.1557 & 0.0754 \\
\hline 10 & 0.1682 & 0.0586 & 0.1343 & 0.1347 & 0.1878 & 0.2352 & 0.2179 & 0.1641 & 0.1601 & 0.0796 \\
\hline
\end{tabular}

\subsubsection{Daily Difference of the Implied Volatility and the Macroeconomic Announcements}

In [32] Fornari studied the relations between the implied volatility in the swaption markets and the economic announcements. He observed a pattern of volatility spikes on certain announcements. This indicates that the daily difference of the implied volatility in the interest cap markets may be affected by the economic announcements. Since the daily difference is taken, it is difficult to apply Method 2. Method 1 is applied to the daily differences of the implied volatility. The result is given in Table 3.8 .

\subsubsection{Unemployment Data}

Among the 21 data, the unemployment data are generally believed to be most influential to the volatility. We regress the implied volatilities with the Initial Unemployment Claims after modifying the unemployment data according to Methods 1 and 2. The results are given in 3.9 and 3.10, respectively. As in Subsection 3.3.1, we see the significant improvement in $R^{2}$ of Method 2 over Method 1. Roughly speaking we observe 5 to 10 fold improvement in the values of $R^{2}$. The unemployment data are weekly data and therefore, the decay in the effect of the announcement is not so significant as the decay of the effect of monthly data or six week data. This may be reflecting in the difference between the two results. 
Table 3.8: R-squared for the regression of the daily difference of implied volatilities. The R-squared for the regression of the daily difference of implied volatilities with the constant and the three principal components of the macroeconomic data. Only the days where the announcements were made are filled with the data. The numbers with bold letters are significant in $90 \%$ F-statistics.

\begin{tabular}{lrllllllllllr} 
& \multicolumn{8}{c}{$\begin{array}{l}\text { R-squared for the regression of daily difference of implied volatility } \\
\text { with three principal components of macroeconomic data }\end{array}$} \\
\hline $\begin{array}{l}\text { Moneyness } \\
\text { Maturity }\end{array}$ & 0.6 & 0.7 & 0.8 & 0.9 & 1.0 & 1.1 & 1.2 & 1.3 & 1.4 & 1.5 \\
\hline 0.5 years & $\mathrm{NaN}$ & 0.0668 & 0.0601 & 0.0078 & 0.0062 & 0.0179 & $\mathbf{0 . 5 1 8 4}$ & $\mathbf{0 . 5 6 1 6}$ & $\mathrm{NaN}$ & $\mathrm{NaN}$ \\
1.0 & $\mathrm{NaN}$ & 0.0472 & 0.0412 & $\mathbf{0 . 1 1 2 5}$ & $\mathbf{0 . 4 8 0 9}$ & $\mathbf{0 . 5 2 4 3}$ & $\mathrm{NaN}$ & $\mathrm{NaN}$ & $\mathrm{NaN}$ & $\mathrm{NaN}$ \\
1.5 & 0.0119 & 0.0221 & $\mathbf{0 . 0 4 1 9}$ & $\mathbf{0 . 0 2 4 8}$ & $\mathbf{0 . 0 2 6 4}$ & 0.0199 & $\mathbf{0 . 0 2 8 2}$ & $\mathbf{0 . 0 7 8 2}$ & $\mathbf{0 . 1 4 4 3}$ & $\mathbf{0 . 2 1 9 6}$ \\
2.0 & 0.0230 & 0.0004 & 0.0001 & 0.0001 & 0.0003 & 0.0007 & 0.0091 & $\mathbf{0 . 0 4 3 9}$ & 0.0251 & $\mathbf{0 . 0 7 7 3}$ \\
2.5 & 0.0040 & 0.0001 & 0.0000 & 0.0015 & 0.0053 & 0.0147 & $\mathbf{0 . 0 2 5 4}$ & 0.0135 & 0.0288 & $\mathbf{0 . 0 4 9 5}$ \\
3.0 & 0.0129 & 0.0018 & 0.0018 & 0.0007 & 0.0025 & 0.0077 & 0.0116 & 0.0221 & $\mathbf{0 . 0 3 2 1}$ & 0.0076 \\
3.5 & 0.0011 & 0.0015 & 0.0058 & 0.0065 & 0.0071 & 0.0092 & 0.0019 & 0.0013 & 0.0019 & 0.0329 \\
4.0 & 0.0035 & 0.0068 & 0.0107 & 0.0110 & 0.0143 & $\mathbf{0 . 0 3 7 5}$ & $\mathbf{0 . 0 2 8 3}$ & 0.0071 & 0.0017 & 0.0012 \\
4.5 & 0.0012 & 0.0061 & 0.0069 & 0.0081 & 0.0111 & 0.0096 & 0.0125 & 0.0007 & 0.0006 & 0.0022 \\
5.0 & 0.0049 & 0.0050 & 0.0060 & 0.0072 & 0.0099 & 0.0154 & 0.0107 & 0.0007 & 0.0014 & 0.0015 \\
6.0 & 0.0028 & 0.0073 & 0.0046 & 0.0050 & 0.0185 & 0.0073 & 0.0047 & 0.0027 & 0.0031 & 0.0025 \\
7.0 & 0.0112 & 0.0041 & 0.0024 & 0.0010 & 0.0018 & 0.0078 & 0.0025 & 0.0032 & 0.0033 & 0.0050 \\
8.0 & 0.0004 & 0.0009 & 0.0026 & 0.0093 & 0.0029 & 0.0036 & 0.0014 & 0.0009 & 0.0005 & 0.0086 \\
9.0 & 0.0039 & 0.0063 & 0.0080 & 0.0073 & 0.0106 & 0.0106 & 0.0034 & 0.0017 & 0.0008 & 0.0053 \\
10.0 & 0.0017 & 0.0022 & 0.0031 & 0.0043 & 0.0025 & 0.0075 & 0.0239 & 0.0057 & 0.0044 & 0.0050 \\
\hline
\end{tabular}

Table 3.9: R-squared for the regression of implied volatilities with unemployment data. The R-squared for the regression of implied volatilities with unemployment data are given. Only the days where the announcements were made are filled with the data. The numbers with bold letters are significant in $90 \%$ F-statistics.

\begin{tabular}{|c|c|c|c|c|c|c|c|c|c|c|}
\hline $\begin{array}{l}\text { Moneyness } \\
\text { Maturity }\end{array}$ & 0.6 & 0.7 & 0.8 & 0.9 & 1.0 & 1.1 & 1.2 & 1.3 & 1.4 & 1.5 \\
\hline 5 years & $\mathrm{NaN}$ & 0.0000 & 0.0014 & 0.0001 & 0.0004 & 0.0158 & 0.0068 & 0.0064 & $\mathrm{NaN}$ & $\mathrm{NaN}$ \\
\hline .0 & 0.0003 & 0.0238 & 0.0015 & 0.0038 & 0.0001 & 0.0000 & $\mathrm{NaN}$ & $\mathrm{NaN}$ & $\mathrm{NaN}$ & $\mathrm{NaN}$ \\
\hline .5 & 001 & 0.0005 & 0.0000 & 0.0004 & 0.0014 & 0.0010 & 0.0030 & 0.0168 & 0.0277 & 0.0315 \\
\hline 0 & 0006 & 0.0007 & 0.0018 & 0.0017 & 0.0023 & 0.0035 & 0.0052 & 0.0105 & 0.0232 & 0.0310 \\
\hline 5 & 0.0024 & 0.0051 & 0.0038 & 0.0036 & 0.0047 & 0.0053 & 0.0062 & 0.0071 & 0.0172 & 0.0070 \\
\hline 0 & 0020 & 0.0050 & 0.0038 & 0.0060 & 0.0083 & 0.0109 & 0.0126 & & 82 & 009 \\
\hline .5 & 0113 & 0.0043 & 0.0059 & 0.0067 & 0.0079 & 0.0098 & 0.0076 & & 103 & 0.0003 \\
\hline .0 & 075 & 0.0027 & 0.0044 & 0.0050 & 0.0074 & 0.0091 & 0.0033 & & 002 & 0.0001 \\
\hline .5 & 024 & 0.0000 & 0.0002 & 0.0005 & 0.0018 & 0.0028 & 0.0076 & & 001 & 0.0003 \\
\hline 5.0 & 015 & 0.0001 & 0.0007 & 0.0000 & 0.0007 & 0.0013 & 0.0008 & 0.0039 & 0.0000 & 0.0010 \\
\hline 6.0 & 063 & 0.0006 & 0.0004 & 0.0017 & 0.0066 & 0.0108 & 0.0067 & 0.0007 & 0.0004 & 0.0006 \\
\hline 7.0 & 076 & 0.0025 & 0.0019 & 0.0037 & 0.0083 & 0.0078 & 0.0126 & 0.0031 & 0.0021 & 0.0019 \\
\hline 8.0 & 0081 & 0.0007 & 0.0015 & 0.0030 & 0.0052 & 0.0010 & 0.0060 & 0.0004 & 0.0003 & 0.0008 \\
\hline 9.0 & & 0.0009 & 0.0015 & 0.0008 & & 0.0018 & 0.0047 & & 0.0001 & 0.0004 \\
\hline 10.0 & 0.0039 & 0.0011 & 0.0035 & 0.0014 & 0.0032 & 0.0013 & 0.0000 & 0.0000 & 0.0000 & 0.0002 \\
\hline
\end{tabular}

\subsection{Fed Fund Rates}

In this section we discuss the effects of the target federal funds rate. Bernanke and Kuttner [8] discuss this issue in stock market. The Fed meets every 6 weeks to adjust the target federal funds rate. The Target Federal Funds Rate are announced every six week. This rate is decompose in the expected component and the surprise component and has the following relation

$$
\triangle i=\triangle i^{e}+\triangle i^{u},
$$


where $\triangle i$ is the rate change in the target federal funds rate, $\triangle i^{e}$ is the expected component and $\triangle i$ is the surprise component. We use the regression analysis to examine how the implied volatilities are affected by the Fed announcements. There are 18 Fed announcements between the data period $8 / 1 / 2000$ to $7 / 31 / 2002$.

Table 3.10: R-squared for the regression of implied volatilities with daily unemployment data. R-squared for the regression of implied volatilities with daily unemployment data. Between the two consecutive announcements economic data are filled with the same values. The numbers with bold letters are significant in $90 \%$ F-statistics.

\begin{tabular}{|c|c|c|c|c|c|c|c|c|c|c|}
\hline $\begin{array}{l}\text { Moneyness } \\
\text { Maturity }\end{array}$ & 0.6 & 0.7 & 0.8 & 0.9 & 1.0 & 1.1 & 1.2 & 1.3 & 1.4 & 1.5 \\
\hline .5 years & 0.0414 & 0.0798 & 0.0070 & 0.0002 & 0.0284 & 0.0491 & 0.0599 & 0.0431 & 0.1217 & 0.0770 \\
\hline .0 & 0077 & .0033 & 0.0005 & 0.0144 & 0.0321 & 0.0081 & $\mathrm{NaN}$ & $\mathrm{NaN}$ & $\mathrm{NaN}$ & $\mathrm{NaN}$ \\
\hline .5 & 0130 & 0.0063 & 0.0091 & 0.0072 & 0.0130 & 0.0108 & 0.0152 & 0.0466 & 0.0863 & 0.0694 \\
\hline .0 & 0048 & 0.0113 & 0.0078 & 0.0040 & 0.0059 & 0.0119 & 0.0223 & 0.0367 & 0.0417 & 0.0458 \\
\hline .5 & 0.0083 & 0.0257 & 0.0263 & 0.0262 & 0.0284 & 0.0297 & 0.0301 & 0.0293 & 0.0448 & 0.0414 \\
\hline .0 & & & 0.0246 & 0.0300 & 0.0363 & 0.0427 & 0.0402 & 0.0591 & 0.0559 & 0.0019 \\
\hline 5 & & & 0.04 & 0.0362 & 0.0398 & 432 & 423 & 0.0447 & 178 & 0.0011 \\
\hline .0 & 886 & 364 & 0.0337 & 0.0278 & 0.0362 & 360 & 545 & 0.0403 & 018 & 0.0004 \\
\hline 5 & & & 0.00 & 13 & 247 & & & 286 & 07 & 012 \\
\hline 0 & & & 0.00 & 81 & 202 & 22 & & 077 & 011 & 008 \\
\hline .0 & & & 0.0 & 324 & 358 & & & 42 & 67 & 000 \\
\hline .0 & & & & & & & & & 02 & 000 \\
\hline 8.0 & & & 0.0258 & 0.0296 & 0.0395 & 0.0615 & 0.0684 & 0.0062 & 0.0065 & 0.0019 \\
\hline 9.0 & 32 & & 0.0186 & 0.0126 & 0.0209 & 0.0568 & 0.0390 & 0.0086 & 0.0080 & 0.0012 \\
\hline 10.0 & 0.0225 & 0.0080 & 0.0250 & 0.0123 & 0.0271 & 0.0500 & 0.0311 & 0.0197 & 0.0183 & 0.0019 \\
\hline
\end{tabular}

There are a few ways to use the data. For each case, we do both

$$
v_{t}=a+b \triangle i_{t}+\varepsilon_{t}
$$

and

$$
v_{t}=a+b \triangle i_{t}^{e}+c \triangle i_{t}^{u}+\varepsilon_{t},
$$

where $v_{t}$ is the implied volatility. In both specifications, the error term $\varepsilon_{t}$ represents factors other than monetary policy that affect the implied volatility. These factors are assumed to be orthogonal to the changes in the Federal funds rate appearing on the right hand side of the regression. There are several ways to apply the regression analysis to the data.

1. (Method 1) Choose the implied volatilities of the days when the Fed announcements are made and regress them using (3.4.2) and (3.4.3). The result is given in Table 3.11.

2. Choose the daily difference of the implied volatilities of the days when the Fed announcements are made and regress them using (3.4.2) and (3.4.3). The results are given in Tables 3.12 and 3.13 .

3. (Method 2) It is reasonable to think that the announcement by the Fed affects the implied volatility till the next announcement. This suggests that we use the same values of $\triangle i_{t}$ or $\triangle i_{t}^{e}$ and $\triangle i_{t}^{u}$ between two meetings to do the regression. In this case we use all implied volatilities in the data period. The results are given in Tables 3.14 and 3.15. 
Table 3.11: Regressions of implied volatility with Fed announcements. The table reports the results of Case 1 with the regressions $v_{t}=a+b \triangle i_{t}+\varepsilon_{t}$, where we use $\triangle i_{t}$. The numbers with bold letter indicate that the regression results are significant in F-test.

\begin{tabular}{|c|c|c|c|c|c|c|c|c|c|c|}
\hline & & $\begin{array}{l}\text { squa } \\
\text { th fec }\end{array}$ & $\begin{array}{l}\text { for the } \\
\text { ds tar }\end{array}$ & $\begin{array}{l}\text { gress } \\
\text { t rates }\end{array}$ & of im & vo & & & & \\
\hline \multicolumn{11}{|l|}{ Maturity } \\
\hline 0.5 years & $\mathrm{NaN}$ & $\mathrm{NaN}$ & $\mathrm{NaN}$ & 0.1297 & 0.0005 & $\mathrm{NaN}$ & $\mathrm{NaN}$ & $\mathrm{NaN}$ & $\mathrm{NaN}$ & $\mathrm{NaN}$ \\
\hline 1.0 & $\mathrm{NaN}$ & $\mathrm{NaN}$ & 0.0755 & 0.3678 & 0.1535 & $\mathrm{NaN}$ & $\mathrm{NaN}$ & $\mathrm{NaN}$ & $\mathrm{NaN}$ & $\mathrm{NaN}$ \\
\hline 1.5 & $\mathrm{NaN}$ & 0.0049 & 0.0002 & 0.0297 & 0.0594 & 0.0406 & 0.0484 & 0.1093 & 0.3165 & $\mathrm{NaN}$ \\
\hline 2.0 & 0.5211 & 0.1364 & 0.0017 & 0.0135 & 0.0256 & 0.0308 & 0.0409 & 0.0438 & 0.0297 & 0.6103 \\
\hline 2.5 & 0.0763 & 0.0483 & 0.0050 & 0.0003 & 0.0194 & 0.0333 & 0.0324 & 0.0205 & 0.0051 & 0.0025 \\
\hline 3.0 & 0.0249 & 0.0244 & 0.0086 & 0.0228 & 0.0055 & 0.0201 & 0.0182 & 0.0006 & 0.0000 & 0.0219 \\
\hline 3.5 & 0.0988 & 0.0788 & 0.0146 & 0.0088 & 0.0299 & 0.0359 & 0.0150 & 0.0084 & 0.0034 & 0.0664 \\
\hline 4.0 & 0.0741 & 0.0480 & 0.0075 & 0.0112 & 0.0361 & 0.0412 & 0.0166 & 0.0063 & 0.0345 & 0.1199 \\
\hline 4.5 & 0.0049 & 0.0976 & 0.0499 & 0.0313 & 0.0130 & 0.0066 & 0.0076 & 0.0087 & 0.0061 & 0.0003 \\
\hline 5.0 & 0.0028 & 0.1616 & 0.0634 & 0.0481 & 0.0315 & 0.0247 & 0.0213 & 0.0165 & 0.0149 & 0.0012 \\
\hline 6.0 & 0.1124 & 0.0037 & 0.0406 & 0.0920 & 0.0176 & 0.0001 & 0.0006 & 0.0003 & 0.0011 & 0.0196 \\
\hline 7.0 & 0.0314 & 0.0184 & 0.0105 & 0.0068 & 0.0120 & 0.0099 & 0.0039 & 0.0098 & 0.0082 & 0.2403 \\
\hline 8.0 & 0.1642 & 0.0000 & 0.0030 & 0.0087 & 0.0001 & 0.0003 & 0.0003 & 0.0029 & 0.0017 & 0.0695 \\
\hline 9.0 & 0.1139 & 0.0115 & 0.0020 & 0.0011 & 0.0156 & 0.0011 & 0.0029 & 0.0110 & 0.0071 & 0.1488 \\
\hline 10.0 & 0.0472 & 0.0004 & 0.0085 & 0.0545 & 0.0167 & 0.0016 & 0.0000 & 0.0012 & 0.0017 & 0.0318 \\
\hline
\end{tabular}

In Tables 3.11 to 3.15 the numbers with bold letter indicate that the regression results are significant in F-test. It is interesting to observe that the Fed announcements have effects on the deep-in-the-money daily difference of the implied volatility (Case 2). The regressions in Case 3 are much better than the others. Especially good result is obtained when both $\triangle i_{t}^{e}$ and $\triangle i_{t}^{u}$ are used in the regressions. There are not clear patters in the expected component. On the other hand, the unexpected component has a definite pattern. Most of results significant in F-static are implied volatilities in the money.

Table 3.12: Regressions of implied volatility with Fed announcements. The table reports the results of Case 2 with the regressions $v_{t}=a+b \triangle i_{t}+\varepsilon_{t}$, where we use $\triangle i_{t}$. The numbers with bold letters are significant in $90 \%$ F-statistics.

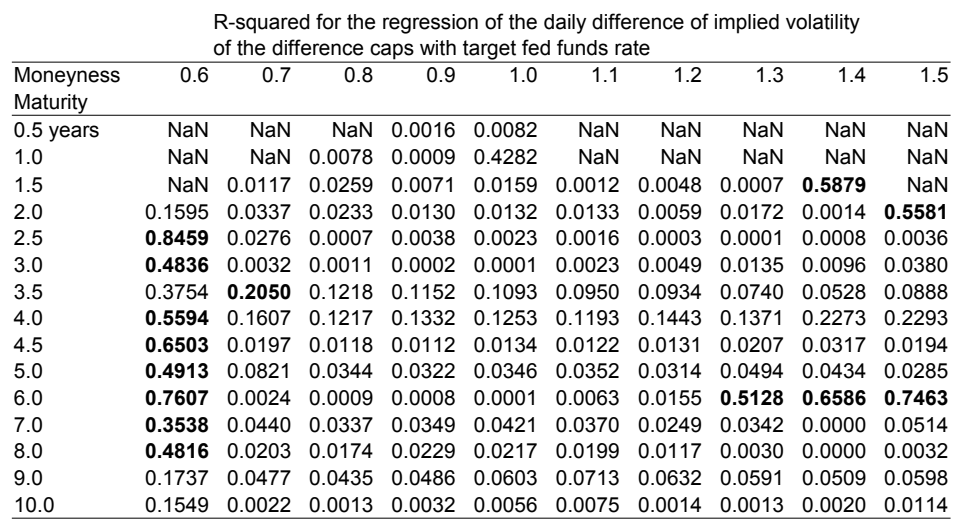


Table 3.13: Regressions of implied volatility with Fed announcements. The table reports the results of Case 2 with the regressions $v_{t}=a+b \triangle i_{t}^{e}+c \triangle i_{t}^{u}+\varepsilon_{t}$, where we use $\triangle i_{t}^{e}$ and $\triangle i_{t}^{u}$. The numbers with bold letters are significant in $90 \%$ F-statistics.

\begin{tabular}{lrrrrrrrrrrr}
\multicolumn{8}{c}{$\begin{array}{l}\text { R-squared for the regression of the daily difference of implied volatility of difference } \\
\text { caps with the expected and unexpected components of target fed funds rate }\end{array}$} \\
$\begin{array}{l}\text { Moneyness } \\
\text { Maturity }\end{array}$ & 0.6 & 0.7 & 0.8 & 0.9 & 1.0 & 1.1 & 1.2 & 1.3 & 1.4 & 1.5 \\
\hline 0.5 years & $\mathrm{NaN}$ & $\mathrm{NaN}$ & $\mathrm{NaN}$ & 0.1956 & 0.8033 & $\mathrm{NaN}$ & $\mathrm{NaN}$ & $\mathrm{NaN}$ & $\mathrm{NaN}$ & $\mathrm{NaN}$ \\
1.0 & $\mathrm{NaN}$ & $\mathrm{NaN}$ & 0.0206 & 0.0736 & 0.4284 & $\mathrm{NaN}$ & $\mathrm{NaN}$ & $\mathrm{NaN}$ & $\mathrm{NaN}$ & $\mathrm{NaN}$ \\
1.5 & $\mathrm{NaN}$ & 0.2297 & 0.1400 & 0.0103 & 0.0162 & 0.0028 & 0.0052 & 0.0012 & $\mathbf{0 . 8 5 9 2}$ & $\mathrm{NaN}$ \\
2.0 & 0.9717 & $\mathbf{0 . 5 7 0 3}$ & 0.0259 & 0.0168 & 0.0172 & 0.0174 & 0.0110 & 0.0185 & 0.0020 & 0.7670 \\
2.5 & $\mathbf{0 . 8 5 4 9}$ & 0.1950 & 0.0107 & 0.0165 & 0.0135 & 0.0122 & 0.0144 & 0.0156 & 0.0102 & 0.0060 \\
3.0 & $\mathbf{0 . 4 8 7 7}$ & 0.1063 & 0.0012 & 0.0014 & 0.0027 & 0.0041 & 0.0063 & 0.0135 & 0.0096 & 0.0382 \\
3.5 & 0.3757 & $\mathbf{0 . 3 3 4 2}$ & 0.1464 & 0.1313 & 0.1188 & 0.1014 & 0.1003 & 0.0909 & 0.0701 & 0.1215 \\
4.0 & $\mathbf{0 . 5 9 1 5}$ & 0.1842 & 0.1221 & 0.1333 & 0.1253 & 0.1195 & 0.1463 & 0.1371 & 0.2274 & 0.2348 \\
4.5 & $\mathbf{0 . 6 8 7 4}$ & 0.0517 & 0.0156 & 0.0145 & 0.0159 & 0.0142 & 0.0163 & 0.0230 & 0.0361 & 0.0399 \\
5.0 & $\mathbf{0 . 5 7 3 0}$ & 0.1300 & 0.0402 & 0.0372 & 0.0388 & 0.0396 & 0.0395 & 0.0563 & 0.0501 & 0.0518 \\
6.0 & $\mathbf{0 . 7 8 1 0}$ & 0.0102 & 0.0063 & 0.0090 & 0.0179 & 0.0200 & 0.0285 & $\mathbf{0 . 6 1 3 2}$ & $\mathbf{0 . 7 4 0 3}$ & $\mathbf{0 . 8 0 8 6}$ \\
7.0 & $\mathbf{0 . 5 5 1 6}$ & 0.0493 & 0.0378 & 0.0374 & 0.0422 & 0.0377 & 0.0270 & 0.0433 & 0.0279 & 0.0523 \\
8.0 & $\mathbf{0 . 6 3 6 1}$ & 0.0203 & 0.0179 & 0.0233 & 0.0228 & 0.0201 & 0.0157 & 0.0357 & 0.0340 & 0.1001 \\
9.0 & 0.2361 & 0.1454 & 0.1648 & 0.1801 & 0.1972 & 0.2220 & 0.2989 & 0.3666 & 0.3328 & 0.3676 \\
10.0 & 0.2869 & 0.0234 & 0.0300 & 0.0275 & 0.0253 & 0.0543 & 0.1736 & 0.1700 & 0.1775 & 0.2023 \\
\hline
\end{tabular}

The results in Table 3.15 motivates to construct portfolios so that we are able to see the relation between the moneyness and maturity. We build nine portfolios of differential caps classified by the moneyness and maturities. In moneyness, the portfolios are classified in three categories. The portfolios are also classified in three categories in the maturities. These categories are listed in Tables 3.3 and 3.4, respectively. We apply the regression analysis for the nine portfolios in Tables 3.3 and 3.4 as done for differential caps. For Cases 1 and 2, except for the constant terms, neither T-statistics nor F-statistics are significant. On the other hand, in Case 3 there are several coefficients significant in the T-statistics and (/or) F-statistics. In Table 3.16 we report the result of the regressions of nine portfolios with raw funds rate change. It seems that the raw funds rate change may be affecting maturities. In Table 3.17 we report the result of the regressions of nine portfolios with expected and unexpected funds rate changes. It seems that the unexpected funds rate change may be affecting in the money portfolios.

The Durbin-Watson statistics are between 0.11 to 0.26 in the regressions 3.4 .2 and 0.11 to 0.29 in the regressions 3.4.3. This shows that the regressions are highly autocorelated. Therefore, we use the Newey West with 20 lags. For the regressions 3.4.2, the coefficients of raw funds rate become insignificant. For the regressions 3.4.3, the coefficients of expected rate change become insignificant except one. On the other hand, the all coefficients of unexpected rate change which are significant in the ordinary least square regressions remain significant. 
Table 3.14: Regressions of implied volatility with Fed announcements. The table reports the results of Case (3) with the regressions $v_{t}=a+b \triangle i_{t}^{e}+c \triangle i_{t}^{u}+\varepsilon_{t}$, where we use the same values of $\triangle i_{t}$ between two meetings are used. The numbers with bold letters are significant in $90 \%$ F-statistics.

\begin{tabular}{|c|c|c|c|c|c|c|c|c|c|c|}
\hline & & $\begin{array}{l}\text {-squar } \\
\text { fferen }\end{array}$ & $\begin{array}{l}\text { for the } \\
\text { caps wit }\end{array}$ & $\begin{array}{l}\text { regress } \\
\text { th the fe }\end{array}$ & funds ta & get rate & & & & \\
\hline $\begin{array}{l}\text { Moneyness } \\
\text { Maturity }\end{array}$ & 0.6 & 0.7 & \multicolumn{8}{|c|}{ Maturity } \\
\hline 0.5 years & 0.0033 & 0.3304 & 0.0113 & 0.0044 & 0.0267 & 0.0330 & 0.0307 & 0.0761 & $\mathrm{NaN}$ & $\mathrm{NaN}$ \\
\hline 1.0 & 0.2924 & 0.0423 & 0.0592 & 0.3118 & 0.0341 & 0.0817 & $\mathrm{NaN}$ & $\mathrm{NaN}$ & $\mathrm{NaN}$ & $\mathrm{NaN}$ \\
\hline 1.5 & 0.0005 & 0.0027 & 0.0023 & 0.0074 & 0.0145 & 0.0095 & 0.0001 & 0.0009 & 0.1175 & 0.1665 \\
\hline 2.0 & 0.2944 & 0.0000 & 0.0006 & 0.0002 & 0.0001 & 0.0013 & 0.0045 & 0.0024 & 0.0028 & 0.0138 \\
\hline 2.5 & 0.0046 & 0.0012 & 0.0014 & 0.0012 & 0.0023 & 0.0024 & 0.0056 & 0.0057 & 0.0057 & 0.0090 \\
\hline 3.0 & 0.0074 & 0.0003 & 0.0005 & 0.0000 & 0.0000 & 0.0000 & 0.0009 & 0.0004 & 0.0001 & 0.0114 \\
\hline 3.5 & 0.0406 & 0.0046 & 0.0029 & 0.0031 & 0.0043 & 0.0063 & 0.0072 & 0.0076 & 0.0110 & 0.0453 \\
\hline 4.0 & 0.0254 & 0.0018 & 0.0010 & 0.0020 & 0.0053 & 0.0074 & 0.0086 & 0.0076 & 0.0164 & 0.0465 \\
\hline 4.5 & 0.0692 & 0.0087 & 0.0063 & 0.0006 & 0.0003 & 0.0001 & 0.0037 & 0.0044 & 0.0010 & 0.0062 \\
\hline 5.0 & 0.0810 & 0.0157 & 0.0102 & 0.0025 & 0.0015 & 0.0024 & 0.0136 & 0.0110 & 0.0075 & 0.0006 \\
\hline 6.0 & 0.0955 & 0.0340 & 0.0028 & 0.0072 & 0.0001 & 0.0013 & 0.0003 & 0.0033 & 0.0032 & 0.0471 \\
\hline 7.0 & 0.0623 & 0.0278 & 0.0625 & 0.0597 & 0.0014 & 0.0026 & 0.0042 & 0.0116 & 0.0208 & 0.0384 \\
\hline 8.0 & 0.0277 & 0.0001 & 0.0000 & 0.0001 & 0.0000 & 0.0037 & 0.0017 & 0.0002 & 0.0014 & 0.0046 \\
\hline 9.0 & 0.0199 & 0.0000 & 0.0001 & 0.0006 & 0.0000 & 0.0049 & 0.0015 & 0.0000 & 0.0011 & 0.0000 \\
\hline 10.0 & 0.0914 & 0.0136 & 0.0091 & 0.0094 & 0.0165 & 0.0320 & 0.0161 & 0.0093 & 0.0046 & 0.0429 \\
\hline
\end{tabular}

Table 3.15: Regressions of implied volatility with Fed announcements. The table reports the results of Case (3) with the regressions $v_{t}=a+b \triangle i_{t}^{e}+c \triangle i_{t}^{u}+\varepsilon_{t}$, where the most recent values of $\triangle i_{t}^{e}$ and $\triangle i_{t}^{u}$ between two meetings are used. The numbers with bold letters are significant in $90 \%$ F-statistics.

R-squared for the regression of implied volatility of difference caps with the expected and unexpected components of the fed funds target rates

\begin{tabular}{|c|c|c|c|c|c|c|c|c|c|c|}
\hline $\begin{array}{l}\text { Moneyness } \\
\text { Maturity }\end{array}$ & 0.6 & 0.7 & 0.8 & 0.9 & 1.0 & 1.1 & 1.2 & 1.3 & 1.4 & 1.5 \\
\hline 0.5 years & 0.0137 & 0.3738 & 0.0698 & 0.0399 & 0.1048 & 0.1750 & 0.2708 & 0.5061 & $\mathrm{NaN}$ & $\mathrm{NaN}$ \\
\hline 1.0 & 0.7285 & 0.5481 & 0.4533 & 0.3126 & 0.3232 & 0.2853 & $\mathrm{NaN}$ & $\mathrm{NaN}$ & $\mathrm{NaN}$ & $\mathrm{NaN}$ \\
\hline 1.5 & 0.2001 & 0.0272 & 0.0174 & 0.0628 & 0.0263 & 0.0133 & 0.0151 & 0.2165 & 0.2504 & 0.3060 \\
\hline 2.0 & 0.3360 & 0.0917 & 0.0237 & 0.0012 & 0.0001 & 0.0019 & 0.0065 & 0.0086 & 0.0069 & 0.0183 \\
\hline 2.5 & 0.2963 & 0.0441 & 0.0113 & 0.0113 & 0.0023 & 0.0035 & 0.0076 & 0.0060 & 0.0060 & 0.0090 \\
\hline 3.0 & 0.3033 & 0.0284 & 0.0784 & 0.0614 & 0.0026 & 0.0001 & 0.0011 & 0.0048 & 0.0108 & 0.0129 \\
\hline 3.5 & 0.3918 & 0.0193 & 0.0282 & 0.0196 & 0.0045 & 0.0067 & 0.0075 & 0.0106 & 0.0174 & 0.0491 \\
\hline 4.0 & 0.3451 & 0.0257 & 0.0417 & 0.0190 & 0.0060 & 0.0074 & 0.0113 & 0.0187 & 0.0268 & 0.0498 \\
\hline 4.5 & 0.4281 & 0.0575 & 0.0534 & 0.0143 & 0.0025 & 0.0001 & 0.0052 & 0.0069 & 0.0037 & 0.0265 \\
\hline 5.0 & 0.3950 & 0.0603 & 0.0429 & 0.0096 & 0.0028 & 0.0024 & 0.0139 & 0.0110 & 0.0075 & 0.0403 \\
\hline 6.0 & 0.4921 & 0.0969 & 0.0670 & 0.0554 & 0.0007 & 0.0016 & 0.0019 & 0.0044 & 0.0049 & 0.1195 \\
\hline 7.0 & 0.3613 & 0.0474 & 0.0889 & 0.0910 & 0.0027 & 0.0029 & 0.0050 & 0.0144 & 0.0285 & 0.1127 \\
\hline 8.0 & 0.3167 & 0.0632 & 0.1276 & 0.1540 & 0.0084 & 0.0043 & 0.0044 & 0.0052 & 0.0074 & 0.1061 \\
\hline 9.0 & & & 0.1366 & 864 & 080 & 058 & 0.0052 & 0.0079 & 0.0167 & 0.1349 \\
\hline 10.0 & 0.1590 & 0.1112 & 0.1977 & 0.2249 & 0.0356 & 0.0321 & 0.0208 & 0.0192 & 0.0170 & 0.1136 \\
\hline
\end{tabular}


Table 3.16: The coefficients of the intercepts and raw funds rate change. We report the coefficients of the intercepts and raw funds rate change in the regressions (3.4.2) of the nine portfolios. The numbers in parentheses are t-statistics. Bold letters are t-significant. This regression is Case (3) where we use the same values of $\triangle i_{t}$ or $\triangle i_{t}^{e}$ and $\triangle i_{t}^{u}$ between two meetings to do the regression and we use all implied volatility data available. The numbers with bold letters are significant in $90 \% \mathrm{~F}$-statistics.

\begin{tabular}{lrrr}
\multicolumn{4}{c}{$\begin{array}{c}\text { Coefficients of intercepts in the regression } \\
\text { with raw funds rate change }\end{array}$} \\
$\begin{array}{lrrr}\text { Moneyness } \\
\text { Maturities }\end{array}$ & $\begin{array}{l}\text { In the money } \\
\text { Short }\end{array}$ & At the money & Out of the money \\
& $\begin{array}{r}\mathbf{0 . 1 9 0 2} \\
(58.7842)\end{array}$ & $\begin{array}{r}\mathbf{0 . 1 9 0 0} \\
\text { (68.1187) }\end{array}$ & $\begin{array}{r}\mathbf{0 . 2 1 1 4} \\
\text { (87.5865) }\end{array}$ \\
Intermediate & $\mathbf{0 . 2 4 3 8}$ & $\mathbf{0 . 2 0 9 8}$ & $\mathbf{0 . 2 0 4 8}$ \\
& $(100.3451)$ & $(137.7728)$ & $(117.3865)$ \\
Long & $\mathbf{0 . 2 1 4 5}$ & $\mathbf{0 . 1 8 4 7}$ & $\mathbf{0 . 1 7 0 5}$ \\
& $(141.4428)$ & $(199.9595)$ & $(151.0737)$ \\
\hline
\end{tabular}

\begin{tabular}{lrrr}
\multicolumn{4}{c}{ Coefficients of raw funds rate change } \\
\hline $\begin{array}{l}\text { Moneyness } \\
\text { Maturities }\end{array}$ & In the money & At the money & Out of the money \\
\hline Short & $\mathbf{0 . 0 6 4 6}$ & $\mathbf{0 . 0 4 5 9}$ & $\mathbf{0 . 0 3 4 7}$ \\
& $(2.3984)$ & $(1.952)$ & $(1.7064)$ \\
Intermediate & -0.0018 & 0.0040 & 0.0199 \\
& $(-0.0903)$ & $(0.312)$ & $(1.4049)$ \\
Long & -0.0133 & -0.0076 & 0.0003 \\
& $(-1.0426)$ & $(-0.9764)$ & $(0.0357)$ \\
\hline
\end{tabular}


Table 3.17: Coefficients of the intercepts, expected and unexpected funds rate change. Coefficients of the intercepts, expected and unexpected funds rate change in the regressions (3.4.3) of the nine portfolios. The numbers in parentheses are t-statistics. Bold letters are t-significant. This regression is Case (3) where we use the same values of $\triangle i_{t}$ or $\triangle i_{t}^{e}$ and $\triangle i_{t}^{u}$ between two meetings to do the regression and we use all implied volatility data available. The numbers with bold letters are significant in $90 \%$ F-statistics.

\begin{tabular}{lrrr}
\multicolumn{4}{l}{ Coefficients for intercepts in funds rate change } \\
\hline $\begin{array}{l}\text { Moneyness } \\
\text { Maturities }\end{array}$ & In the money & At the money & Out of the money \\
\hline Short & $\mathbf{0 . 1 8 2 1}$ & $\mathbf{0 . 1 8 8 9}$ & $\mathbf{0 . 2 1 2 5}$ \\
& $(52.693)$ & $(61.1028)$ & $(79.4426)$ \\
Intermediate & $\mathbf{0 . 2 3 9 5}$ & $\mathbf{0 . 2 0 8 6}$ & $\mathbf{0 . 2 0 5 5}$ \\
& $(90.1514)$ & $(123.8611)$ & $(106.4573)$ \\
Long & & & \\
& $\mathbf{0 . 2 0 9 6}$ & $\mathbf{0 . 1 8 3 2}$ & $\mathbf{0 . 1 7 0 8}$ \\
& $(130.9567)$ & $(181.0453)$ & $(136.3246)$ \\
\hline
\end{tabular}

\begin{tabular}{|c|c|c|c|}
\hline $\begin{array}{l}\text { Moneyness } \\
\text { Maturities }\end{array}$ & In the money & At the money & Out of the money \\
\hline Short & $\begin{array}{l}-0.0042 \\
(-0.147)\end{array}$ & $\begin{array}{r}0.0365 \\
(1.4044)\end{array}$ & $\begin{array}{l}\mathbf{0 . 0 4 3 6} \\
(1.938)\end{array}$ \\
\hline Intermediate & $\begin{array}{r}-0.0377 \\
(-1.6877)\end{array}$ & $\begin{array}{r}-0.0058 \\
(-0.4076)\end{array}$ & $\begin{array}{r}0.0257 \\
(1.6347)\end{array}$ \\
\hline Long & $\begin{array}{r}-0.0545 \\
(-4.0544)\end{array}$ & $\begin{array}{r}-\mathbf{0 . 0 2 0 4} \\
(-2.3982)\end{array}$ & $\begin{array}{r}0.0028 \\
(0.3245)\end{array}$ \\
\hline
\end{tabular}

\begin{tabular}{lrrr}
\multicolumn{4}{l}{ Coefficients for unexpected change in funds rate change } \\
\hline $\begin{array}{l}\text { Moneyness } \\
\text { Maturities }\end{array}$ \\
\hline Short & \multicolumn{3}{l}{} \\
& $\mathbf{0 . 4 2 0 3}$ & 0.0942 & -0.0112 \\
Intermediate & $(6.1035)$ & $(1.5206)$ & $(-0.2096)$ \\
& $\mathbf{0 . 1 8 3 4}$ & 0.0545 & -0.0095 \\
& $(3.4431)$ & $(1.6143)$ & $(-0.2543)$ \\
Long & $\mathbf{0 . 1 9 9 7}$ & $\mathbf{0 . 0 5 8 5}$ & -0.0116 \\
& $(6.2257)$ & $(2.8872)$ & $(-0.5814)$ \\
\hline
\end{tabular}


Table 3.18: The result of the Newey West correction with 20 lags. We report the result of the Newey West correction with 20 lags in the regression of the implied volatility with raw funds rate change. The t-statistics are smaller then those in Table 3.16. The numbers with bold letters are significant in $90 \%$ F-statistics.

\begin{tabular}{|c|c|c|c|}
\hline $\begin{array}{l}\text { Moneyness } \\
\text { Maturities }\end{array}$ & In the money & At the money & Out of the money \\
\hline Short & $\begin{array}{r}\mathbf{0 . 1 9 0 2} \\
(15.2585)\end{array}$ & $\begin{array}{r}\mathbf{0 . 1 9 0 0} \\
(16.1682)\end{array}$ & $\begin{array}{r}\mathbf{0 . 2 1 1 4} \\
(20.8678)\end{array}$ \\
\hline Intermediate & $\begin{array}{r}\mathbf{0 . 2 4 3 8} \\
(24.0222)\end{array}$ & $\begin{array}{r}\mathbf{0 . 2 0 9 8} \\
(32.9523)\end{array}$ & $\begin{array}{r}\mathbf{0 . 2 0 4 8} \\
(27.8849)\end{array}$ \\
\hline Long & $\begin{array}{r}\mathbf{0 . 2 1 4 5} \\
(34.9976) \\
\end{array}$ & $\begin{array}{r}\mathbf{0 . 1 8 4 7} \\
(51.7076) \\
\end{array}$ & $\begin{array}{r}\mathbf{0 . 1 7 0 5} \\
(43.7124) \\
\end{array}$ \\
\hline
\end{tabular}

Coefficients of raw funds rate change

\begin{tabular}{lrrr}
\hline $\begin{array}{l}\text { Moneyness } \\
\text { Maturities }\end{array}$ & In the money & At the money & Out of the money \\
\hline Short & 0.0646 & 0.0459 & 0.0347 \\
& $(0.9392)$ & $(0.9813)$ & $(0.7769)$ \\
Intermediate & -0.0018 & 0.0040 & 0.0199 \\
& $(-0.0536)$ & $(0.164)$ & $(0.7248)$ \\
& & & 0.0003 \\
Long & -0.0133 & -0.0076 & $(0.0144)$ \\
& $(-0.6476)$ & $(-0.4608)$ & \\
\hline
\end{tabular}


Table 3.19: The result of the Newey West correction with 20 lags. We report the result of the Newey West correction with 20 lags in the regression of the implied volatility with expected and unexpected funds rate change. The number of t-significant entries in the expected funds rate change dropped while the number of t-significant entries in the unexpected funds rate change remain the same. The numbers with bold letters are significant in $90 \% \mathrm{~F}$-statistics.

\begin{tabular}{|c|c|c|c|}
\hline $\begin{array}{l}\text { Moneyness } \\
\text { Maturities }\end{array}$ & In the money & At the money & Out of the money \\
\hline Short & $\begin{array}{r}\mathbf{0 . 1 8 2 1} \\
(13.3133)\end{array}$ & $\begin{array}{r}\mathbf{0 . 1 8 8 9} \\
(14.1693)\end{array}$ & $\begin{array}{r}\mathbf{0 . 2 1 2 5} \\
(18.6123)\end{array}$ \\
\hline Intermediate & $\begin{array}{r}\mathbf{0 . 2 3 9 5} \\
(20.3359)\end{array}$ & $\begin{array}{r}0.2086 \\
(28.8671)\end{array}$ & $\begin{array}{r}\mathbf{0 . 2 0 5 5} \\
(24.9858)\end{array}$ \\
\hline Long & $\begin{array}{r}\mathbf{0 . 2 0 9 6} \\
(30.151)\end{array}$ & $\begin{array}{r}\mathbf{0 . 1 8 3 2} \\
(45.1862) \\
\end{array}$ & $\begin{array}{r}\mathbf{0 . 1 7 0 8} \\
(38.9921) \\
\end{array}$ \\
\hline
\end{tabular}

\begin{tabular}{lrrr}
\multicolumn{4}{l}{ Coefficients for expected change in funds rate change } \\
\hline $\begin{array}{l}\text { Moneyness } \\
\text { Maturities }\end{array}$ & \multicolumn{1}{l}{ th the money } & At the money & Out of the money \\
Short & -0.0042 & 0.0365 & 0.0436 \\
& $(-0.0741)$ & $(0.636)$ & $(0.7277)$ \\
Intermediate & -0.0377 & -0.0058 & 0.0257 \\
& $(-0.8787)$ & $(-0.1632)$ & $(0.7001)$ \\
Long & -0.0545 & -0.0204 & 0.0028 \\
& $(-1.957)$ & $(-0.8338)$ & $(0.1273)$ \\
\hline
\end{tabular}

\begin{tabular}{lrrr}
\multicolumn{4}{l}{ Coefficients for unexpected change in funds rate change } \\
\hline $\begin{array}{l}\text { Moneyness } \\
\text { Maturities }\end{array}$ & In the money & At the money & Out of the money \\
\hline Short & $\mathbf{0 . 4 2 0 3}$ & 0.0942 & -0.0112 \\
& $(3.6402)$ & $(0.613)$ & $(-0.0835)$ \\
Intermediate & $\mathbf{0 . 1 8 3 4}$ & 0.0545 & -0.0095 \\
& $(1.8478)$ & $(0.8205)$ & $(-0.115)$ \\
Long & & & -0.0116 \\
& $\mathbf{0 . 1 9 9 7}$ & $\mathbf{0 . 0 5 8 5}$ & $(-0.3479)$ \\
\hline
\end{tabular}

\subsection{Unspanned Volatility}

It has been observed that the volatility of caps are not spanned by those of bonds. Interest rate caps are derivatives written on LIBOR, and their prices should be determined by the same set of risk factors that determine LIBOR. However, several recent studies have shown that there seem to be risk factors that affect the prices of caps but that are not spanned by the underlying LIBOR. This risk factor is called unspanned volatility (UV). One question is the effects of macroeconomic announcements and Fed announcements for UV. If we use the implied volatility as a measure of the volatility of caps, UV is a part of implied volatility which is not synchronized with the volatility 
of LIBOR. The purpose of this section is to examine candidates for a reasonable proxy of UV and study the effects of the announcements to them. We choose two candidates. One is the residuals of the regression of the implied volatility with LIBOR and the second is the residuals of the regression of the implied volatility with the volatility of LIBOR based on GARCH.

In Subsection 3.5.1 we examine the case where the proxy of UV is the residuals of the regressions of the implied volatility with LIBOR and in Subsection we study the case where we use the GARCH based volatility of the LIBOR to obtain the proxy for UV.

\subsubsection{LIBOR Based Unspanned Volatility}

There are 15 maturities and 10 moneyness for the implied volatility. In order to find the UV based on LIBOR, we calculate the three principal components of LIBOR and we regress the implied volatility with them. We use the residuals as the proxy for UV for each maturity and moneyness. We now regress the residuals with the three principal components of macroeconomic data and also with the three principal components of macroeconomic data and the fed announcements.

In the regression, the residuals are thought of as the unspanned components of the implied volatility in the regressions with LIBOR and it is interesting to see how much is regressed (explained) by other data besides LIBOR. We use the macroeconomic data as an example of other data which may explain the residuals of implied volatility.

A purpose is to see if there is a pattern in the R-squared in both regressions. The regressions of residuals with the three components of the macroeconomic announcements are relatively good near at the money and mid to longer maturity. For the moneyness between 0.6 to 0.9 we see that R-squared is below 0.1 except 2 data. On the other hand, for the moneyness between 1.0 and 1.3 we observe that R-squared are generally better and there are number of R-squared exceeding 0.1 . Within the moneyness between 1.0 and 1.3 we see better values of R-squared for the maturities 3years and longer. The caps in the money are similar to LIBOR based bonds. This may explain that the R-squared of the regression with LIBOR for the caps in the money are generally high and the R-squared of the regression with macroeconomic announcements are low. The caps out of the money are similar to an insurance premium and the R-squared of LIBOR and macroeconomic announcements are generally low.

The principal components of LIBOR, implied volatility and macroeconomic data are computed as follows. For LIBOR, we use the time series data of 3-months LIBOR to compute the principal components. Each day there are ten rates raging from 3-month forward, 6 month forward, 1 year forward, 2 year forward, 3 year forward, 4 year forward, 5 year forward, 7 year forward and 10 year forward. From the above 10 time series of the forward rates, we compute the three principal components. For the implied volatility of the difference caps, we construct a matrix with columns consisting of the time series of each maturity and strike rate and apply the principal component analysis to the matrix to choose three principal components. For the macroeconomic data, we use the 21 economic announcements with (2) in Subsection 2.1.1. For each macroeconomic data we construct the time series by filling the days without that announcement the most recent data. Then, we obtain the first three principal components. 
Table 3.20: R-square of the regression of implied volatility. The R-square for the regression of implied volatility with the three principal components of LIBOR.

\begin{tabular}{lrlllllllll}
\multicolumn{8}{c}{$\begin{array}{l}\text { R-square of regressions of implied volatilities with three principal } \\
\text { Components of LIBOR }\end{array}$} \\
\begin{tabular}{l}
\hline Strike Rates \\
Maturity
\end{tabular} & 0.040 & 0.045 & 0.050 & 0.055 & 0.060 & 0.065 & 0.070 & 0.080 & 0.090 & 0.100 \\
\hline 0.5 years & 0.332 & 0.175 & 0.233 & 0.237 & 0.776 & 0.803 & 0.755 & 0.908 & 0.981 & 0.988 \\
1.0 & 0.710 & 0.623 & 0.658 & 0.116 & 0.430 & 0.756 & NaN & NaN & NaN & NaN \\
1.5 & 0.668 & 0.132 & 0.051 & 0.406 & 0.693 & 0.778 & 0.791 & 0.784 & 0.764 & 0.811 \\
2.0 & 0.220 & 0.707 & 0.666 & 0.551 & 0.640 & 0.727 & 0.797 & 0.800 & 0.784 & 0.741 \\
2.5 & 0.648 & 0.868 & 0.849 & 0.842 & 0.865 & 0.866 & 0.847 & 0.826 & 0.772 & 0.627 \\
3.0 & 0.808 & 0.859 & 0.744 & 0.739 & 0.829 & 0.853 & 0.839 & 0.815 & 0.741 & 0.652 \\
3.5 & 0.823 & 0.845 & 0.800 & 0.816 & 0.868 & 0.844 & 0.831 & 0.789 & 0.656 & 0.551 \\
4.0 & 0.830 & 0.779 & 0.727 & 0.803 & 0.819 & 0.799 & 0.811 & 0.698 & 0.530 & 0.403 \\
4.5 & 0.690 & 0.554 & 0.550 & 0.605 & 0.706 & 0.702 & 0.723 & 0.621 & 0.508 & 0.361 \\
5.0 & 0.680 & 0.509 & 0.463 & 0.457 & 0.558 & 0.556 & 0.573 & 0.489 & 0.439 & 0.273 \\
6.0 & 0.874 & 0.644 & 0.670 & 0.753 & 0.809 & 0.788 & 0.762 & 0.655 & 0.638 & 0.449 \\
7.0 & 0.738 & 0.276 & 0.287 & 0.472 & 0.588 & 0.575 & 0.513 & 0.430 & 0.303 & 0.333 \\
8.0 & 0.810 & 0.696 & 0.680 & 0.637 & 0.674 & 0.650 & 0.619 & 0.500 & 0.465 & 0.365 \\
9.0 & 0.628 & 0.453 & 0.390 & 0.362 & 0.449 & 0.494 & 0.474 & 0.387 & 0.350 & 0.222 \\
10.0 & 0.337 & 0.178 & 0.249 & 0.238 & 0.220 & 0.279 & 0.244 & 0.242 & 0.272 & 0.163 \\
\hline
\end{tabular}

Table 3.21: R-square of the regression of the residuals of the implied volatility. R-square for the regression of the LIBOR based residuals of the implied volatility with the three principal components of macroeconomic announcements. The numbers with bold letters are significant in $90 \%$ F-statistics.

R-square of regressions of LIBOR based residuals of implied volatilities

with three principal components of macroeconomic announcements

\begin{tabular}{lrlllllllllr}
\multicolumn{7}{c}{ with three principal components of macroeconomic announcements } \\
$\begin{array}{l}\text { Strike Rates } \\
\text { Maturity }\end{array}$ & 0.040 & 0.045 & 0.050 & 0.055 & 0.060 & 0.065 & 0.070 & 0.080 & 0.090 & 0.100 \\
\hline 0.5 years & 0.136 & $\mathbf{0 . 1 3 7}$ & 0.027 & 0.031 & $\mathbf{0 . 0 6 5}$ & $\mathbf{0 . 2 5 4}$ & 0.032 & 0.023 & 0.223 & 0.417 \\
1.0 & 0.110 & $\mathbf{0 . 0 6 2}$ & $\mathbf{0 . 0 6 2}$ & $\mathbf{0 . 1 6 8}$ & $\mathbf{0 . 1 2 5}$ & $\mathbf{0 . 1 0 9}$ & NaN & NaN & NaN & NaN \\
1.5 & 0.008 & $\mathbf{0 . 0 5 8}$ & $\mathbf{0 . 0 5 9}$ & $\mathbf{0 . 0 8 8}$ & $\mathbf{0 . 0 3 9}$ & $\mathbf{0 . 0 2 1}$ & $\mathbf{0 . 0 6 4}$ & $\mathbf{0 . 0 4 3}$ & 0.030 & $\mathbf{0 . 1 1 5}$ \\
2.0 & $\mathbf{0 . 0 5 5}$ & $\mathbf{0 . 1 2 9}$ & 0.002 & $\mathbf{0 . 0 1 5}$ & $\mathbf{0 . 0 2 6}$ & $\mathbf{0 . 0 6 4}$ & $\mathbf{0 . 0 9 3}$ & $\mathbf{0 . 0 1 8}$ & $\mathbf{0 . 0 8 1}$ & $\mathbf{0 . 1 6 6}$ \\
2.5 & $\mathbf{0 . 0 3 1}$ & $\mathbf{0 . 0 9 9}$ & $\mathbf{0 . 0 3 9}$ & $\mathbf{0 . 0 3 7}$ & $\mathbf{0 . 0 7 9}$ & $\mathbf{0 . 0 8 6}$ & $\mathbf{0 . 1 0 1}$ & $\mathbf{0 . 0 6 8}$ & 0.015 & $\mathbf{0 . 1 4 5}$ \\
3.0 & 0.022 & $\mathbf{0 . 0 3 7}$ & $\mathbf{0 . 0 2 1}$ & $\mathbf{0 . 0 2 5}$ & $\mathbf{0 . 0 8 0}$ & $\mathbf{0 . 1 1 3}$ & $\mathbf{0 . 1 5 7}$ & $\mathbf{0 . 0 8 0}$ & $\mathbf{0 . 0 5 6}$ & $\mathbf{0 . 0 3 1}$ \\
3.5 & $\mathbf{0 . 0 5 8}$ & $\mathbf{0 . 0 1 7}$ & $\mathbf{0 . 0 2 0}$ & $\mathbf{0 . 0 4 9}$ & $\mathbf{0 . 1 0 1}$ & $\mathbf{0 . 1 1 7}$ & $\mathbf{0 . 0 5 1}$ & $\mathbf{0 . 0 4 5}$ & $\mathbf{0 . 0 3 3}$ & $\mathbf{0 . 1 0 5}$ \\
4.0 & 0.010 & $\mathbf{0 . 0 2 4}$ & $\mathbf{0 . 0 3 2}$ & $\mathbf{0 . 0 8 0}$ & $\mathbf{0 . 0 6 2}$ & $\mathbf{0 . 0 8 7}$ & $\mathbf{0 . 1 2 3}$ & $\mathbf{0 . 0 4 9}$ & $\mathbf{0 . 0 7 1}$ & 0.005 \\
4.5 & 0.010 & $\mathbf{0 . 0 2 9}$ & $\mathbf{0 . 0 4 1}$ & $\mathbf{0 . 0 6 4}$ & $\mathbf{0 . 1 1 5}$ & $\mathbf{0 . 1 3 5}$ & $\mathbf{0 . 1 7 2}$ & $\mathbf{0 . 1 3 4}$ & $\mathbf{0 . 0 4 9}$ & $\mathbf{0 . 0 4 7}$ \\
5.0 & $\mathbf{0 . 0 2 8}$ & $\mathbf{0 . 0 4 0}$ & $\mathbf{0 . 0 4 2}$ & $\mathbf{0 . 0 5 4}$ & $\mathbf{0 . 0 9 1}$ & $\mathbf{0 . 1 5 7}$ & $\mathbf{0 . 1 5 1}$ & $\mathbf{0 . 1 1 8}$ & $\mathbf{0 . 0 8 6}$ & $\mathbf{0 . 0 6 1}$ \\
6.0 & 0.017 & 0.005 & $\mathbf{0 . 0 1 6}$ & $\mathbf{0 . 0 2 8}$ & $\mathbf{0 . 1 7 0}$ & $\mathbf{0 . 1 9 9}$ & $\mathbf{0 . 1 5 0}$ & $\mathbf{0 . 0 6 8}$ & $\mathbf{0 . 0 6 2}$ & $\mathbf{0 . 0 4 2}$ \\
7.0 & $\mathbf{0 . 0 9 4}$ & $\mathbf{0 . 0 3 7}$ & $\mathbf{0 . 0 4 0}$ & $\mathbf{0 . 0 4 7}$ & $\mathbf{0 . 0 8 9}$ & $\mathbf{0 . 0 8 1}$ & $\mathbf{0 . 0 7 0}$ & $\mathbf{0 . 0 7 6}$ & $\mathbf{0 . 0 5 2}$ & $\mathbf{0 . 0 4 5}$ \\
8.0 & $\mathbf{0 . 0 3 5}$ & $\mathbf{0 . 0 1 9}$ & $\mathbf{0 . 0 2 1}$ & $\mathbf{0 . 0 4 4}$ & $\mathbf{0 . 1 5 6}$ & $\mathbf{0 . 0 7 2}$ & $\mathbf{0 . 1 1 8}$ & $\mathbf{0 . 0 2 5}$ & 0.006 & $\mathbf{0 . 0 6 9}$ \\
9.0 & 0.016 & $\mathbf{0 . 0 2 5}$ & $\mathbf{0 . 0 1 6}$ & 0.012 & $\mathbf{0 . 0 8 2}$ & $\mathbf{0 . 1 2 1}$ & $\mathbf{0 . 1 3 5}$ & $\mathbf{0 . 0 7 1}$ & $\mathbf{0 . 0 5 0}$ & 0.029 \\
10.0 & $\mathbf{0 . 0 1 9}$ & $\mathbf{0 . 0 2 1}$ & 0.011 & $\mathbf{0 . 0 3 4}$ & $\mathbf{0 . 0 7 2}$ & $\mathbf{0 . 0 9 8}$ & $\mathbf{0 . 0 7 8}$ & $\mathbf{0 . 0 4 9}$ & $\mathbf{0 . 0 6 1}$ & 0.026 \\
\hline
\end{tabular}


Table 3.22: R-square of the regression of the residuals of the implied volatility. R-square of the regression of the residuals of the implied volatility with the three principal components of macroeconomic announcements and the fed surprise data. The numbers with bold letters are significant in $90 \%$ F-statistics.

\begin{tabular}{lrrrrrrrrrrrr}
\multicolumn{8}{c}{$\begin{array}{l}\text { R-squared for the regression of implied volatility with the three principal } \\
\text { components of macroeconomic announcements and Fed surprise data }\end{array}$} \\
$\begin{array}{l}\text { Moneyness } \\
\text { Maturity }\end{array}$ & 0.6 & 0.7 & 0.8 & 0.9 & 1.0 & 1.1 & 1.2 & 1.3 & 1.4 & 1.5 \\
\hline 0.5 years & 0.0731 & $\mathbf{0 . 1 2 3 9}$ & $\mathbf{0 . 0 9 1 8}$ & 0.0203 & $\mathbf{0 . 0 6 0 7}$ & $\mathbf{0 . 3 0 7 1}$ & 0.0538 & 0.0530 & 0.3049 & 0.4163 \\
1.0 & 0.1920 & $\mathbf{0 . 1 5 8 1}$ & $\mathbf{0 . 1 3 9 3}$ & $\mathbf{0 . 1 9 0 5}$ & $\mathbf{0 . 1 9 7 5}$ & $\mathbf{0 . 2 1 7 0}$ & NaN & NaN & NaN & NaN \\
1.5 & $\mathbf{0 . 1 5 1 7}$ & $\mathbf{0 . 1 3 7 8}$ & $\mathbf{0 . 0 7 8 0}$ & $\mathbf{0 . 2 3 3 0}$ & $\mathbf{0 . 1 5 3 1}$ & $\mathbf{0 . 0 8 4 4}$ & $\mathbf{0 . 1 3 1 9}$ & $\mathbf{0 . 2 1 6 1}$ & $\mathbf{0 . 0 9 2 4}$ & $\mathbf{0 . 1 8 8 4}$ \\
2.0 & $\mathbf{0 . 0 8 6 8}$ & $\mathbf{0 . 1 6 2 7}$ & $\mathbf{0 . 0 3 3 8}$ & 0.0098 & $\mathbf{0 . 0 0 6 5}$ & $\mathbf{0 . 0 1 8 9}$ & $\mathbf{0 . 0 6 1 5}$ & $\mathbf{0 . 0 5 1 5}$ & $\mathbf{0 . 0 9 4 2}$ & $\mathbf{0 . 2 3 4 5}$ \\
2.5 & $\mathbf{0 . 0 7 8 0}$ & $\mathbf{0 . 1 2 3 5}$ & $\mathbf{0 . 0 8 4 9}$ & $\mathbf{0 . 0 7 5 6}$ & 0.0825 & $\mathbf{0 . 0 9 1 2}$ & $\mathbf{0 . 1 0 4 0}$ & $\mathbf{0 . 0 8 5 6}$ & $\mathbf{0 . 0 3 7 5}$ & $\mathbf{0 . 1 8 7 7}$ \\
3.0 & $\mathbf{0 . 0 4 2 0}$ & $\mathbf{0 . 0 5 0 3}$ & $\mathbf{0 . 0 8 1 5}$ & $\mathbf{0 . 0 6 0 9}$ & $\mathbf{0 . 0 8 5 6}$ & $\mathbf{0 . 1 2 2 4}$ & $\mathbf{0 . 1 6 4 9}$ & $\mathbf{0 . 1 0 0 0}$ & $\mathbf{0 . 1 0 3 1}$ & $\mathbf{0 . 3 0 3 9}$ \\
3.5 & $\mathbf{0 . 0 8 0 7}$ & $\mathbf{0 . 0 2 8 0}$ & $\mathbf{0 . 0 3 3 0}$ & $\mathbf{0 . 0 4 9 8}$ & $\mathbf{0 . 1 0 6 9}$ & $\mathbf{0 . 1 1 8 3}$ & $\mathbf{0 . 0 6 3 1}$ & $\mathbf{0 . 0 5 6 1}$ & $\mathbf{0 . 0 4 7 9}$ & $\mathbf{0 . 2 8 6 8}$ \\
4.0 & 0.0218 & $\mathbf{0 . 0 3 3 8}$ & $\mathbf{0 . 0 4 5 9}$ & $\mathbf{0 . 0 8 0 6}$ & $\mathbf{0 . 0 6 8 0}$ & $\mathbf{0 . 0 8 7 2}$ & $\mathbf{0 . 1 2 9 8}$ & $\mathbf{0 . 0 5 7 0}$ & $\mathbf{0 . 0 7 3 6}$ & 0.0241 \\
4.5 & 0.0112 & $\mathbf{0 . 0 4 9 7}$ & $\mathbf{0 . 0 5 3 5}$ & $\mathbf{0 . 0 7 1 3}$ & $\mathbf{0 . 1 2 0 1}$ & $\mathbf{0 . 1 4 7 1}$ & $\mathbf{0 . 1 8 3 5}$ & $\mathbf{0 . 1 3 6 2}$ & $\mathbf{0 . 0 5 6 2}$ & $\mathbf{0 . 1 4 4 6}$ \\
5.0 & $\mathbf{0 . 0 4 3 6}$ & $\mathbf{0 . 0 6 6 7}$ & $\mathbf{0 . 0 4 4 7}$ & $\mathbf{0 . 0 6 1 4}$ & $\mathbf{0 . 0 9 9 4}$ & $\mathbf{0 . 1 8 7 7}$ & $\mathbf{0 . 1 8 2 8}$ & $\mathbf{0 . 1 2 1 6}$ & $\mathbf{0 . 0 8 7 5}$ & $\mathbf{0 . 1 4 8 8}$ \\
6.0 & $\mathbf{0 . 0 5 7 8}$ & $\mathbf{0 . 0 4 7 7}$ & $\mathbf{0 . 1 1 1 2}$ & $\mathbf{0 . 1 6 4 1}$ & $\mathbf{0 . 1 7 3 0}$ & $\mathbf{0 . 2 0 9 9}$ & $\mathbf{0 . 1 6 2 5}$ & $\mathbf{0 . 0 9 7 1}$ & $\mathbf{0 . 0 7 5 0}$ & $\mathbf{0 . 0 8 3 9}$ \\
7.0 & $\mathbf{0 . 1 1 4 2}$ & $\mathbf{0 . 0 5 9 8}$ & $\mathbf{0 . 0 5 8 1}$ & $\mathbf{0 . 0 6 7 9}$ & $\mathbf{0 . 1 0 2 3}$ & $\mathbf{0 . 0 8 8 7}$ & $\mathbf{0 . 1 0 1 9}$ & $\mathbf{0 . 1 2 8 3}$ & $\mathbf{0 . 0 9 5 0}$ & $\mathbf{0 . 0 6 3 1}$ \\
8.0 & $\mathbf{0 . 0 6 5 8}$ & $\mathbf{0 . 0 3 9 1}$ & $\mathbf{0 . 0 4 4 4}$ & $\mathbf{0 . 0 6 9 9}$ & $\mathbf{0 . 1 5 8 5}$ & $\mathbf{0 . 0 7 7 3}$ & $\mathbf{0 . 1 2 1 9}$ & $\mathbf{0 . 0 4 1 5}$ & 0.0207 & $\mathbf{0 . 0 9 0 0}$ \\
9.0 & 0.0234 & $\mathbf{0 . 0 3 0 0}$ & 0.0171 & 0.0187 & $\mathbf{0 . 0 9 9 3}$ & $\mathbf{0 . 1 5 1 8}$ & $\mathbf{0 . 1 6 6 7}$ & $\mathbf{0 . 0 9 6 8}$ & $\mathbf{0 . 0 6 5 5}$ & 0.0290 \\
10.0 & $\mathbf{0 . 0 4 2 6}$ & $\mathbf{0 . 0 2 7 2}$ & 0.0131 & $\mathbf{0 . 0 4 1 6}$ & $\mathbf{0 . 0 8 1 4}$ & $\mathbf{0 . 1 2 4 3}$ & $\mathbf{0 . 1 1 3 7}$ & $\mathbf{0 . 0 8 4 5}$ & $\mathbf{0 . 0 7 3 3}$ & $\mathbf{0 . 0 7 6 6}$ \\
\hline
\end{tabular}

\subsubsection{GARCH Based Unspanned Volatility}

To generate the conditional volatility in GARCH frame work, we use the LIBOR bonds (actually the reciprocal of LIBOR bonds) created from the LIBOR since the caps term premium is a linear combination of cap prices. We subtract the mean from the LIBOR bonds and use "tarch" program available in [50] to generate the conditional volatility for 15 maturities. To regress the implied volatility we use the three principal components of the conditional volatility based on GARCH. The residuals can be thought of as a proxy for unspanned volatilities. The R-squares of the regressions of implied volatility with the three principal components of GARCH based conditional volatility of LIBOR bonds are given in Table 3.23. Compared to the R-square for the regression of implied volatility with the three principal components of LIBOR, the values are in general lower. R-squares for the regressions of the GARCH based residuals of the implied volatility with the three principal components of macroeconomic announcements are given in Table 3.24. The numbers are in general higher than the R-square for the regression of the LIBOR based residuals of the implied volatility with the three principal components of macroeconomic announcements. 
Table 3.23: R-square of the regression of implied volatility. The R-square for the regression of implied volatility with the three principal components of GARCH based conditional volatility of LIBOR bonds.

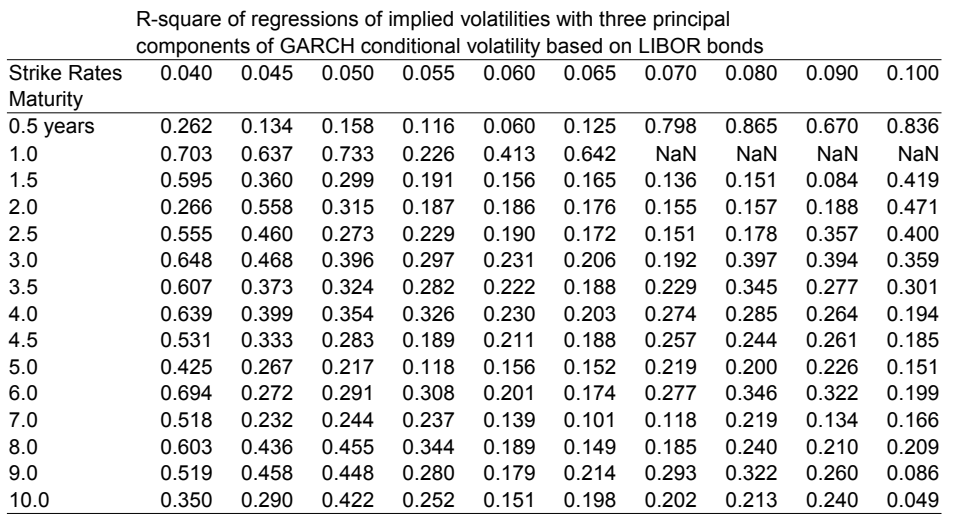

Table 3.24: R-square of the regression of the residuals of the implied volatility. R-square for the regression of the GARCH based residuals of the implied volatility with the three principal components of macroeconomic announcements. The numbers with bold letters are significant in $90 \%$ F-statistics.

\begin{tabular}{|c|c|c|c|c|c|c|c|c|c|c|}
\hline & $\begin{array}{l}\text { square } \\
\text { ith three }\end{array}$ & & & nts 0 & acroe & omic & lounc & ents & & \\
\hline \multicolumn{11}{|l|}{ Maturity } \\
\hline 0.5 years & 0.088 & 0.142 & 0.025 & 0.057 & 0.180 & 0.039 & 0.099 & 0.099 & 0.683 & 0.055 \\
\hline 1.0 & 0.042 & 0.015 & 0.005 & 0.246 & 0.041 & 0.058 & $\mathrm{NaN}$ & $\mathrm{NaN}$ & $\mathrm{NaN}$ & $\mathrm{NaN}$ \\
\hline 1.5 & 0.024 & 0.025 & 0.022 & 0.059 & 0.118 & 0.133 & 0.068 & 0.061 & 0.150 & 0.035 \\
\hline 2.0 & 0.013 & 0.163 & 0.053 & 0.098 & 0.119 & 0.160 & 0.178 & 0.030 & 0.015 & 0.046 \\
\hline 2.5 & 0.119 & 0.102 & 0.191 & 0.191 & 0.207 & 0.206 & 0.213 & 0.227 & 0.172 & 0.009 \\
\hline 3.0 & 0.165 & 0.024 & 0.143 & 0.165 & 0.213 & 0.213 & 0.251 & 0.197 & 0.140 & 0.018 \\
\hline 3.5 & 0.095 & 0.032 & 0.177 & 0.196 & 0.212 & 0.225 & 0.208 & 0.149 & 0.082 & 0.059 \\
\hline 4.0 & 0.010 & 0.076 & 0.161 & 0.205 & 0.175 & 0.191 & 0.164 & 0.070 & 0.123 & 0.024 \\
\hline 4.5 & 0.005 & 0.144 & 0.172 & 0.180 & 0.223 & 0.229 & 0.300 & 0.217 & 0.120 & 0.031 \\
\hline 5.0 & 0.026 & 0.165 & 0.157 & 0.150 & 0.199 & 0.260 & 0.265 & 0.196 & 0.153 & 0.042 \\
\hline 6.0 & 0.057 & 0.111 & 0.135 & 0.166 & 0.240 & 0.253 & 0.188 & 0.149 & 0.147 & 0.039 \\
\hline 7.0 & 0.131 & 0.064 & 0.054 & 0.086 & 0.130 & 0.162 & 0.079 & 0.177 & 0.143 & 0.026 \\
\hline 8.0 & 0.123 & 0.160 & 0.182 & 0.182 & 0.207 & 0.218 & 0.133 & 0.079 & 0.056 & 0.126 \\
\hline 9.0 & 0.064 & 0.064 & 0.067 & 0.077 & 0.124 & 0.181 & 0.060 & 0.033 & 0.015 & 0.076 \\
\hline 10.0 & 0.042 & 0.048 & 0.039 & 0.064 & 0.070 & 0.059 & 0.015 & 0.004 & 0.001 & 0.050 \\
\hline
\end{tabular}

\subsubsection{Comparison}

We examined two candidates for the proxy of unspanned volatility observed in bonds and their derivative markets. The comparison makes it interesting to think about what is a good proxy for the unspanned volatility observed in bonds and their derivative markets. The R-squares of the regressions of implied volatility with LIBOR is much better than those with GARCH. In return, the R-squares of the regressions of the residuals with GARCH looks better than those with LIBOR. The price of caps is determined from LIBOR. Therefore, the implied volatility of caps may reflect the change in LIBOR more so than GARCH and this may imply that after the regression of implied volatility with LIBOR the less relevant information is left in the residuals. 


\subsection{Impulse Response Function Analysis}

We apply the impulse response functions to some of the macroeconomic data to see how the implied volatility responds to the impulse in macroeconomic announcements. Also, this will justify the regression analysis we did in this section. As the macro economic data we choose unemployment data and fed data.

First, we use the unemployment data. We construct the data in which the values are zero except the days when the weekly announcements on unemployment are made. The impulse response functions are shown in Figures 3.4 and 3.5. It is difficult to see in the eyes, but there is a small negative bump in the response of implied volatility to the impulse in unemployment for the first several days. Somewhat strange, but the result says that implied volatility affects unemployment data negatively. The period of high volatility could be the period where the economy is unstable and there could be more lay-offs. They are typical graphs for the above combination. The effect of unemployment on the implied volatility is not clear. On the other hand, surprisingly enough, the implied volatility influences the unemployment.

We also use the fed data. The fed data consist of the expected and unexpected components. In Figures 3.6 and 3.7, the graphs of impulse response functions for implied volatility and the expected component of target fed fund rates are given. Compared to the unemployment, the effects of target fed fund rates are clear. Also, the graphs of impulse response functions for implied volatility and the unexpected component of target fed fund rates are given in 3.8 and 3.9. Another thing to observe is that the there is a difference between in-the-money and out-of-the-money (or low and high strike rate) difference caps. The confidence interval for the response functions for the implied volatility is wide for the out-of-the-money difference caps. On the other hand, the confidence interval for the in-the-money difference caps is narrow. Also, the shape of the graph changes across at-the-money.

The response functions decay but the decays are not too fast. In the case of the initial unemployment claim which comes out every week (every 5 business days), the negative small bumps are lasting for a few days. For the target fed funds rate which is announced every 6 weeks (30 business days), the responses are lasting about that many days. If we do the regressions with Method 2, the regressor will pick up some information from the response functions, roughly speaking some information related to the average response between the announcements. 

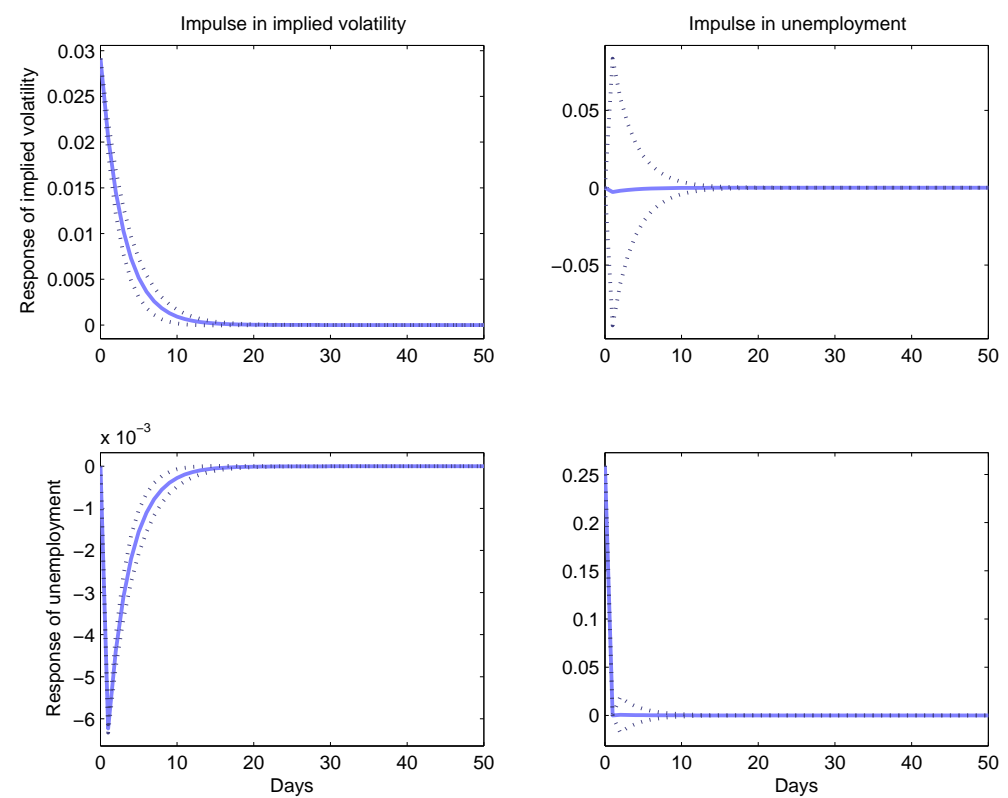

Figure 3.4: Impulse response functions for implied volatility and unemployment data. A typical impulse response functions for implied volatility and unemployment data are given. The maturity of the difference cap is 3 years and the moneyness is 0.8 and in in-the-money. 

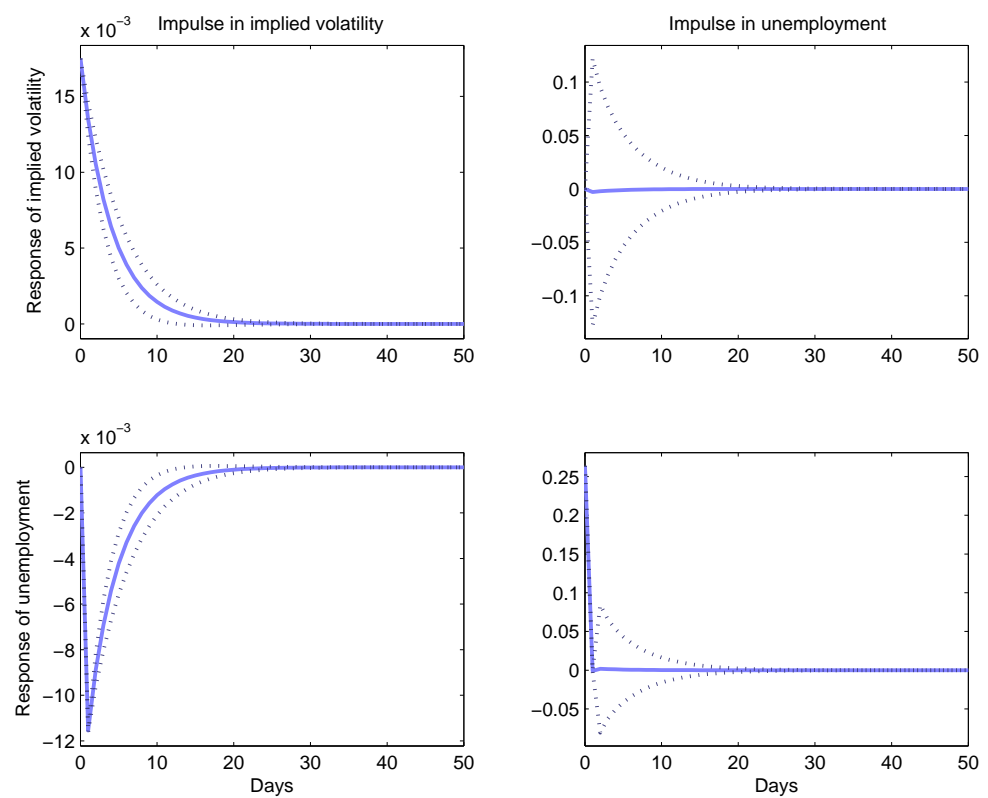

Figure 3.5: Impulse response functions for implied volatility and unemployment data. A typical impulse response functions for implied volatility and unemployment data are given. The maturity of the difference cap is 3 years and the moneyness is 0.8 and in in-the-money. 

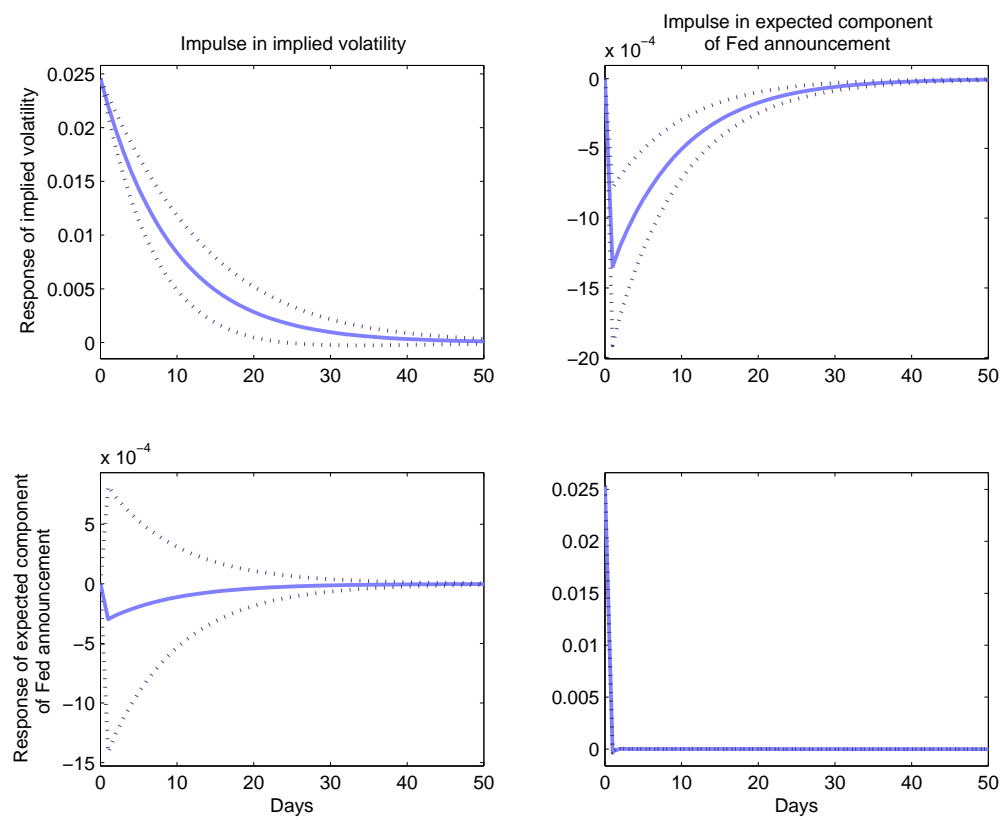

Figure 3.6: Impulse response functions for implied volatility and the expected component of Fed announcement. A typical impulse response functions for implied volatility and the expected component of Fed announcement are given. The maturity of the difference cap is 3 years and the moneyness is 0.8 and it is in-the-money. 

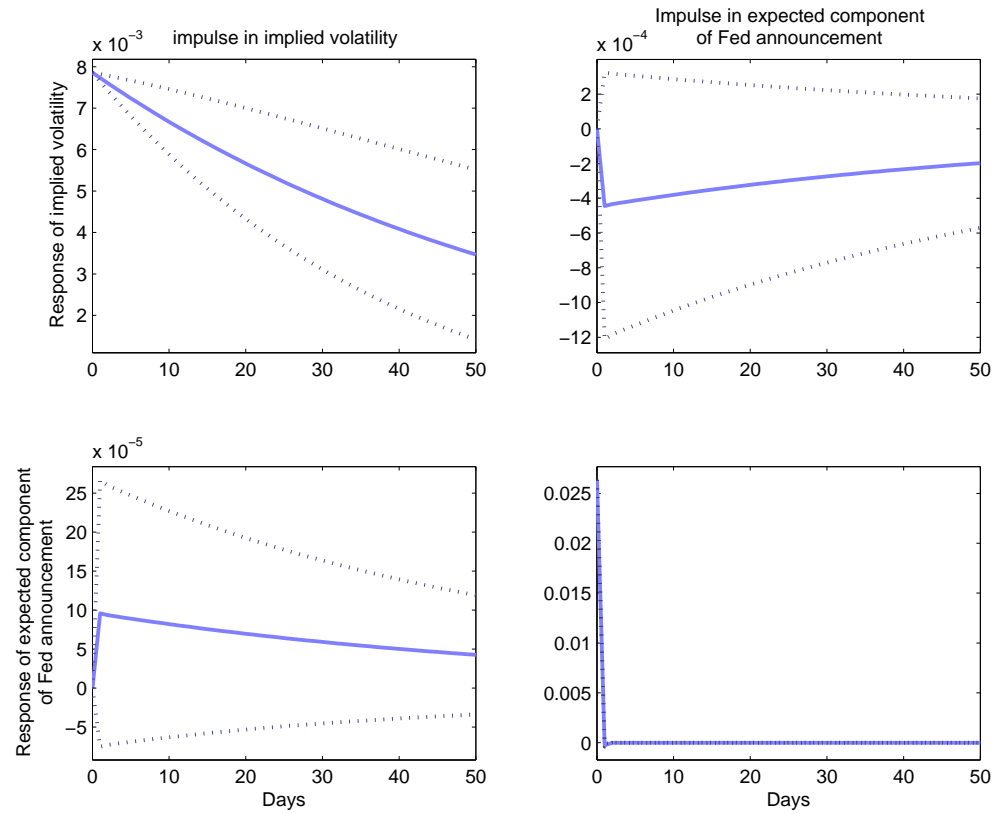

Figure 3.7: Impulse response functions for implied volatility and the expected component of Fed announcement. A typical impulse response functions for implied volatility and the expected component of Fed announcement are given. The maturity of the difference cap is 3 years and the moneyness is 1.2 and it is out-of-the-money. 

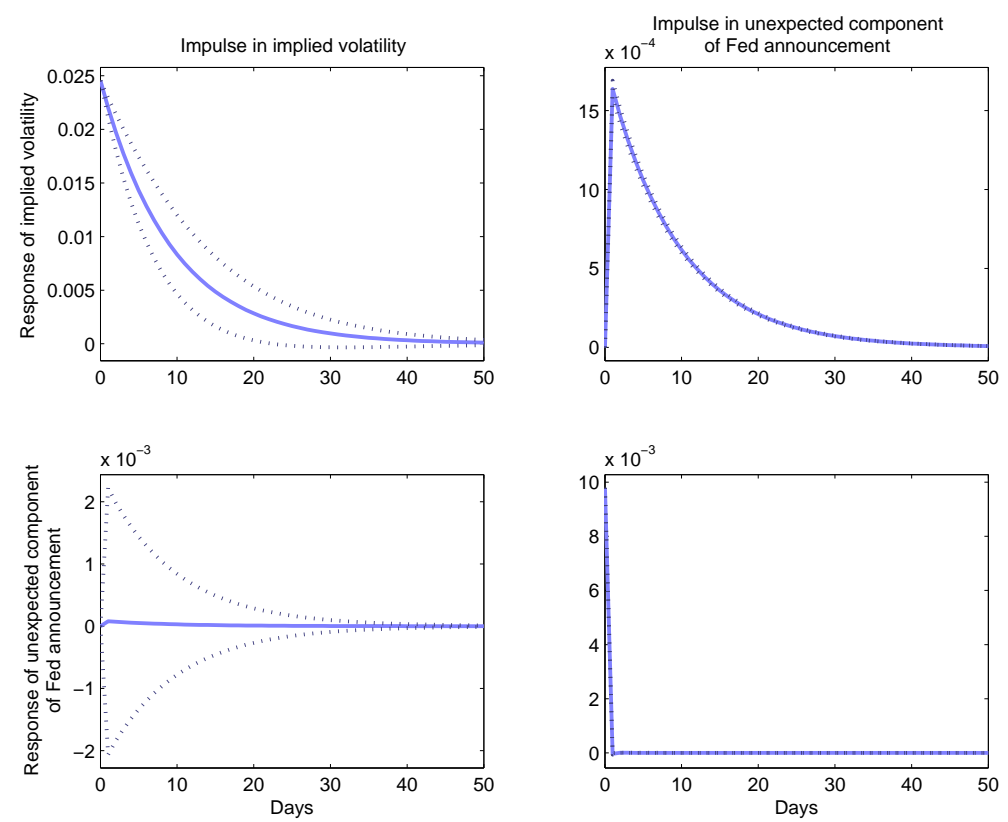

Figure 3.8: Impulse response functions for implied volatility and the unexpected component of Fed announcement. A typical impulse response functions for implied volatility and the unexpected component of Fed announcement are given. The maturity of the difference cap is 3 years and the moneyness is 0.8 and it is in-the-money. 

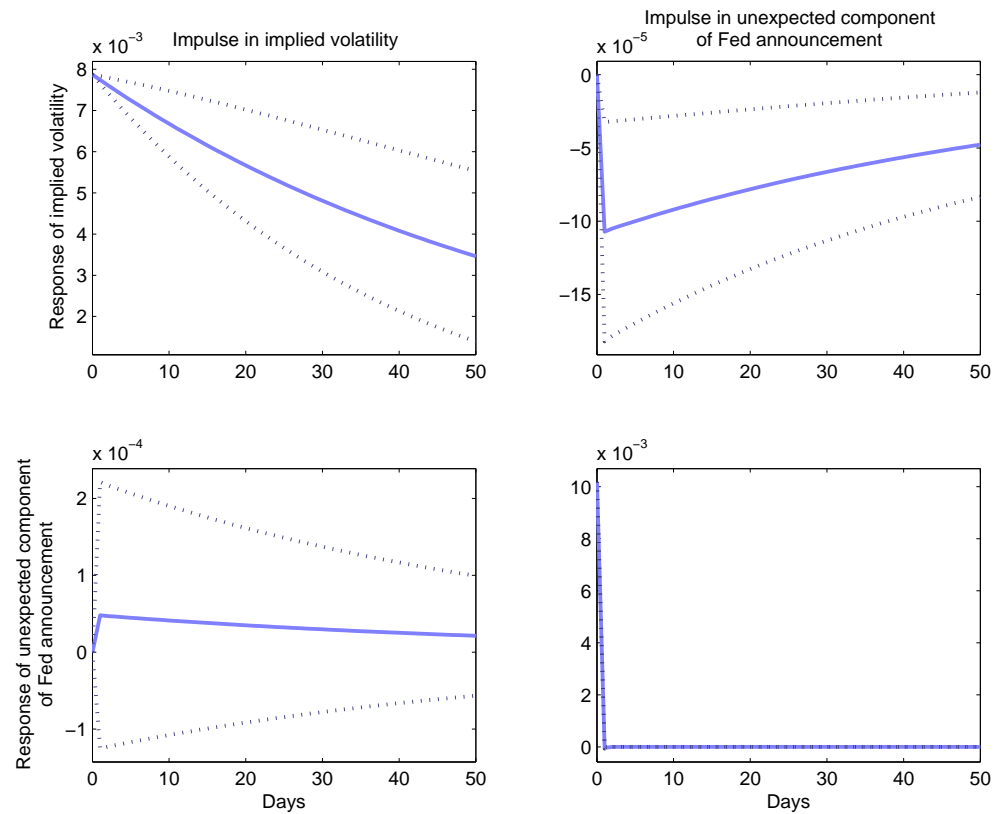

Figure 3.9: Impulse response functions for implied volatility and the unexpected component of Fed announcement. A typical impulse response functions for implied volatility and the unexpected component of Fed announcement are given. The maturity of the difference cap is 3 years and the moneyness is 1.2 and it is out-of-the-money.

\subsection{Conclusions}

We empirically examined the effects of 21 available macroeconomic announcements on the implied volatility of difference caps. We also examined the effects of target federal funds rates (fed announcements) on the implied volatility of difference caps.

First, we performed the event analysis using 21 macroeconomic announcements. We regressed 142 time series of implied volatility with 21 macroeconomic announcements. To see the effect of announcements for moneyness and maturity, the numbers are counted for in-the-money, at-themoney, and out-of-the-money in the moneyness and short, intermediate, and long maturities for maturity. Also, the number of times when the coefficients are positive are counted. We see that the influence of PPI is most significant and the signs of the coefficient are all negative. National Association of Purchasing Management (NAPM) Index comes second. The signs of the coefficients are mostly positive. It is somewhat puzzling that the signs of PPI and NAPM are different. These are related to production side. The other important indices on the production side are Industrial Production (INP) and Factory Orders (FOR). Indices important on the consumer side are Retail Sale (RES) and Personal Consumption Expenditures (PEC). The other important indices on the consumer side are Consumer Confidence Index and Unemployment Rate. Also, concerning the moneyness, both PEC and RES are affecting the out-of-the-money caps more than in-the-money or at-the-money caps. FOR and CCO are affecting in-the-money and at-the-money caps.

Second, we constructed the Principal components and tested effects of the first three principal components on the implied volatility of difference caps. There are at least two ways to use the available macroeconomic data. One way is to select the days when at least one new macroeco- 
nomic announcement becomes available to public and construct the time series with the data on the selected days (Method 1). Another way is to construct the time series of a macroeconomic announcement by filling the days without that announcement the most recent data (Method 2). We see vivid difference between Methods 1 and 2. We observe that Method 2 gives better results than Method 1. This may show that the effects of macroeconomic announcements are not instantaneous but rather transient or persistent. The unemployment Data is a weekly data. Therefore, it is able to explain the volatility in caps market better than other data. We found that Method 2 gives better R-squared.

We also examined the effects of target federal funds rates (fed announcements) on the implied volatility of difference caps. The fed announcements have expected and unexpected components. We observed that Method 2 in the regressions of implied volatility of difference caps with expected and unexpected gave much better R-squared. The effects of unexpected components are clearly shown especially for the in-the-money difference caps. From this result, we constructed 9 portfolios of difference caps to examine the effects of fed announcements. We observed that the unexpected components have effects on in-the -money portfolios.

Method 2 is not the regression commonly done. In Section 3.6, we constructed the impulse response functions to justify the validity of Method 2 at least for the unemployment and the fed announcements. In a crude sense, the step-shaped regressor could be regarded as an approximation for the average impact of an announcement between two consecutive announcement dates. 


\section{Chapter 4}

\section{Caps Term Premiums}

\subsection{Introduction}

In this chapter we study the caps term premium. We define the term premium of caps to be

$$
r c_{t+1}^{(n)}(k)=c_{t+1}^{(n-1)}(k)-c_{t}^{(n)}(k)+c_{t}^{(1)}(k),
$$

where $k$ is a strike rate. In finance, the caps term premium represents selling one year cap short, buying $n$ year cap, and selling it as $(n-1)$ year cap at $t+1$. This compares the risk of holding $n$ year cap and that of holding one year cap and then holding $(n-1)$ year cap after one year. The difference measures the risk premium for holding longer maturity caps. With slight abuse of terminology, we call $r c_{t+1}^{(n)}(k) n$-year caps term premium.

The term premiums are first introduced in Cochrane and Piazzesi $[16,17]$ to study the expectation theory for treasury bonds. As in the caps the term premium measures the risk of holding longer maturity bonds and is also termed excess return. Cochrane and Piazzesi did the regression analysis of the term premium with the forward rates and observed that the term premium is regressed by a hump shaped linear combination of forward rates very well. They termed this hump shaped linear combination the forecaster. They also observed that the forecaster along with the level, slope, and curvature explains the term premium well.

We examine whether the similar results hold for caps. For this purpose we construct the caps term premiums and regress them with the difference caps. If there is no uncertainty, the term premium is zero, because holding longer term caps and holding two shorter term caps would not make any difference. Uncertainty causes the deviation from being equal. It would be interesting to see if persistent patterns are observed or not. If such a pattern is observed, it would aid the predictability of cap prices. Although it would be desirable to use one year cap as a benchmark, I used 6 month caps as a benchmark due to the fact that the strike rates changed several times during the data period and the first change took place a little after one year from the beginning of the data.

We also regress the caps term premium with the unspanned volatility to see if the volatility of the cap market has some effects on the caps term premium. As in Section 3.5, we use the residuals of the regressions of implied volatility with LIBOR and those with the conditional volatility of LIBOR bonds based on GARCH as proxies of the unspanned volatility. We use the Granger causality test to examine if the unspanned volatility of caps market Granger causes the caps term 
premium. For the sake of comparison, we also examine if the implied volatility Granger cause the caps term premium. This way, we see if there are effects on using the residuals of regressions.

Also, for the sake of investing we examine the relation between the performance of caps term premiums and the above three measures of volatility. For each maturity and strike rate, we choose the dates when the 20 highest and lowest values of caps term premiums occur and also choose the dates when the 20 highest and lowest volatilities occur in each of the above measure of volatilities. Then, we see how many matches we get for each pairing. We see if the higher volatility leads to the higher caps term premiums or the other way is more likely to be the case.

The various discussions about the term premium such as the definition and how to measure it are given in Kim and Orphanides [44]. Collin-Defresne and Solnik [20] studied the term structure of default premium in the swap and LIBOR markets. De Jong and Pelsser [24] examined the relation between the variance covariance matrix implied by cap and swaption prices and estimated by interest rate data and showed that they are significantly different.

We describe the caps and LIBOR data in Section 2. In Section 3 we regress the term premium of caps with the difference caps to see if there are patterns in the regression coefficients which may aid the predictability of the caps term premium. In Section 4 we study the effect of volatility on the term premium. We use the Granger causality test to show that the unspanned volatility of caps market Granger causes the caps term premium. We also examine the relation between the performance of caps term premiums and the three measures of volatility and see if they are useful for investing. Section 5 concludes.

\subsection{LIBOR and Caps Data}

The LIBOR is the abbreviation for the London Interbank Offer Rates and we use the data from August 1, 2000 to July 31, 2002. The data consists of $0.0,0.25,0.5,1.0,2.0,3.0,4.0,5,0,7.0$, and 10.0 year LIBOR forward rates. We construct the LIBOR data for each quarter period using the spline interpolation, from which we construct the zero coupon LIBOR bond prices $P(t, T)$ using the relation

$$
P(t, t+\tau)=\frac{1}{1+\tau L(t, \tau)} .
$$

Interest rate caps are a contract where the interest rates are capped at some fixed value $\bar{r}$. Purchasers of caps pay the prevailing interest rate if it is below $\bar{r}$, but pay the interest rate $\bar{r}$ if the prevailing rate is above $\bar{r}$. In the latter case the sellers of caps pay the difference. Therefore, the purchasers are able to prevent risks associated with the future change in interest rates. Caps consist of caplets which are European options on bonds based on LIBOR. Caps data set spans from August 1, 2000 to July 31, 2002. Throughout the whole sample period, caps have 15 different maturities, which are 0.5, 1.0, 1.5, 2.0, 2.5, 3.0, 3.5, 4.0, 4.5, 5.0, 6.0, 7.0, 8.0, 9.0, and 10.0 years. For each maturity, there are 10 different strike prices, which changed several times during the period. Between August 1, 2000 and October 17, 2001 the strike prices were 4.0, 4.5, 5.0, 5.5, $6.0,6.5,7.0,8.0,9.0$, and 10.0\%. The strike prices were lowered to 1.0, 1.5, 2.0, 2.5, 3.0, 3.5, 4.0, 4.5, 5.0, and 5.5\% between October 18, 2001 and November 1, 2001. Between November 2, 2001 and July 15, 2002 they were 2.5, 3.0, 3.5, 4.0, 4.5, 5.0, 5.5, 6.0, 6.5, and 7.0\%. Then, between July 16, 2001 and April 14, 2003 they were lowered to 2, 2.5, 3.0, 3.5, 4.0, 4.5, 5.0, 5.5, 6.0, and $6.5 \%$. The number of trading days are 494 . There are some observations about the cap prices that needs to be mentioned. Starting 6/4/01, 6 month cap price is zero except the lowest strike rate 0.04. Starting $9 / 7 / 01,6$ month cap price is zero. This lasted until 10/17/01. There are caps with maturities $m=0.5,1.0,1.5$. In some regressions they are excluded from our study due to the short maturities. This practice is commonly done. For the market caps data, we clean the data and remove the outliers and inconsistent data. 
To see how LIBOR changed from August 1, 2000 to July 31, 2002, the graphs of 6 month, 5 year, and 10 year LIBOR rates are provided for reference in Figure 4.1. It is interesting to see that the 6 month LIBOR rates decreased dramatically but both 5 and 10 year LIBOR rates held up well. US Treasury rates are also provided for the sake of comparison in Figure 4.2.
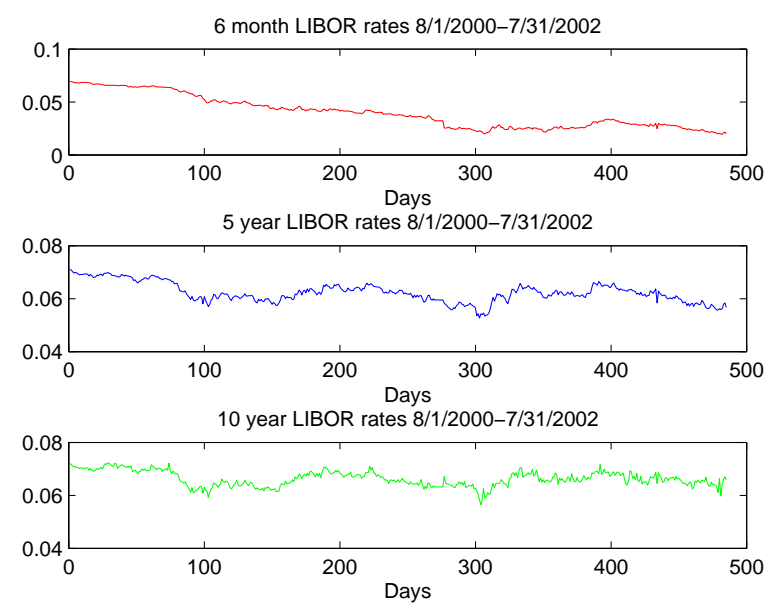

Figure 4.1: Time series of LIBOR rates. The graphs of the time series of 6 month, 5 year, and 10 year LIBOR rates from August 1, 2000 to July 31, 2002 are given. 
6 month Treasury rates 8/1/2000-7/31/2002

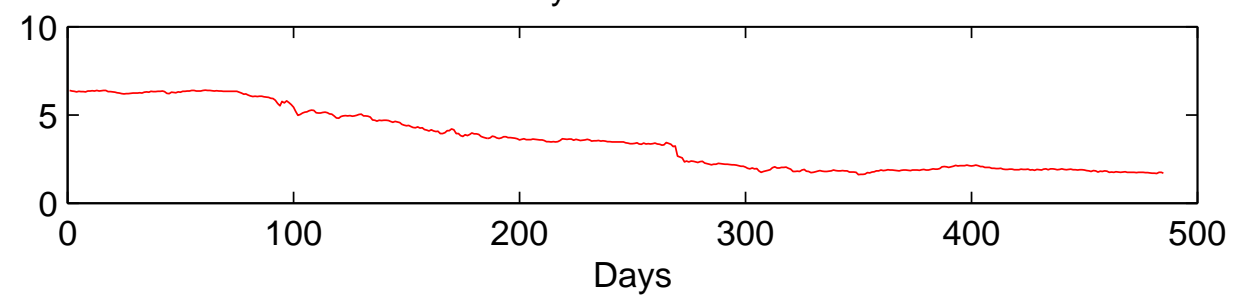

5 year Treasury rates 8/1/2000-7/31/2002

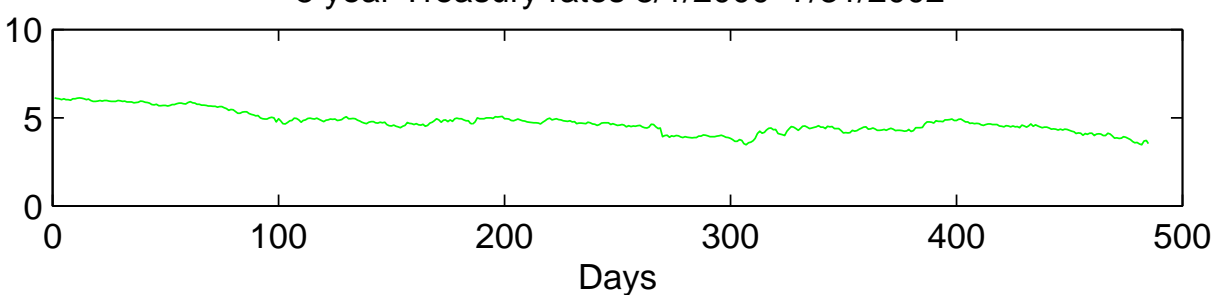

10 year Treasury rates 8/1/2000-7/31/2002

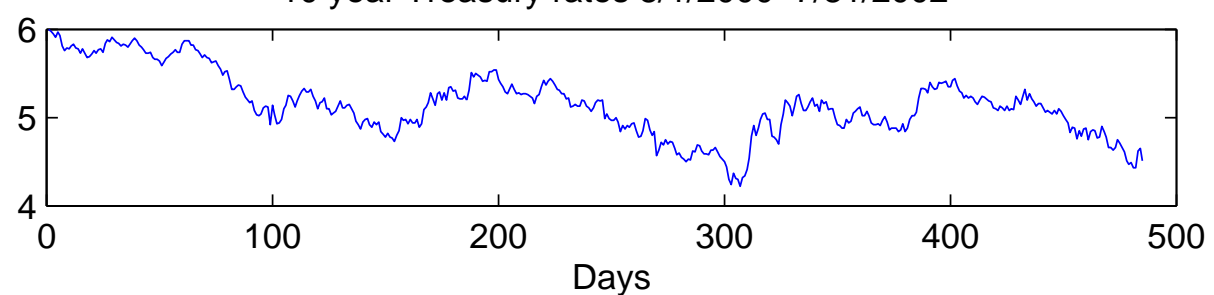

Figure 4.2: Time series of Treasury rates. The graphs of the time series of 6 month, 5 year, and 10 year Treasury rates from August 1, 2000 to July 31, 2002 are given.

\subsection{Caps Term Premium and Difference Caps}

In this section we study the information contents in the term premiums of caps and LIBOR bonds. Their definitions and graphs of time series are given in Subsection 4.3.1.

\subsubsection{Term Premium of Bonds and Caps}

Cochrane and Piazzesi examined the expectation theory of bond prices. They define

$$
r x_{t+1}^{(n)}=p_{t+1}^{(n-1)}-p_{t}^{(n)}+p_{t}^{(1)}
$$

to be the term premium of bonds, where $p_{t}^{(n)}$ is the $\log n$ year bond at $t$. In finance, the term premium represents selling one year bond short, buying $n$ year bond, and selling it as $(n-1)$ year bond at $t+1$. If the expectation theory holds, the term premium is zero. Therefore, this measures the deviation from the expectation theory and the risk of holding longer maturity bonds.

For the caps we define the term premium of caps to be

$$
r c_{t+1}^{(n)}(k)=c_{t+1}^{(n-1)}(k)-c_{t}^{(n)}(k)+c_{t}^{(1)}(k),
$$


where $k$ is a strike rate. This compares the risk of holding $n$ year cap and that of holding one year cap and then holding $(n-1)$ year cap after one year. The difference measures the risk premium for holding longer maturity caps.

The graphs of the time series of LIBOR and caps term premiums are given in Figures 4.3 and 4.4, respectively. It is interesting to observe that caps term premiums are negative. This shows that buyers of caps pay more to protect the future uncertainty and sellers can demand more premium for providing protection against longer uncertainty.
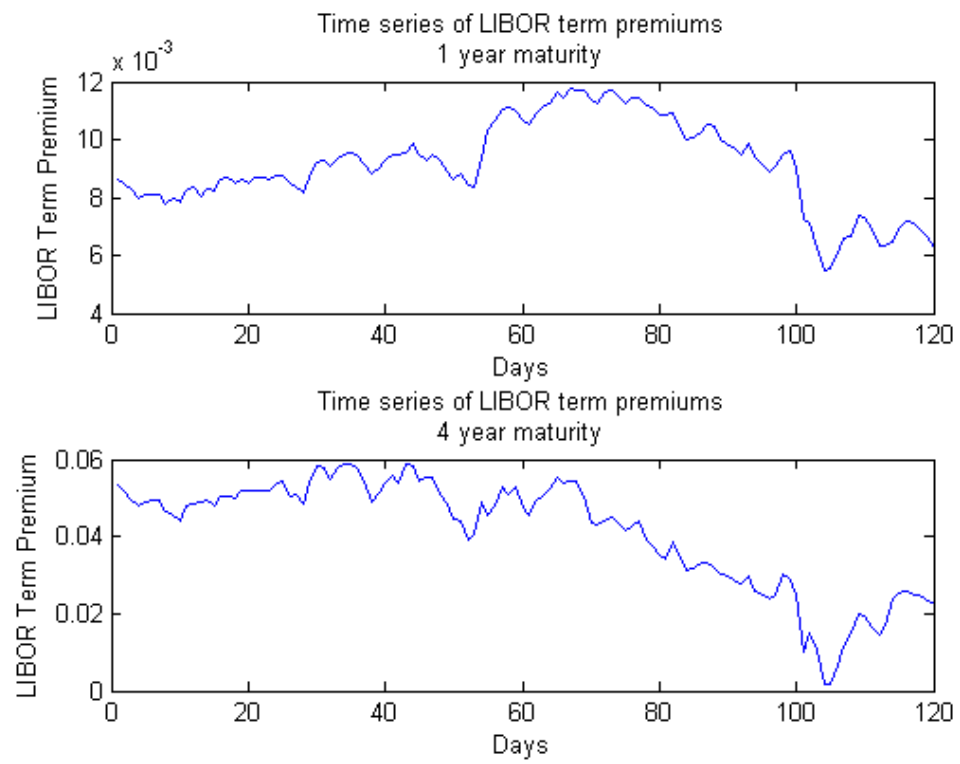

Figure 4.3: The time series of LIBOR term premiums. The time series of LIBOR term premiums for 1 and 4 year maturities are given. 

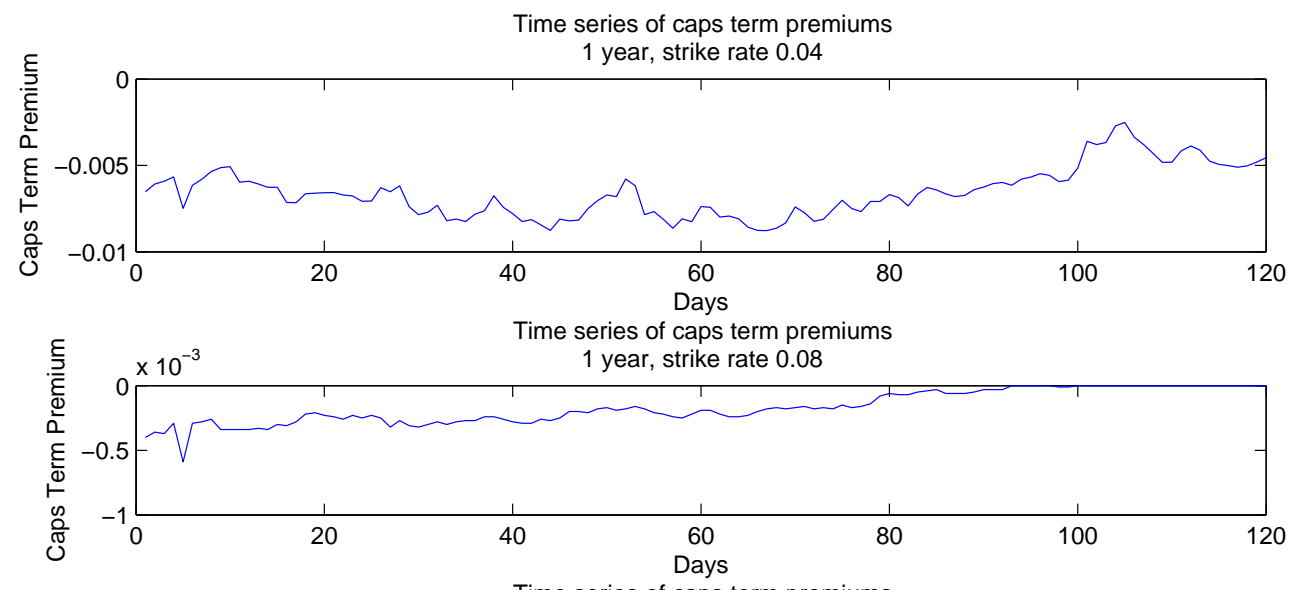

Time series of caps term premiums

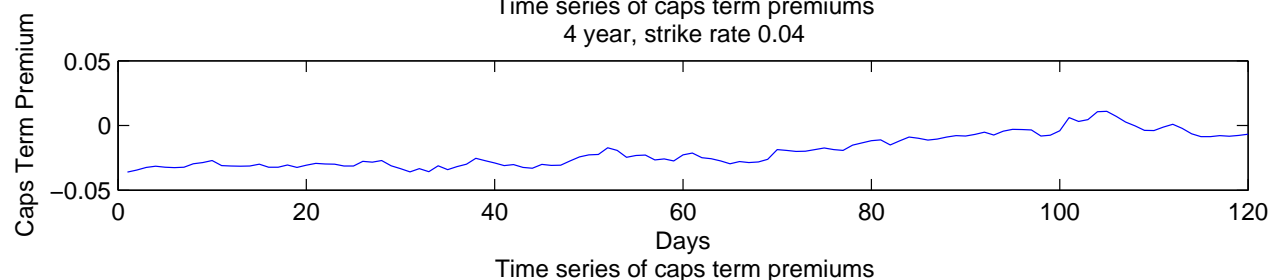

Time series of caps term premiums

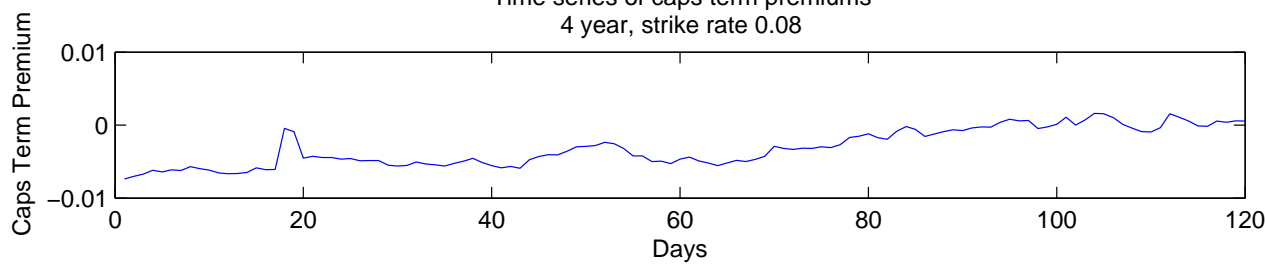

Figure 4.4: The time series of caps term premiums. The time series of caps term premiums for 1 and 4 year maturities are given.

\subsubsection{Regressions by Cochrane and Piazzesi}

Cochrane and Piazzesi examined the expectation theory of bond prices. They define

$$
r x_{t+1}^{(n)}=p_{t+1}^{(n-1)}-p_{t}^{(n)}+p_{t}^{(1)}
$$

to be the term premium, where $p_{t}^{(n)}$ is the $\log n$ year bond at $t$. In finance, the term premium represents selling one year bond short, buying $n$ year bond, and selling it as $(n-1)$ year bond at $t+1$. They also define the $\log$ forward rates at time $t$ for loans between time $t+n-1$ and $t+n$ as

$$
f_{t}^{(n)}=p_{t}^{(n-1)}-p_{t}^{(n)}, \quad n \geq 1,
$$

where $p_{t}^{(0)}=0$. They use five forward rates to define the regressors

$$
F_{t}=\left[1, f_{t}^{(1)}, f_{t}^{(2)}, f_{t}^{(3)}, f_{t}^{(4)}, f_{t}^{(5)}\right]
$$

and studied the regressions

$$
r x_{t+1}^{(n)}=F_{t} \beta^{(n)}+\varepsilon^{(n)} .
$$


They observed that the coefficients form a tent-shaped pattern. Motivated by this observation, they did the restricted regression

$$
r x_{t+1}^{(n)}=b_{n}\left(\gamma_{0}+\gamma_{1} f_{t}^{(1)}+\gamma_{2} f_{t}^{(2)}+\cdots+\gamma_{l} f_{t}^{(5)}\right),
$$

where $\gamma_{i}$ and $b_{n}$ are determined as follows. First, we regress

$$
\overline{r x}_{t+1}=\frac{1}{4} \sum_{n=1}^{4} r x_{t+1}^{(n)}=\gamma_{0}+\gamma_{1} f_{t}^{(1)}+\gamma_{2} f_{t}^{(2)}+\cdots+\gamma_{l} f_{t}^{(5)}
$$

to determine $\gamma_{i}$ and then we regress (4.3.1).
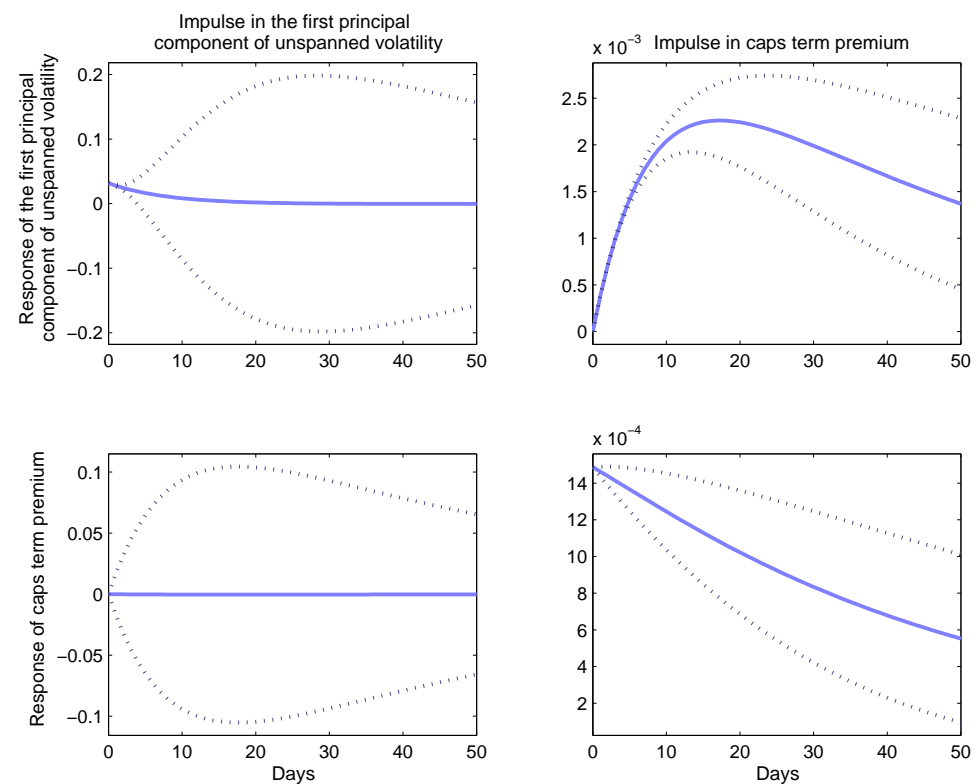

Figure 4.5: Impulse response functions for unspanned volatility and caps term premiums. The impulse response functions for the first principal component of the unspanned volatility and caps term premium are given. The cap is 3 year maturity and at-the-money.

The bonds and the forward rates satisfy

$$
P(t, t+n)=\exp \left[-\int_{t}^{t+n} f(t, s) d s\right]
$$

where $P(t, T)$ is the price of bond at $t$ which will mature at $T$ and $f(t, s)$ is the forward rate at $s$ which can be locked in at $t$. Therefore, the $\log$ bond price $p_{t}^{(n)}$ satisfies

$$
p_{t}^{(n)}=-\int_{t}^{t+n} f(t, s) d s=-\int_{t}^{t+1} f(t, s) d s-\int_{t+1}^{t+n} f(t, s) d s .
$$

On the other hand, the term premium is expressed as

$$
\begin{aligned}
r x_{t+1}^{(n)} & =p_{t+1}^{(n-1)}-p_{t}^{(n)}+p_{t}^{(1)} \\
& =-\int_{t+1}^{t+n} f(t+1, s) d s+\int_{t}^{t+n} f(t, s) d s-\int_{t}^{t+1} f(t, s) d s .
\end{aligned}
$$


If the expectation theory is supposed to hold, $r x_{t+1}^{(n)}=0$ and under this assumption we have

$$
\int_{t+1}^{t+n} f(t+1, s) d s=\int_{t+1}^{t+n} f(t, s) d s .
$$

Since

$$
\begin{gathered}
f_{t}^{(n)}=p_{t}^{(n-1)}-p_{t}^{(n)}=-\int_{t}^{t+(n-1)} f(t, s) d s+\int_{t}^{t+n} f(t, s) d s=\int_{t+(n-1)}^{t+n} f(t, s) d s, \quad n \geq 1, \\
p_{t}^{(n)}-p_{t}^{(1)}=f_{t}^{(2)}+\ldots+f_{t}^{(n)},
\end{gathered}
$$

we see that

$$
\begin{aligned}
\int_{t+1}^{t+n} f(t, s) d s & =\int_{t+1}^{t+2} f(t, s) d s+\ldots+\int_{t+(n-1)}^{t+n} f(t, s) d s \\
& =f_{t}^{(2)}+\ldots+f_{t}^{(n)} .
\end{aligned}
$$

What this indicates is that we may regress the term premium with the log forward rates as regressors under the null hypothesis that all the coefficients are zero. If the coefficients deviate from zero, we may infer that there is a term premium. In what follows, we examine if the similar observations can be made for the caps.

\subsubsection{Regressions of Caps Term Premiums with Difference Caps}

In Cochrane and Piazzesi log bond prices are used to study the term premium. In caps we use the difference caps to study the term premium. There are 122 days in 6 months from August 1st, 2000 to January 13,2001 . In this subsection the strike rate is 0.04 . The other strike rates are discussed in Subsection. The number of data points (the number of days in the regression) are 120. The number of nontrivial regressors is 5 , which means we take the five difference caps stating from the 6 month cap. We regress 10 term premiums using the above regressors. For example, the tenth term premium is to compare holding the 6month cap and holding 5year cap and selling it after 6 months.

We do the various regressions to make observations about regressing caps term premiums with difference caps. To compare our results with Cochrane and Piazzesi, we use the difference cap prices. Define the cap price to be $c(j, m, k)$, where $j$ is the date, $m$ is the maturity, and $k$ is the strike rate. Since the maturity of caps is 6 month increment up to 5 years and then one year increment, we use the first 10 entries in maturity. We define the caps term premium to be

$$
r x_{t+1}^{(n)}=c(j+q, n-1, k)-c(j, n, k)+c(j, 1, k) .
$$

This means we sell 6 month maturity cap and purchase $6 n$ month cap and sell it after 6 month as $6(n-1)$ month cap. Here, $q$ is the number of days for 6 months and we take $n=4,5, \ldots, 10$. We call $r x_{t+1}^{(n)}$ the cap term premium of maturity $n$. We regress the above $r x_{t+1}^{(n)}$ with the difference caps defined by

$$
d_{t}^{(n)}=c(j, n, k)-c(j, n-1, k), n=1,2, \ldots, 10
$$

with the understanding that $c(j, 0, k)=0$.

Regressing the caps term premium with the difference caps has the similar meaning to regressing the term premium in bonds with the log forward rates. If the term premium is zero,

$$
\begin{aligned}
c(j+q(n), n-1, k) & =c(j, n, k)-c(j, 1, k) \\
& =d_{t}^{(1)}+d_{t}^{(2)}+\ldots+d_{t}^{(n)} .
\end{aligned}
$$


This indicates that we may regress the term premium with the difference caps as regressors under the null hypothesis that all the coefficients are zero. If the coefficients are not zero, we may infer that there is a term premium in caps as in bonds.

For treasury bonds, Cochrane and Piazzesi [16, 17] observed that a hump shaped linear combination of $\log$ forward rates forecasts the term premium well. We see if the similar observation is valid for the caps. First, we consider the regression of the term premium with the difference caps. Define

$$
D_{t}=\left[1, d_{t}^{(i)}, d_{t}^{(i+1)}, d_{t}^{(i+2)}, \ldots, d_{t}^{(l)}\right]
$$

and consider the regression of the form

$$
r x_{t+1}^{(n)}=D_{t} \beta^{(n)}+\varepsilon^{(n)} .
$$

The beta (coefficients), t-stats and R-squared of the regressions (4.3.2) for each term premium with the difference caps are listed in Table 4.1. The first few columns do not fit well with the rest of columns. This shows that the term premiums of shorter maturity caps are more volatile than the term premium of longer maturity caps. The graphs of the first five and the last four coefficients are given in Figures 4.6 and 4.7, respectively. Unlike Cochrane and Piazzesi we do not get a nice hump shape. Instead, coefficients $\beta^{(i)}$ s are oscillatory.

In what follows, we use the last five columns to find the restricted regression.

$$
r x_{t+1}^{(n)}=b_{n}\left(\gamma_{0}+\gamma_{1} d_{t}^{(1)}+\gamma_{2} d_{t}^{(2)}+\cdots+\gamma_{l} d_{t}^{(l)}\right),
$$

where $l=5$ and $\gamma_{i}$ and $b_{n}$ are determined as follows. First, we regress

$$
\overline{r x}_{t+1}=\frac{1}{4} \sum_{n=7}^{10} r x_{t+1}^{(n)}=\gamma_{0}+\gamma_{1} d_{t}^{(1)}+\gamma_{2} d_{t}^{(2)}+\cdots+\gamma_{l} d_{t}^{(l)}
$$

to determine $\gamma_{i}$ and then we regress (4.3.3) to determine $b_{n}$. The coefficients for the regression on the average term premium of the last five term premiums are given in Table 4.2 and the R-squared and R-bar are given, respectively, by 0.96351 and $0.96191 . b_{n}$ s for the restricted regressions are given in Table 4.3. The corresponding R-squared for the unrestricted regressions are given in Table 4.4. The graphs of the coefficients of the restricted regressions are given in Figures 4.8 and 4.9.

Table 4.2: The values of $\gamma_{i}$. The values of $\gamma_{i}$ in the regression $\overline{r x}_{t+1}=\frac{1}{4} \sum_{n=7}^{10} r x_{t+1}^{(n)}=$ $\gamma_{0}+\gamma_{1} d_{t}^{(1)}+\gamma_{2} d_{t}^{(2)}+\cdots+\gamma_{l} d_{t}^{(l)}$ are listed. The numbers in parentheses are $t$-statistics. The strike rate is 0.04 .

\begin{tabular}{llllll}
\hline$\gamma_{0}$ & $\gamma_{1}$ & $\gamma_{2}$ & $\gamma_{3}$ & $\gamma_{4}$ & $\gamma_{5}$ \\
\hline 0.03 & -1.78 & 0.72 & -0.93 & 1.18 & -4.46 \\
$(11.11)$ & $(-4.43)$ & $(0.97)$ & $(-0.97)$ & $(0.91)$ & $(-4.35)$ \\
\hline
\end{tabular}

Table 4.3: The values of $b_{n}$. The values of $b_{n}$ in the restricted regression $r x_{t+1}^{(n)}=b_{n}\left(\gamma_{0}+\gamma_{1} d_{t}^{(1)}+\right.$ $\left.\gamma_{2} d_{t}^{(2)}+\cdots+\gamma_{l} d_{t}^{(l)}\right)$. The strike rate is 0.04 .

\begin{tabular}{lllll}
\hline & $b_{7}$ & $b_{8}$ & $b_{9}$ & $b_{10}$ \\
\hline & 1.18 & 1.24 & 1.27 & 1.30 \\
& $(146.19)$ & $(109.9)$ & $(82.95)$ & $(66.31)$ \\
R2 & 0.96 & 0.94 & 0.91 & 0.88 \\
\hline
\end{tabular}




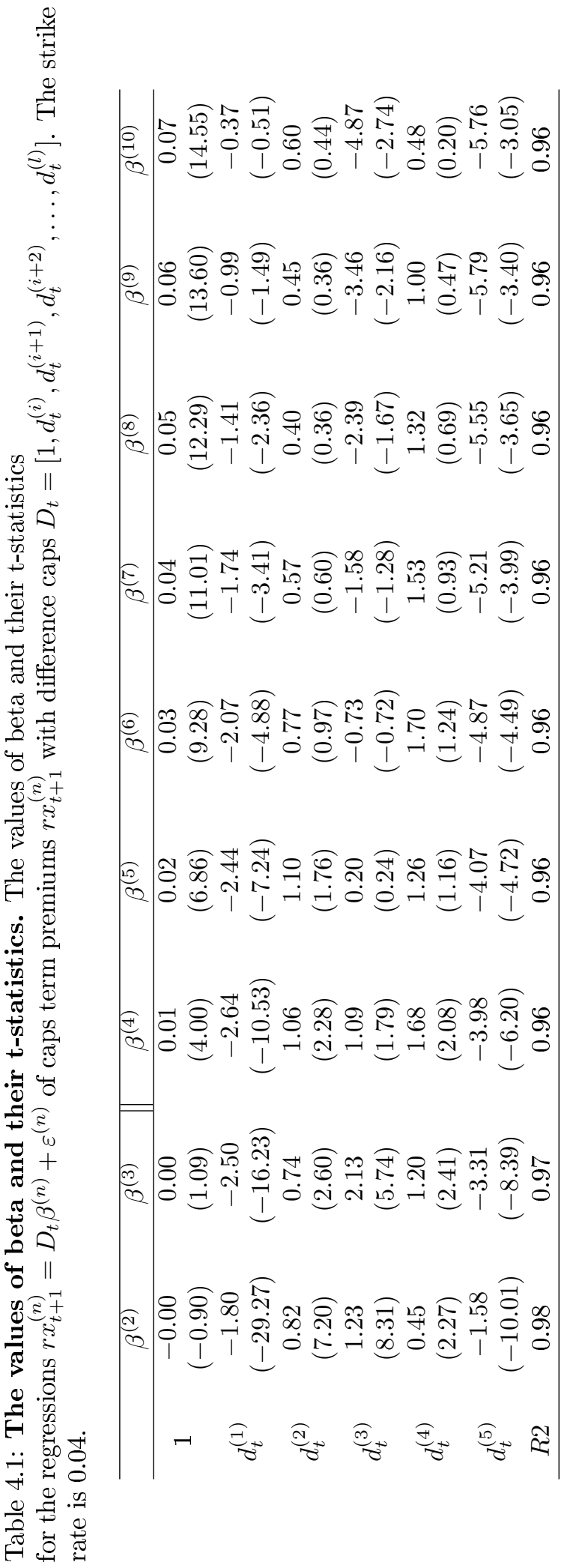


Table 4.4: The R-squared for $b_{n}$. The R-squared for $b_{n}$ in the restricted regression $r x_{t+1}^{(n)}=$ $b_{n}\left(\gamma_{0}+\gamma_{1} d_{t}^{(1)}+\gamma_{2} d_{t}^{(2)}+\cdots+\gamma_{l} d_{t}^{(l)}\right)$. The strike rate is 0.04 .

\begin{tabular}{ccccc}
\hline & $r x_{t+1}^{(7)}$ & $r x_{t+1}^{(8)}$ & $r x_{t+1}^{(9)}$ & $r x_{t+1}^{(10)}$ \\
\hline R2 & 0.96 & 0.96 & 0.96 & 0.96 \\
\hline
\end{tabular}

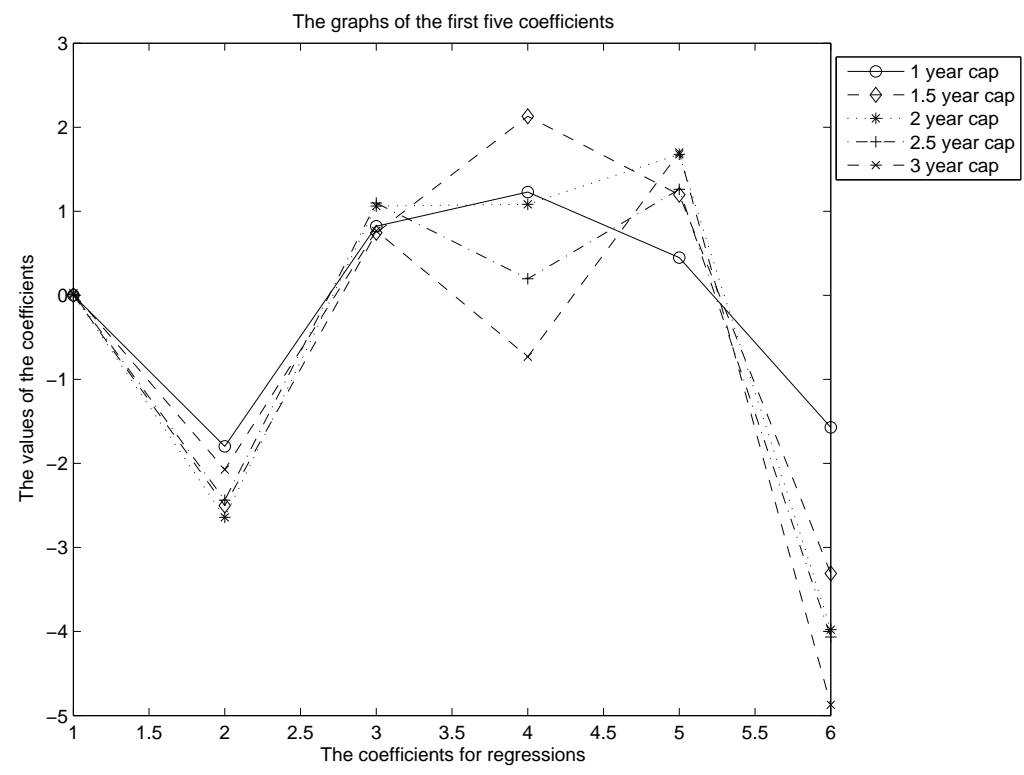

Figure 4.6: The graph of the first five coefficients. The graph of the first five coefficients in the regression $r x_{t+1}^{(n)}=D_{t} \beta^{(n)}+\varepsilon^{(n)}$ of caps term premiums $r x_{t+1}^{(n)}$ with difference caps $D_{t}=$ $\left[1, d_{t}^{(i)}, d_{t}^{(i+1)}, d_{t}^{(i+2)}, \ldots, d_{t}^{(l)}\right]$. The strike rate is 0.04 . 


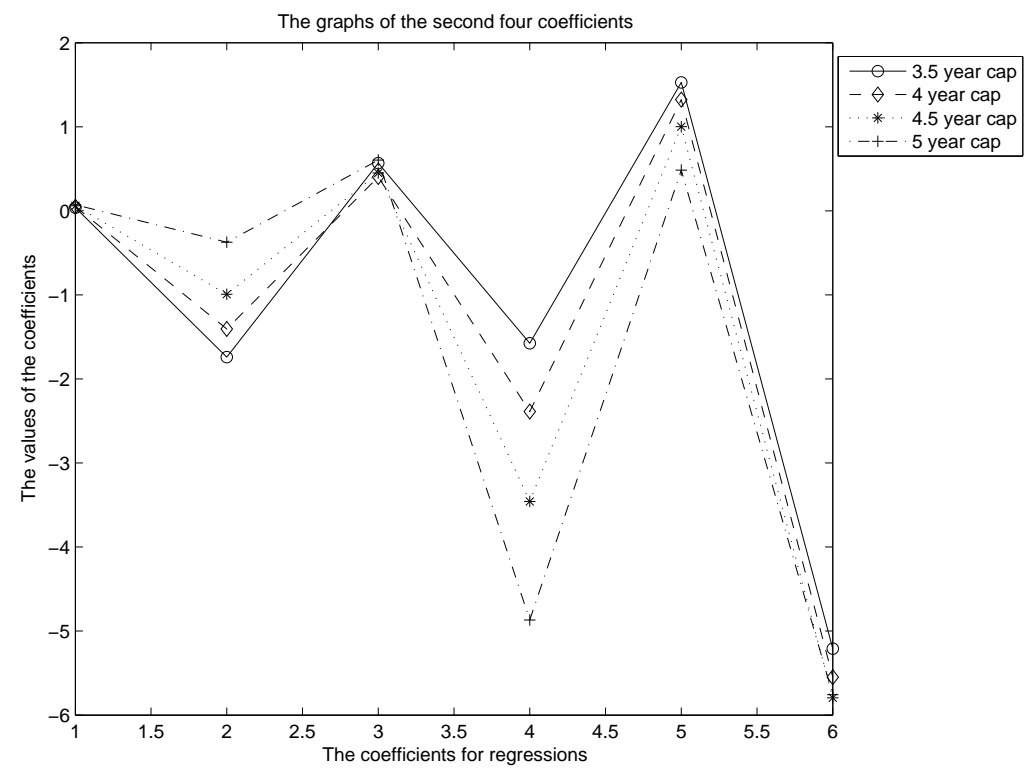

Figure 4.7: The graph of the second four coefficients. The graph of the second four coefficients in the regression $r x_{t+1}^{(n)}=D_{t} \beta^{(n)}+\varepsilon^{(n)}$ of caps term premiums $r x_{t+1}^{(n)}$ with difference caps $D_{t}=$ $\left[1, d_{t}^{(i)}, d_{t}^{(i+1)}, d_{t}^{(i+2)}, \ldots, d_{t}^{(l)}\right]$. The strike rate is 0.04 .

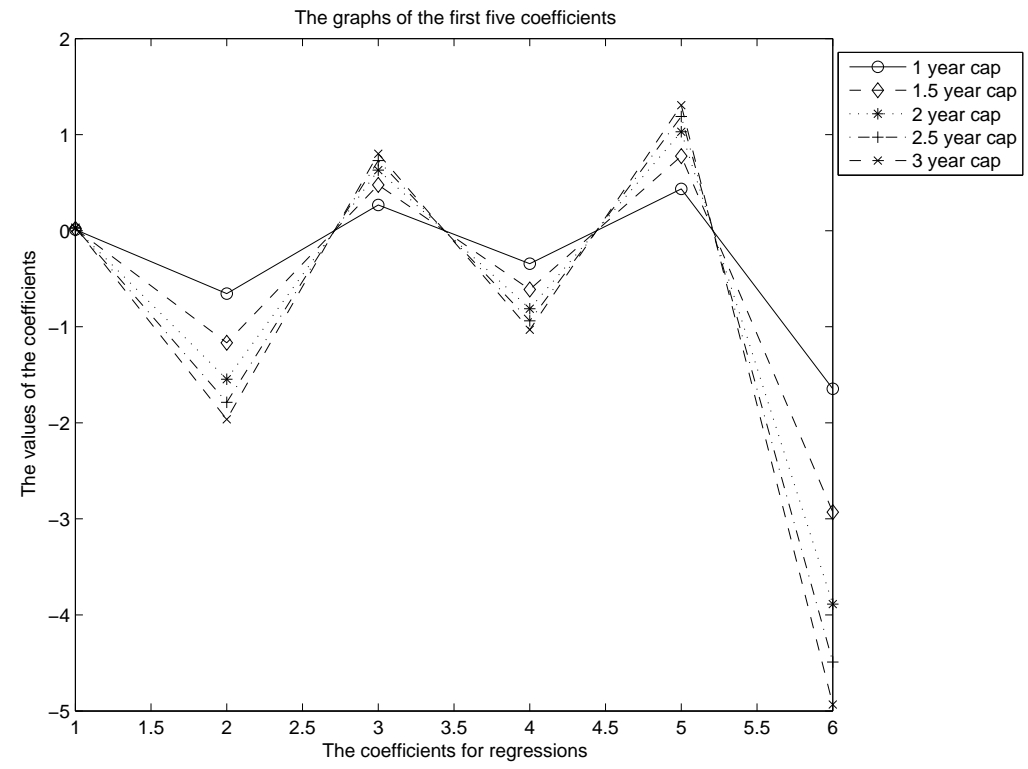

Figure 4.8: The graphs of the first five coefficients of the restricted regressions. The graphs of the first five coefficients of the restricted regressions $r x_{t+1}^{(n)}=b_{n}\left(\gamma_{0}+\gamma_{1} d_{t}^{(1)}+\gamma_{2} d_{t}^{(2)}+\right.$ $\left.\cdots+\gamma_{l} d_{t}^{(l)}\right),(4.3 .3)$. The first five caps term premiums are regressed. The strike rate is 0.04 . 


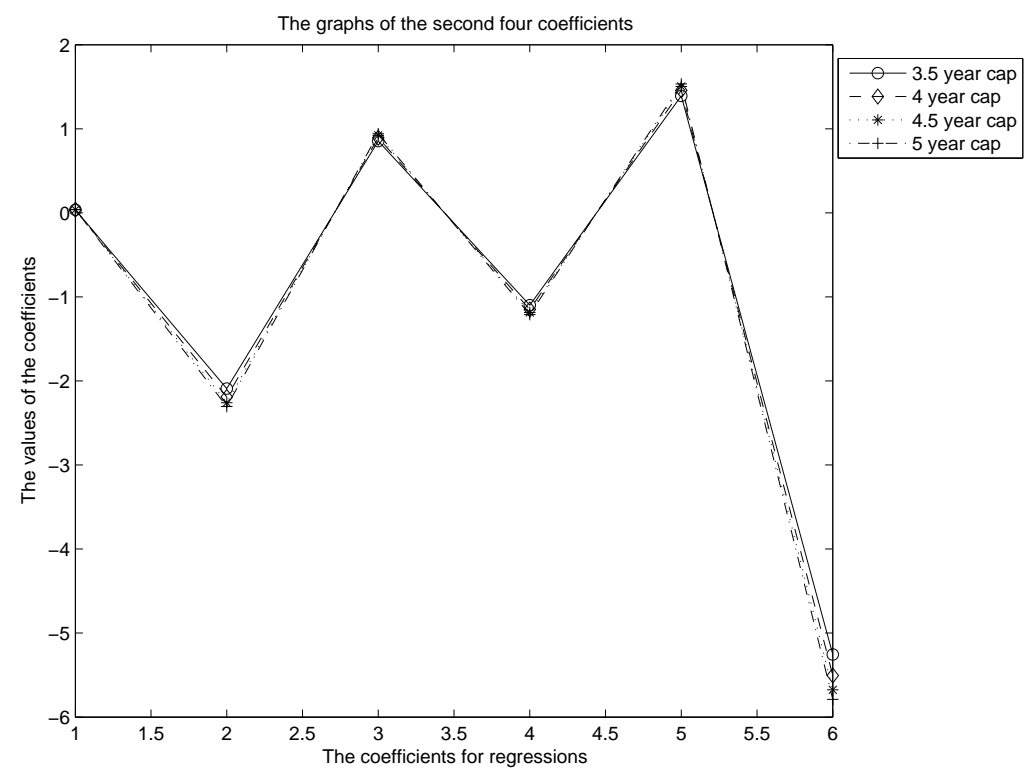

Figure 4.9: The graph of the second four coefficients of the restricted regressions. The graph of the second four coefficients of the restricted regressions $r x_{t+1}^{(n)}=b_{n}\left(\gamma_{0}+\gamma_{1} d_{t}^{(1)}+\gamma_{2} d_{t}^{(2)}+\right.$ $\left.\cdots+\gamma_{l} d_{t}^{(l)}\right)(4.3 .3)$. The strike rate is 0.04 .

\subsubsection{The Other Strike Rates}

In Subsection 4.3.2 the regressions are performed with strike rate 0.04, which represents the low strike rates. In this subsection the regressions with medium and high strike rates are performed. We choose 0.06 and 0.1 as the examples of medium and high strike rates, respectively.

First, the results of the strike rate 0.06 are presented. The graphs of the first five and the last four coefficients are given in Figures 4.10 and 4.11, respectively. The values of R-squared for the unrestricted regressions (4.3.2) are given in 4.5. The coefficients for the regressions on the average of the last five term premiums are given in 4.6. The R-squared and R-bar are given, respectively, by 0.98799 and $0.98747 . b_{n} \mathrm{~s}$ for the restricted regressions are given in Table 4.7. The graphs of the coefficients of the restricted regressions are given in Figures 4.12 and 4.13, respectively.

Next, the results concerning the strike rate 0.1 are summarized. The graphs of the first five and the last four coefficients are given in Figures 4.14 and 4.15, respectively. The values of R-squared for the regressions (4.3.2) are given in 4.8. The coefficients for the regression on the average of the last five term premiums are given in 4.9. The R-squared and R-bar are given, respectively, by 0.79742 and $0.78854 . b_{n}$ s for the restricted regressions are given in 4.10 . The graphs of the coefficients of the restricted regressions (4.3.3) are given in Figures 4.16 and 4.17. 


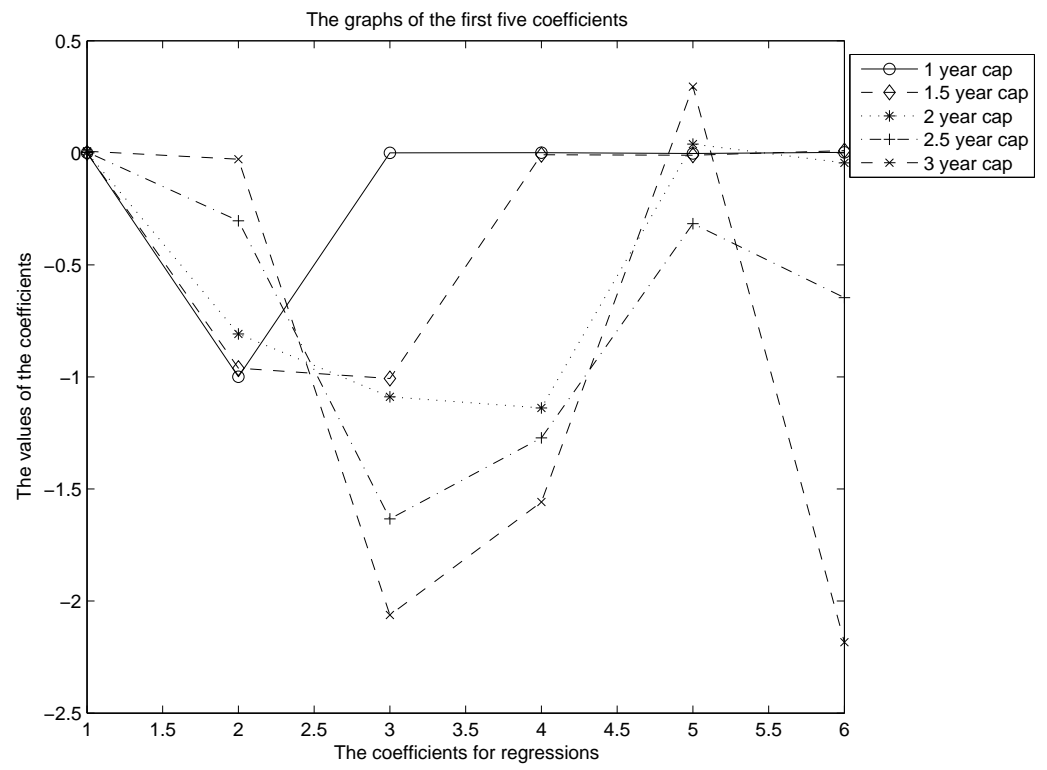

Figure 4.10: The graphs of the first five coefficients with strike rate $\mathbf{0 . 0 6}$. The graphs of the first five coefficients with strike rate 0.06 for the unrestricted regressions $r x_{t+1}^{(n)}=D_{t} \beta^{(n)}+\varepsilon^{(n)}$ of caps term premiums $r x_{t+1}^{(n)}$ with difference caps $D_{t}=\left[1, d_{t}^{(i)}, d_{t}^{(i+1)}, d_{t}^{(i+2)}, \ldots, d_{t}^{(l)}\right]$ are given.

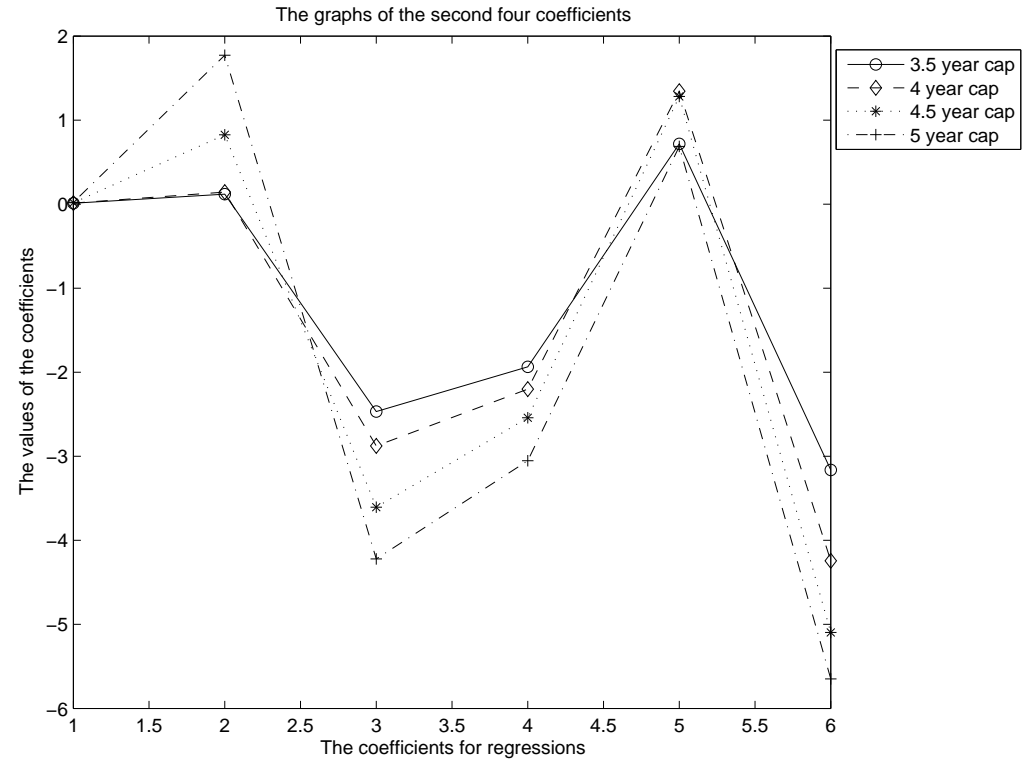

Figure 4.11: The graphs of the last four coefficients with strike rate $\mathbf{0 . 0 6}$. The graphs of the last four coefficients with strike rate 0.06 for the unrestricted regressions $r x_{t+1}^{(n)}=D_{t} \beta^{(n)}+\varepsilon^{(n)}$ of caps term premiums $r x_{t+1}^{(n)}$ with difference caps $D_{t}=\left[1, d_{t}^{(i)}, d_{t}^{(i+1)}, d_{t}^{(i+2)}, \ldots, d_{t}^{(l)}\right]$ are given. 
Table 4.5: The values of $\mathbf{R}$-squared for the unrestricted regressions. The values of $\mathrm{R}$ squared for the unrestricted regressions $r x_{t+1}^{(n)}=D_{t} \beta^{(n)}+\varepsilon^{(n)}$ of caps term premiums $r x_{t+1}^{(n)}$ with difference caps $D_{t}=\left[1, d_{t}^{(i)}, d_{t}^{(i+1)}, d_{t}^{(i+2)}, \ldots, d_{t}^{(l)}\right]$ with strike rate 0.06 are listed.

\begin{tabular}{cccccccccc}
\hline & $\beta^{(2)}$ & $\beta^{(3)}$ & $\beta^{(4)}$ & $\beta^{(5)}$ & $\beta^{(6)}$ & $\beta^{(7)}$ & $\beta^{(8)}$ & $\beta^{(9)}$ & $\beta^{(10)}$ \\
\hline R2 & 1.0 & 1.0 & 1.0 & 1.0 & 0.99 & 0.99 & 0.98 & 0.98 & 0.97 \\
\hline
\end{tabular}

Table 4.6: The values of $\gamma_{i}$. The values of $\gamma_{i}$ and t-statistics for the regression $\overline{r x}_{t+1}=$ $\frac{1}{4} \sum_{n=7}^{10} r x_{t+1}^{(n)}=\gamma_{0}+\gamma_{1} d_{t}^{(1)}+\gamma_{2} d_{t}^{(2)}+\cdots+\gamma_{l} d_{t}^{(l)}(4.3 .4)$ with strike rate 0.06 are listed.

\begin{tabular}{llllll}
\hline$\gamma_{0}$ & $\gamma_{1}$ & $\gamma_{2}$ & $\gamma_{3}$ & $\gamma_{4}$ & $\gamma_{5}$ \\
\hline 0.01 & -0.03 & -2.11 & -1.52 & 0.45 & -2.33 \\
$(12.42)$ & $(-0.08)$ & $(-6.75)$ & $(-5.84)$ & $(0.41)$ & $(-3.37)$ \\
\hline
\end{tabular}

Table 4.7: The values of $b_{n}$. The values of $b_{n}$ in the restricted regression $r x_{t+1}^{(n)}=b_{n}\left(\gamma_{0}+\gamma_{1} d_{t}^{(1)}+\right.$ $\left.\gamma_{2} d_{t}^{(2)}+\cdots+\gamma_{l} d_{t}^{(l)}\right),(4.3 .3)$ are listed.

\begin{tabular}{lllll}
\hline & $b_{7}$ & $b_{8}$ & $b_{9}$ & $b_{10}$ \\
\hline & 1.22 & 1.34 & 1.46 & 1.57 \\
& $(177.81)$ & $(154.5)$ & $(113.63)$ & $(87.57)$ \\
$\mathrm{R} 2$ & 0.98 & 0.98 & 0.97 & 0.95 \\
\hline
\end{tabular}




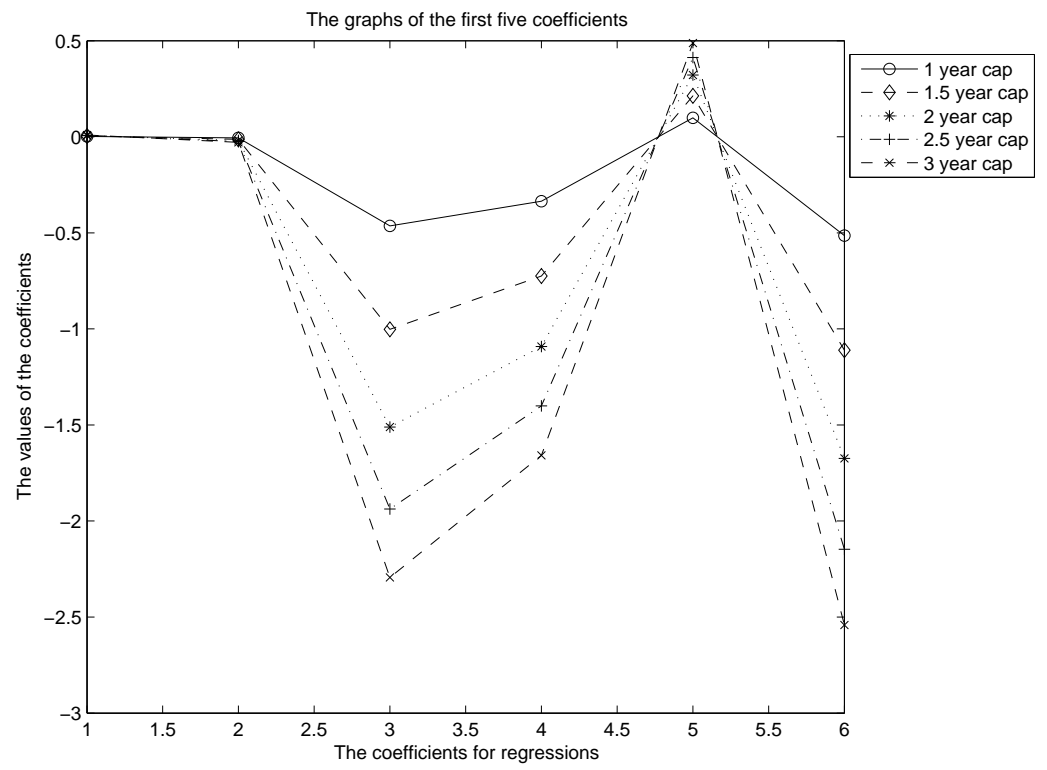

Figure 4.12: The graphs of the first five coefficients. The graphs of the first five coefficients of the restricted regressions $r x_{t+1}^{(n)}=b_{n}\left(\gamma_{0}+\gamma_{1} d_{t}^{(1)}+\gamma_{2} d_{t}^{(2)}+\cdots+\gamma_{l} d_{t}^{(l)}\right)$, (4.3.3) for the strike rate 0.06 are given.

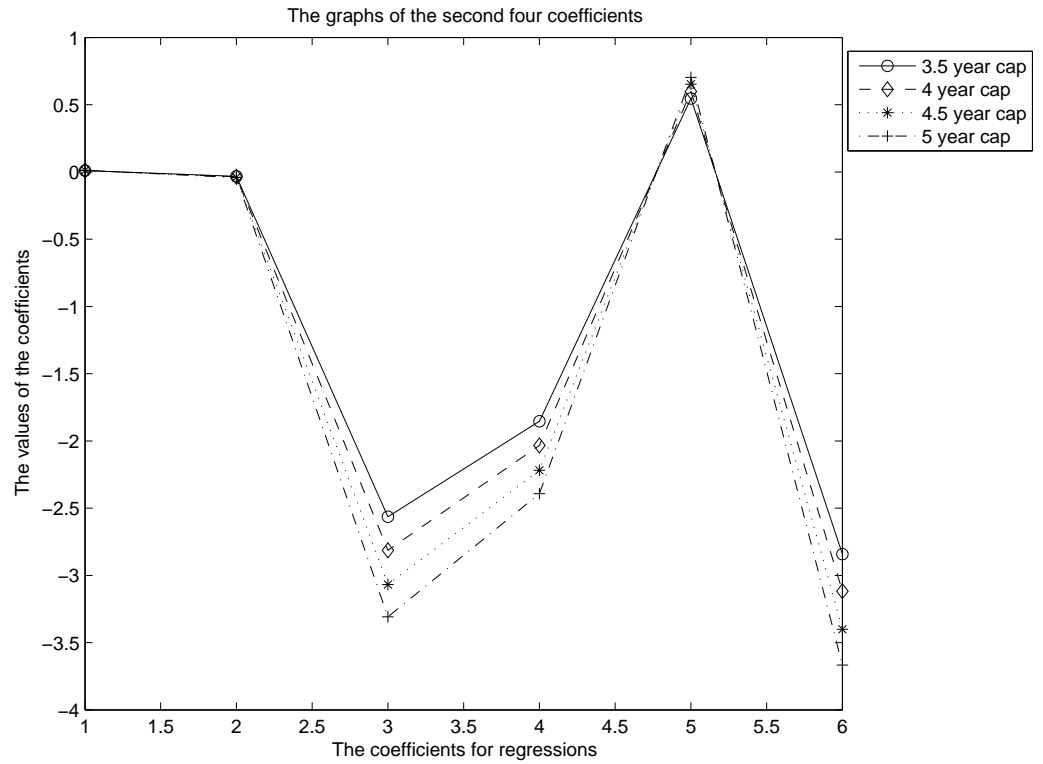

Figure 4.13: The graph of the second four coefficients. The graphs of the second four coefficients of the restricted regressions $r x_{t+1}^{(n)}=b_{n}\left(\gamma_{0}+\gamma_{1} d_{t}^{(1)}+\gamma_{2} d_{t}^{(2)}+\cdots+\gamma_{l} d_{t}^{(l)}\right)$, (4.3.3) for the strike rate 0.06 are given. 


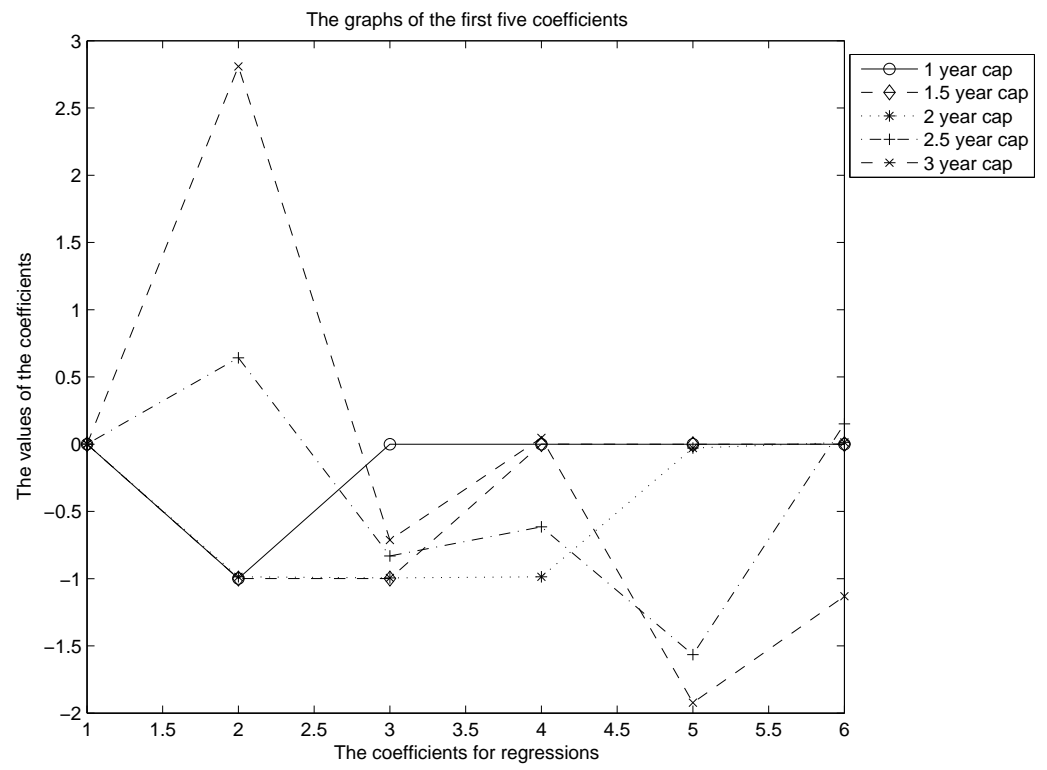

Figure 4.14: The graphs of the first five coefficients with strike rate 0.1 . The graphs of the first five coefficients with strike rate 0.1 for the unrestricted regressions $r x_{t+1}^{(n)}=D_{t} \beta^{(n)}+\varepsilon^{(n)}$ of caps term premiums $r x_{t+1}^{(n)}$ with difference caps $D_{t}=\left[1, d_{t}^{(i)}, d_{t}^{(i+1)}, d_{t}^{(i+2)}, \ldots, d_{t}^{(l)}\right]$ are given.

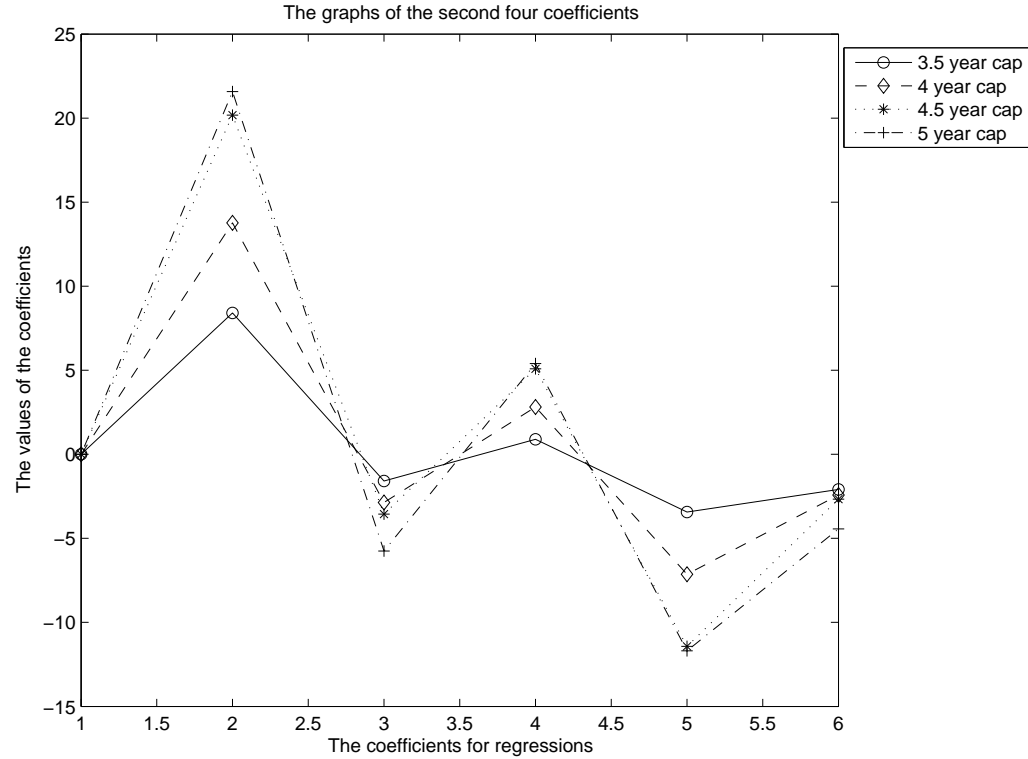

Figure 4.15: The graphs of the last four coefficients with strike rate 0.1 . The graphs of the last four coefficients with strike rate 0.1 for the unrestricted regressions $r x_{t+1}^{(n)}=D_{t} \beta^{(n)}+\varepsilon^{(n)}$ of caps term premiums $r x_{t+1}^{(n)}$ with difference caps $D_{t}=\left[1, d_{t}^{(i)}, d_{t}^{(i+1)}, d_{t}^{(i+2)}, \ldots, d_{t}^{(l)}\right]$ are given. 
Table 4.8: The values of $\mathbf{R}$-squared for the regressions with strike rate $\mathbf{0 . 1}$. The values of R-squared for the unrestricted regressions $r x_{t+1}^{(n)}=D_{t} \beta^{(n)}+\varepsilon^{(n)}$ of caps term premiums $r x_{t+1}^{(n)}$ with difference caps $D_{t}=\left[1, d_{t}^{(i)}, d_{t}^{(i+1)}, d_{t}^{(i+2)}, \ldots, d_{t}^{(l)}\right]$ with strike rate 0.1 are listed.

\begin{tabular}{cccccccccc}
\hline & $\beta^{(2)}$ & $\beta^{(3)}$ & $\beta^{(4)}$ & $\beta^{(5)}$ & $\beta^{(6)}$ & $\beta^{(7)}$ & $\beta^{(8)}$ & $\beta^{(9)}$ & $\beta^{(10)}$ \\
\hline R2 & 1.0 & 1.0 & 1.0 & 0.91 & 0.94 & 0.94 & 0.87 & 0.68 & 0.69 \\
\hline
\end{tabular}

Table 4.9: The values of $\gamma_{i}$. The values of $\gamma_{i}$ in the regression (4.3.4) with strike rate 0.1 are given.

\begin{tabular}{lllllll}
\hline & $\gamma_{0}$ & $\gamma_{1}$ & $\gamma_{2}$ & $\gamma_{3}$ & $\gamma_{4}$ & $\gamma_{5}$ \\
\hline & 0.00 & 7.16 & -1.92 & 1.40 & -4.13 & -1.40 \\
t-statistics & $(8.20)$ & $(1.06)$ & $(-1.87)$ & $(1.47)$ & $(-2.86)$ & $(-2.37)$ \\
\hline
\end{tabular}

Table 4.10: The values of $b_{n}$. The values of $b_{n}$ in the regressions $r x_{t+1}^{(n)}=b_{n}\left(\gamma_{0}+\gamma_{1} d_{t}^{(1)}+\gamma_{2} d_{t}^{(2)}+\right.$ $\left.\cdots+\gamma_{l} d_{t}^{(l)}\right),(4.3 .3)$ with strike rate 0.1 are reported.

\begin{tabular}{lllll}
\hline & $b_{7}$ & $b_{8}$ & $b_{9}$ & $b_{10}$ \\
\hline & 1.14 & 1.614 & 2.14 & 2.72 \\
t-statistics & $(69.81)$ & $(46.39)$ & $(25.35)$ & $(26.31)$ \\
R2 & 0.92 & 0.87 & 0.68 & 0.68 \\
\hline
\end{tabular}




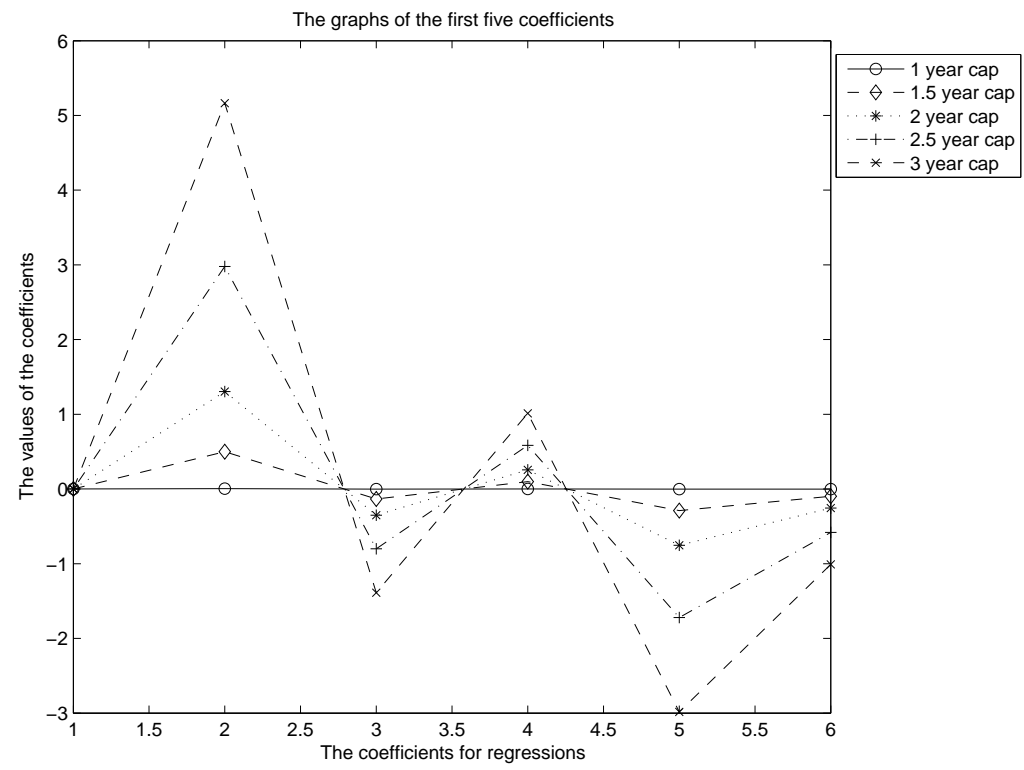

Figure 4.16: The graph of the first five coefficients. The graph of the first five coefficients of the restricted regressions $r x_{t+1}^{(n)}=b_{n}\left(\gamma_{0}+\gamma_{1} d_{t}^{(1)}+\gamma_{2} d_{t}^{(2)}+\cdots+\gamma_{l} d_{t}^{(l)}\right),(4.3 .3)$ for the strike rate 0.1 are reported.

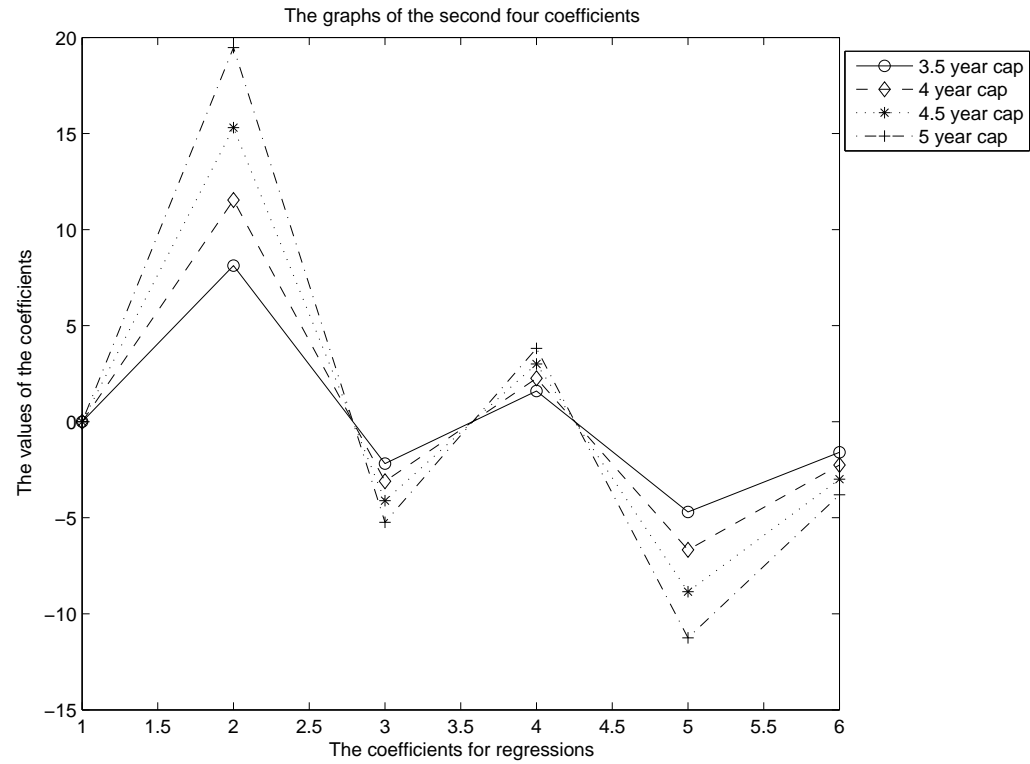

Figure 4.17: The graph of the second four coefficients. The graph of the second four coefficients of the restricted regressions $r x_{t+1}^{(n)}=b_{n}\left(\gamma_{0}+\gamma_{1} d_{t}^{(1)}+\gamma_{2} d_{t}^{(2)}+\cdots+\gamma_{l} d_{t}^{(l)}\right)$, (4.3.3) for the strike rate 0.1 are reported.. 


\subsubsection{Real Time Forecasts and Trading Rule Profits}

Cochrane and Piazzesi [16] (Appendix to "Bond Risk Premia") use $\overline{r x}_{t+1} \times E_{t}\left(\bar{r}_{t+1}\right)$ to define the trading rule profits. Here, $\overline{r x}_{t+1}$ is the average of term premiums given by

$$
\overline{r x}_{t+1}=\frac{1}{9} \sum_{n=1}^{9} r x_{t+1}^{(n)},
$$

where

$$
r x_{t+1}^{(n)}=p_{t+1}^{(n-1)}-p_{t}^{(n)}+p_{t}^{(1)} .
$$

$E_{t}\left(\overline{r x}_{t+1}\right)$ is calculated as follows. First, we regress the average of term premium $\frac{1}{9} \sum_{n=1}^{9} r x_{t+1}^{(n)}$ with the difference caps

$$
\frac{1}{9} \sum_{n=1}^{9} r x_{t+1}^{(n)}=\gamma_{0}+\gamma_{1} d_{t}^{(1)}+\gamma_{2} d_{t}^{(2)}+\cdots+\gamma_{l} d_{t}^{(5)}+\bar{\epsilon}_{t+1}=\gamma^{T} f_{t}+\bar{\epsilon}_{t+1}
$$

to find the coefficients $\gamma$. Then, $E_{t}\left(\overline{r x}_{t+1}\right)$ is computed by

$$
E_{t}\left(\bar{r}_{t+1}\right)=\gamma^{T}\left(\alpha_{0} d_{t}+\alpha_{1} d_{t-1}+\alpha_{2} d_{t-2}\right),
$$

where $\sum \alpha_{i}=1$. The result of $\overline{r x}_{t+1} \times E_{t}\left(\overline{r x}_{t+1}\right)$ with $\alpha_{0}=1$ and $\alpha_{1}=\alpha_{2}=0$ is given in Figure 4.18. Due to the size of data, the other choice such as $\alpha_{1}=1, \alpha_{0}=\alpha_{2}=0$ is difficult to calculate.
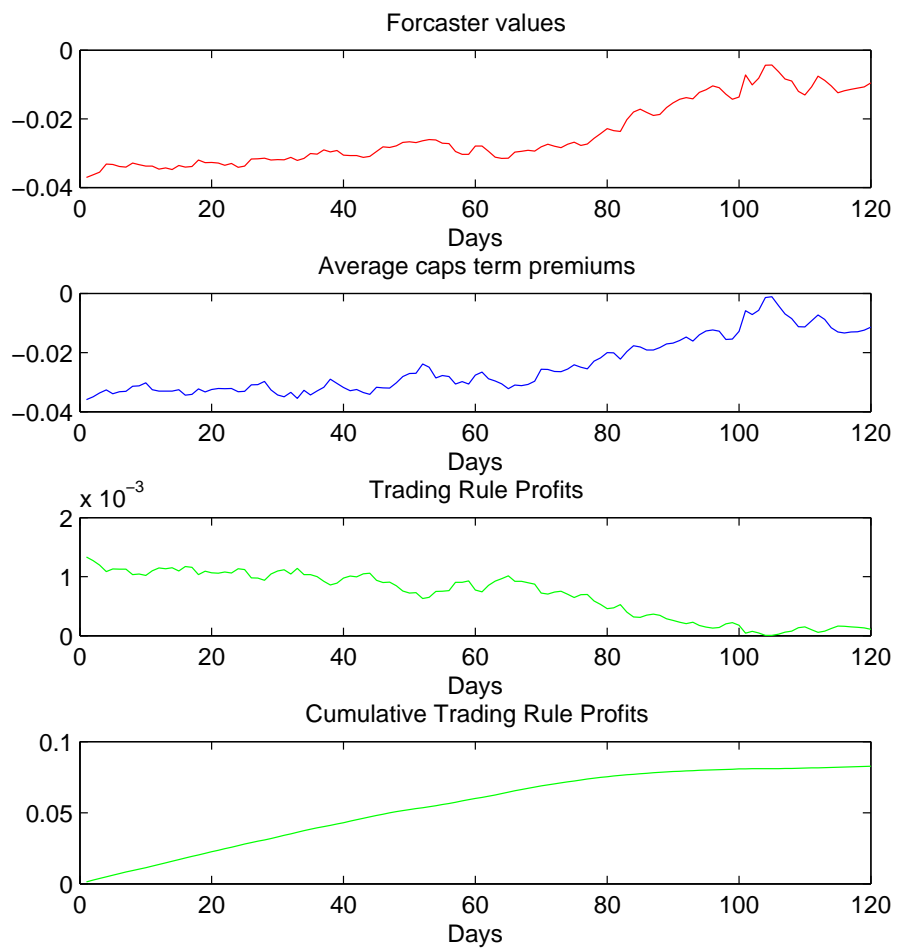

Figure 4.18: The forecaster values. The forecaster values are $\gamma^{T} f_{t}$, the average caps term premiums are $\overline{r x}_{t+1}$, the trading rule profits are $\overline{r x}_{t+1} \times E_{t}\left(\overline{r x}_{t+1}\right)$. 


\subsection{Caps Term Premiums and Unspanned Volatility}

\subsubsection{Granger Causality Tests}

We examine if the unspanned volatility affects the caps term premiums. For this purpose, we do three sets of Granger causality tests.

(1) We use the corresponding implied volatility to the caps term premium and examine if it Granger causes the caps term premium.

(2) We regress the implied volatility with the three principal components of LIBOR to obtain the residuals of the regressions. The residuals can be regarded as a proxy for the unspanned volatility. Using the proxy, we examine if this proxy Granger causes the caps term premium.

(3) We compute the conditional variances of LIBOR for all maturity via GARCH facility and regressing the implied volatility with the three principal components to obtain the residuals. Use them as a proxy for the unspanned volatility to see if this proxy Granger causes the caps term premium.

The purpose of (1) is to compare the Granger causality tests of implied volatility and the proxies for unspanned volatility and see if the proxies for unspanned volatility show some difference in the Granger causality tests. We use the the implied volatility of $m$-year maturity caps to test the caps term premiums of $m$-year maturity with the same strike rates. This result is given in Table 4.11.

In (2) we regress the implied volatility with the three principal components of LIBOR rates to obtain the residuals of the regression. The residuals can be regarded as a proxy for the unspanned volatility. The R-squares of the regressions are given in Table 4.12. We perform the Granger causality tests to see if the unspanned volatility based on LIBOR Granger causes the caps term premium. We use the the unspanned volatility of $m$-year maturity caps to test the caps term premiums of $m$-year maturity with the same strike rates. The result of Granger causality tests are based on the $F$ test and they are given in Table 4.13 .

In (3) we first find the conditional variance for each maturity of LIBOR using GARCH and take the square root to find the volatility based on GARCH. Then, we find the three principal components and use them to regress the implied volatility. The R-squares of the regressions are given in Table 4.14. We take the residuals of the regression as a proxy for the unspanned volatility to see if this proxy Granger causes caps term premiums. The result is shown in Table 4.15.

The results in (2) are much worse than the results in (1) and (3). One explanation could be that R-squares of the regressions of implied volatility with LIBOR are relatively good compared to those of regressions of implied volatility with LIBOR GARCH volatility so that there is not much relevant information left in the residual. Also, it might be that using GARCH may leave out some important dynamics in LIBOR so there are better results for residuals of implied volatility on the principal components on LIBOR GARCH volatility.

Table 4.11: Implied volatility Granger causes caps term premiums. Table reports that the implied volatility Granger causes caps term premiums. The bold letters show that it is significant with the $90 \%$ F-tests.

\begin{tabular}{lrrlrrrrrrr}
\multicolumn{10}{c}{ Implied volatility Granger causes caps term premiums } \\
\hline $\begin{array}{l}\text { Strike rates } \\
\text { Maturity }\end{array}$ & 0.040 & 0.045 & 0.050 & 0.055 & 0.060 & 0.065 & 0.070 & 0.080 & 0.090 & 0.100 \\
\hline 2.0 & & & & & & & & & & \\
2.5 & NaN & $\mathbf{1 0 . 5 5}$ & $\mathbf{1 1 . 9 8}$ & $\mathbf{8 . 6 4}$ & $\mathbf{8 . 2 7}$ & $\mathbf{9 . 7 5}$ & $\mathbf{1 0 . 5 2}$ & NaN & NaN & NaN \\
3.0 & $\mathbf{6 . 8 6}$ & $\mathbf{1 5 . 5 2}$ & $\mathbf{1 3 . 3 1}$ & $\mathbf{7 . 0 2}$ & $\mathbf{4 . 6 8}$ & $\mathbf{6 . 8 4}$ & $\mathbf{1 2 . 1 6}$ & $\mathbf{1 6 . 6}$ & 1.03 & $\mathrm{NaN}$ \\
3.5 & $\mathbf{3 7 . 2 7}$ & $\mathbf{5 5 . 4 4}$ & $\mathbf{3 0 . 8 4}$ & $\mathbf{8 . 8 2}$ & $\mathbf{4 . 3 9}$ & $\mathbf{4 . 2 3}$ & $\mathbf{4 . 8 9}$ & $\mathbf{1 8 . 3 7}$ & $\mathbf{3 . 1 2}$ & 1.26 \\
4.0 & $\mathbf{3 . 7 1}$ & $\mathbf{1 5 . 7 3}$ & $\mathbf{4 1 . 5 1}$ & $\mathbf{9 . 7 3}$ & $\mathbf{7 . 0 3}$ & $\mathbf{7 . 4 4}$ & $\mathbf{9 . 1 4}$ & $\mathbf{6 . 2 4}$ & $\mathbf{2 . 0 4}$ & 0.29 \\
4.5 & $\mathbf{1 3 . 7 5}$ & $\mathbf{2 4 . 9 3}$ & $\mathbf{3 8 . 7 6}$ & $\mathbf{1 3 . 4 8}$ & $\mathbf{6 . 3 3}$ & $\mathbf{1 0 . 5 5}$ & $\mathbf{1 1 . 2 3}$ & $\mathbf{4 . 5 6}$ & 1.24 & 0.06 \\
5.0 & $\mathbf{3 7 . 4 9}$ & $\mathbf{3 8 . 1 5}$ & $\mathbf{2 0 . 2 2}$ & $\mathbf{1 9 . 9 3}$ & $\mathbf{9 . 2}$ & $\mathbf{1 0 . 5}$ & $\mathbf{1 3 . 4 9}$ & $\mathbf{1 0 . 4 9}$ & $\mathbf{5 . 7 4}$ & $\mathbf{3 . 0 1}$ \\
& $\mathbf{2 3 . 7 5}$ & $\mathbf{2 9 . 6}$ & $\mathbf{2 5 . 5 5}$ & $\mathbf{2 4 . 6 3}$ & $\mathbf{7 . 1 1}$ & $\mathbf{1 8 . 9 4}$ & $\mathbf{1 8 . 2 6}$ & $\mathbf{1 1 . 4 5}$ & $\mathbf{8 . 6 5}$ & $\mathbf{4 . 6 7}$ \\
\hline
\end{tabular}


Table 4.12: R-square of the regressions of implied volatility with the LIBOR rates. The R-squared of the regressions of implied volatility of difference caps with the LIBOR rates are given. The residuals of regressions are a proxy of unspanned volatility.

\begin{tabular}{|c|c|c|c|c|c|c|c|c|c|c|}
\hline \multicolumn{11}{|c|}{$\begin{array}{l}\text { R-square of regressions of implied volatilities with } \\
\text { three principal components of LIBOR }\end{array}$} \\
\hline $\begin{array}{l}\text { Strike Rates } \\
\text { Maturity }\end{array}$ & 0.040 & 0.045 & 0.050 & 0.055 & 0.060 & 0.065 & 0.070 & 0.080 & 0.090 & 0.100 \\
\hline 2.0 & $\mathrm{NaN}$ & 0.203 & 0.342 & 0.573 & 0.666 & 0.764 & 0.775 & $\mathrm{NaN}$ & $\mathrm{NaN}$ & $\mathrm{NaN}$ \\
\hline 2.5 & 0.043 & 0.093 & 0.397 & 0.587 & 0.640 & 0.718 & 0.694 & 0.752 & 0.626 & $\mathrm{NaN}$ \\
\hline 3.0 & 0.220 & 0.293 & 0.699 & 0.756 & 0.710 & 0.664 & 0.469 & 0.646 & 0.626 & 0.586 \\
\hline 3.5 & 0.128 & 0.352 & 0.487 & 0.742 & 0.747 & 0.787 & 0.801 & 0.729 & 0.573 & 0.539 \\
\hline 4.0 & 0.234 & 0.482 & 0.543 & 0.763 & 0.704 & 0.800 & 0.797 & 0.691 & 0.533 & 0.506 \\
\hline 4.5 & 0.291 & 0.376 & 0.569 & 0.510 & 0.352 & 0.627 & 0.773 & 0.741 & 0.691 & 0.642 \\
\hline 5.0 & 0.280 & 0.421 & 0.536 & 0.417 & 0.273 & 0.551 & 0.753 & 0.715 & 0.678 & 0.646 \\
\hline 6.0 & 0.243 & $\mathrm{NaN}$ & $\mathrm{NaN}$ & $\mathrm{NaN}$ & 0.765 & $\mathrm{NaN}$ & 0.669 & 0.701 & 0.580 & 0.492 \\
\hline 7.0 & 0.590 & 0.557 & $\mathrm{NaN}$ & $\mathrm{NaN}$ & 0.552 & $\mathrm{NaN}$ & 0.488 & 0.521 & 0.432 & 0.249 \\
\hline 8.0 & 0.505 & 0.627 & 0.689 & 0.785 & 0.867 & $\mathrm{NaN}$ & 0.827 & 0.543 & 0.791 & 0.780 \\
\hline 9.0 & 0.446 & 0.630 & 0.676 & 0.711 & $\mathrm{NaN}$ & $\mathrm{NaN}$ & $\mathrm{NaN}$ & 0.800 & 0.819 & 0.793 \\
\hline 10.0 & 0.375 & 0.470 & 0.491 & 0.681 & $\mathrm{NaN}$ & $\mathrm{NaN}$ & $\mathrm{NaN}$ & 0.784 & 0.679 & 0.820 \\
\hline
\end{tabular}

Table 4.13: Unspanned volatility Granger causes caps term premium. Table reports that the proxy based on LIBOR for unspanned volatility Granger causes caps term premiums. The bold letters show that it is significant with the $90 \%$ F-tests.

\begin{tabular}{lrrrrrrrrrrr} 
& \multicolumn{10}{c}{ LIBOR based unspanned volatility Granger causes caps term premiums } \\
\hline $\begin{array}{l}\text { Strike rates } \\
\text { Maturity }\end{array}$ & 0.040 & 0.045 & 0.050 & 0.055 & 0.060 & 0.065 & 0.070 & 0.080 & 0.090 & 0.100 \\
\hline 2.0 & $\mathrm{NaN}$ & 0.43 & 0.07 & 0.07 & 0 & 0 & 0.2 & $\mathrm{NaN}$ & $\mathrm{NaN}$ & $\mathrm{NaN}$ \\
2.5 & 0.73 & 0.03 & 0 & 0 & 0 & 0.01 & 0.02 & 0.01 & 1.11 & $\mathrm{NaN}$ \\
3.0 & 0.09 & 0.24 & 0.01 & 0 & 0 & 0 & 0.03 & 0.02 & 0.41 & 1.18 \\
3.5 & 0.06 & 0.01 & 0 & 0.02 & 0.05 & 0 & 0.1 & 0.19 & 0 & 1.01 \\
4.0 & 0.04 & 0 & 0.01 & 0 & 0.09 & 0 & 0.05 & 0.01 & 0.31 & 1 \\
4.5 & 0.39 & 0.52 & 0.31 & 0.23 & 0.02 & 0.01 & 0.06 & 0.02 & 0.12 & 0.85 \\
5.0 & 0.13 & 0.45 & 0.81 & 0.49 & 0.02 & 0.05 & 0.1 & 0.02 & 0 & 0.4 \\
\hline
\end{tabular}


Table 4.14: R-squares of the regressions of implied volatility with the GARCH based volatility. The R-squares of the regressions of implied volatility of difference caps with the GARCH based volatility are given. The residuals of regressions are a proxy of unspanned volatility.

\begin{tabular}{|c|c|c|c|c|c|c|c|c|c|c|}
\hline $\begin{array}{l}\text { Strike Rates } \\
\text { Maturity }\end{array}$ & 0.040 & 0.045 & 0.050 & 0.055 & 0.060 & 0.065 & 0.070 & 0.080 & 0.090 & 0.100 \\
\hline 2.0 & $\mathrm{NaN}$ & 0.492 & 0.567 & 0.714 & 0.645 & 0.519 & 0.425 & $\mathrm{NaN}$ & $\mathrm{NaN}$ & $\mathrm{NaN}$ \\
\hline 2.5 & 0.194 & 0.255 & 0.571 & 0.693 & 0.722 & 0.662 & 0.525 & 0.475 & 0.418 & $\mathrm{NaN}$ \\
\hline 3.0 & 0.213 & 0.239 & 0.581 & 0.689 & 0.698 & 0.594 & 0.357 & 0.459 & 0.432 & 0.402 \\
\hline 3.5 & 0.086 & 0.214 & 0.253 & 0.497 & 0.435 & 0.484 & 0.371 & 0.349 & 0.318 & 0.331 \\
\hline 4.0 & 0.127 & 0.216 & 0.220 & 0.428 & 0.340 & 0.416 & 0.320 & 0.300 & 0.262 & 0.287 \\
\hline 4.5 & 0.170 & 0.262 & 0.462 & 0.420 & 0.412 & 0.568 & 0.527 & 0.453 & 0.404 & 0.375 \\
\hline 5.0 & 0.129 & 0.255 & 0.379 & 0.291 & 0.254 & 0.480 & 0.509 & 0.449 & 0.412 & 0.380 \\
\hline 6.0 & 0.324 & $\mathrm{NaN}$ & $\mathrm{NaN}$ & $\mathrm{NaN}$ & 0.527 & $\mathrm{NaN}$ & 0.380 & 0.378 & 0.325 & 0.311 \\
\hline 7.0 & 0.392 & 0.399 & $\mathrm{NaN}$ & $\mathrm{NaN}$ & 0.278 & $\mathrm{NaN}$ & 0.185 & 0.199 & 0.148 & 0.069 \\
\hline 8.0 & 0.488 & 0.556 & 0.580 & 0.553 & 0.519 & $\mathrm{NaN}$ & 0.442 & 0.296 & 0.364 & 0.334 \\
\hline 9.0 & 0.377 & 0.558 & 0.608 & 0.542 & $\mathrm{NaN}$ & $\mathrm{NaN}$ & $\mathrm{NaN}$ & 0.401 & 0.377 & 0.365 \\
\hline 10.0 & 0.430 & 0.561 & 0.617 & 0.573 & $\mathrm{NaN}$ & $\mathrm{NaN}$ & $\mathrm{NaN}$ & 0.482 & 0.414 & 0.436 \\
\hline
\end{tabular}

Table 4.15: GARCH based Unspanned volatility Granger causes caps term premium. Table reports that the proxy based on GARCH conditional volatility for unspanned volatility Granger causes caps term premiums. The bold letters show that it is significant with the $90 \%$ F-tests. The GARCH conditional volatility is created from LIBOR bonds by

\begin{tabular}{lrrrrrrrrrr}
\multicolumn{10}{c}{ GARCH based unspanned volatility Granger causes caps term premiums } \\
$\begin{array}{l}\text { Strike rates } \\
\text { Maturity }\end{array}$ & 0.040 & 0.045 & 0.050 & 0.055 & 0.060 & 0.065 & 0.070 & 0.080 & 0.090 & 0.100 \\
\hline 2.0 & & & & & & & & & & \\
2.5 & NaN & NaN & NaN & $\mathbf{2 . 7 3}$ & $\mathbf{1 4 . 2 3}$ & $\mathbf{1 3 . 6 6}$ & $\mathbf{4 . 5 6}$ & $\mathbf{3 3 . 5 5}$ & NaN & NaN \\
3.0 & NaN & 0.65 & 0 & $\mathbf{1 . 9 5}$ & $\mathbf{3 . 8 6}$ & $\mathbf{6 . 8}$ & $\mathbf{6 . 3 8}$ & $\mathbf{9 . 3 7}$ & $\mathbf{3 . 3 3}$ & NaN \\
3.5 & $\mathbf{2 . 3 8}$ & 0.92 & 0.62 & $\mathbf{1 . 9 6}$ & $\mathbf{2 . 8 8}$ & $\mathbf{6 . 1 1}$ & $\mathbf{5 . 1 3}$ & $\mathbf{1 0 . 3 6}$ & $\mathbf{3 . 7 1}$ & 0.04 \\
4.0 & 0.91 & $\mathbf{3 . 6 7}$ & $\mathbf{5 . 0 8}$ & $\mathbf{3 . 4 3}$ & $\mathbf{2 . 8 6}$ & $\mathbf{2 . 1 4}$ & 0.72 & $\mathbf{7 . 1 9}$ & $\mathbf{5 . 8 1}$ & 1.18 \\
4.5 & 0.28 & $\mathbf{3 . 8 3}$ & $\mathbf{9 . 9 8}$ & $\mathbf{7 . 8}$ & $\mathbf{3 . 4 9}$ & $\mathbf{6 . 3 8}$ & $\mathbf{8 . 9 2}$ & $\mathbf{8 . 4 1}$ & $\mathbf{5 . 6 9}$ & $\mathbf{2 . 6 7}$ \\
5.0 & $\mathbf{3 . 6 8}$ & $\mathbf{7 . 4 5}$ & $\mathbf{1 1 . 3 4}$ & $\mathbf{7 . 7 9}$ & $\mathbf{2 . 1}$ & $\mathbf{6 . 7 9}$ & $\mathbf{9 . 9 5}$ & $\mathbf{6 . 0 6}$ & $\mathbf{2 . 5 4}$ & 0.88 \\
& $\mathbf{7 . 7 5}$ & $\mathbf{9 . 6 2}$ & $\mathbf{7 . 8 3}$ & $\mathbf{6 . 7 2}$ & 0.88 & $\mathbf{5 . 6 9}$ & $\mathbf{9 . 0 2}$ & $\mathbf{6 . 6}$ & $\mathbf{5 . 1 6}$ & $\mathbf{2 . 7 2}$ \\
\hline
\end{tabular}

\subsubsection{Caps Term Premiums and Volatility - An Investment Implication}

In the previous subsection, we examined if the three volatilities, i.e. the LIBOR based UV, GARCH based UV, and the implied volatility, Granger cause the caps term premiums. An investor may wish to see if these volatilities can be useful in constructing the portfolio of caps based on caps term premiums. For each maturity and strike rate we have time series of volatility and caps term premium with up to 122 components. For each maturity and strike rate, we take 20 highest and lowest volatility components and caps term premiums in the time series and examine how many of highest or lowest volatilities match with the 20 highest or lowest caps term premiums. The number 20 is somewhat ad hock, but it is a reasonable number of samples. In Table 4.16 the number of matches between the 20 highest GARCH based unspanned volatilities and 20 highest caps term premiums is listed. In Tables 4.17, 4.18, and 4.19 similar results are reported. An interesting observation is that for 1 and 1.5 year maturity caps term premiums we see more matches in high unspanned volatility with low caps term premiums and in low unspanned volatility with high caps term premiums. For 2.5 and 3 year maturity caps term premiums we see more matches in high unspanned volatility with high caps term premiums and in low unspanned volatility with low caps term premiums. 
We also examine the same statistics with the LIBOR based unspanned volatility. The results are listed in Tables 4.20, 4.21, 4.22, and 4.23. For the lower maturity caps term premiums, the agreement of 20 highest implied volatilities and 20 highest caps term premiums, and that of 20 lowest implied volatilities and 20 lowest caps term premiums are very good. On the other hand for the higher maturity caps term premiums, matches are not good.

For the sake of comparison we also examine the same statistics with the implied volatility. The results are listed in Tables 4.24, 4.25, 4.26, and 4.27.

Among the three volatilities LIBOR based unspanned volatility has an interesting relation with the caps term premiums. We observe that the matching of 20 highest and lowest short maturity caps term premiums with 20 highest and lowest LIBOR based unspanned volatility are very good. If the fact that the caps term premiums are negative in the data period can be extrapolated to other period, one way to use the LIBOR based unspanned volatility would be the following. On the days when the LIBOR based unspanned volatility are low compared to the its historical data, we sell short the one year or one and half a year caps and use the proceed to purchase the same units of half year caps with the same strike rate and put the rest in an interest bearing account. Then after a half year we buy back the shorted caps using the money from the interest bearing account. As the data period is rather short, the more test should be performed.

Table 4.16: Match between the 20 highest GARCH based unspanned volatilities and the 20 highest caps term premiums. The table reports the number of the times the 20 highest GARCH based unspanned volatilities matches the 20 highest caps term premiums.

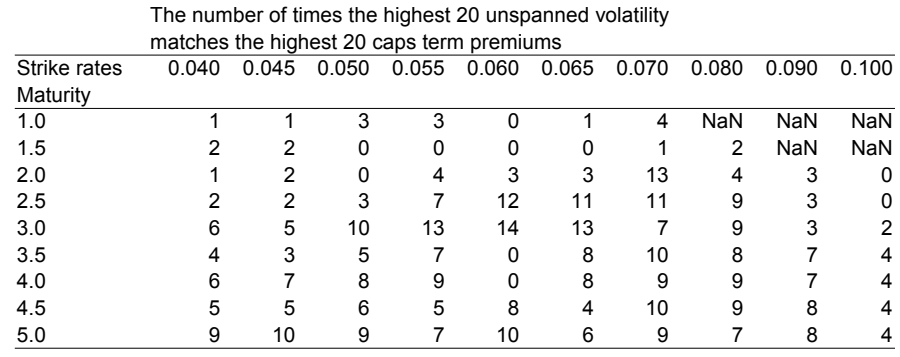

Table 4.17: Match between the 20 highest GARCH based unspanned volatilities and the 20 lowest caps term premiums. The table reports the number of the times the 20 highest GARCH based unspanned volatilities matches the 20 lowest caps term premiums.

\begin{tabular}{lrrrrrrrrrrr} 
The number of times the highest 20 unspanned volatility \\
matches the lowest 20 caps term premiums \\
$\begin{array}{lrrrrrrrrrrr}\text { Strike rates } \\
\text { Maturity }\end{array}$ & 0.040 & 0.045 & 0.050 & 0.055 & 0.060 & 0.065 & 0.070 & 0.080 & 0.090 & 0.100 \\
\hline 1.0 & 7 & 11 & 13 & 11 & 8 & 4 & 8 & NaN & NaN & NaN \\
1.5 & 5 & 12 & 17 & 17 & 15 & 11 & 4 & 4 & NaN & NaN \\
2.0 & 10 & 8 & 5 & 2 & 0 & 0 & 0 & 3 & 8 & 13 \\
2.5 & 7 & 5 & 3 & 1 & 0 & 0 & 0 & 0 & 2 & 8 \\
3.0 & 7 & 4 & 1 & 0 & 0 & 0 & 1 & 0 & 1 & 1 \\
3.5 & 3 & 0 & 0 & 0 & 0 & 0 & 0 & 0 & 2 & 6 \\
4.0 & 1 & 0 & 0 & 0 & 0 & 0 & 0 & 0 & 4 & 10 \\
4.5 & 2 & 0 & 0 & 0 & 0 & 0 & 0 & 0 & 1 & 3 \\
5.0 & 1 & 0 & 0 & 0 & 1 & 1 & 1 & 1 & 2 & 3 \\
\hline
\end{tabular}


Table 4.18: Match between the 20 lowest GARCH based unspanned volatilities and the 20 highest caps term premiums. The table reports the number of the times the 20 lowest GARCH based unspanned volatilities matches the 20 highest caps term premiums.

\begin{tabular}{lrrrrrrrrrrr}
\multicolumn{1}{l}{ The number of times the lowest 20 unspanned volatility } \\
matches the highest 20 caps term premiums \\
$\begin{array}{lrrrrrrrr}\text { Strike rates } \\
\text { Maturity }\end{array}$ & 0.040 & 0.045 & 0.050 & 0.055 & 0.060 & 0.065 & 0.070 & 0.080 & 0.090 & 0.100 \\
\hline 1.0 & 1 & 3 & 0 & 4 & 5 & 2 & 3 & NaN & NaN & NaN \\
1.5 & 14 & 14 & 11 & 3 & 8 & 10 & 12 & 6 & NaN & NaN \\
2.0 & 6 & 6 & 3 & 7 & 6 & 5 & 1 & 6 & 10 & 7 \\
2.5 & 1 & 4 & 5 & 4 & 4 & 4 & 4 & 3 & 4 & 6 \\
3.0 & 1 & 2 & 2 & 4 & 3 & 3 & 3 & 3 & 4 & 3 \\
3.5 & 2 & 2 & 2 & 2 & 2 & 2 & 2 & 2 & 1 & 1 \\
4.0 & 1 & 2 & 2 & 2 & 1 & 2 & 2 & 1 & 2 & 2 \\
4.5 & 2 & 2 & 2 & 3 & 5 & 4 & 2 & 3 & 1 & 1 \\
5.0 & 1 & 1 & 1 & 3 & 5 & 4 & 2 & 3 & 2 & 2 \\
\hline
\end{tabular}

Table 4.19: Match between the 20 lowest GARCH based unspanned volatilities and the 20 lowest caps term premiums. The table reports the number of the times the 20 lowest GARCH based unspanned volatilities matches the 20 lowest caps term premiums.

\begin{tabular}{lrlrrrrrrrrr}
\multicolumn{1}{l}{$\begin{array}{l}\text { The number of times the lowest } 20 \text { unspanned volatility } \\
\text { matches the lowest 20 caps term premiums }\end{array}$} \\
$\begin{array}{l}\text { Strike rates } \\
\text { Maturity }\end{array}$ & 0.040 & 0.045 & 0.050 & 0.055 & 0.060 & 0.065 & 0.070 & 0.080 & 0.090 & 0.100 \\
\hline 1.0 & 1 & 1 & 1 & 1 & 0 & 10 & 4 & NaN & NaN & NaN \\
1.5 & 1 & 1 & 1 & 1 & 1 & 2 & 0 & 0 & NaN & NaN \\
2.0 & 1 & 2 & 2 & 4 & 6 & 3 & 2 & 8 & 4 & 1 \\
2.5 & 0 & 1 & 3 & 2 & 3 & 3 & 1 & 4 & 5 & 6 \\
3.0 & 1 & 4 & 8 & 7 & 5 & 3 & 2 & 3 & 4 & 5 \\
3.5 & 2 & 4 & 6 & 5 & 4 & 4 & 6 & 3 & 2 & 4 \\
4.0 & 3 & 5 & 5 & 7 & 4 & 6 & 7 & 4 & 3 & 2 \\
4.5 & 4 & 5 & 4 & 5 & 4 & 2 & 3 & 4 & 2 & 1 \\
5.0 & 4 & 5 & 5 & 4 & 3 & 1 & 3 & 4 & 3 & 3 \\
\hline
\end{tabular}

Table 4.20: Match between the 20 highest LIBOR based unspanned volatilities and the 20 highest caps term premiums. The table reports the number of the times the 20 highest LIBOR based unspanned volatilities matches the 20 highest caps term premiums.

\begin{tabular}{lrrrrrrrrrr} 
The number of times the 20 highest LIBOR unspanned volatilities \\
matches the 20 highest caps term premiums \\
$\begin{array}{l}\text { Strike rates } \\
\text { Maturity }\end{array}$ & 0.040 & 0.045 & 0.050 & 0.055 & 0.060 & 0.065 & 0.070 & 0.080 & 0.090 & 0.100 \\
\hline 1.0 & 4 & 11 & 16 & 17 & 17 & 17 & 17 & 19 & 2 & 0 \\
1.5 & 4 & 12 & 17 & 17 & 1 & 17 & 17 & 16 & 1 & 0 \\
2.0 & 5 & 2 & 0 & 0 & 0 & 0 & 2 & 17 & 8 & 0 \\
2.5 & 2 & 1 & 0 & 0 & 0 & 0 & 3 & 0 & 0 & 0 \\
3.0 & 1 & 4 & 3 & 1 & 0 & 0 & 7 & 0 & 0 & 0 \\
3.5 & 3 & 3 & 1 & 1 & 0 & 0 & 0 & 3 & 1 & 0 \\
4.0 & 4 & 3 & 1 & 1 & 0 & 0 & 4 & 5 & 1 & 0 \\
4.5 & 4 & 4 & 4 & 3 & 3 & 2 & 1 & 2 & 1 & 0 \\
5.0 & 6 & 6 & 4 & 4 & 5 & 4 & 2 & 2 & 1 & 0 \\
\hline
\end{tabular}


Table 4.21: Match between the 20 highest LIBOR based unspanned volatilities and the 20 lowest caps term premiums. The table reports the number of the times the 20 highest LIBOR based unspanned volatilities matches the 20 lowest caps term premiums.

\begin{tabular}{lrrrrrrrrrr} 
The number of times the 20 highest LIBOR unspanned volatilities \\
matches the 20 lowest caps term premiums \\
$\begin{array}{l}\text { Strike rates } \\
\text { Maturity }\end{array}$ & 0.040 & 0.045 & 0.050 & 0.055 & 0.060 & 0.065 & 0.070 & 0.080 & 0.090 & 0.100 \\
\hline 1.0 & 0 & 0 & 0 & 0 & 0 & 0 & 0 & 0 & 0 & 0 \\
1.5 & 0 & 0 & 0 & 0 & 4 & 0 & 0 & 0 & 0 & 0 \\
2.0 & 0 & 6 & 6 & 8 & 6 & 3 & 4 & 0 & 0 & 0 \\
2.5 & 8 & 9 & 9 & 9 & 11 & 8 & 5 & 3 & 7 & 0 \\
3.0 & 10 & 10 & 9 & 10 & 8 & 2 & 4 & 1 & 6 & 8 \\
3.5 & 5 & 5 & 5 & 6 & 4 & 4 & 2 & 3 & 6 & 13 \\
4.0 & 3 & 2 & 1 & 1 & 1 & 2 & 2 & 1 & 7 & 13 \\
4.5 & 4 & 3 & 3 & 2 & 4 & 6 & 2 & 1 & 5 & 10 \\
5.0 & 3 & 1 & 0 & 0 & 1 & 5 & 1 & 2 & 7 & 10 \\
\hline
\end{tabular}

Table 4.22: Match between the 20 lowest LIBOR based unspanned volatilities and the 20 highest caps term premiums. The table reports the number of the times the 20 lowest LIBOR based unspanned volatilities matches the 20 highest caps term premiums.

\begin{tabular}{lrlrlrrrrrrr} 
The number of times the 20 lowest LIBOR unspanned volatilities \\
matches the 20 highest caps term premiums \\
$\begin{array}{l}\text { Strike rates } \\
\text { Maturity }\end{array}$ & 0.040 & 0.045 & 0.050 & 0.055 & 0.060 & 0.065 & 0.070 & 0.080 & 0.090 & 0.100 \\
\hline 1.0 & 0 & 0 & 0 & 0 & 0 & 0 & 0 & 0 & 0 & 0 \\
1.5 & 0 & 0 & 0 & 0 & 1 & 0 & 0 & 0 & 0 & 0 \\
2.0 & 0 & 0 & 0 & 2 & 4 & 6 & 7 & 0 & 0 & 2 \\
2.5 & 0 & 0 & 1 & 3 & 5 & 9 & 7 & 6 & 7 & 2 \\
3.0 & 0 & 1 & 3 & 5 & 9 & 11 & 5 & 6 & 5 & 7 \\
3.5 & 2 & 2 & 5 & 4 & 4 & 8 & 7 & 6 & 5 & 4 \\
4.0 & 2 & 2 & 4 & 5 & 2 & 8 & 6 & 4 & 6 & 8 \\
4.5 & 6 & 7 & 8 & 7 & 4 & 6 & 6 & 6 & 6 & 6 \\
5.0 & 4 & 4 & 6 & 6 & 4 & 6 & 6 & 8 & 5 & 5 \\
\hline
\end{tabular}

Table 4.23: Match between the 20 lowest LIBOR based unspanned volatilities and the 20 lowest caps term premiums. The table reports the number of the times the 20 lowest LIBOR based unspanned volatilities matches the 20 lowest caps term premiums.

\begin{tabular}{lrrrrrrrrrrr}
\multicolumn{1}{l}{$\begin{array}{l}\text { The number of times the 20 lowest LIBOR unspanned volatilities } \\
\text { matches the 20 lowest caps term premiums }\end{array}$} \\
$\begin{array}{l}\text { Strike rates } \\
\text { Maturity }\end{array}$ & 0.040 & 0.045 & 0.050 & 0.055 & 0.060 & 0.065 & 0.070 & 0.080 & 0.090 & 0.100 \\
\hline 1.0 & 20 & 20 & 20 & 20 & 20 & 20 & 20 & 20 & 20 & 20 \\
1.5 & 20 & 20 & 20 & 20 & 7 & 20 & 20 & 20 & 20 & 20 \\
2.0 & 20 & 5 & 7 & 5 & 5 & 2 & 1 & 18 & 19 & 18 \\
2.5 & 1 & 3 & 4 & 5 & 4 & 3 & 2 & 2 & 4 & 18 \\
3.0 & 0 & 1 & 6 & 5 & 5 & 3 & 3 & 1 & 3 & 5 \\
3.5 & 3 & 4 & 4 & 4 & 4 & 2 & 1 & 1 & 1 & 0 \\
4.0 & 2 & 3 & 4 & 4 & 2 & 1 & 3 & 2 & 1 & 1 \\
4.5 & 5 & 7 & 7 & 6 & 5 & 4 & 4 & 3 & 0 & 0 \\
5.0 & 4 & 7 & 7 & 6 & 5 & 4 & 5 & 2 & 0 & 0 \\
\hline
\end{tabular}


Table 4.24: Match between the 20 highest implied volatilities and the 20 highest caps term premiums. The table reports the number of the times the 20 highest implied volatilities matches the 20 highest caps term premiums.

\begin{tabular}{lrlrrrrrrrrr}
\multicolumn{1}{l}{ The number of times the 20 highest implied volatilities } \\
matches the 20 highest caps term premiums \\
$\begin{array}{l}\text { Strike rates } \\
\text { Maturity }\end{array}$ & 0.040 & 0.045 & 0.050 & 0.055 & 0.060 & 0.065 & 0.070 & 0.080 & 0.090 & 0.100 \\
\hline 1.0 & 0 & 0 & 3 & 3 & 0 & 0 & 3 & NaN & NaN & NaN \\
1.5 & 0 & 0 & 0 & 0 & 0 & 0 & 0 & 11 & NaN & NaN \\
2.0 & 0 & 1 & 0 & 0 & 0 & 0 & 10 & 4 & 2 & 0 \\
2.5 & 2 & 1 & 1 & 2 & 2 & 3 & 7 & 11 & 4 & 0 \\
3.0 & 2 & 4 & 7 & 9 & 10 & 8 & 7 & 10 & 3 & 0 \\
3.5 & 4 & 4 & 3 & 3 & 0 & 2 & 14 & 13 & 11 & 7 \\
4.0 & 5 & 6 & 7 & 6 & 0 & 5 & 10 & 12 & 11 & 4 \\
4.5 & 5 & 6 & 7 & 4 & 7 & 3 & 5 & 11 & 13 & 5 \\
5.0 & 7 & 8 & 8 & 7 & 11 & 3 & 7 & 9 & 11 & 4 \\
\hline
\end{tabular}

Table 4.25: Match between the 20 highest implied volatilities and the 20 lowest caps term premiums. The table reports the number of the times the 20 highest implied volatilities matches the 20 lowest caps term premiums.

\begin{tabular}{lrrrrrrrrrrr}
\multicolumn{1}{l}{ The number of times the 20 highest implied volatilities } \\
matches the 20 lowest caps term premiums \\
$\begin{array}{lrrrrrrrrr}\text { Strike rates } \\
\text { Maturity }\end{array}$ & 0.040 & 0.045 & 0.050 & 0.055 & 0.060 & 0.065 & 0.070 & 0.080 & 0.090 & 0.100 \\
\hline 1.0 & 16 & 17 & 0 & 12 & 0 & 0 & 9 & NaN & NaN & NaN \\
1.5 & 12 & 16 & 15 & 0 & 8 & 16 & 14 & 0 & NaN & NaN \\
2.0 & 5 & 0 & 0 & 0 & 0 & 0 & 0 & 6 & 10 & 5 \\
2.5 & 0 & 0 & 0 & 0 & 0 & 0 & 0 & 0 & 5 & 7 \\
3.0 & 0 & 0 & 0 & 0 & 0 & 0 & 0 & 0 & 3 & 5 \\
3.5 & 1 & 1 & 1 & 1 & 0 & 0 & 0 & 0 & 0 & 0 \\
4.0 & 1 & 0 & 0 & 0 & 0 & 0 & 0 & 0 & 1 & 0 \\
4.5 & 0 & 0 & 0 & 0 & 1 & 0 & 0 & 0 & 0 & 0 \\
5.0 & 1 & 1 & 1 & 1 & 2 & 1 & 0 & 1 & 0 & 0 \\
\hline
\end{tabular}

Table 4.26: Match between the 20 lowest implied volatilities and the 20 highest caps term premiums. The table reports the number of the times the 20 lowest implied volatilities matches the 20 highest caps term premiums.

\begin{tabular}{lrrrrrrrrrr}
\multicolumn{1}{l}{ The number of times the 20 lowest implied volatilities } \\
matches the 20 highest caps term premiums \\
$\begin{array}{l}\text { Strike rates } \\
\text { Maturity }\end{array}$ & 0.040 & 0.045 & 0.050 & 0.055 & 0.060 & 0.065 & 0.070 & 0.080 & 0.090 & 0.100 \\
\hline 1.0 & 7 & 10 & 13 & 10 & 14 & 17 & 16 & NaN & NaN & NaN \\
1.5 & 4 & 12 & 18 & 18 & 17 & 13 & 2 & 4 & NaN & NaN \\
2.0 & 6 & 6 & 2 & 0 & 0 & 0 & 0 & 1 & 7 & 14 \\
2.5 & 7 & 6 & 2 & 2 & 1 & 0 & 0 & 0 & 0 & 3 \\
3.0 & 4 & 2 & 0 & 0 & 0 & 0 & 1 & 0 & 0 & 0 \\
3.5 & 3 & 0 & 0 & 0 & 0 & 0 & 0 & 0 & 0 & 1 \\
4.0 & 1 & 0 & 0 & 0 & 0 & 0 & 0 & 0 & 0 & 1 \\
4.5 & 2 & 0 & 0 & 0 & 0 & 0 & 0 & 0 & 0 & 0 \\
5.0 & 1 & 0 & 0 & 0 & 1 & 1 & 0 & 1 & 0 & 0 \\
\hline
\end{tabular}


Table 4.27: Match between the 20 lowest implied volatilities and the 20 lowest caps term premiums. The table reports the number of the times the 20 lowest implied volatilities matches the 20 lowest caps term premiums.

\begin{tabular}{lrrrrrrrrrrr}
\multicolumn{1}{c}{ The number of times the 20 lowest implied volatilities } \\
matches the 20 lowest caps term premiums \\
$\begin{array}{lrrrrrrrrr}\text { Strike rates } \\
\text { Maturity }\end{array}$ & 0.040 & 0.045 & 0.050 & 0.055 & 0.060 & 0.065 & 0.070 & 0.080 & 0.090 & 0.100 \\
\hline 1.0 & 0 & 0 & 0 & 0 & 0 & 0 & 1 & NaN & NaN & NaN \\
1.5 & 0 & 0 & 0 & 0 & 0 & 0 & 0 & 0 & NaN & NaN \\
2.0 & 2 & 10 & 16 & 14 & 11 & 6 & 6 & 11 & 6 & 0 \\
2.5 & 2 & 10 & 15 & 14 & 14 & 15 & 12 & 8 & 3 & 4 \\
3.0 & 13 & 14 & 15 & 14 & 9 & 7 & 7 & 11 & 10 & 9 \\
3.5 & 7 & 12 & 13 & 13 & 13 & 7 & 8 & 9 & 8 & 5 \\
4.0 & 9 & 13 & 12 & 13 & 12 & 10 & 10 & 10 & 6 & 5 \\
4.5 & 11 & 11 & 10 & 9 & 7 & 10 & 9 & 6 & 5 & 3 \\
5.0 & 10 & 10 & 9 & 7 & 5 & 10 & 9 & 8 & 5 & 6 \\
\hline
\end{tabular}

\subsection{Information Contents in Caps and LIBOR Bond Markets}

Before studying the caps and LIBOR term premiums, we first study the relation between caps and LIBOR bonds and extract information contents in these markets. Since caps are the derivatives on LIBOR rates, it is natural to expect the causality. We examine if LIBOR Granger causes caps prices and caps implied volatility. We also construct the impulse response functions for them.

There are 15 maturities and 10 strike rates. The strike rates changes four times during the data period. Therefore, in order to make fair comparison, we use the moneyness. The moneyness for difference caps is defined as the ratio between the strike rates and the average LIBOR forward rates underlying the few caplets that form the difference cap. On the other hand, it is rather difficult to define the moneyness of caps. LIBOR forward rates change significantly, especially for the shorter maturities. For example, the spot rates are around $6.7 \%$ and 10 year rates are around $7.1 \%$ in August 2000 while the spot rates are around $1.6 \%$ and 10 year rates are around $6.6 \%$ in July 2002. We define the moneyness for caps to be the weighted average of moneyness of difference caps. The weights reflect the fact that the lengths of difference caps are not uniform. It is well known that interest rates are stationary but close to unit root. Even though we are dealing with small sample we use the assumption of stationarity and examine the information contents in caps and LIBOR bonds.

First we regress the caps prices with the first three principal components of LIBOR bond prices and see how their price movements are related. The R-square of the regressions are given in Table 4.28. The high R-squared suggests that there may be a causality between caps and LIBOR bonds. 
Table 4.28: R-squared of the regressions of cap prices with the LIBOR bonds. The $\mathrm{R}$-squared of the regressions of cap prices with the LIBOR bonds are listed.

\begin{tabular}{lcccccccccc}
\multicolumn{10}{c}{$\begin{array}{l}\text { R-squared for the regressions of cap prices } \\
\text { with the LIBOR bonds }\end{array}$} \\
$\begin{array}{llllllllllll}\text { Moneyness } \\
\text { Maturity }\end{array}$ & 0.60 & 0.70 & 0.80 & 0.90 & 1.00 & 1.10 & 1.20 & 1.30 & 1.40 & 1.50 \\
\hline 2.00 & 0.53 & 0.52 & 0.51 & 0.48 & 0.42 & 0.34 & 0.35 & 0.50 & & \\
2.50 & 0.43 & 0.42 & 0.41 & 0.39 & 0.36 & 0.36 & 0.43 & 0.55 & 0.57 & 0.58 \\
3.00 & 0.36 & 0.36 & 0.36 & 0.36 & 0.37 & 0.41 & 0.48 & 0.57 & & \\
3.50 & 0.32 & 0.33 & 0.34 & 0.36 & 0.38 & 0.44 & 0.51 & 0.58 & 0.60 & 0.60 \\
4.00 & 0.31 & 0.33 & 0.35 & 0.37 & 0.41 & 0.46 & 0.52 & 0.59 & 0.60 & 0.61 \\
4.50 & 0.31 & 0.33 & 0.36 & 0.39 & 0.42 & 0.48 & 0.53 & 0.59 & 0.60 & 0.61 \\
5.00 & 0.32 & 0.34 & 0.37 & 0.40 & 0.44 & 0.49 & 0.53 & 0.59 & 0.61 & 0.60 \\
6.00 & 0.35 & 0.37 & 0.40 & 0.44 & 0.48 & 0.52 & 0.55 & 0.60 & 0.61 & 0.61 \\
7.00 & 0.37 & 0.40 & 0.43 & 0.46 & 0.50 & 0.53 & 0.55 & 0.59 & 0.61 & 0.61 \\
8.00 & 0.40 & 0.42 & 0.45 & 0.49 & 0.51 & 0.54 & 0.56 & 0.59 & 0.61 & 0.61 \\
9.00 & 0.42 & 0.44 & 0.47 & 0.50 & 0.53 & 0.55 & 0.56 & 0.59 & 0.61 & 0.61 \\
10.00 & 0.44 & 0.46 & 0.49 & 0.52 & 0.54 & 0.56 & 0.57 & 0.59 & 0.61 & 0.61 \\
\hline
\end{tabular}

A $p$ th order vector auto regression is given by

$$
\mathbf{y}_{t}=\mathbf{c}+\boldsymbol{\Phi}_{1} \mathbf{y}_{t-1}+\mathbf{\Phi}_{2} \mathbf{y}_{t-2}+\cdots+\boldsymbol{\Phi}_{p} \mathbf{y}_{t-p}+\varepsilon_{t}
$$

where $\mathbf{y}_{t}$ is the time series of vector, $\mathbf{c}$ is a constant vector, $\boldsymbol{\Phi}_{i}$ is an $n \times n$ matrix of auto regressive coefficients, and $\varepsilon_{t}$ is an error vector satisfying

$$
E\left[\varepsilon_{t}\right]=0, E\left[\varepsilon_{t} \varepsilon_{\tau}^{\prime}\right]=\left\{\begin{array}{cc}
\boldsymbol{\Omega} & t=\tau \\
\mathbf{0} & t \neq \tau,
\end{array}\right.
$$

with $\Omega$ an $n \times n$ positive definite matrix. In our case $\mathbf{y}_{t}(0 \leq t \leq T)$ consists of weekly data of LIBOR and caps. We applied the vector auto regression with 5 lags and Granger causality tests are obtained. The program used is MFE-Toolbox by K. Sheppard [50]. As far as the price is concerned, LIBOR bonds Granger cause caps but not the other way. On the other hand it is not clear if LIBOR rates Granger cause the implied volatility of difference caps.

We also did the impulse response functions where we plot $\frac{\partial y_{i, t+s}}{\partial \varepsilon_{j t}}$ as a function of $s$. This describes the response of $y_{i, t+s}$ to a one-time impulse in $y_{j, t}$ with all other variables dated $t$ or earlier held constant. The graphs of the impulse response functions for LIBOR bonds and caps of maturity 3 years with moneyness 1.0 are given in Figure 4.19 as an example. The shapes of graphs seem to be not sensitive to the maturities and moneyness except the magnitude. In the graphs lag is one and $s=50$ are used. The columns are the impulses and the rows are the responses of LIBOR bonds and caps, respectively. The responses to impulses of a LIBOR bond or a cap to itself are decreasing functions of time. The response of LIBOR to the impulse in caps are increasing in time, which suggests that the effect of impulse is gradual. On the other hand the response of caps to the impulse in LIBOR is not clear.

The graphs of the impulse response functions for LIBOR rates and caps implied volatility of maturity 3 years with moneyness 1.0 are also given in Figure 4.20 as an example. 

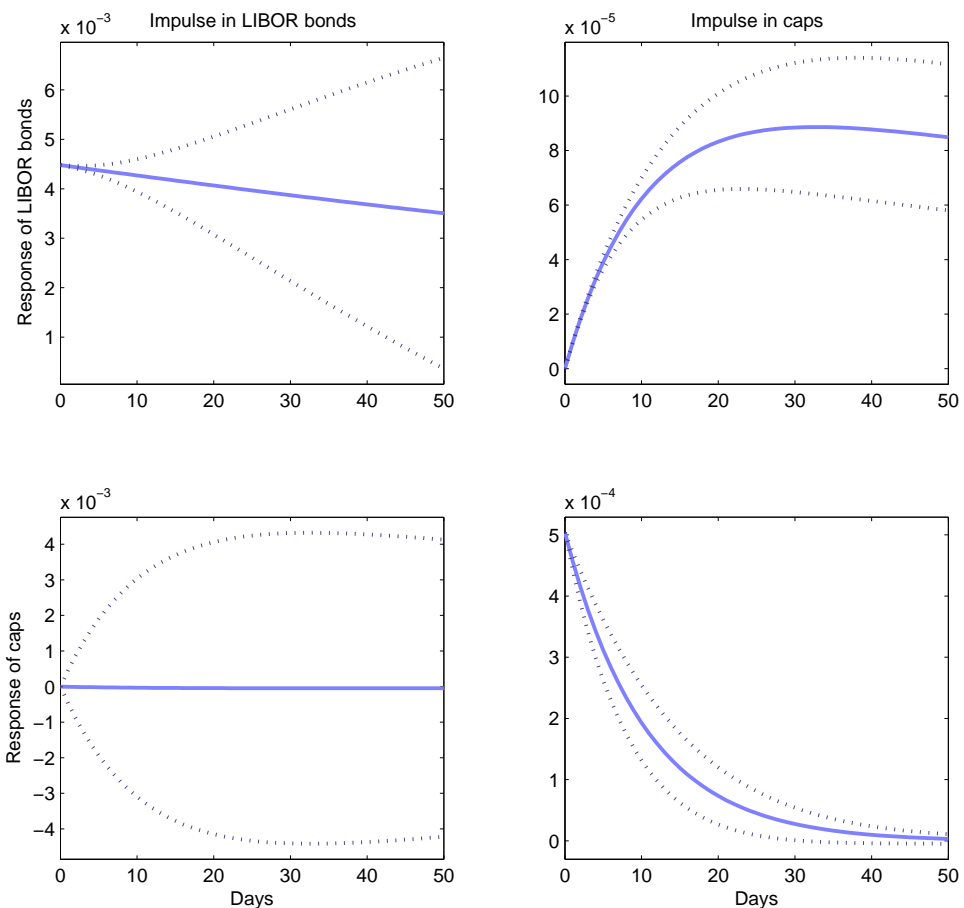

Figure 4.19: Impulse response functions for LIBOR bonds and caps. Graphs of impulse response functions for LIBOR bonds and caps are shown. The maturity of LIBOR bond and cap is 3 years and the cap is at the money. 

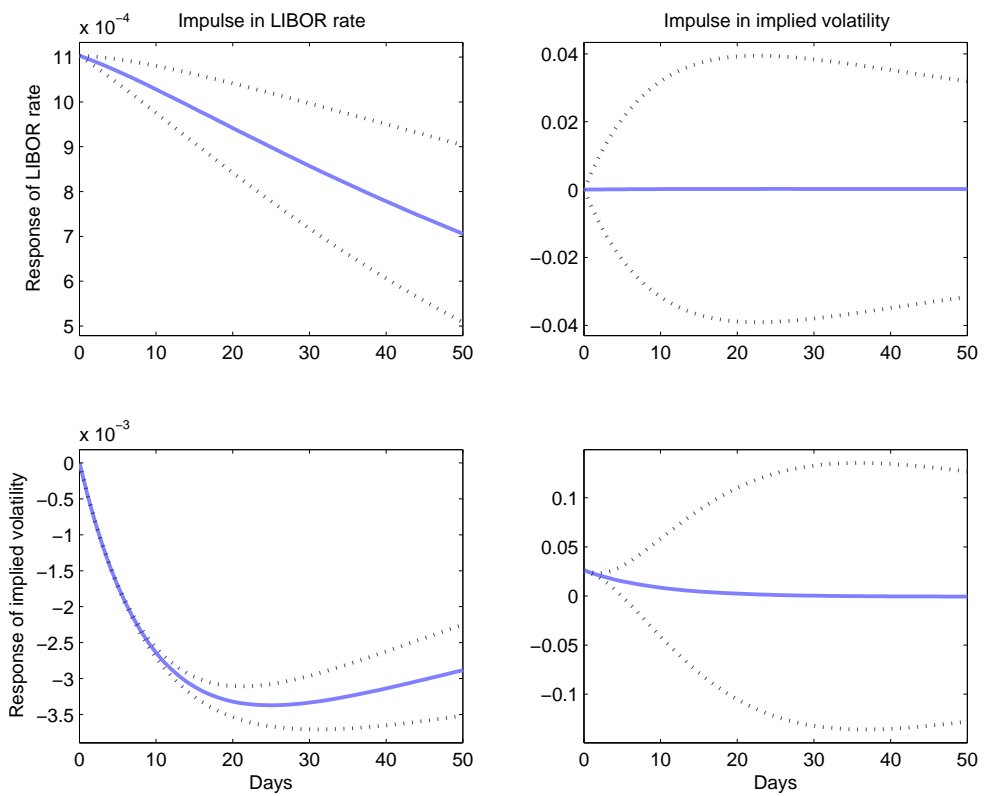

Figure 4.20: Impulse response functions for LIBOR rates and implied volatility. Graphs of impulse response functions for LIBOR rates and implied volatility are shown. The maturity of LIBOR bond is 3 years.

\subsection{Conclusions}

Cochrane and Piazzesi $[16,17]$ did the regression analysis of the bond term premium with the forward rates and observed that the term premium is regressed by a hump shaped linear combination of forward rates very well. They termed this hump shaped linear combination the forecaster. They also observed that the forecaster along with the level, slope, and curvature explains the term premium well.

We examined whether the similar results hold for caps. If there is no uncertainty, the caps term premium is zero, because holding longer term caps and holding two shorter term caps would not make any difference. Uncertainty causes the deviation from being equal. We regressed the caps term premiums with the difference caps and persistent patterns are observed for longer maturity. Although it would be desirable to use one year cap as a benchmark, I used 6 month caps as a benchmark due to the fact that the strike rates changed several times during the data period and the first change took place a little after one year from the beginning of the data.

We used the Granger causality test to examine if the unspanned volatility of caps market Granger causes the caps term premium. As in Section 3.5, we used the residuals of the regressions of implied volatility with LIBOR and those with the conditional volatility of LIBOR bonds based on GARCH as proxies of the unspanned volatility. For the sake of comparison, we also examined if the implied volatility Granger cause the caps term premium. This way, we see if there are effects on using the residuals of regressions. We find out that the unspanned volatility based on GARCH performed much better than the those based on LIBOR. The regressions of implied volatility with LIBOR is much better than those with the conditional volatility of GARCH based LIBOR bonds. Therefore, the residuals of the regressions with LIBOR may contain less relevant information for 
the Granger causality.

For the sake of investing we examined the relation between the performance of caps term premiums and the above three measures of volatility. Among the three volatilities we see that the LIBOR based unspanned volatility has an interesting relation with the caps term premiums. We observe that the matching of 20 highest and lowest short maturity caps term premiums with 20 highest and lowest LIBOR based unspanned volatility are very good. One way to use this observation for investing is suggested. 


\section{Chapter 5}

\section{Conclusions}

In Chapter 2 we studied the calibration of difference caps using USV models. The basic model is a version of an HJM formulation discussed in [14]. One interesting aspect of this model is that the volatility which affects pricing of caps and floors is independent of bond market. In other words, the volatility of bond derivatives are not sensitive to the volatility of underlying assets. We calibrate the cap prices using the above model and compare them with the market caps. We choose the parameters of the model so that the difference between prices of the theoretical (the model based) caps and those of the market caps will be minimum. We also study the effects of jump processes. The unexpected news about macro economy generates jumps in interest rates and they are important for pricing interest rate options.

The class of models we study is called the affine-class. Despite some problems with the predictability, they became a dominant class of models because of its analytical tractability. The main method of derivation of cap prices is the Fourier transform. We make use of the fact that the characteristic function is basically the Fourier transform of the solution. We apply the Fourier transform to the partial differential equation governing the caps and obtain the ordinary differential equations (ODEs). Then, after solving the ODEs, we apply the inverse transform to obtain the solution representations.

We calibrated the caps data. We compared the USV models with the Vasicek model. We also compared the models with and without jumps to see the effects of jumps. We observe that USV models with jumps provide better results. We also notice that jumps in interest rates calibrate the data better than the jumps in volatilities. Further calibrations should be carried out especially for the models with jumps. Possible future calibrations include changing the starting values, increasing the number of points where the FFT is evaluated, and examining the forms of jumps.

In Chapter 3 we empirically examined the effects of macroeconomic announcements on the implied volatility of difference caps. First, using 21 available macroeconomic announcements, we did the event study. We find out that PPI is the most influential among them. We also constructed the principal components and tested effects of the first three principal components on the implied volatility of difference caps. There are at least two ways to use the available macroeconomic data. One way is to select the days when at least one new macroeconomic announcement becomes available to public and construct the time series with the data on the selected days (Method 1). Another way is to construct the time series of a macroeconomic announcement by filling the days without that announcement the most recent data (Method 2). We see vivid difference between Methods 1 and 2. We observe that Method 2 gives better results than Method 1. This may show that the effects of macroeconomic announcements are not instantaneous but rather transient or persistent. 
The unemployment Data is a weekly data. Therefore, it is able to explain the volatility in caps market better than other data. We found that Method 2 gives better R-squared.

We also examined the effects of target federal funds rates (fed announcements) on the implied volatility of difference caps. The fed announcements have expected and unexpected components. We observed that Method 2 in the regressions of implied volatility of difference caps with expected and unexpected components gave much better R-squared. The effects of unexpected components are clearly shown especially for the in-the-money difference caps.

Based on this result, we constructed 9 portfolios of difference caps to examine the effects of fed announcements. We observed that the unexpected components have effects on in-the -money portfolios.

In Chapter 4 we studied the caps term premiums. Cochrane and Piazzesi $[16,17]$ did the regression analysis of the term premium with the forward rates and observed that the term premium is regressed by a hump shaped linear combination of forward rates very well. We examined whether the similar results hold for caps. If there is no uncertainty, the caps term premium is zero, because holding longer term caps and holding two shorter term caps would not make any difference. Uncertainty causes the deviation from being equal. We regressed the term premium of caps with the difference caps and observed persistent patterns for longer maturity caps term premiums. This would aid the predictability of cap prices.

We used the Granger causality test to examine if the unspanned volatility of caps market Granger causes the caps term premium. As in Section 3.5, we used the residuals of the regressions of implied volatility with LIBOR and those with the conditional volatility of LIBOR bonds based on GARCH as proxies of the unspanned volatility. For the sake of comparison, we also examined if the implied volatility Granger cause the caps term premium. This way, we see if there are effects on using the residuals of regressions. We find out that the unspanned volatility based on GARCH performed much better than the those based on LIBOR. The regressions of implied volatility with LIBOR is much better than those with the conditional volatility of GARCH based LIBOR bonds. Therefore, the residuals of the regressions with LIBOR may contain less relevant information for the Granger causality.

Also, for the sake of investing we examined the relation between the performance of caps term premiums and the above three measures of volatility. Among the three volatilities we see that the LIBOR based unspanned volatility has an interesting relation with the caps term premiums. We observe that the matching of 20 highest and lowest short maturity caps term premiums with 20 highest and lowest LIBOR based unspanned volatility are very good. One way to use this observation for investing is suggested. 


\section{Bibliography}

[1] Ahn, D.H., R.F. Dittmar, and A. Robert Gallant, Quadratic term structure models: Theory and evidence, Review of Financial Studies, 15 (2002), 243-288.

[2] Ahn, D.H., and B. Gao, A parametric nonlinear model of term structure dynamics, Review of Financial Studies 12 (1999), 721-762.

[3] Aït-Sahalia, Y., and R. Kimmel, Maximum Likelihood Estimation of Stochastic Volatility Models, Journal of Financial Economics 83 (2007), 413-452.

[4] Aït-Sahalia, Y., Disentangling Diffusion from Jumps, Journal of Financial Economics 74 (2004), 487-528.

[5] Bakshi, G., Charles Cao, and Zhiwu Chen, Empirical Performance of Alternative Option Pricing Models, Journal of Finance 52 (1997), 2003-49.

[6] Basistha, A., and A. Kurov, Macroeconomic cycles and the stock market's reaction to monetary policy, Journal of banking \& Finance 32 (2008), 2606-2616.

[7] Bates, D.S., Jumps and Stochastic Volatility: Exchange Rate and Social Processes Implicit in Deutsche mark Options, Review of Financial Studies 9 (1996), 69-107.

[8] Bernanke, B.S., and K.N. Kuttner, What explains the stock market's reaction to Federal reserve policy, Journal of Finance, 50(3) (2005), 1221-1257.

[9] Berndt, E.K., B.H. Hall, R.E. Hall, and J.A. Hausman, Estimation and Inference in Nonlinear Structural Models, Annals of Economic and Social Measurement 3 (1974), 653-65.

[10] Bikbov, R., and M. Chernov, Term Structure and Volatility: Lessons from the Eurodollar Futures and Options, SSRN working paper (2004).

[11] Brace, A., T. Dun, and G. Barton, Towards a Central Interest Rate Model, ICBI Global Derivatives Conference, Paris (1998).

[12] Carr, P., and D.B. Madan, Towards a theory of volatility trading. Option pricing, interest rates and risk management, 458-476, Handb. Math. Finance, Cambridge Univ. Press, Cambridge, (2001).

[13] Carr, P., and L. Wu, What Type of Process Underlies Options? A Simple Robust Test, Journal of Finance, 58 (2003), 2581-2610.

[14] Casassus, J., P. Collin-Dufresne, and B. Goldstein, Unspanned Stochastic Volatility and Fixed Income Derivatives Pricing, Journal of Banking \& Finance 29 (2005), 2723-2749. 
[15] Chen, R.R., and L. Scott, Stochastic Volatility and Jumps in Interest Rates: An Empirical Analysis, SSRN working paper (2004).

[16] Cochrane, J.H., and M. Piazzesi, Bond risk premia, The American Economic Review 95 (2005), 138-160.

[17] Cochrane, J.H., and M. Piazzesi, Decomposing the yield curve, SSRN working paper (2009).

[18] Collin-Dufresne, P., and R.S. Goldstein, Do Bonds Span Fixed Income Markets? Theory and evidence for 'Unspanned' Stochastic volatility, The Journal of Finance, 57 (2002), 1685-1730.

[19] Collin-Dufresne, P., R.S. Goldstein, and C. Jones, Can the volatility of interest rates be extracted from the cross section of bond yields? An investigation of unspanned stochastic volatility, NBER Working Paper 10756 (2004).

[20] Collin-Dufresne, P., and B. Solnik, On the term structure of default premia in the swap and LIBOR markets, Journal of Finance 56 (2001), 1095-1115.

[21] Cotton,P., J.P. Fouque, G. Papanicolaou, and R. Sircar, Stochastic Volatility Corrections for Interest Rate Derivatives, Mathematical Finance 14 (2004), 173-200.

[22] Cox, J.C., J.E. Ingersoll Jr., and S.A. Ross, A theory of the term structure of interest rates, Econometrica 53 (1985), 385-407.

[23] Dai, Q., and K.J. Singleton, Specification Analysis of Affine Term Structure Models, Journal of Finance, 55 (2000), 1943-1978.

[24] De J.P., and A. Pelsser, On the information in the interest rate term structure and option prices, Review of derivative research, 7 (2004), 99-127.

[25] Duffee, G.R., Term Premia and Interest Rate Forecasts in Affine Models, The Journal of Finance, 57 (2002), 405-443.

[26] Duffie, D. and K.J. Singleton, Simulated moments estimation of Markov models of asset prices, Econometrica 61 (1993), 929-952.

[27] Duffie, D., J. Pan, and K.J. Singleton, Transform analysis and option pricing for affine jumpdiffusions, Econometrica 68 (2000), 1343-1376.

[28] Gallant, A. R., and G. Tauchen, Which Moments to Match?, Econometric Theory, 12 (1996), 657-681.

[29] Fan, R., A. Gupta, and P. Ritchken, Hedging in the Possible Presence of Unspanned Stochastic Volatility: Evidence from Swaption Markets, The Journal of Finance, 58 (2003), 2219-2248.

[30] Flannery, M.J., and A.A. Protopapadakis, Macroeconomic factors do influence aggregate stock returns, Review of Financial Studies, 15 (2002), 751-782.

[31] Fleming, M.J., and E.M. Remolona, What moves bond prices?, Journal of Portfolio Management, Summer 1999, 28-38.

[32] Fornari, F., Macroeconomic announcements and implied volatilities in swaption markets, BIS Quarterly Review, September 2004, 79-86.

[33] Han, B., Stochastic Volatilities and Correlations of Bond Yields, SSRN working paper (2004). 
[34] Hansen, L.P., Large sample properties of generalized method of moments estimators, Econometrica 50 (1982), 1029-1054.

[35] Heston, S.L., A closed form solution for options with stochastic volatility, Review of Financial Studies 6 (1993), 327-343.

[36] Hull, J., and A. White, The pricing of options on assets with stochastic volatilities, Journal of Finance 42 (1987), 281-300.

[37] Heidari, M., and L. Wu, Are Interest Rate Derivatives Spanned by the Term Structure of Interest Rates?, Journal of Fixed Income, 13 (2003), 75-86.

[38] Huang, J.Z., and L. Wu, Specification analysis of option pricing models based on time-changed Lévy processes, Journal of Finance 59 (2004), 1405-1439.

[39] Jamshidian, F., An exact bond option formula, Journal of Finance, 44 (1989), 205-209.

[40] Jarrow, R., H. Li, and F. Zhao, 2004, Interest caps smile too! but can the LIBOR market models capture it?, Journal of Finance 62 (2007), 345 - 382 .

[41] Johannes, M., The statistical and economic role of jumps in continuous-time interest rate models, 59 (2004), 227-260.

[42] Jong, F.D., and J. Driessen, On the information in the interest rate term structure and option prices, Review of Derivatives Research 7 (2004), 99-127.

[43] Joshi, M.S., and R. Rebonato, A stochastic volatility displaced-diffusion extension of the LIBOR market model, Quantitative Finance 3 (2003), 458-469

[44] Kim, D.H., and A. Orphanides, The bond market term premium: what is it, and how can we measure it?, BIS Quarterly Review, June 2007, 27-40.

[45] Ludvigson, S.C., and S. Ng, Macro Factors in Bond Risk Premia, NBER working paper 11703 (2005).

[46] Li, H., and F. Zhao, Unspanned stochastic volatility: Evidence from hedging interest rate derivatives, Journal of Finance, 59 (2004), 341-378.

[47] Nawalkha, S.K., N.A. Beliaeva, and G.M. Soto, Dynamic term structure modeling - The Fixed Income Valuation Course, John Wiley \& Sons, Hoboken, US, (2007).

[48] Pan, J., The Jump-Risk Premia Implicit in Options: Evidence from an Integrated Time-Series Study, Journal of Financial Economics, 63 (2002), 3-50.

[49] R. Riccardo, Modern Pricing of Interest-Rate Derivatives: The LIBOR Market Model and Beyond, Princeton University Press, Princeton NJ (2002).

[50] Sheppard, K., Oxford MFE-Toolbox, http://www.kevinsheppard.com/wiki/MFE_Toolbox.

[51] Singleton, K.J., Estimation of Affine Asset Pricing Models Using the Empirical Characteristic Function, Journal of Econometrics 102 (2001), 111-141.

[52] Singleton, K.J., and L. Umantsev, Pricing Coupon-Bond Options and Swaptions in Affine Term Structure Models, Mathematical Finance 12 (2003), 427-446.

[53] Thompson, S., Identifying Term Structure Volatility From the LIBOR Swap Curve, Review of Financial Studies 21 (2008), 819-854. 
[54] Vasicek, O., An equilibrium characterization of the term structure, Journal of Financial Economics 5 (1977), 177-188.

\section{John $\mathrm{H}$. Virginia University Libraries, $120 \begin{aligned} & \text { ou=Acquisitions Department, } \\ & \text { email=John.Hagen@mail.wvu.e } \\ & \text { du, } \mathrm{c}=\text { US } \\ & \text { Date: } 2010.09 .07 \text { 10:09:49-04'00 }\end{aligned}$}

